Florida International University FIU Digital Commons

$11-14-2011$

\title{
The Potential Role of Environmental Exposures and Genomic Signaling in Development of Central Nervous System Tumors
}

Brian W. Kunkle

Florida International University, bkunk001@fiu.edu

DOI: $10.25148 /$ etd.FI1 1120809

Follow this and additional works at: https://digitalcommons.fiu.edu/etd

\section{Recommended Citation}

Kunkle, Brian W., "The Potential Role of Environmental Exposures and Genomic Signaling in Development of Central Nervous System Tumors" (2011). FIU Electronic Theses and Dissertations. 524.

https://digitalcommons.fiu.edu/etd/524 


\section{FLORIDA INTERNATIONAL UNIVERSITY \\ Miami, Florida}

THE POTENTIAL ROLE OF ENVIRONMENTAL EXPOSURES AND GENOMIC SIGNALING IN DEVELOPMENT OF CENTRAL NERVOUS SYSTEM TUMORS

A dissertation submitted in partial fulfillment of the

requirements for the degree of

DOCTOR OF PHILOSOPHY

in

PUBLIC HEALTH

by

Brian William Kunkle

2011 
To: Interim Dean Michelle Cicazzo

Robert Stempel College of Public Health and Social Work

This dissertation written by Brian William Kunkle, and entitled The Potential Role of Environmental Exposures and Genomic Signaling in Development of Central Nervous System Tumors, having been approved in respect to style and intellectual content, is referred to you for judgment.

We have read this dissertation and recommend that it be approved.

Changwon Yoo

Quentin Felty

Nasar Ahmed

Deodutta Roy, Major Professor

Date of Defense: November 14, 2011

The dissertation of Brian William Kunkle is approved.

Interim Dean Michelle Cicazzo

Robert Stempel College of Public Health and Social Work

Dean Lakshmi N. Reddi

University Graduate School

Florida International University, 2011 
C Copyright 2011 by Brian William Kunkle

All rights reserved. 


\section{ACKNOWLEDGMENTS}

It is my pleasure to acknowledge some of the colleagues, family and friends who have helped complete this dissertation. I would like to express my deepest gratitude to my advisor, Dr. Deodutta Roy, for his excellent guidance, support, patience, and encouragement during the entire dissertation process. I would also like to thank Dr. Changwon Yoo, Dr. Nasar Ahmed, and Dr. Quentin Felty for guiding my research for the past several years and helping me to develop my background in bioinformatics, gene networking, epidemiology, and biochemistry. Their expertise and assistance proved invaluable at critical points in this dissertation. Financial support from the Stempel College of Public Health \& Social Work, as well as the Florida International University Doctoral Evidence Acquisition Fellowship, was greatly appreciated and completion of this dissertation would not have been possible in its absence. Finally, I would like to thank my family and friends. Their support and encouragement was a source of strength for me during this long process, and I greatly value their love and friendship. 


\begin{abstract}
OF THE DISSERTATION
THE POTENTIAL ROLE OF ENVIRONMENTAL EXPOSURES AND GENOMIC SIGNALING IN DEVELOPMENT OF CENTRAL NERVOUS SYSTEM TUMORS

by
\end{abstract}

Brian William Kunkle

Florida International University, 2011

Miami, FL

Professor Deodutta Roy, Major Professor

The etiology of central nervous system tumors (CNSTs) is mainly unknown. Aside from extremely rare genetic conditions, such as neurofibromatosis and tuberous sclerosis, the only unequivocally identified risk factor is exposure to ionizing radiation, and this explains only a very small fraction of cases. Using meta-analysis, gene networking and bioinformatics methods, this dissertation explored the hypothesis that environmental exposures produce genetic and epigenetic alterations that may be involved in the etiology of CNSTs.

A meta-analysis of epidemiological studies of pesticides and pediatric brain tumors revealed a significantly increased risk of brain tumors among children whose mothers had farm-related exposures during pregnancy. A dose response was recognized when this risk estimate was compared to those for risk of brain tumors from maternal exposure to nonagricultural pesticides during pregnancy, and risk of brain tumors among children exposed to agricultural activities. Through meta-analysis of several microarray studies which compared normal tissue to astrocytomas, we were able to identify a list of 554 genes which were differentially expressed in the majority of astrocytomas. Many of 
these genes have in fact been implicated in development of astrocytoma, including EGFR, HIF-1 $\alpha$, c-Myc, WNT5A, and IDH3A. Reverse engineering of these 554 genes using Bayesian network analysis produced a gene network for each grade of astrocytoma (Grade I-IV), and 'key genes' within each grade were identified. Genes found to be most influential to development of the highest grade of astrocytoma, Glioblastoma multiforme (GBM) were: COL4A1, EGFR, BTF3, MPP2, RAB31, CDK4, CD99, ANXA2, TOP2A, and SERBP1. Lastly, bioinformatics analysis of environmental databases and curated published results on GBM was able to identify numerous potential pathways and geneenvironment interactions that may play key roles in astrocytoma development.

Findings from this research have strong potential to advance our understanding of the etiology and susceptibility to CNSTs. Validation of our 'key genes' and pathways could potentially lead to useful tools for early detection and novel therapeutic options for these tumors. 


\section{TABLE OF CONTENTS}

CHAPTER

PAGE

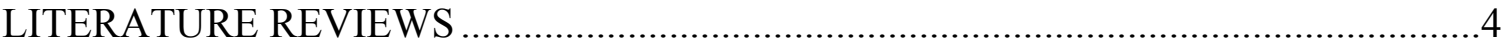

Manuscript 1: Gene-environment interaction and susceptibility to pediatric brain tumors.4

Manuscript 2: Environment, genetic and epigenetic alterations and pediatric central

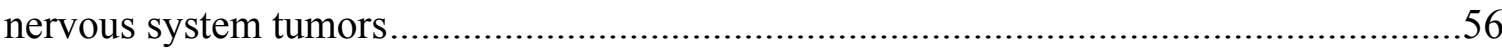

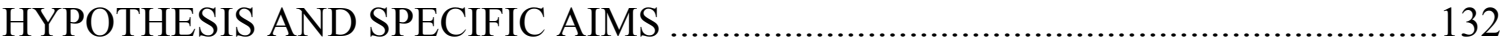

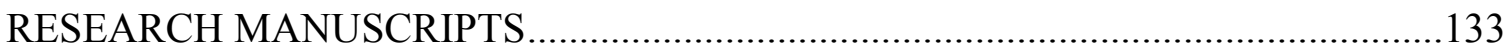

Manuscript 3: Early life exposure of the brain to pesticides and development of childhood brain cancer: A Meta-analysis .......................................................................................133

Manuscript 4: Identifying gene alterations required for the development of astrocytoma

Manuscript 5: Modeling gene-environment interaction in Glioblastoma Multiforme via an

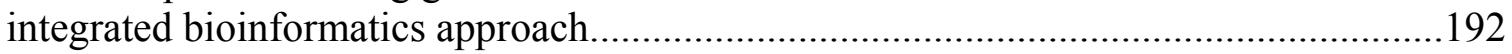

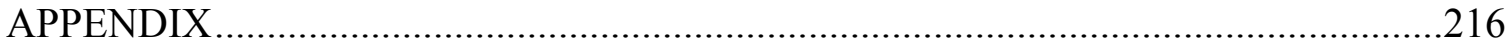

VITA

Error! Bookmark not defined. 


\section{LIST OF TABLES}

TABLE

PAGE

Table 1-1. Summary of overall risk evaluation for selected environmental exposures in relation to pediatric brain tumors.

Table 1-2. Disorders and mutations in genes causing familial forms of pediatric brain tumors.

Table 1-3. Summary of gene-environment interaction studies conducted on pediatric and adult brain tumors. .38

Table 2-1. Common susceptibility genes of pediatric medulloblastoma.............................65

Table 2-2. Common susceptibility genes of pediatric astrocytoma....................................77

Table 2-3. Common susceptibility genes of neuroblastoma..............................................87

Table 3-1. Characteristics of studies included in the meta-analyses of parental pesticide exposure and risk of childhood brain tumor development.

Table 3-2. Summary of results of meta-analyses of the association between pesticides and childhood brain tumors.

Table 4-1. List of Oncomine studies in meta-analysis of Astrocytoma vs. Normal Studies

Table 4-2. Significant over-represented GO Terms for differentially expressed genes in Astrocytoma.

Table 4-3. Significant under-represented GO Terms for differentially expressed genes in Astrocytoma.

Table 4-4. Sample statistics and significance of search score results of Bayesian network analysis.

Table 4-5. Pilocytic Astrocytoma prediction analysis summary. 15 total Markov genes were used in the analysis, except in linear stepwise regression, which used only 10 significant predictor genes in the analysis.

Table 4-6. Diffuse Astrocytoma prediction analysis summary. 18 total Markov genes were used in the analysis, except in linear stepwise regression, which used only 10 significant predictor genes in the analysis. 
Table 4-7. Anaplastic Astrocytoma prediction analysis summary. 18 total Markov genes were used in the analysis, except in linear stepwise regression, which used only 11 significant predictor genes in the analysis.

Table 4-8. Glioblastoma Multiforme prediction analysis summary. 10 total Markov genes were used in the analysis, except in linear stepwise regression, which used only 6 significant predictor genes in the analysis.

Table 4-9. Risk associated with Markov genes vs. non-Markov genes in Glioblastoma Multiforme. Normal Gene Set Risk represents the SEER calculated $0.61 \%$ chance of a person developing a brain tumor in their lifetime.

Table 5-1. List of Glioblastoma studies used for compilation of alterations list.

Table 5-2. KEGG Gene Ontology Results produced by DAVID analysis of 173 GEI

Glioblastoma gene list. 


\section{LIST OF FIGURES}

FIGURE

PAGE

Figure 1-1. A schematic representation of an early life gene-environment interaction model of development of pediatric brain tumors.

Figure 1-2. Dysregulation of developmental pathways in pediatric brain tumors (pBT). Alterations in pathways important to cellular growth, proliferation and differentiation during development appear to be important to pBT etiology. Cross-talk between these pathways has also been shown. Lightning bolts signify alterations in genes linked to development of their respective $\mathrm{pBT}$.

Figure 1-3. Interaction of environmental factors, dysregulation of mt-nuclear signaling and developmental pathways, and development of pediatric brain tumors. .22

Figure 2-1. A schematic representation of an early life gene-environment interaction model for development of pediatric brain tumors.

Figure 3-1. Meta-analysis results for paternal exposure to pesticides during preconception.

Figure 3-2. Meta-analysis results for maternal exposure to pesticides during pregnancy (agricultural/work exposures only).

Figure 3-3. Meta-analysis results for maternal exposure to pesticides during pregnancy (non-agricultural exposures only).

Figure 3-4. Meta-analysis results for paternal exposure to pesticides during pregnancy (agricultural/work exposures only).

Figure 3-5. Meta-analysis results for childhood exposure to agricultural pesticides. .....145

Figure 3-6. Meta-analysis results for childhood exposure to non-agricultural pesticides

Figure 4-1. Characteristics of progression of Astrocytoma from Grade 1 to Grade $4 \ldots . .155$

Figure 4-2. Top Canonical Pathways for Astrocytoma differentially expressed genes. The threshold line denotes the cutoff for significance ( $p$-value $=0.05$ ). Ratio is the number of molecules in the input list vs. the total number of molecules in the function

Figure 4-3. Top Biological Functions for Astrocytoma differentially expressed genes.

The threshold line denotes the cutoff for significance $(p$-value $=0.05)$. 
Figure 4-4. Top Toxicological Functions for Astrocytoma differentially expressed genes. The threshold line denotes the cutoff for significance $(p$-value $=0.05)$. Ratio is the number of molecules in the input list vs. the total number of molecules in the function. 170

Figure 4-5. Markov blanket genes for Bayesian network of Pilocytic Astrocytoma. Darker shade genes are overexpressed genes and lighter shade genes are underexpressed genes from the Oncomine meta-analysis.

Figure 4-6. Markov blanket genes for Bayesian network of Diffuse Astrocytoma. Darker shade genes are overexpressed genes and lighter shade genes are underexpressed genes from the Oncomine meta-analysis.

Figure 4-7. Markov blanket genes for Bayesian network of Anaplastic Astrocytoma. Darker shade genes are overexpressed genes and lighter shade genes are underexpressed genes from the Oncomine meta-analysis.

Figure 4-8. Markov blanket genes for Bayesian network of Glioblastoma Multiforme. Darker shade genes are overexpressed genes and lighter shade genes are underexpressed genes from the Oncomine meta-analysis.

Figure 4-9. Hierarchical clustering of Pilocytic Astrocytoma Markov genes using raw expression values of Rickman study only. No Tumor /Tumor Bar: Light bar areas represent samples without tumors and dark bar areas represent tumor cases. Expression: Darker squares represent underexpression; Lighter squares represent overexpression...175

Figure 4-10. Hierarchical clustering of Diffuse Astrocytoma Markov genes using raw expression values of Sun Study Only. No Tumor /Tumor Bar: Light bar areas represent samples without tumors and dark bar areas represent tumor cases. Expression: Darker squares represent underexpression; Lighter squares represent overexpression.

Figure 4-11. Hierarchical clustering of Anaplastic Astrocytoma Markov genes using raw expression values of Sun study only. No Tumor /Tumor Bar: Light bar areas represent samples without tumors and dark bar areas represent tumor cases. Expression: Darker squares represent underexpression; Lighter squares represent overexpression.

Figure 4-12. Hierarchical clustering of Glioblastoma Multiforme genes using raw expression values of Sun study only. No Tumor /Tumor Bar: Light bar areas represent samples without tumors and dark bar areas represent tumor cases. Expression: Darker squares represent underexpression; Lighter squares represent overexpression.Error! Bookmark not defi

Figure 5-1. Bioinformatics methodology. This flowchart illustrates steps outlined in the methods section by which we identified interactions between three environmentally relevant genomics databases and Glioblastoma alterations. 
Figure 5-2. Top 20 genes mutated in Glioblastoma according to COSMIC database search. Dark bars represent tissue samples with mutations; Light bars represent all tissue

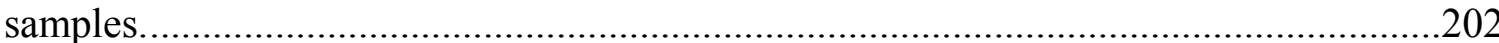

Figure 5-3. Overlap between our Glioblastoma amplified/gain genes, deleted/loss genes, and SNP mutated genes. 


\section{INTRODUCTION}

Pediatric brain tumors ( $\mathrm{pBT}$ ), which may occur in the brain or the spinal cord, are the second most common malignancy among children less than 20 years of age and the most common solid tumor of childhood. Malignant brain tumors rank second in both incidence and mortality by cancer in children, and they are the leading cause of cancer death in children. Approximately 3,200 pBTs are diagnosed each year in U.S. children under the age of 20 , with roughly 800 of these classified as benign. The incidence of these tumors has been steadily increasing since the early 1980s [1;2].

The etiology of pBTs is largely unknown, though several genetic disorders are known risk factors for their development including neurofibromatosis type 1, Li-Fraumeni syndrome, basal cell nevus (Gorlin's) syndrome, Turcot syndrome, and ataxia telangiectasia. Epidemiological evidence supports a genetic component to pBT etiology. Having a sibling or parent with brain cancer has been found to increase risk of pBTs from 3-9 times, while siblings of children with brain tumors have a greater risk of developing other cancers such as leukemia. While the above factors are thought to play a part in less than $5 \%$ of all pBTs, evidence for some combination of genetic and epigenetic changes along with environmental factors in their etiology is accumulating. Although only approximately $1 \%$ of childhood brain tumors are present at birth or diagnosed within the first few months of life, the majority of pBTs occur before the age of five, suggesting that prenatal as well as postnatal insults may be potential etiologic factors. It is becoming more evident that not only can drugs and environmental stressors interfere with normal fetal development by causing structural malformations, but that exposure to environmental stressor during development can also cause biochemical and functional 
abnormalities. In utero exposure to several drugs and environmental toxicants has been proposed to be a primary cause for the increased incidence of childhood brain cancers, which poses a significant clinical problem. Some suspected in utero carcinogens include benzene, pesticides, trichloroethylene, ethanol, arsenic, cigarette smoke, and infectious biological agents. Early childhood exposures may also influence both aBT and pBT development and evidence that pesticides can influence glial development and differentiation well into childhood support this view [3]. Furthermore, many substances, such as 1,3-Butadiene and $\mathrm{N}$-Nitrosomethylurea, have been shown to induce neurogenic tumors in animals, with both the fetus and neonatal animals being at dramatically increased susceptibility to CNST development compared to adults [4].

Aside from the extremely rare genetic conditions mentioned above, the only unequivocally identified risk factor is exposure to ionizing radiation, and this explains only a very small fraction of cases. The most consistent link between exposures and $\mathrm{pBT}$ development aside from radiation is that for maternal consumption of cured meats, but whether a dietary component is responsible has not yet been revealed. A majority of epidemiological studies investing pesticides and cancer risk have reported positive associations, with the risks for children generally higher than adults. While the consistency of results may be affected by type of pesticides being evaluated, exposure circumstances, and tumor classification standards, there is a considerable amount of epidemiological evidence that supports a link between pesticide exposure and pCNSTs. Several viruses have been investigated as causative agents in brain tumors. For instance, $\mathrm{JC}$ virus, a type of polyoma virus, and T-protein, an oncogenic virus product, have been detected at significant levels in PNETs and other tumors [5], though these results are 
challenged by negative results in other studies [6-10]. The ability of MBs to be induced by JC virus in mice models has also been demonstrated however [11;12]. Parental exposure to heat and electromagnetic fields, parental occupational exposure to chemicals, tobacco exposure, maternal hair dye use, and exposure to several medications and vitamins have also been investigated as potential etiologic factors, with equivocal results being found. Many of these exposures could certainly play a role in the etiology of $\mathrm{pBT}$ however, as the high rates of cell proliferation and differentiation during development and childhood increases susceptibility of cells to mutagenic and epigenetic alteration. In addition, the blood-brain barrier, which acts as a barrier to potentially harmful substances, is not fully developed in the fetus and can allow harmful substances to reach sensitive organs such as the brain. In fact, in utero DNA damage resulting from environmental pollution has been associated with somatic gene mutation in newborns [13]. Thus, exposure to environmental factors may be involved in the development of pBTs, and they likely interact with a genetic component and differ based on type of tumor. 


\section{LITERATURE REVIEWS}

Manuscript 1: Gene-environment interaction and susceptibility to pediatric brain tumors*

Brian Kunkle, David Sandberg ${ }^{1}$, Prasanna Jayakar ${ }^{1}$, Quentin Felty, Deodutta Roy

Department of Environmental and Occupational Health, Robert Stempel School of Public

Health, Florida International University, Miami, Florida 33199; ${ }^{1}$ Department of

Neurological Surgery, University of Miami Miller School of Medicine and Miami Children's Hospital, Miami, FL 33155

*Published as a Book Chapter in 'Environmental Factors, Genes, and the Development of Human Cancers', Deodutta Roy and M. Tevfik Dorak, Elsevier, New York, 2010

Keywords: Pediatric brain tumors (pBTs), Gene-environment Interactions, Mitochondrial-Nuclear Signaling, Environment, Individual Susceptibility 


\section{OUTLINE}

I. Introduction

II. Environmental Epidemiology of Pediatric Brain Tumors

III. Origin and Neurobiology of Pediatric Brain Tumors

IV. Genetic and Epigenetic Alterations in Pediatric Brain Tumors

V. Environment, Mitochondrial-Nuclear Interactions, and Development of Pediatric Brain Tumors

VI. Population Studies on Gene-Environment Interactions in Pediatric Brain Tumors VII. Conclusions

\section{INTRODUCTION}

Pediatric brain tumors $(\mathrm{pBT})$ are a genetically, biochemically, and clinically heterogeneous group of tumors located in both the central and peripheral nervous system. Collectively, they are the most common solid tumor of childhood, and rank second to leukemia in both incidence and mortality for childhood cancers. Approximately 2,200 intracranial $\mathrm{pBTs}$, or $16.6 \%$ of all childhood cancers are diagnosed each year in U.S. children under the age of 20 , with $78 \%$ of these neoplasms being classified as malignant in nature and the remaining classified as benign or of unspecified behavior $[1 ; 2]$. Astrocytomas comprise $52 \%$ of these malignancies, primitive neuroectodermal tumor (PNET) comprise 21\%, other gliomas 15\%, and ependymomas an additional 9\% [1]. Neuroblastomas (NB), the most common solid extracranial nervous system tumor, arise in the adrenal medulla and sympathetic ganglia and account for another $6-10 \%$ of all childhood cancers, with approximately 650 new cases occurring in U.S. children each 
year [3]. Nearly $50 \%$ of these extracranial tumors occur in children under the age of two years old [3]. Given the early age of onset of a majority of pBTs, and the current dogma that most cancers have at least a 10 year period of formation, it appears these tumors may have an etiology that contrasts with some of the traditionally accepted ideas on tumor formation. In fact, recent research is beginning to suggest an etiology focused on early life environmental factors interacting with dysregulated developmental mechanisms (e.g. signaling pathways and stem cell/progenitor cell growth and differentiation) and mitochondrial-nuclear signaling in pBTs.

While links between specific environmental exposures and pBTs are not yet fully established, several aspects of developmental biology increase the likelihood of their involvement in pBT etiology, including 1) the increased vulnerability of the fetus/neonatal nervous system to exposures, 2) the high rates of cellular proliferation and differentiation during development of the nervous system, and 3) the ability of environmental factors to produce and/or influence genetic and epigenetic alterations in pathways involved in both development and tumorigenesis. For instance, high rates of cell proliferation and differentiation during development and childhood increases susceptibility of cells to mutagenic and epigenetic alteration. In fact, in utero DNA damage resulting from environmental pollution has been associated with somatic gene mutation in newborns [4]. Furthermore, it is becoming more evident that not only can drugs and environmental stressors interfere with normal fetal development by causing structural malformations, but that exposure to environmental stressors during development can also cause biochemical and functional abnormalities. Additionally, the blood-brain barrier, which acts as a barrier to potentially harmful substances, is not fully 
developed in the fetus and can allow harmful substances to reach sensitive organs such as the brain. Some suspected in utero carcinogens for $\mathrm{pBT}$ include pesticides, N-nitroso compounds, tobacco, and infectious biological agents. While evidence linking several of these exposures to pBTs is substantial, the only exposure known to clearly cause pBTs is ionizing radiation. However, chemicals such as 1,3-Butadiene and N-Nitrosomethylurea have been shown to induce neurogenic tumors in animals, with both the fetus and neonatal animals being at dramatically increased susceptibility to BT development compared to adults [5]. Furthermore, evidence showing that pesticides can influence glial development and differentiation well into childhood suggests that early life exposures may influence both $\mathrm{pBT}$ and adult BT (aBT) [6]. In fact, evidence from several other cancers suggests that susceptibility to adult tumor development may in fact be influenced by early life environmental exposures and their interaction with epigenetic mechanisms [7]. Given the above factors, it is probable that certain genetic, epigenetic, and environmental factors unique a developing fetus/neonate, are part of a multifactorial cascade of differing events that lead to $\mathrm{pBT}$ development. It is likely that these factors exert influences on the growth and differentiation of neural stem cells/progenitor cells, leading to the production of genetic and epigenetic changes that increase an individual's susceptibility to pBTs (Figure 1-1).

The following is a review of the current state of the research on environmental, genetic, and epigenetic factors possibly involved in the development of pBTs. The first section of this review covers epidemiological research on environmental factors that have been investigated in relation to $\mathrm{pBTs}$. Research supporting the involvement of neural stem cells, progenitor cells, and developmental pathways in the etiology of pBTs is then 
summarized. This section is followed by a review of the genetic and epigenetic alterations that have been identified in common pBTs, with the final section focusing on how these factors may interact with mitochondrial-nuclear signaling to increase individual susceptibility to $\mathrm{pBTs}$.

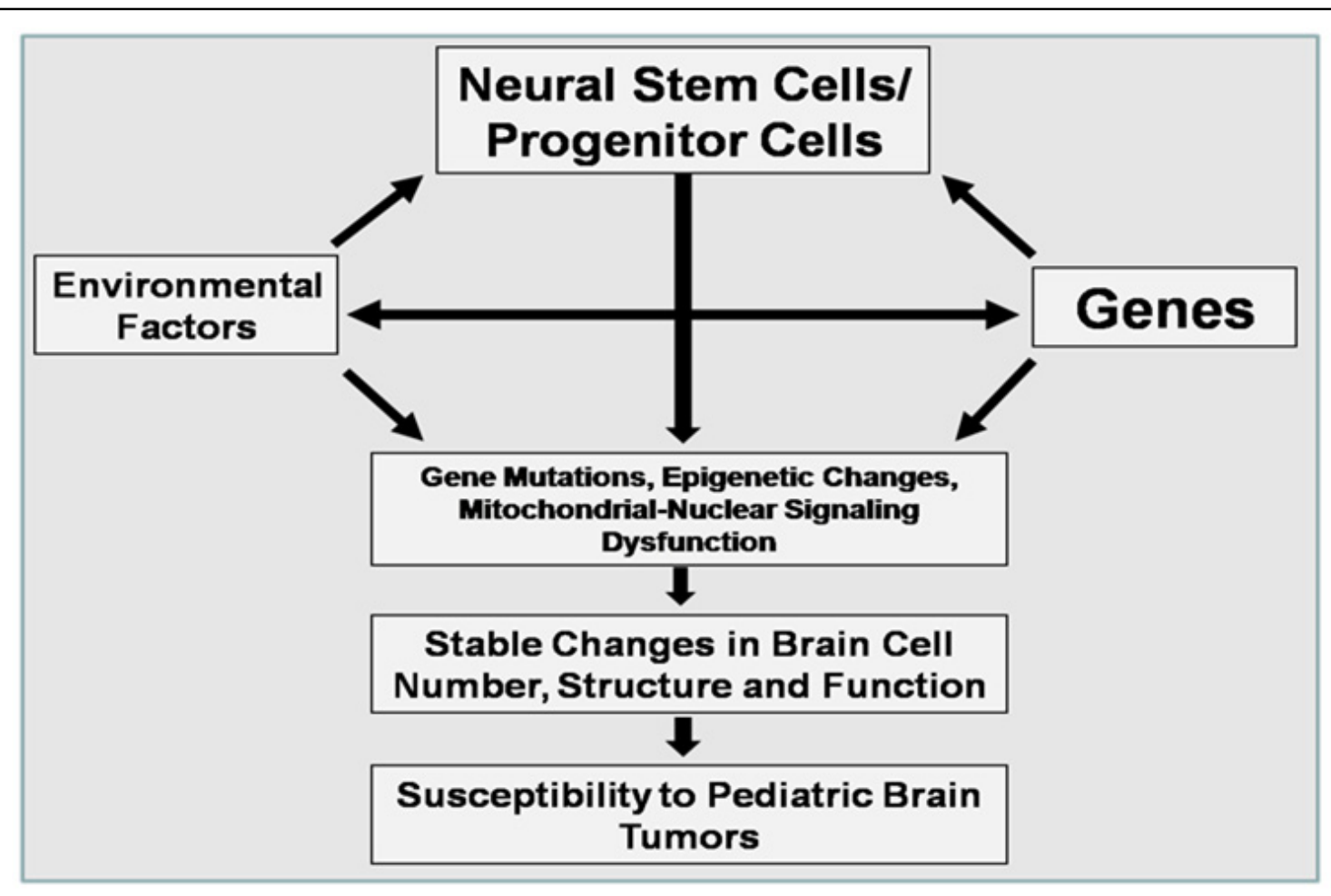

Figure 1-1. A schematic representation of an early life gene-environment interaction model of development of pediatric brain tumors.

\section{ENVIRONMENTAL EPIDEMIOLOGY OF PEDIATRIC BRAIN TUMORS}

\section{Links between the environment and traditional epidemiology and risk factors}

While the incidence of pBTs has been steadily increasing since the early 1980s, debate exists as to the reason for this rise, with some researchers suggesting diagnostic factors as a main cause, while others emphasize the importance of environmental factors [8;9]. In the United States the recorded incidence of pBTs increased by 35\% from 1973 to 1994 
[10]. Similar increases for these tumors were noted in Europe [11] and in England $[12 ; 13]$. Considerable debate exists as to how much these large increases are due to an etiologic factor or the result of better diagnostic methods, improved reporting, and changes in classification (i.e. tumors earlier designated as benign being changed to malignant) [14]. Supporting an increase due to better diagnostics and reporting, Smith et al.'s (1998) detailed statistical analysis concluded that a statistical model with a 'jump' in incidence in the mid-1980s fits the incidence data better than a model with a steady increase [10]. A critical analysis of pBTs over this same period by Linet et al. (1999) also supported this view [15]. However, some researchers remain doubtful that the increase is adequately explained with only this type of statistical analysis [14]. Indeed, recent reports from Europe on childhood cancer incidence over this time period argue for a true increase in incidence over this time period $[11 ; 16]$, suggesting that environmental factors have played a role in this rise in incidence. Researchers have also pointed out that while incidence increases in some subgroups of pBTs can be attributed to better diagnostics and changes in classification, these changes do not explain increases in other pBTs [17].

Though the etiology of pBTs is largely unknown, several genetic disorders are known risk factors for their development including neurofibromatosis type 1, Li-Fraumeni syndrome, basal cell nevus (Gorlin's) syndrome, Turcot syndrome, and ataxia telangiectasia. These single gene disorders are thought to play a part in less than $5 \%$ of all pBTs however. Still, epidemiological evidence does point to a genetic component in pBTs, as having a sibling or parent with brain cancer has been found to increase risk of pBTs from 3-9 times, while siblings of children with brain tumors have a greater risk of 
developing other cancers such as leukemia. These family patterns are likely due to multigenic inheritance patterns ("soft" but interacting mutations), modifiers that alter gene expression or penetrance, or epigenetic gene silencing, rather than the consequence of a highly penetrant gene however [18]. It is also probable that common environmental factors among these family members contribute to this increased risk profile. Gender is another risk factor, as most $\mathrm{pBTs}$ have been found to occur at a higher frequency in males than in females, though the reason for this difference is unknown. This difference varies by tumor, as certain tumors including medulloblastoma and ependymoma show incidence rates in males 1.5-2 times that of females, while other tumor types such as astrocytoma show only small differences between these groups [19-21]. While research on the subject is lacking, it is important to consider that these gender-specific differences may in fact be related to gender-specific responses to a given toxicant. Other common risk factors for pBTs include race (they occur more often among Caucasians than other races) and age (they occur more often in children younger than 8 years old than in older children). Geographically, astrocytoma incidence is low in Asia, intermediate in Central and South America, and relatively higher in North America, Europe, Australia, and New Zealand. Additionally, astrocytoma is most common in Sweden, which has a rate $20 \%$ higher than any other reported rate. Similar to astrocytoma, PNET, a broad tumor group which includes medulloblastoma (MB), has incidence rates that are relatively low in Asia and higher in Europe and North America. Rates for PNET range from 2 to 12 per million per year with the highest rates occurring in Hawaiians in Hawaii and Maori in New Zealand [22]. Dietary patterns and other differences in environmental factors between these geographies could explain some of these patterns, as has been suggested in other cancers. 
Incidence patterns among developed and developing countries may not be comparable however as all brain tumors in developing countries may not come to medical attention and some of the low rates observed might be underestimates.

Studies in North Carolina, Japan, and Norway have found that seasonally, medulloblastoma shows a statistically significant variation in incidence with a peak in October [23-25]. Researchers speculate that exposures during the Spring, when major fetal development would occur for these births, may be involved, including pesticide applications and use of allergic medications. Other tumor types including astrocytoma and ependymoma do not show this seasonal correlation however [26], despite astrocytoma being the tumor most often linked with pesticide exposure. Studies have also assessed clinical parameters and their association with risk of pBTs. Findings on birth weight show only weak or null associations to pBTs, for most studies, although one study which looked at subtypes of tumors found high birth weight to cause an increased OR of 1.71 (95\% CI: 1.01-2.90) for astrocytic tumors [27]. Head circumference has also been studied in relation to pBTs and is positively associated with their occurrence [OR $=$ 1.27 (95\% CI 1.16-1.38) per 1-cm increase in head circumference] [28].

\section{Epidemiologic research on specific environmental exposures and $p B T$}

Whether specific environmental exposures cause pBTs remains unknown, with only high-intensity external ionizing radiation for therapy of childhood leukemia, tinea capitis and other malignancies the only exposure clearly associated with development of nervous system cancer [29-31]; [19;32]. Diagnostic radiography during pregnancy also appears to result in a small but significant increase in risk of $\mathrm{pBT}$ to the fetus, although this 
association is disputed [33]. Neither of these exposures is thought to account for a significant number of $\mathrm{pBTs}$ today however, as diagnostic radiation has decreased in use and dosage, and therapeutic radiation is now used mostly for malignant conditions that do not expose the brain [34]. Research over the past few decades does point to the relevancy of a few environmental exposures in pBT etiology however. A number of these exposures, including pesticides, N-nitroso compounds, and infection with polyomavirus, have been positively linked to $\mathrm{pBT}$, although findings are inconclusive. While positive results have been found, the rarity of the disease, difficulty in assessing exposure during pregnancy and other critical time periods, assessment of diverse pBTs as a single type, and recall bias, distort and confound results for these investigations. Several workrelated exposures have been convincingly linked to aBT however, providing support to the possibility that environmental exposures to a fetus or young child could produce pBTs. These work-related exposures include nuclear workers exposed to radiation, pathologists and embalmers exposed to formaldehyde, plastic workers exposed to vinyl chloride, and textile and plastic workers exposed to acrylonitrile [35]. A summary of the research of several environmental exposures and their relation to $\mathrm{pBT}$ is provided below, and Table 1-1 gives an overall 'risk association level' for each exposure.

\section{ORIGIN AND NEUROBIOLOGY OF PEDIATRIC BRAIN TUMORS}

The majority of pBTs are embryonal in nature, while carcinomas in epithelial tissues, the most frequent type of cancer in adults, are rare in children. A large amount of pediatric gliomas, the most frequent $\mathrm{pBTs}$, arise in the cerebellum and brainstem (infratentorial) from glia, non-neural cells that provide support and nutrition and 


\section{Table 1-1. Summary of overall risk evaluation for selected environmental exposures}

in relation to pediatric brain tumors.

\begin{tabular}{|c|c|c|}
\hline Risk Factors & Risk Evaluation & Risks for Exposures (OR/RR with 95\% CI) \\
\hline $\begin{array}{l}\text { Ionizing } \\
\text { Radiation }\end{array}$ & Conclusive & $\begin{array}{l}\text { 33.1 (9.4-116.5) for benign nerve sheath tumors of head/neck } \\
{[31]} \\
\text { - } \\
\text { 9.5 (3.5-25.7) for meningioma's [31] } \\
21.7 \text {-fold increase in CNS neoplasms in a large cohort of } \\
9720 \text { children who had undergone radiation for leukemia } \\
\text { [30] } \\
\text { Atomic bomb exposure followed a dose-response curve } \\
\text { [(excess relative risk (ERR) }=1.2(0.6 \text { to } 2.1) \text {, with the } \\
\text { highest ERR found in relation to schwannoma } 4.5 \text { (1.9 to } \\
\text { 9.2) [36]. }\end{array}$ \\
\hline Pesticides & $\begin{array}{l}\text { Suggestive but } \\
\text { not Conclusive }\end{array}$ & $\begin{array}{l}\text { - Agricultural pesticide use and } \mathrm{pBT} \text { risk in children aged } 0 \text { to } \\
14 \text { years }[\mathrm{RR}=3.37(1.63-6.94)][37] . \\
\text { - Increased risk of astrocytoma for exposure to herbicides from } \\
\text { residential use }[\mathrm{OR}=1.9(1.2-3.0)][38]\end{array}$ \\
\hline N-nitroso & $\begin{array}{l}\text { Suggestive but } \\
\text { not Conclusive }\end{array}$ & $\begin{array}{l}\text { - Four of eight studies on cured meat exposure found } 2 \text { to } 2.5 \\
\text { times increased risk of pBT [39-42] } \\
\text { Mother's frequent ingestion of hot dogs }[(\mathrm{RR}=1.33(1.08- \\
1.66)] \text { and sausage [(RR }=1.44(1.01-2.06)] \text { during } \\
\text { pregnancy [43] } \\
\text { Meta-analysis of cured meat consumption }[\mathrm{RR}=1.68(1.30- \\
\text { 2.17)] [43] } \\
\text { Use of metronidazole and neuroblastoma }(\mathrm{RR}=2.60(0.89- \\
7.59)][44] \text {. } \\
\text { - Use of narcotics [OR }=1.3(1.0-1.6)] \text { and the anasthic } \\
\text { penthrane [OR }=1.5(1.1-2.0)] \text { during delivery }[45] \text {. } \\
\text { Anticonvulsant use during pregnancy [(OR = } 1.4(0.6-3.2)] \\
\text { [46] }\end{array}$ \\
\hline Infectious Agents & $\begin{array}{l}\text { Inconsistent or } \\
\text { limited }\end{array}$ & $\begin{array}{l}\text { Viral infection during pregnancy }[\mathrm{OR}=10.6(1.1-503.2)[47] \\
\text { - } \quad \text { Thfluenza during gestation }[\mathrm{OR}=3.15(\mathrm{CI}=1.13-8.77)][48] \\
\text { astrocytoma }(\mathrm{RR}=1.34) \text {, medulloblastoma }(\mathrm{RR}=2.30), \\
\text { ependymoma }(\mathrm{RR} \text { of } 2.61), \text { meningioma }(\mathrm{RR}=3.71), \text { and } \\
\text { neuroblastoma }(\mathrm{RR}=2.31) \text { [49]. }\end{array}$ \\
\hline Tobacco & $\begin{array}{l}\text { Inconsistent or } \\
\text { limited }\end{array}$ & $\begin{array}{l}\text { - Meta-analysis of } 12 \text { observational studies on maternal } \\
\text { smoking during pregnancy }[R R=1.05(0.90-1.21)][50] \\
\text { - } \quad \text { Paternal smoking exposure }[R R=1.22(1.05-1.40)][50] \\
\text { pecond meta-analysis on maternal smoking during } \\
\text { pregnancy }[\mathrm{RR}=1.04 \text { (CI: 0.92-1.18)] [51]. }\end{array}$ \\
\hline $\begin{array}{l}\text { Electromagnetic } \\
\text { Frequencies }\end{array}$ & $\begin{array}{l}\text { Inconsistent or } \\
\text { limited }\end{array}$ & $\begin{array}{l}\text { - Electromagetic Frequencies and childhood exposure [OR }= \\
0.97(0.46-2.05)][52] .\end{array}$ \\
\hline Trauma & $\begin{array}{l}\text { Inconsistent or } \\
\text { limited }\end{array}$ & - Medical attention for head injury [OR = $1.4(1.0-1.9)][53]$ \\
\hline Vitamins & $\begin{array}{l}\text { Inconsistent or } \\
\text { limited }\end{array}$ & $\begin{array}{l}\text { - Children of mothers who used multivitamins }[\mathrm{OR}=0.7(0.4- \\
1.0)] \text { and had a diet high in iron and folate [OR for iron, } 0.5 \\
(0.3-0.9) \text {; OR for folate, } 0.5(0.3-0.9)][54]\end{array}$ \\
\hline
\end{tabular}


participate in signal transmission in the nervous system. While childhood gliomas originating in the cerebellum (supratentorial) are also fairly common, the majority aBTs are supratentorial in nature. Glial tumors are usually broken down into more specific subtypes based on their predicted cell type of origin. The most common glial tumors in patients under 20 years of age are astrocytoma (from astrocytes), oligodendroglioma (from oligodendrocytes), brain stem glioma (from brain stem cells), and ependymoma (from ependymal cells). Some pBTs are composed of primitive or undifferentiated cells, as would be expected given their origin during early life when the nervous system is still developing. These include the primitive neuroectodermal tumors (PNETs) of the brain, notably medulloblastoma (MB), ependymoblastoma, and neuroblastoma (NB). One other common brain tumor in childhood is the germ cell tumor. Germ cells, which are special cells in a developing embryo, can travel to other areas of the body, in this case the brain, and become cancerous. Mixed forms of brain tumors also exist. For instance, mixed gliomas (aka oligoastrocytomas) have both an astrocytic and an oligodendroglial cell component. Additionally, mixed glio-neuronal tumors (tumors displaying a neuronal, as well as a glial component, e.g. gangliogliomas, disembryoplastic neuroepithelial tumors) and tumors originating from neuronal cells (e.g. gangliocytoma, central gangliocytoma) can also develop in the central nervous system (CNS). Other varieties of primary brain tumors include: tumors of the pineal parenchyma (e.g. pineocytoma, pineoblastoma), choroid plexus tumors, and neuroepithelial tumors of uncertain origin (e.g. gliomatosis cerebri, astroblastoma). Additionally, many subtypes of these tumors also exist and are often grouped by histological grade (i.e. Astrocytoma grades I-IV). 


\section{Cellular Origins of $p B T s$}

One of the critical issues involving NT biology has been the inability to determine a definitive cell of origin of each individual tumor type, including the three most prevalent tumors of the pediatric CNS: pilocytic astrocytoma, MB, and NB. Identification of these cell types would allow for better comparisons to normal cell counterparts, and a more definitive genomic profile of the tumor cells involved. Currently, tumors are classified by the World Health Organization (WHO) according to the cell type that tumor cells resemble most in the developing embryo or adult. The three main cell types from which tumor cells are thought to arise are neural stem cells, progenitor cells, or differentiated cells, and genetic changes in each cell type have been associated with BT development [55]. It is likely these genetic changes, which may be either inherited or somatic in nature, deregulate normal proliferation and differentiation, and initiate tumor formation. Therefore, most $\mathrm{pBTs}$ (which are predominantly immature tumors) likely arise from neural stem cells (which produce both glial and neuronal cells) or progenitor cells in their respective precursor cell type (i.e. granule cell precursors for MBs), while most adult tumors probably form from differentiated cell types (i.e. astrocytes in astrocytoma) that have acquired stem cell-like or progenitor cell-like properties [55]. Recent research on MBs in mice models does in fact suggest that alterations in either cell type can produce $\mathrm{MB}$, with the critical determinant of tumorigenesis being neuronal lineage commitment of the cell [56;57]. Additionally, alterations in genes such as Bmil, an oncogene involved in proliferation of differentiated cells and self-renewal of stem cells, likely lead to different phenotypic outcomes of BT [58;59]. Also, tumors arising in different regions

of the brain retain distinct patterns of gene expression, though cells in different parts of 
the brain carry the same genes. This is a result of factors that have modified the use of these genes differently in distinct parts of the brain, suppressing some genes and activating others to allow the cells to take on specialized characteristics as the brain matures. Extensive debate exists within this framework however, as evidence for differing points of view exists in the literature. For example, MB having a neuronal cell of origin as suggested by Wright et al. is currently being opposed by those investigators who support a view by Bailey and Cushing that because MBs generate both glial and neuronal cells, they may originate from a cell they termed as an embryonic neuroepithelial [60;61]. For a complete review of the current information on cell of origin in brain tumors the reader is referred a review by Read et al. [55]. While the cellular origins of these tumors is still debated, recent research is beginning to elucidate how the deregulation of developmental pathways within these cells contributes to $\mathrm{pBT}$ etiology, and an overview of this research is provided below.

\section{Disruption of developmental pathways, 'tumor precursor cells', and pBTs}

Most pBTs are embryonal tumors that arise from abnormal development of nervous system tissue. Embryonal development is marked by organogenesis from stem cell populations producing 'precursor' cells that give rise to lineage-committed progenitor cells. These progenitor cells then undergo stages of proliferation and differentiation to produce tissue. Several cellular pathways that regulate these developmental processes have been implicated in the development of pBT, including the Sonic Hedgehog (SHh) pathway, the WNT-wingless (WNT) pathway, Mycn signaling, and the NOTCH signaling pathway. During normal nervous system development, these signaling 
pathways regulate growth and differentiation of progenitor cells, including granule cell precursors (GCPs) in the cerebellum and neural crest cells in the peripheral neural system (PNS). These cell populations ultimately form the cerebellum, peripheral neural crest, and other nervous system components. In cerebellar development, SHh accomplishes regulation of GCPs in part via expression of N-myc, a commonly expressed tumor suppressor gene thought to be an essential downstream target of SHh signaling in both normal and neoplastic cerebellar growth [62]. Mutations that dysregulate the SHh pathway can cause excessive growth and failure in cell differentiation, producing 'tumor precursor cells' that predispose an individual to MB [63]. Note that we use the term 'tumor precursor cells' as a generic term for all forms of stem, precursor, or progenitor cells that have acquired tumor producing alterations. Similar to dysregulation of SHh pathway in $\mathrm{MB}, \mathrm{N}-\mathrm{myc}$ signaling appears to direct proliferation and differentiation of neural crest cells in PNS development, and its dysregulation appears to make a large contribution to development of neuroblastoma [64]. Finally, several alterations identified in astrocytic tumors are located in genes important for normal differentiation of astroglial cells during development, including changes in several SHh pathway proteins [65-67]. Figure 1-2 provides a schematic showing commonly mutated genes in these and other developmentally regulated pathways thought to be involved in $\mathrm{pBT}$ tumorigenesis. There are possible roles for environmental regulation within these pathways. For instance, regulation of N-myc by SHh is thought to occur through activation of phosphoinositide 3kinase (PI3K), which, through downstream activation of Akt, and inactivation of

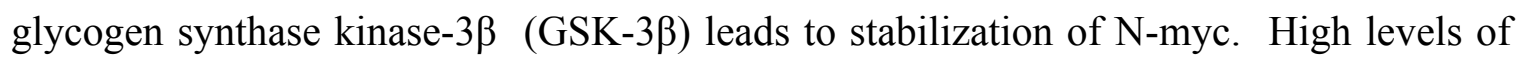
N-myc, which are linked to cellular transformation and aggressive tumors, lead to 
proliferation, migration, and cell cycle activation, while reduced levels produce cell cycle exit and differentiation. Thus, when SHh signaling is activated, Akt signaling and amplification of N-myc, promotes cell survival and growth, and possibly tumor initiation and promotion [68]. Interestingly, the PI3K/Akt pathway is implicated in ROS related disorders and has been linked to control of nuclear-receptor factor 1 (NRF-1) signaling in mitochondrial biogenesis [69], linking two biological mechanisms thought to be important in environmental disease.

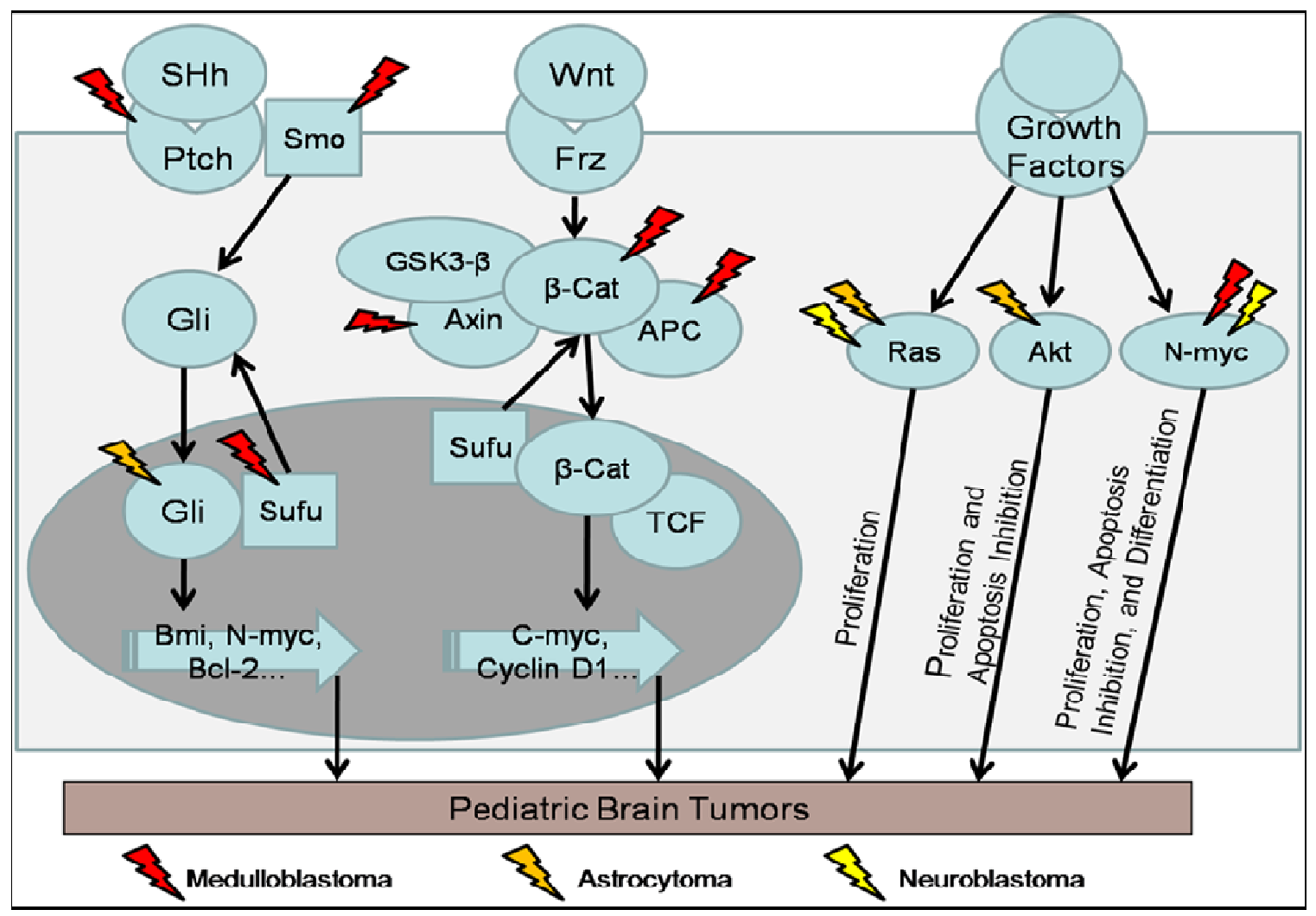

Figure 1-2. Dysregulation of developmental pathways in pediatric brain tumors (pBT). Alterations in pathways important to cellular growth, proliferation and differentiation during development appear to be important to $\mathrm{pBT}$ etiology. Cross-talk between these pathways has also been shown. Lightning bolts signify alterations in genes linked to development of their respective $\mathrm{pBT}$. 


\section{GENETIC AND EPIGENETIC ALTERATIONS IN PEDIATRIC BRAIN TUMORS}

The differing demographic profiles and heterogeneity within and between types of pBT suggests differing etiology for these tumors, with genetic alterations possibly playing a more substantial role in some tumor types than in others, and individual cell types perhaps being more vulnerable to toxins at different stages of development [70]. Additionally, this heterogeneity suggests the probable involvement of epigenetic and mitochondrial mechanisms of disease, both of which have been shown to interact with the environment to produce heterogeneous disease profiles [7]. Despite these probable etiologic differences, the research highlighted above suggests that many pBTs may have a common origin through in utero and early life disruption of developmental pathways. Alterations in developmental pathways do not currently account for a majority of pBTs however, and few other significant genetic changes in these tumors have been established. However, when taken as a whole, the collective alterations identified within some of the common pBTs does fit a model where environmental factors interacting with numerous genetic and epigenetic changes influences cellular proliferation and function to produce tumorigenesis. As referenced in section II, several genetic disorders have been linked to development of pBTs. Several mutations in genes causing these familial forms of pBT have been identified (Table 1-2). These genes, most of which are tumor suppressors, also appear altered in sporadic cases of their respective brain tumor types. Moreover, some also function in the developmental processes discussed above. 
Table 1-2. Disorders and mutations in genes causing familial forms of pediatric brain tumors.

\begin{tabular}{|c|c|c|c|c|}
\hline Disorder & pBT Туре & $\begin{array}{l}\text { Germline } \\
\text { Mutation }\end{array}$ & Locus & $\begin{array}{l}\text { Signaling } \\
\text { Pathway }\end{array}$ \\
\hline $\begin{array}{c}\text { Neurofibromatosis } \\
\text { Type-1 }\end{array}$ & Astrocytoma & NF1 & $17 \mathrm{q} 11.2$ & Ras \\
\hline $\begin{array}{l}\text { Li-Fraumeni } \\
\text { Sydrome }\end{array}$ & Astrocytoma, PNET & $\mathrm{p} 53$ & $17 \mathrm{p} 13$ & $\mathrm{p} 53$ \\
\hline $\begin{array}{c}\text { Basal Cell Nevus } \\
\text { (Gorlin's) } \\
\text { Syndrome }\end{array}$ & Medulloblastoma & PTCH & $9 q 22.3-q 31$ & $\mathrm{SHh}$ \\
\hline Turcot Syndrome & $\begin{array}{l}\text { Medulloblastoma } \\
\text { Malignant Glioma }\end{array}$ & APC & $5 \mathrm{q} 21$ & Wnt \\
\hline $\begin{array}{c}\text { Ataxia } \\
\text { Telangiectasia }\end{array}$ & $\begin{array}{c}\text { Medulloblastoma } \\
\text { Pilocytic Astrocytoma }\end{array}$ & ATM & $11 q 22-23$ & ATM/p53 \\
\hline
\end{tabular}

V. ENVIRONMENT, MITOCHONDRIAL-NUCLEAR INTERACTIONS, AND DEVELOPMENT OF PEDIATRIC BRAIN TUMORS

Given that mutations in mtDNA have been reported in most cancers (reviewed in [71]), it appears important to consider their effect on tumorigenesis. A key argument in cancer initiation to date however, has been 'what comes first, mitochondrial dysfunction or tumor formation?'. Until recently, most reports have suggested that mitochondrial dysfunction occurs after tumor formation. However, research in 2000 and 2001 showing that inherited and sporadic cases of brain tumors (paraganglioma and pheochromocytoma) are caused by mutation of succinate dehydrogenase, a mitochondrial-specific protein of the Krebs cycle, provided support to the idea that mitochondria (mt) may control tumorigenesis. Subsequently, mutations in another mitochondrial Krebs cycle protein, fumarase, were associated with the development of uterine fibroids, skin leiomyomata and renal cell cancer. Though the specific mechanisms for tumor formation in these instances are yet to be determined, it has been suggested that accumulation of these proteins in mitochondria could lead to a decrease in 
the ROS-scavenging activity of the respiratory chain, causing excess superoxide and tumor initiation [72]. Importantly, it appears mutations in either the mitochondrial or nuclear genomes could lead to tumorigenesis, as alterations in both genomes have been shown to lead to mitochondrial diseases [73;74]. Alterations in the epigenome of both the nucleus and mitochondria may also play a role in tumorigenesis, as recent research demonstrating that depletion of mtDNA can regulate epigenetic modification in the nucleus suggests [75]. These tumorigenic scenarios described above fit well with a model where both cell death and proliferation are in large part controlled by the functioning state of the mitochondria. In this model, the redox state of the cell would be of ultimate importance to development of disease. While a low level of ROS would allow for normal cellular function, increasing ROS amounts would signal increased cell proliferation, and an overwhelming excess of ROS would trigger apoptosis. Importantly, research showing that mtDNA-depleted cells increased antioxidant levels (MnSOD) and resisted apoptosis even in an elevated ROS environment, suggest that mitochondrial apoptosis pathways may often be blocked even in dysregulated mitochondria, allowing for cellular transformation to occur [76]. Given that interaction between mitochondrial and nuclear genomes is essential for normal cellular function, variations in the mitochondrial redox state could be of tremendous importance for the fate of the cell, and ROS signaling could have a central role in communication between mitochondria and the nucleus.

Because mitochondria play a large part in brain development [77] and are abundant in brain tissue [78], their health is critical to the wellbeing of the pediatric brain. The pediatric brain is at high risk of oxidative stress and very susceptible to free radical 
oxidative damage [79]. The electron transport chain (ETC) found in brain mitochondria can be impaired by both inherited and acquired mutations (Stewart et al. 2000). An impaired ETC leads to decreased ATP production, increased ROS formation, and altered calcium homeostasis. Thus, mutations in mitochondrial DNA (mtDNA) and nuclear DNA (nDNA) could affect cellular energy levels, increase oxidative stress, cause ROSmediated damage to both the mitochondrial and nuclear genome, affect cellular differentiation, and alter the cellular response to apoptosis [80-83]. Figure 1-3 provides a schematic overview of how environmental factors could interact with dysfunction in mitochondrial-nuclear signaling pathways and developmental pathways to produce $\mathrm{pBTs}$.

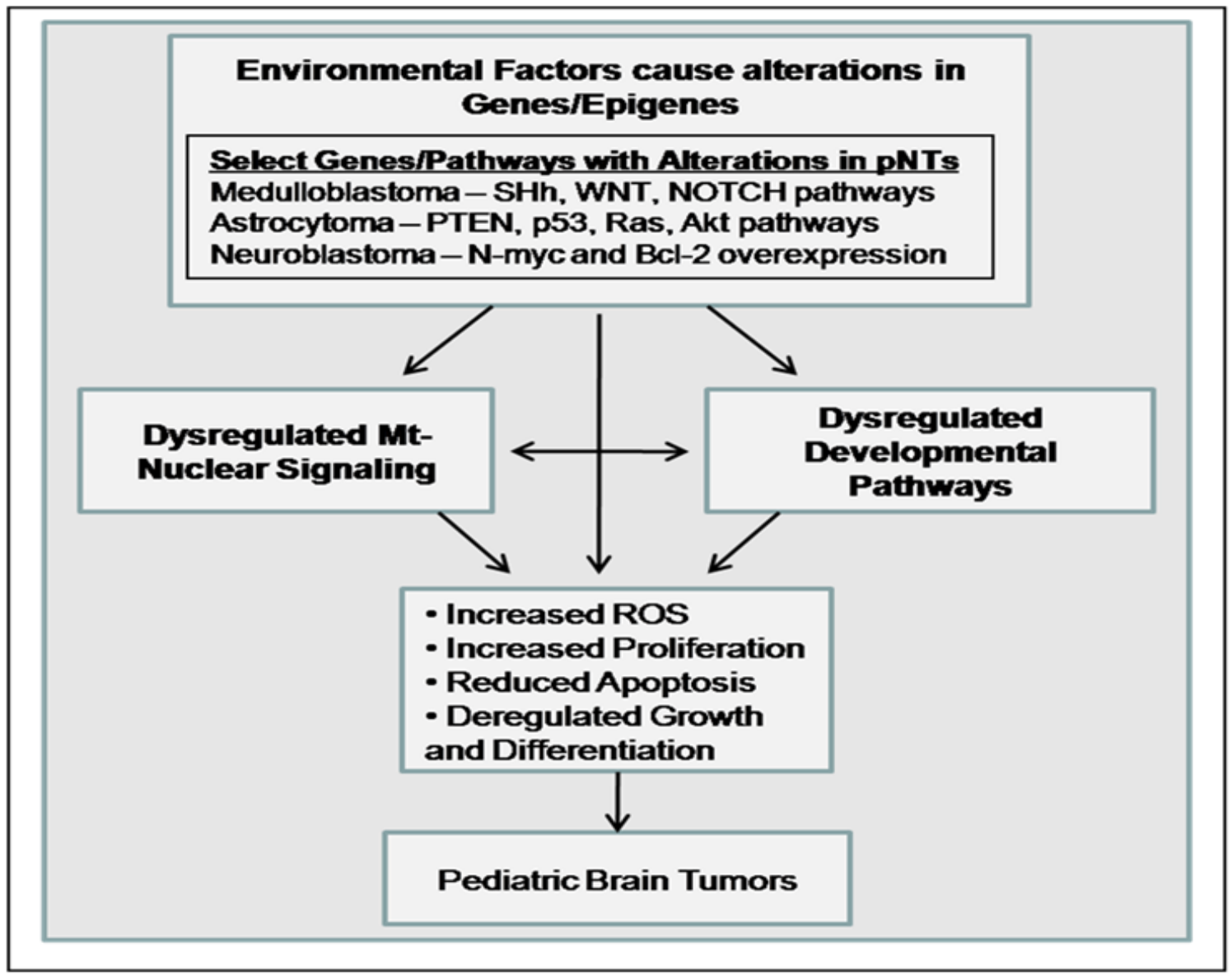

Figure 1-3. Interaction of environmental factors, dysregulation of mt-nuclear signaling and developmental pathways, and development of pediatric brain tumors. 


\section{Effects of early life exposures on mitochondria and the pediatric brain}

There is a growing body of evidence suggesting that there are critical periods of time extending from conception to puberty when the reproductive [84], immune [85], nervous [84], and endocrine [86] systems in children may be more affected by chemical exposures. In fact, a consensus group has concluded that there is sufficient evidence to support the hypothesis that in utero and early life exposures can lead to cancer in both children and adults [87]. Evidence supporting this conclusion includes experimental findings that suggest tumors initiated in utero can be promoted postnatally, resulting in cancerous growths [88]. Additionally, the ability of environmental exposures to cause micronuclei, chromosomal aberrations, sister chromatic exchanges, DNA adducts, DNA single-strand breaks, and somatic mutations in the DNA of a fetus has been demonstrated (reviewed in $[89 ; 90]$ ).

Several characteristics of the developing brain in pediatrics may make agents normally thought not to target the central nervous system harmful to the brain during these critical time periods. These include the blood-brain barrier of the fetus being incompletely developed, the immune system being compromised due to its immaturity, and the increased vulnerability of the developing nervous system to carcinogenesis [91]. Furthermore, several factors including high rates of cell division, lowered detoxification capabilities, and clonal expansion of initiated cells are thought to explain the increased sensitivity of embryos, fetuses, and newborns to chemical carcinogens (reviewed in [92]). Many carcinogens, including ENU, cadmium, and monosodium glutamate, have been shown to freely traverse the blood-brain barrier of a developing fetus in experimental animals, while being blocked from entering the mature brain [93;94]. Furthermore, 
numerous agents including rubella virus, lead, methylmercury, retinoids and thalidomide have been shown to be neurotoxic when exposure occurs during gestation. These same agents show no neurotoxicity after adult exposures [94]. Though few quantitative studies on this topic have been completed, one study assessing the blood-brain barrier of sheep during the last two months of gestation and the first month of neonatal compared to adult animals found that the influx of radioactive compounds in all regions of the brain decreased significantly with maturation $(\mathrm{p}<0.0001)$. A more in depth review on this topic has been published by Adinolfi 1985. [95]

Experimental evidence linking early life exposures to mitochondrial dysfunction and $p B T$ development

The effects of environmental exposures on BT development have been studied both in vitro and in animal models. Several studies have investigated manganese toxicity in brain tumor cell lines. Manganese (Mn) exposure in humans is rare but can occur through occupational pathways. Mn targets brain mitochondria and interferes with energy metabolism in both astrocytoma and neuroblastoma cells through reduction of activity of glycolytic and TCA enzymes such as hexokinase, pyruvate kinase, lactate dehydrogenase, citrate synthase, and malate dehydrogenase [96]. As a result of this metabolic change, Mn exposure may increase oxidative stress via activation of the mitochondrial permeability transition pore (mPTP), a result found in Mn exposed astrocytes [97]. Manganese-induced cell death in both astrocytoma and neuroblastoma cells is primarily necrotic in nature and is enhanced by glutathione depletion [98]. Interestingly, neuroblastoma cells are more susceptible to Mn toxicity than GBM cells, 
possibly because of Mn treatments effects on apoptosis in GBM cells. On treatment in GBM cells, Mn increases apoptosis and has differential effects on proliferation pathways as it induces down-regulation of MAPK pathway, but does not significantly affect the AKT pathway. Furthermore, Mn reduces levels of c-Jun, c-Fos, and MMP-2 (an extracellular matrix degrading enzyme), which are all associated with invasiveness of GBM [96].

An in vitro study investigating the effect of chlorpyrifos exposure on glioma cells found that the cell signaling interference produced by chlorpyrifos exposure was greater in undifferentiated cells compared to differentiating cells, though effects were still noticed on this cell type as well. However, differentiation enhanced reactive oxygen species (ROS) production from chlorpyrifos exposure and provoked shortage of the nuclear transcription factor $\mathrm{Sp} 1$, an essential molecule in differentiation [6]. Other in vitro studies include a report which found selenium levels in the cerebrospinal fluid of patients with malignant brain tumors to be lower than those with benign tumors. Furthermore, selenium's anticancer effects are seen in its ability to preferentially target human glioma cells for cell death through induction of superoxide and its subsequent disruption of mitochondria [99]. In vivo studies showing environmental exposure effects on BT have been performed on several animal species. Studies in rats and mice showing transplacental induction of BT from chemical exposures have mainly produced glial tumors (most commonly oligodendrogliomas), with some meningeal tumors being induced as well, and peripheral nervous tumors only rare occurrences. Significant incidences of BTs in rats using long-term bioassays have also been produced through exposure to acrylonitrile, acrylamide, 1,3-butadiene, ethylene oxide, glycidol, and 
isoprene; the alkylating agents1,3-propane sultone and 2-methylaziridine; and a several hydrazine derivatives including 1,2-diethylhydrazine [5]. Studies in mice show increased susceptibility to brain mutations for prenatal and neonatal (N-ethyl-N-nitrosourea) ENUexposed mice over adult ENU-exposed mice [100]. It should be noted that while numerous tumor types have been produced from transplacental exposure of rodents, most tumors are not of embryonal origin, but instead are of glial origin and only become clinically evident in adult rats. Other in vivo studies have found that phenothiazine chlorpromazine can cause CNS abnormalities in the fetus (Kovacic and Jacintho 2001b), while cadmium has been shown to be toxic to sensory ganglia in many animal species (Habeebu et al. 2001).

Experiments on mitochondrial function in the nervous system point to their involvement in environmentally-induced BTs. Because mitochondria are the main source of superoxide in physiologic conditions, the detoxification of superoxide by mitochondrial MnSOD plays an important role in neuroprotection and ROS homeostasis [101]. Even a modest increase in endogenous ROS could damage both mtDNA and nDNA, leading to cancer development, genetic instability, and disease progression. MnSOD has been shown to have high activity in mice brain when compared to other tissues such as lungs [102]. Because the MnSOD by-product $\mathrm{H}_{2} \mathrm{O}_{2}$ is itself a ROS, it is interesting to note that overexpression of MnSOD in rat glioma cells increased risk for oxidative damage [103]. However, loss of MnSOD also produces neurodegeneration, DNA oxidative damage and mitochondrial respiratory chain abnormalities, indicating that both overexpression and underexpression of MnSOD can be harmful [104]. A more 
focused discussion on mitochondrial ROS production and its effects on the pediatric nervous system is provided below.

\section{Mitochondrial ROS, electron transport chain defects, and pediatric susceptibility}

Mitochondrial ETC disorders are believed to occur with an incidence of 1/10,000 live births and research correlates increases in mitochondrial ROS production with both neurodegenerative disease and cancer in animal models [105;106]. In fact, the importance of ROS levels and pBT development can be seen in the fact that numerous genes and signal transduction pathways important to normal fetal brain development (i.e. myc) can be influenced by ROS $[107 ; 108]$. While, no studies to date have been published on age-dependent differences in brain mitochondrial ROS production in immature animals, research has documented developmental disparities in antioxidant defense systems. Both Mavelli et al. [109] and Khan et al. [110] reported increases in mitochondrial MnSOD in the first weeks of life in mice. Mavelli et al. reported no significant changes with age were noted for $\mathrm{Cu}, \mathrm{Zn}-\mathrm{SOD}$ or GPX activity, while catalase activities were inconclusive. On the contrary, Khan et al. did report an increase in GPX activity near birth. One report also noted a developmental lag in SOD-1 and SOD-2 when compared with GPX and catalase levels present in prenatal telecephalic white matter [111]. On the whole, the above studies describe a profile where a newborn brain must be protected from oxidative stress through increased activity of antioxidant enzymes in utero and around birth.

The large transmembrane protein cytochrome $c$ oxidase (aka complex IV or COX) is the last enzyme in the ETC of mitochondria. This complex catalyzes the transfer of 
electrons from reduced $\mathrm{COX}$ to molecular oxygen to form water, and ultimately, ATP through the coupled process of oxidative phosphorylation. The importance of COX to neurons is seen in this enzyme's reduced expression in neurodegenerative diseases, such as Alzheimer disease [112]. This is because neurons, which are highly dependent upon ATP for their activity and functions [113], receive roughly $90 \%$ of their ATP from mitochondria via oxidative phosphorylation [114]. MtDNA diseases exhibit low COX activity and evidence points to clonal expansion of individual mtDNA deletions within single cells as a reason for this decreased action [115]. Moreover, COX deficiency most often manifests in high energy demand organs, such as the brain [78], and is the most prominent ETC defect in infancy and early childhood [116]. Finally, genotype of Tfam, a key regulator of mtDNA copy number and mitochondrial transcription, is associated with a moderate risk for Alzheimer's disease [117]. Evidence suggests that Tfam may protect against mtDNA damage by preventing a decrease in mtDNA copy number and ETC function, an action that ultimately may protect against oxidative stress and its effects on lipid peroxidation, apoptosis, and mtDNA [118]. Importantly, Tfam, appears to accomplish much of these actions through interaction with NRF-1 and other nuclear genes controlling mitochondrial biogenesis and function [119-121]. Furthermore, while nuclear proteins contribute to mitochondrial regulation, mitochondria can also modulate the expression of nuclear cell cycle genes [119], suggesting the importance of cross-talk between the cell nucleus and mitochondria in the apoptosis, proliferation, and differentiation of both normal and malignant cells. We now discuss possible implications of this cross-talk on $\mathrm{pBT}$ development. 


\section{Evidence of mitochondrial-nuclear interactions and mitochondrial dysfunction in $p B T s$}

Recent evidence is beginning to provide a foundation which does in fact support a model of mitochondrial-nuclear signaling dysfunction in formation of tumors, including pBTs. Studies in yeast models and human cancer cell models showed that depletion of mtDNA increased oxidative stress which then produced extensive damage to the nuclear genome [81;122]. Additionally, it appears that expression of certain nuclear genes may play a key role in mitochondrial mediated tumorigenesis. In fact, APE1, a nuclear encoded gene involved in redox regulation, apoptosis, and DNA repair (both independently and through interaction with p53), may be one such gene, as it was shown to underexpressed in $68 \%$ (13 of 19) of CNS tumors [123]. It appears mitochondrial defects can lead to down regulation of APE1 to produce tumors. Restoration of expression of APE1 in mtDNA depleted cells reversed the tumorigenic feature of anchorage independence, suggesting that restoration of mtDNA could reverse tumorigenesis in these cells. Significantly, DNA binding activity of genes regulated by APE1 is sensitive to reduction-oxidation (redox). Proteins for which APE1 functions as a

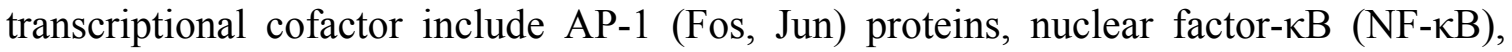
polyoma virus enhancer-binding protein, early growth response-1, Myb members of the ATF/CREB family, HIF-1 $\alpha$, HIF-like factor, Oak5 and Pax-8 [123;124]. Interestingly, AP1 and NF-KB have been shown to mediate the expression of proteins involved in neuronal function and survival [124;125], and APE1 itself has been shown to promote survival of neurons after oxidative stress [126] and to be essential for proper embryonic development [125]. Additionally, APE1 has been shown to repair DNA, influence 
apoptosis, and interact with $\mathrm{p} 53$, a protein found upregulated in many cancers, including many pBTs.

The above evidence highlights a nuclear protein and its links to redox signaling in pBT development. We now present other evidence of mitochondrial dysfunction in $\mathrm{pBT}$, first on mitochondrial genome alterations, and then on mitochondrial apoptotic pathways.

Identified alterations in the mitochondrial genome of BTs: Several features distinguish the mitochondrial and nuclear genomes, some of which allow mtDNA to be far more vulnerable to mutations than nDNA. mtDNA's lack of histone protection, limited repair capacity, and close proximity to the electron transport chain (and hence superoxide radicals), are a few major reasons for this increased susceptibility to damage. While mtDNA is more vulnerable to damage, the fact that only a small percentage of its proteins are coded by mtDNA increases the chances that a mutation that affects mitochondrial function will occur in chromosomal DNA. In fact, of over 3000 mitochondrial proteins, mtDNA only encodes (1) 13 subunits of respiratory chain complexes: seven subunits (ND 1-6 and 4L) of complex I, cytochrome b (Cyt b) of complex III, the COX I-III subunits of cytochrome oxidase or complex IV, ATPase 6 and 8 subunits of $\mathrm{F}_{\mathrm{O}} \mathrm{F}_{1}$ ATP synthase; (2) the $12 \mathrm{~S}$ and $16 \mathrm{~S}$ rRNA genes; and (3) 22 tRNA genes. The remainder of the proteins are encoded by nuclear DNA and imported into the mitochondria by chaperones. Still, somatic mtDNA mutations have been linked to several cancers, and while their contribution to tumorigenesis has been debated, recent studies have concluded that mutant mitochondria positively and directly contribute to tumorigenesis by preventing apoptosis [127]. Additionally, novel research showing depletion of mtDNA encoded OXPHOS genes plays a role in tumor cell transformation 
supports the involvement of mtDNA alterations and depletion in tumorigenesis [128]. Here we review alterations in mtDNA that have been observed in the mitochondrial genome of both pediatric and adult BTs.

The D-loop region of mitochondria is a region important for replication and $\mathrm{mt}$ nucleoid organization found mutated in many cancers. Several BTs, including meningiomas, schwannomas, gliomatosis cerebri, neurofibroma, astrocytoma and GBMs have been shown to have mitochondrial genome instability in the hypervariable regions of the D-loop. Somatic mtDNA mutations of this region have been found in tumors of NF1, a familial disease which predisposes to development of pilocytic astrocytoma [129]. Astrocytic tumors themselves, in fact contain mutations in this region, as a recent study of 42 cases of malignant astrocytomas (39 GBMs, two anaplastic astrocytomas, and one anaplastic oligoastrocytoma) showed alterations in $36 \%$ of the cases in the D-loop region, including 16 different somatic alterations [three in the hypervariable 1 region (HV1) and thirteen in the D310 region] [130]. This frequency is comparable to other reports of mtDNA instability in malignant gliomas $[131 ; 132]$. These alterations do not appear to be associated with increased aggressiveness however [130]. Furthermore, somatic mtDNA mutations have been observed in a series of chemically induced and spontaneous mouse brain tumors in regions that correspond to the hypervariable regions of human mtDNA, though they do not appear to alter the amino acid sequence however, and therefore may not affect disease status [133].

Studies have also found mitochondrial mutations in other regions of the mitochondria as well. One study, which analyzed the entire mitochondrial genome of 15 cases of MB and the cerebrospinal fluid (CSF) of eight of these 15 cases, found that $40 \%$ (6 of 15 ) of 
the tumors and $87.5 \%$ ( 7 of 8 ) of the CSF samples had at least one mtDNA mutation. The somatic mutations identified in this study, which were located primarily in regions of mononucleotide repeats but also in respiratory chain related genes, include: three coding region mutations 1) G7521A mutation in tRNA aspartate that changes a GT base pairing to AT base pairing at the amino acyl stem region, 2) the T15904C mutation in tRNA threonine at the loop region, and 3) the A15937G mutation at the first bp next to the loop, all of which may affect tRNA structure and stability; two missense mutations that can alter mt structure and function: 1) $\mathrm{Y} 496 \mathrm{H}$ in cytochrome c oxidase and 2) L96P in NADH subunit 4, which are involved in the substitution of the hydrophobic aromatic tyrosine with positively charged histidine, and the hydrophobic leucine residue with $\alpha$ helix destabilizing secondary amino acid proline; and several noncoding region mutations in areas such as transcription factor binding sites and replication primer sites that can affect mtDNA replication, transcription, and expression. 5 (29.4\%) mutations were located in the $\mathrm{np} 303-315$ polyC tract region and $11(61 \%)$ were in the previously discussed D-loop region.

Studies have also identified other alterations in BTs, with the most frequent observation involving changes in the copy number of mtDNA. A study that examined 45 glioma specimens found that mtDNA was highly amplified in $87 \%$ of the cases. In comparison, a nuclear-encoded reference gene (erb-b) that is frequently amplified in human cancers, increased in only $18 \%$ of the tumor specimens, indicating that mtDNA alterations may be much more frequent in gliomas than nuclear-encoded gene alterations. In addition, a high frequency of mtDNA copy number changes has been found in comparison to normal control tissue in both low and high grade gliomas. Furthermore, 
the mt content of gliomas is significantly lower than normal rat brain tissue, as is activity levels of cytochrome c oxidase and citrate synthase. Differential hybridization experiments have also revealed decreased expression of seven mt genes in GBM tumors. Genes downregulated were mt NADH dehydrogenase subunits 1 and 4 (ND1; ND4); mt cytochrome oxidase subunits I, II, and III (COXI; COXII; COXIII); mt ATP synthase subunit 6 (ATP6); and mt 12S rRNA. Regardless of their functional significance, the above studies clearly show that mtDNA alterations are a frequent event in the development and progression of brain disease pathologies and warrant further investigation.

Mitochondrial-directed apoptosis and pBTs: Defects in the regulation of apoptosis (programmed cell death) can contribute to development of cancer by a failure to eliminate harmful cells. The mitochondria's link to control of apoptosis could play an important role in $\mathrm{pBT}$ etiology, as most tumors are often relatively resistant to the induction of the mPTP, the rate-limiting step of the intrinsic pathway of apoptosis. Mitochondria play a large role in apoptosis, with their intermembrane space acting as a storage site for numerous pro-apoptotic proteins, including cytochrome $\mathrm{c}$ and apoptosisinducing factor (AIF). Both oxidative stress and mitochondrial calcium $\left(\mathrm{Ca}^{2+}\right)$ overload can favor activation of the mPTP (Crompton 2004), leading to release of cytochrome c and the induction of caspase-mediated apoptosis [134]. In addition, as mentioned above, a more specific pathway to apoptosis exists in which Bcl-2 family proteins (e.g. Bax, Bid) regulate cytochrome $\mathrm{c}$ release through binding to the outer mitochondrial membrane. Other proteins involved in apoptosis, such as AIF, endonuclease G, and Smac/Diablo are also released in this process [135]. It appears environmental factors may be important in 
determining which apoptotic pathway is chosen as research on the ERK signaling pathway, shows that $\mathrm{H}_{2} \mathrm{O}_{2}$-induced apoptosis in glioma cells may be initiated upstream of the mitochondria [136]. In contrast, a study investigating exposure of neuroblastoma cells to thimerosal, an organomercury compound used in vaccines, found that apoptosis was induced through the cytochrome c/caspase mitochondrial cascade described above [137]. Additionally, experiments on the proapoptotic Apoptosis Related Protein in TGF beta Signaling Pathway (ARTS) using astrocytic tumors also point to mitochondrialmediated apoptosis in brain tumors [138].

Selective programmed apoptosis is an important part of normal brain development. In fact, more than $50 \%$ of some neuronal populations actually die during the pre- and postnatal period [139]. Several major apoptotic pathways, working through the mitochondria, play a major part in these early developmental processes, and their dysregulation may affect risk of pBT development. The Bcl-2/Bax, cytochrome c complex governs apoptosis through control of the cytochrome c levels via the mitochondrial permeability transition pore (mPTP) of the mitochondria. The antiapoptotic Bcl-2 protein strongly protects against free radical-mediated cell death by preventing release of cytochrome c, while other members of the bcl family (i.e. Bax) promote apoptosis [140]. Studies have shown Bcl-2 expression levels in the neocortex and hippocampus of the developing rat to be extremely elevated during development and the first week of life. These levels then show a rapid decrease to low levels in childhood and relatively non-existent levels in adulthood [141]. Caspases, which can be activated by the Bcl-2/cytochrome c complex, also regulate many aspects of apoptosis during development. It appears the interplay between these systems during development may be 
important in the etiology of brain-related disorders as deletion of caspase-3, -9 or Apaf-1 in mice results in gross malformations specific to brain because of defective apoptosis and hyperplasia [142]. Furthermore, recent evidence shows that SHh signaling promotes survival of medulloblastoma cells via up-regulation of Bcl-2, linking a developmental pathway and mitochondrial-mediated apoptosis to pBT development [143].

\section{POPULATION STUDIES ON GENE-ENVIRONMENT INTERACTIONS IN PEDIATRIC BRAIN TUMORS}

Very few epidemiological studies to date have investigated GEI in relation to BT development, especially in pediatric populations (see Table 1-3 for a summary of current research). To date, only one epidemiologic study has assessed the effect of environmental interactions with gene mutations on development of pBT. In this study, two frequent polymorphisms in Paraoxonase (PON1), a gene that metabolizes two residentially used insecticides (chlorpyrifos and diazinon), were investigated in relation to BT [n = astrocytoma (37), PNET (15), other (14)]. A non-significantly increased risk of $\mathrm{pBT}$ in relation to the inefficient PON1 promoter allele (PON1-108T allele, relative to PON1-108CC: odds ratio $(\mathrm{OR})=1.4 ; 95 \%$ confidence interval $(\mathrm{CI}), 1.0-2.2 ; \mathrm{p}$-value for trend $=0.07]$ was found. However, this association was strongest and reached statistical significance among children whose mothers reported chemical treatment of the home for pests during pregnancy or childhood $\left(\mathrm{PON} 1_{-108 \mathrm{~T}}\right.$ allele: among exposed, $\mathrm{OR}=2.6 ; 95 \%$ $\mathrm{CI}, 1.2-5.5$; among unexposed, $\mathrm{OR}=0.9 ; 95 \% \mathrm{CI}, 0.5-1.6)$ and when primitive neuroectodermal tumors were assessed alone (per PON1-108T allele: $\mathrm{OR}=2.4 ; 95 \% \mathrm{CI}$, $1.1-5.4)[144]$. 
In addition to the above GEI study on pBT, two studies have assessed GEI in adult glioma. A case-control study on lead exposure, the lead toxicity associated gene $\delta$ aminolevulinic acid dehydratase (ALAD), and risk of brain tumors found increased risk of meningioma with occupational lead exposure. Risk of meningioma, a tumor present mainly in later life, was markedly increased in individuals with the ALAD2 variant allele, for whom risks increased in a dose dependent fashion from $1.1(0.3-4.5)$ to $5.6(0.7-45.5)$ and 12.8 (1.4-120.8) compared to unexposed persons. Risk for glioma was not associated with occupational lead exposure [145]. A second adult GEI study on glutathione transferases (GST) polymorphisms, cigarette smoke exposure, and development of adult glioma failed to find any significant GEI [146]. Several other studies have investigated genes involved in detoxification of carcinogens, and their relation to both $\mathrm{pBT}$ and aBT development, though no exposure was considered in these studies. Polymorphisms in the carcinogen metabolizing genes GSTM1, GSTP1, and GSTT1 have been investigated for their effect on risk of pBT. The frequency of the GSTM1 null allele was found to be significantly lower in high-grade pediatric astrocytomas $(\mathrm{p}<0.002)$. Additionally, a significant increase in the frequency of the rare GSTP1 variant Val114/Val114 was found in all pediatric astrocytomas combined $(\mathrm{p}<0.002)$ and all pediatric brain tumor types that displayed microsatellite instability (MSI) from mismatch repair (MMR) defects (0.003), suggesting this genotype may define a population susceptible to $\mathrm{pBT}$ development. This same study assessed these polymorphisms in relation to aBT and found no relation of GST polymorphisms to tumor development [147]. Another study found the relative risk of $\mathrm{pBT}$ to be increased 4.9-fold for patients carrying one non-null (GSTM1*A) allele of GSTM1 compared to patients with two null alleles $(95 \%$ confidence interval $1.5-16, \mathrm{P}=$ 
0.009) [148]. Finally, a meta-analysis on GST polymorphisms and adult brain tumor risk also failed to find any association between GST and tumor development, though the GSTT1 null genotype was associated with meningioma development (OR $=1.95 ; 95 \% \mathrm{CI}$, $1.02-3.76)[149]$.

Population studies on folate involvement in BT development have also been performed. Folate is an important micronutrient molecule involved in DNA synthesis and methylation. Studies have linked folate deficiency with both pediatric cancer [150;151] and genomic damage [152]. Disturbances in DNA synthesis, methylation, and repair of this pathway may be involved in BT development [153]. An investigation of single nucleotide polymorphisms (SNPs) in the folate pathway [methylenetetrahydrofolate reductase (MTHFR) C677Tand A1298C, methionine synthase (MTR) A2756G, thymidylate synthase (TS) 28-bp tandem repeat, and reduced folate carrier (RFC) G80A] and their relation to NT susceptibility in pediatrics found that the homozygous CC allele of MTHFR A1298C, which reduces MTHFR activity, conferred an increased risk of BT (medulloblastoma, pineaoblastoma, and PNETs) (OR: 3.9; $95 \%$ CI: $1.3-11.4, \mathrm{p}=0.02$ ). $\quad$ SNPs in glial tumors (astrocytoma, oligodendroglioma, and ependymoma) were not related to development of disease [154]. A recent report on folate pathway SNPs in adult meningioma and high grade glioma found that MTHFR C677T and A1298C genotypes associated with increased 5,10 methylenetetrahydrofolate levels elevated disease risk while another report on these tumors failed to associate the MTHFR 677T SNP with tumor development [155]. Dietary influence on brain tumors also find support in animal models as incidence and degree of aggressiveness of gliomas has been shown to be influenced by dietary 
Table 1-3. Summary of gene-environment interaction studies conducted on pediatric and adult brain tumors.

\begin{tabular}{|c|c|c|c|}
\hline $\begin{array}{c}\text { Study } \\
\text { Reference }\end{array}$ & Tumor Type (n) & Population & $\begin{array}{c}\text { Results (risk estimate; 95\% Confidence } \\
\text { Interval) }\end{array}$ \\
\hline $\begin{array}{l}\text { Searles } 2005 \\
{[144]}\end{array}$ & $\begin{array}{l}\text { Glioma (37); } \\
\text { PNET (15); } \\
\text { Other (14) }\end{array}$ & $\begin{array}{c}\text { Children } 0-20 \text { yrs } \\
\text { old from Seattle, } \\
\text { WA area }\end{array}$ & $\begin{array}{l}\text { PON1 interaction with insecticide } \\
\text { (chlorpyrifos, diazinon) found non-significant } \\
\text { risk increase in inefficient promoter allele }(1.4 \text {; } \\
1.0-2.2) \text {; children whose mothers treated home } \\
\text { for pests during pregnancy or childhood }(2.6 ; \\
1.2-5.5) \text { and PNET alone }(2.4 ; 1.1-5.4) \text { reached } \\
\text { significance in inefficient allele however }\end{array}$ \\
\hline $\begin{array}{l}\text { Rajaraman } \\
2006[145]\end{array}$ & $\begin{array}{l}\text { Glioma(382); } \\
\text { Meningioma } \\
\quad(158)\end{array}$ & $\begin{array}{l}\text { Adults from } \\
\text { Phoenix, AZ, } \\
\text { Boston, MA, and } \\
\text { Pittsburgh, PA }\end{array}$ & $\begin{array}{l}\text { Lead exposure and ALAD gene found } \\
\text { significant increased risk for meningioma and } \\
\text { ALAD2 variant allele in a dose dependent } \\
\text { fashion }(1.1 ; 0.3-4.5 \text { to } 5.6 ; 0.7-45.5 \text { to } 12.8 \text {; } \\
1.4-120.8)\end{array}$ \\
\hline $\begin{array}{l}\text { Schwarzbaum } \\
2007[146]\end{array}$ & $\begin{array}{l}\text { Glioblastoma } \\
\text { (329); } \\
\text { Meningioma } \\
\quad(546)\end{array}$ & $\begin{array}{l}\text { Adults from } \\
\text { Sweden, southeast } \\
\text { England, } \\
\text { Denmark, and } \\
\text { Finland. }\end{array}$ & $\begin{array}{l}\text { No associations between the } G S T M 3, G S T P 1 \text {, } \\
N Q O 1, C Y P 1 A 1, G S T M 1 \text {, or GSTT1 } \\
\text { polymorphisms and adult brain tumor risk with } \\
\text { the possible exception of a weak association } \\
\text { between the } G-C \text { (Val-Ala) GSTP1 } 105 / 114 \\
\text { haplotype and glioma [odds ratio (OR), } 0.73 \text {; } \\
95 \% \text { confidence interval }(95 \% \text { CI), } 0.54,0.99 \text { ], } \\
\text { nor was there an interaction between the effects } \\
\text { of the } G S T M 3 \text { or } G S T P 1 \text { polymorphisms and } \\
\text { cigarette smoking. }\end{array}$ \\
\hline $\begin{array}{c}\text { Barnette } 2004 \\
{[148]}\end{array}$ & $\begin{array}{l}\text { Glioma (32); } \\
\text { Medulloblastoma } \\
\text { (20); } \\
\text { Neuroblastoma } \\
\quad(18)\end{array}$ & $\begin{array}{l}\text { Children } 0-18 \text { yrs } \\
\text { old from Utah }\end{array}$ & $\begin{array}{l}\text { SNP's in GSTM1, GSTM3, GSTP1, and } \\
\text { GSTT1 were analyzed. The relative risk of glial } \\
\text { brain tumors was } 4.9 \text {-fold higher for subjects } \\
\text { carrying one non-null }\left(G S T M 1^{*} \text { A) allele of }\right. \\
\text { GSTM1 in comparison to subjects with two null } \\
\text { alleles ( } 95 \% \text { confidence interval } 1.5-16, P= \\
0.009) \text {. }\end{array}$ \\
\hline $\begin{array}{l}\text { Ezer 2002 } \\
\quad[147]\end{array}$ & $\begin{array}{l}394 \text { brain tumors } \\
\text { (221 adult and } \\
173 \text { pediatric } \\
\text { cases consisting } \\
\text { of } 197 \text { astrocytic } \\
\text { and } 197 \text { non- } \\
\text { astrocytic } \\
\text { tumors) }\end{array}$ & $\begin{array}{l}\text { Children and } \\
\text { adults }\end{array}$ & $\begin{array}{l}\text { SNP's in GSTM1, GSTT1, and GSTP1 were } \\
\text { analyzed. Significant increases in the } \\
\text { frequencies of the functional GSTM1 allele in } \\
\text { high-grade pediatric astrocytomas }(\mathrm{p}<0.002) \text {, } \\
\text { the rare GSTP1 variant Val114/Val114 in } \\
\text { pediatric astrocytomas ( }<00.002) \text {, and the rare } \\
\text { GSTP1 Val114/Val1 } 14 \text { genotype among } \\
\text { pediatric tumors showing microsatellite } \\
\text { instability (MSI) due to defects in mismatch } \\
\text { repair (MMR) proteins ( } \mathrm{p}=0.003) \text {. }\end{array}$ \\
\hline Lai 2005 [149] & $\begin{array}{l}\text { Glioma }(1,630) \\
\text { Meningioma } \\
\quad(245)\end{array}$ & $\begin{array}{l}\text { Meta-analysis of } 8 \\
\text { studies on adults, } \\
5 \text { of which were } \\
\text { from the United } \\
\quad \text { States }\end{array}$ & $\begin{array}{l}\text { No association between any of the GST variants } \\
\text { and the risk of glioma ( } 1.08 ; 0.95-1.22) \text {. } \\
\text { Subgroups of glioma also showed no } \\
\text { association. The T1 null genotype was } \\
\text { significantly associated with a risk of } \\
\text { meningioma }(1.95 ; 1.02-3.76)\end{array}$ \\
\hline $\begin{array}{l}\text { Sirachainan } \\
2008[154]\end{array}$ & $\begin{array}{l}\text { Gliomas (31); } \\
\text { Embryonal (28); } \\
\text { Germ cell (13); } \\
\text { Meningioma (1) }\end{array}$ & $\begin{array}{l}\text { Children from } \\
\text { Thailand }\end{array}$ & $\begin{array}{l}\text { Increased risk of embryonal CNS tumors for } \\
\text { homozygous CC allele of MTHFR A } 1298 \mathrm{C} \\
\text { (OR: } 3.9 ; 95 \% \text { CI: } 1.3-11.4, p=0.02 \text { ) }\end{array}$ \\
\hline
\end{tabular}




\begin{tabular}{|c|c|c|c|}
\hline $\begin{array}{c}\text { Study } \\
\text { Reference }\end{array}$ & Tumor Type (n) & Population & $\begin{array}{c}\text { Results (risk estimate; 95\% Confidence } \\
\text { Interval) }\end{array}$ \\
\hline $\begin{array}{c}\text { Kafadar } 2006 \\
{[155]}\end{array}$ & $\begin{array}{l}74 \text { tumors total } \\
\text { (Glioma; } \\
\text { Meningioma) }\end{array}$ & $\begin{array}{l}\text { Adults from } \\
\text { Turkey }\end{array}$ & $\begin{array}{l}\text { Though not significant }(\mathrm{p}=0.194) \text {, the } \\
\text { homozygous MTHFR TT genotype was found } \\
\text { at a higher frequency in glioma patients } \\
\text { compared to controls }(15.4 \% \text { and } 7.1 \% \text {, } \\
\text { respectively). The MTHFR genotype was not } \\
\text { associated with meningioma patients. Defining } \\
\text { patients with the CC genotype as reference, the } \\
\text { relative risk of glioma for subjects with the T } \\
\text { allele (CT+ TT genotype) was } 1.17 \text {. }\end{array}$ \\
\hline
\end{tabular}

supplementation of rats with phytochemicals. Rats fed a diet high in phytochemicals show both reduced incidence and aggressiveness of tumors and was associated with an increase in bcl-II and catalase and a decrease in ki-67, sod-1 and sod-2 transcripts [156]. This result correlates with an epidemiology study on adult glioma which showed reduced risk of glioma for those consuming a diet high in phytoestrogens [157].

\section{CONCLUSIONS}

There is a growing body of scientific evidence suggesting that there are critical periods of time extending from conception to puberty when the central nervous system in children may be more affected by toxic exposures. While only $1 \%$ of pediatric brain tumors are diagnosed at birth or in the first few months of life, the majority of pBTs occur early in childhood, strongly suggesting that both prenatal and postnatal exposures may be involved in their etiology. These exposures likely interact with the genome/epigenome of the fetus or young child to produce alterations in their genetic makeup which can predispose to development of disease including pBTs. Importantly, the ability of environmental exposures to cause micronuclei, chromosomal aberrations, sister chromatic exchanges, DNA adducts, DNA single-strand breaks, and somatic 
mutations in the DNA of a fetus has been demonstrated. Furthermore, many of these alterations have been shown to predispose to tumor development. These alterations likely play a role in $\mathrm{pBT}$ etiology and so we have discussed the frequent alterations. We have also highlighted a role for both developmental pathway alteration and mitochondrial dysfunction in the etiology of these tumors. It is likely, that pBTs result from the interplay of environmental factors with these biological mechanisms at critical developmental periods in a child's life.

Though past research has elucidated several potentially significant environmental, genetic and epigenetic factors in $\mathrm{pBTs}$, evidence linking a majority of $\mathrm{pBTs}$ to specific genetic or environmental exposures is limited. Factors such as the relatively low numbers of accessible tumor tissue for pBTs and the heterogeneity of these tumors have contributed to the considerable difficulty involved with determining their etiology. Moreover, most epidemiological research on these tumors has not considered important factors such as timing of exposure, gene-environment interaction, and gene-gene interaction within their design. Additionally, the ability to appropriately measure levels of exposure at time of development or predisposition to disease through molecular biomarkers has been limited. Improved research methods and tools, combined with larger studies involving homogenous tumor types, should help answer questions on the etiology of pBTs in the future.

While several genetic disorders have been linked to development of pBTs, it is likely that the majority of pBTs are a result of low-penetrant gene alterations in common pathways. Importantly, alterations and pathways that may be important to etiology in certain tumor types may not play a role in other $\mathrm{pBT}$ types. It is probable, that 
heterogeneity in alterations, and possibly even pathways, exists within tumor groups as well. Identification of which pathways are most significant in the etiology of each pBT type will be critical in developing therapies for these tumors. While therapies for single gene mutations have been successful in the past for certain cancers, it appears that therapies based on pathway inhibition will prove to be more successful in the treatment of tumors that have several mutations throughout a pathway such as pBTs. 


\section{Reference List}

1.Gurney J.G., Smith M.A., and Bunin G.R. CNS and miscellaneous intracranial and intraspinal neoplasms (ICCC III). Reis L.A.G., Gurney J.G., Linet M., Tamra T., Young J.L., and Bunin G.R. Online NIH Pub. no. 99-4649, 51-63. 1999.

Bethesda, MD, Cancer Statistics Branch, Cancer Surveillance Research Program, Division of Cancer Control and Population Sciences, National Cancer Institute. Cancer Incidence and Surival among Children and Adolescents: United States SEER Program 1975-1995.

2. Gurney,J.G., Wall,D.A., Jukich,P.J., and Davis,F.G. (1999) The contribution of nonmalignant tumors to CNS tumor incidence rates among children in the United States. Cancer Causes Control, 10, 101-105.

3. Brodeur G.M. and Castleberry R.P. (1997) Neuroblastoma. In Pizzo PA and Poplack DG (eds.) Principles and practice of pediatric oncology., pp 761-97.

4. Perera,F., Hemminki,K., Jedrychowski,W., Whyatt,R., Campbell,U., Hsu,Y., Santella,R., Albertini,R., and O'Neill,J.P. (2002) In utero DNA damage from environmental pollution is associated with somatic gene mutation in newborns. Cancer Epidemiol Biomarkers Prev., 11, 1134-1137.

5. Rice,J.M. and Wilbourn,J.D. (2000) Tumors of the nervous system in carcinogenic hazard identification. Toxicol.Pathol, 28, 202-214.

6. Garcia,S.J., Seidler,F.J., Crumpton,T.L., and Slotkin,T.A. (2001) Does the developmental neurotoxicity of chlorpyrifos involve glial targets? Macromolecule synthesis, adenylyl cyclase signaling, nuclear transcription factors, and formation of reactive oxygen in C6 glioma cells. Brain Res, 891, 54-68.

7. Jirtle,R.L. and Skinner,M.K. (2007) Environmental epigenomics and disease susceptibility. Nat.Rev.Genet., 8, 253-262.

8. Hjalmars,U., Kulldorff,M., Wahlqvist,Y., and Lannering,B. (1999) Increased incidence rates but no space-time clustering of childhood astrocytoma in Sweden, 1973-1992: a population-based study of pediatric brain tumors. Cancer, 85, 2077 2090 .

9. McNeil,D.E., Cote,T.R., Clegg,L., and Rorke,L.B. (2002) Incidence and trends in pediatric malignancies medulloblastoma/primitive neuroectodermal tumor: a SEER update. Surveillance Epidemiology and End Results. Med Pediatr.Oncol., 39, 190-194.

10. Smith,M.A., Freidlin,B., Ries,L.A., and Simon,R. (1998) Trends in reported incidence of primary malignant brain tumors in children in the United States. $J$ Natl.Cancer Inst., 90, 1269-1277. 
11. Steliarova-Foucher,E., Stiller,C., Kaatsch,P., Berrino,F., Coebergh,J.W., Lacour,B., and Parkin,M. (2004) Geographical patterns and time trends of cancer incidence and survival among children and adolescents in Europe since the 1970s (the ACCISproject): an epidemiological study. Lancet, 364, 2097-2105.

12. Birch,J.M., Alston,R.D., Kelsey,A.M., Quinn,M.J., Babb,P., and McNally,R.J. (2002) Classification and incidence of cancers in adolescents and young adults in England 1979-1997. Br.J Cancer, 87, 1267-1274.

13. McNally,R.J., Kelsey,A.M., Cairns,D.P., Taylor,G.M., Eden,O.B., and Birch,J.M. (2001) Temporal increases in the incidence of childhood solid tumors seen in Northwest England (1954-1998) are likely to be real. Cancer, 92, 1967-1976.

14. Kaiser,J. (1999) No meeting of minds on childhood cancer. Science, 286, 18321834.

15. Linet,M.S., Ries,L.A., Smith,M.A., Tarone,R.E., and Devesa,S.S. (1999) Cancer surveillance series: recent trends in childhood cancer incidence and mortality in the United States. J Natl.Cancer Inst., 91, 1051-1058.

16. Magnani,C., Dalmasso,P., Pastore,G., Terracini,B., Martuzzi,M., Mosso,M.L., and Merletti,F. (2003) Increasing incidence of childhood leukemia in Northwest Italy, 1975-98. Int.J Cancer, 105, 552-557.

17. Jukich,P.J., McCarthy,B.J., Surawicz,T.S., Freels,S., and Davis,F.G. (2001) Trends in incidence of primary brain tumors in the United States, 1985-1994. Neuro.Oncol., 3, 141-151.

18. National Cancer Institute, National Institute of Neurological Disorders and Stroke. Report of the Brain Tumor Progress Review Group. NIH Publication Number 01-4902. 2000.

19. Preston-Martin,S., Munir R., and Chakrabarti I. (2006) Neoplasms of the nervous system. In Schottenfield D. and Fraumeni J.F. (eds.) Cancer Epidemiology and Prevention. Oxford University Press, New York.

20. Mealey,J., Jr. and Hall,P.V. (1977) Medulloblastoma in children. Survival and treatment. J Neurosurg., 46, 56-64.

21. Schoenberg,B.S., Schoenberg,D.G., Christine,B.W., and Gomez,M.R. (1976) The epidemiology of primary intracranial neoplasms of childhood. A population study. Mayo Clin.Proc., 51, 51-56.

22. International incidence of childhood cancer. Parkin D.M., Kramarova E., Draper G.J., Masuyer E., Michaelis J., Neglia J.P., Qureshi S., and Stiller C.A. 1998. Lyon, France, International Agency for Research on Cancer. 
23. Halperin,E.C., Miranda,M.L., Watson,D.M., George,S.L., and Stanberry,M. (2004) Medulloblastoma and birth date: evaluation of 3 U.S. datasets.

Arch.Environ Health, 59, 26-30.

24. Manshande,J.P., Van,T.J., Coppens,M., and Casaer,P. (1985) Seasonal variation in incidence of cerebellar medulloblastoma. Brain Dev., 7, 525-526.

25. Yamakawa,Y., Fukui,M., Kinoshita,K., Ohgami,S., and Kitamura,K. (1979) Seasonal variation in incidence of cerebellar medulloblastoma by month of birth. Fukuoka Igaku Zasshi, 70, 295-300.

26. Hoffman,S., Schellinger,K.A., Propp,J.M., McCarthy,B.J., Campbell,R.T., and Davis,F.G. (2007) Seasonal variation in incidence of pediatric medulloblastoma in the United States, 1995-2001. Neuroepidemiology, 29, 89-95.

27. Von,B.J. and Reynolds,P. (2003) Birth characteristics and brain cancers in young children. Int J Epidemiol, 32, 248-256.

28. Samuelsen,S.O., Bakketeig,L.S., Tretli,S., Johannesen,T.B., and Magnus,P. (2006) Head circumference at birth and risk of brain cancer in childhood: a population-based study. Lancet Oncol., 7, 39-42.

29. Meadows,A.T., Baum,E., Fossati-Bellani,F., Green,D., Jenkin,R.D., Marsden,B., Nesbit,M., Newton,W., Oberlin,O., Sallan,S.G., and . (1985) Second malignant neoplasms in children: an update from the Late Effects Study Group. $J$ Clin.Oncol., 3, 532-538.

30. Neglia,J.P., Meadows,A.T., Robison,L.L., Kim,T.H., Newton,W.A., Ruymann,F.B., Sather,H.N., and Hammond,G.D. (1991) Second neoplasms after acute lymphoblastic leukemia in childhood. N.Engl.J Med., 325, 1330-1336.

31. Ron,E., Modan,B., Boice,J.D., Jr., Alfandary,E., Stovall,M., Chetrit,A., and Katz,L. (1988) Tumors of the brain and nervous system after radiotherapy in childhood. N.Engl.J Med., 319, 1033-1039.

32. Rice,J.M. (2006) Inducible and transmissible genetic events and pediatric tumors of the nervous system. J Radiat.Res (Tokyo), 47 Suppl B, B1-B11.

33. Doll,R. and Wakeford,R. (1997) Risk of childhood cancer from fetal irradiation. Br.J.Radiol., 70, 130-139.

34. Bunin,G.R. (2004) Nongenetic causes of childhood cancers: evidence from international variation, time trends, and risk factor studies.

Toxicol.Appl.Pharmacol., 199, 91-103. 
35. National Institutes of Health. What you need to know about brain tumors. National Cancer Institute. NIH Publication No. 02-1558. 2002.

36. Preston,D.L., Ron,E., Yonehara,S., Kobuke,T., Fujii,H., Kishikawa,M., Tokunaga,M., Tokuoka,S., and Mabuchi,K. (2002) Tumors of the nervous system and pituitary gland associated with atomic bomb radiation exposure. $J$ Natl.Cancer Inst., 94, 1555-1563.

37. Kristensen,P., Andersen,A., Irgens,L.M., Bye,A.S., and Sundheim,L. (1996) Cancer in offspring of parents engaged in agricultural activities in Norway: incidence and risk factors in the farm environment. Int.J Cancer, 65, 39-50.

38. Shim Y.K., Mlynarek S.P., and van Wijngaarden E. (2009) Parental exposure to pesticides and childhood brain cancer: United States Atlantic Coast Childhood Brain Cancer Study. Environ Health Perspect. .

39. Kuijten,R.R., Bunin,G.R., Nass,C.C., and Meadows,A.T. (1990) Gestational and familial risk factors for childhood astrocytoma: results of a case-control study. Cancer Res., 50, 2608-2612.

40. McCredie,M., Maisonneuve,P., and Boyle,P. (1994) Antenatal risk factors for malignant brain tumours in New South Wales children. Int.J Cancer, 56, 6-10.

41. Preston-Martin,S., Yu,M.C., Benton,B., and Henderson,B.E. (1982) N-Nitroso compounds and childhood brain tumors: a case-control study. Cancer Res., 42, 5240-5245.

42. Preston-Martin,S., Pogoda,J.M., Mueller,B.A., Holly,E.A., Lijinsky,W., and Davis,R.L. (1996) Maternal consumption of cured meats and vitamins in relation to pediatric brain tumors. Cancer Epidemiol.Biomarkers Prev., 5, 599-605.

43. Huncharek,M. and Kupelnick,B. (2004) A meta-analysis of maternal cured meat consumption during pregnancy and the risk of childhood brain tumors.

Neuroepidemiology, 23, 78-84.

44. Thapa,P.B., Whitlock,J.A., Brockman Worrell,K.G., Gideon,P., Mitchel,E.F., Jr., Roberson,P., Pais,R., and Ray,W.A. (1998) Prenatal exposure to metronidazole and risk of childhood cancer: a retrospective cohort study of children younger than 5 years. Cancer, 83, 1461-1468.

45. Linet,M.S., Gridley,G., Cnattingius,S., Nicholson,H.S., Martinsson,U., Glimelius,B., Adami,H.O., and Zack,M. (1996) Maternal and perinatal risk factors for childhood brain tumors (Sweden). Cancer Causes Control, 7, 437-448.

46. Gurney,J.G., Mueller,B.A., Preston-Martin,S., McDaniel,A.M., Holly,E.A., Pogoda,J.M., and Davis,R.L. (1997) A study of pediatric brain tumors and their 
association with epilepsy and anticonvulsant use. Neuroepidemiology, 16, 248255.

47. Fear,N.T., Roman,E., Ansell,P., and Bull,D. (2001) Malignant neoplasms of the brain during childhood: the role of prenatal and neonatal factors (United Kingdom). Cancer Causes Control, 12, 443-449.

48. Linos,A., Kardara,M., Kosmidis,H., Katriou,D., Hatzis,C., Kontzoglou,M., Koumandakis,E., and Tzartzatou-Stathopoulou,F. (1998) Reported influenza in pregnancy and childhood tumour. Eur.J Epidemiol., 14, 471-475.

49. Altieri,A., Castro,F., Bermejo,J.L., and Hemminki,K. (2006) Association between number of siblings and nervous system tumors suggests an infectious etiology. Neurology, 67, 1979-1983.

50. Huncharek,M., Kupelnick,B., and Klassen,H. (2002) Maternal smoking during pregnancy and the risk of childhood brain tumors: a meta-analysis of 6566 subjects from twelve epidemiological studies. J Neurooncol., 57, 51-57.

51. Boffetta,P., Tredaniel,J., and Greco,A. (2000) Risk of childhood cancer and adult lung cancer after childhood exposure to passive smoke: A meta-analysis. Environ.Health Perspect., 108, 73-82.

52. UK Childhood Cancer Study Investigators (1999) Exposure to power frequency electric fields and the risk of childhood cancer in the UK. Lancet, 354, 19251931.

53. Gurney,J.G., Preston-Martin,S., McDaniel,A.M., Mueller,B.A., and Holly,E.A. (1996) Head injury as a risk factor for brain tumors in children: results from a multicenter case-control study. Epidemiology, 7, 485-489.

54. Bunin,G.R., Gallagher,P.R., Rorke-Adams,L.B., Robison,L.L., and Cnaan,A. (2006) Maternal supplement, micronutrient, and cured meat intake during pregnancy and risk of medulloblastoma during childhood: a children's oncology group study. Cancer Epidemiol Biomarkers Prev., 15, 1660-1667.

55. Read,T.A., Hegedus,B., Wechsler-Reya,R., and Gutmann,D.H. (2006) The neurobiology of neurooncology. Ann.Neurol., 60, 3-11.

56. Schuller,U., Heine,V.M., Mao,J., Kho,A.T., Dillon,A.K., Han,Y.G., Huillard,E., Sun,T., Ligon,A.H., Qian,Y., Ma,Q., Alvarez-Buylla,A., McMahon,A.P., Rowitch,D.H., and Ligon,K.L. (2008) Acquisition of granule neuron precursor identity is a critical determinant of progenitor cell competence to form Shhinduced medulloblastoma. Cancer Cell, 14, 123-134.

57. Yang,Z.J., Ellis,T., Markant,S.L., Read,T.A., Kessler,J.D., Bourboulas,M., Schuller,U., Machold,R., Fishell,G., Rowitch,D.H., Wainwright,B.J., and 
Wechsler-Reya,R.J. (2008) Medulloblastoma can be initiated by deletion of Patched in lineage-restricted progenitors or stem cells. Cancer Cell, 14, 135-145.

58. Bruggeman,S.W., Hulsman,D., Tanger,E., Buckle,T., Blom,M., Zevenhoven,J., van,T.O., and van,L.M. (2007) Bmil controls tumor development in an Ink4a/Arf-independent manner in a mouse model for glioma. Cancer Cell, 12, 328-341.

59. Dirks,P. (2007) Bmil and cell of origin determinants of brain tumor phenotype. Cancer Cell, 12, 295-297.

60. Bailey P and Cushing H (1925) Medulloblastoma cerebelli: a common type of midcerebellar glioma of childhood. Arch Neurol Psychiatry, 14, 192-223.

61. Wright J (1910) Neurocytoma and neuroblastomas, a kind of tumor not generally recognized. $J$ Exp Med,556-561.

62. Hatton,B.A., Knoepfler,P.S., Kenney,A.M., Rowitch,D.H., de Alboran,I.M., Olson,J.M., and Eisenman,R.N. (2006) N-myc is an essential downstream effector of Shh signaling during both normal and neoplastic cerebellar growth. Cancer Res., 66, 8655-8661.

63. Marino,S. (2005) Medulloblastoma: developmental mechanisms out of control. Trends Mol.Med., 11, 17-22.

64. Maris,J.M. (2005) The biologic basis for neuroblastoma heterogeneity and risk stratification. Curr.Opin.Pediatr., 17, 7-13.

65. Katayam,M., Yoshida,K., Ishimori,H., Katayama,M., Kawase,T., Motoyama,J., and Kamiguchi,H. (2002) Patched and smoothened mRNA expression in human astrocytic tumors inversely correlates with histological malignancy. $J$ Neurooncol., 59, 107-115.

66. Kinzler,K.W., Ruppert,J.M., Bigner,S.H., and Vogelstein,B. (1988) The GLI gene is a member of the Kruppel family of zinc finger proteins. Nature, 332, 371-374.

67. Ligon,K.L., Alberta,J.A., Kho,A.T., Weiss,J., Kwaan,M.R., Nutt,C.L., Louis,D.N., Stiles,C.D., and Rowitch,D.H. (2004) The oligodendroglial lineage marker OLIG2 is universally expressed in diffuse gliomas. $J$ Neuropathol.Exp Neurol, 63, 499-509.

68. Grimmer,M.R. and Weiss,W.A. (2006) Childhood tumors of the nervous system as disorders of normal development. Curr.Opin.Pediatr., 18, 634-638.

69. Suliman,H.B., Carraway,M.S., Welty-Wolf,K.E., Whorton,A.R., and Piantadosi,C.A. (2003) Lipopolysaccharide stimulates mitochondrial biogenesis via activation of nuclear respiratory factor-1. J Biol.Chem., 278, 41510-41518. 
70. Baldwin,R.T. and Preston-Martin,S. (2004) Epidemiology of brain tumors in childhood--a review. Toxicol.Appl.Pharmacol., 199, 118-131.

71. Modica-Napolitano,J.S. and Singh,K.K. (2002) Mitochondria as targets for detection and treatment of cancer. Expert.Rev.Mol.Med., 4, 1-19.

72. Rustin,P. (2002) Mitochondria, from cell death to proliferation. Nat.Genet., 30, 352-353.

73. Enns,R. and Criddle,R.S. (1977) Investigation of the structural arrangement of the protein subunits of mitochondrial ATPase. Arch.Biochem.Biophys., 183, 742-752.

74. Larsson,N.G. and Luft,R. (1999) Revolution in mitochondrial medicine. FEBS Lett., 455, 199-202.

75. Smiraglia,D.J., Kulawiec,M., Bistulfi,G.L., Gupta,S.G., and Singh,K.K. (2008) A novel role for mitochondria in regulating epigenetic modification in the nucleus. Cancer Biol.Ther., 7, 1182-1190.

76. Park S.Y., Chang I, Kim J, Kang S.W., ark S, ingh K, and Lee M (2004) Resistance of mitochondrial DNA-depleted cells against cell death. The Journal of Biological Chemistry, 279, 7512-7520.

77. Erecinska,M., Cherian,S., and Silver,I.A. (2004) Energy metabolism in mammalian brain during development. Prog.Neurobiol., 73, 397-445.

78. Lerman-Sagie,T., Leshinsky-Silver,E., Watemberg,N., Luckman,Y., and Lev,D. (2005) White matter involvement in mitochondrial diseases. Mol.Genet.Metab, $84,127-136$.

79. Buonocore,G., Perrone,S., and Bracci,R. (2001) Free radicals and brain damage in the newborn. Biol.Neonate, 79, 180-186.

80. Carew,J.S. and Huang,P. (2002) Mitochondrial defects in cancer. Mol.Cancer, 1, 9.

81. Delsite,R.L., Rasmussen,L.J., Rasmussen,A.K., Kalen,A., Goswami,P.C., and Singh,K.K. (2003) Mitochondrial impairment is accompanied by impaired oxidative DNA repair in the nucleus. Mutagenesis, 18, 497-503.

82. Copeland,W.C., Wachsman,J.T., Johnson,F.M., and Penta,J.S. (2002) Mitochondrial DNA alterations in cancer. Cancer Invest, 20, 557-569.

83. Penta,J.S., Johnson,F.M., Wachsman,J.T., and Copeland,W.C. (2001) Mitochondrial DNA in human malignancy. Mutat.Res., 488, 119-133. 
84. Lemasters,G.K., Perreault,S.D., Hales,B.F., Hatch,M., Hirshfield,A.N., Hughes,C.L., Kimmel,G.L., Lamb,J.C., Pryor,J.L., Rubin,C., and Seed,J.G. (2000) Workshop to identify critical windows of exposure for children's health: reproductive health in children and adolescents work group summary. Environ.Health Perspect., 108 Suppl 3, 505-509.

85. Dietert,R.R., Etzel,R.A., Chen,D., Halonen,M., Holladay,S.D., Jarabek,A.M., Landreth,K., Peden,D.B., Pinkerton,K., Smialowicz,R.J., and Zoetis,T. (2000) Workshop to identify critical windows of exposure for children's health: immune and respiratory systems work group summary. Environ.Health Perspect., 108 Suppl 3, 483-490.

86. Sadler,T.W. (2000) Susceptible periods during embryogenesis of the heart and endocrine glands. Environ.Health Perspect., 108 Suppl 3, 555-561.

87. Olshan,A.F., Anderson,L., Roman,E., Fear,N., Wolff,M., Whyatt,R., Vu,V., Diwan,B.A., and Potischman,N. (2000) Workshop to identify critical windows of exposure for children's health: cancer work group summary. Environ.Health Perspect., 108 Suppl 3, 595-597.

88. Autrup,H. (1993) Transplacental transfer of genotoxins and transplacental carcinogenesis. Environ.Health Perspect., 101 Suppl 2, 33-38.

89. Neri,M., Fucic,A., Knudsen,L.E., Lando,C., Merlo,F., and Bonassi,S. (2003) Micronuclei frequency in children exposed to environmental mutagens: a review. Mutat.Res., 544, 243-254.

90. Neri,M., Ugolini,D., Bonassi,S., Fucic,A., Holland,N., Knudsen,L.E., Sram,R.J., Ceppi,M., Bocchini,V., and Merlo,D.F. (2006) Children's exposure to environmental pollutants and biomarkers of genetic damage. II. Results of a comprehensive literature search and meta-analysis. Mutat.Res., 612, 14-39.

91. Rice,J.M. and Ward,J.M. (1982) Age dependence of susceptibility to carcinogenesis in the nervous system. Ann.N.Y.Acad.Sci., 381, 274-289.

92. Anderson,L.M., Diwan,B.A., Fear,N.T., and Roman,E. (2000) Critical windows of exposure for children's health: cancer in human epidemiological studies and neoplasms in experimental animal models. Environ.Health Perspect., 108 Suppl 3, 573-594.

93. Branstetter,D.G., Stoner,G.D., Schut,H.A., Senitzer,D., Conran,P.B., and Goldblatt,P.J. (1987) Ethylnitrosourea-induced transplacental carcinogenesis in the mouse: tumor response, DNA binding, and adduct formation. Cancer Res, 47, 348-352. 
94. Rodier,P.M. (1995) Developing brain as a target of toxicity. Environ.Health Perspect., 103 Suppl 6, 73-76.

95. Adinolfi,M. (1985) The development of the human blood-CSF-brain barrier. Dev.Med.Child Neurol., 27, 532-537.

96. Malthankar,G.V., White,B.K., Bhushan,A., Daniels,C.K., Rodnick,K.J., and Lai,J.C. (2004) Differential lowering by manganese treatment of activities of glycolytic and tricarboxylic acid (TCA) cycle enzymes investigated in neuroblastoma and astrocytoma cells is associated with manganese-induced cell death. Neurochem.Res, 29, 709-717.

97. Rao,G., Pedone,C.A., Del,V.L., Reiss,K., Holland,E.C., and Fults,D.W. (2004) Sonic hedgehog and insulin-like growth factor signaling synergize to induce medulloblastoma formation from nestin-expressing neural progenitors in mice. Oncogene, 23, 6156-6162.

98. Dukhande,V.V., Malthankar-Phatak,G.H., Hugus,J.J., Daniels,C.K., and Lai,J.C. (2006) Manganese-induced neurotoxicity is differentially enhanced by glutathione depletion in astrocytoma and neuroblastoma cells. Neurochem.Res, 31, 13491357.

99. Kim,E.H., Sohn,S., Kwon,H.J., Kim,S.U., Kim,M.J., Lee,S.J., and Choi,K.S. (2007) Sodium selenite induces superoxide-mediated mitochondrial damage and subsequent autophagic cell death in malignant glioma cells. Cancer Res, 67, 6314-6324.

100. Slikker,W., III, Mei,N., and Chen,T. (2004) N-ethyl-N-nitrosourea (ENU) increased brain mutations in prenatal and neonatal mice but not in the adults. Toxicol.Sci., 81, 112-120.

101. Robertson,C.L., Soane,L., Siegel,Z.T., and Fiskum,G. (2006) The potential role of mitochondria in pediatric traumatic brain injury. Dev.Neurosci., 28, 432-446.

102. Van,R.H., Salvador,C., Yang,H., Huang,T.T., Epstein,C.J., and Richardson,A. (1999) Characterization of the antioxidant status of the heterozygous manganese superoxide dismutase knockout mouse. Arch.Biochem.Biophys., 363, 91-97.

103. Zhong,W., Oberley,L.W., Oberley,T.D., Yan,T., Domann,F.E., and St Clair,D.K. (1996) Inhibition of cell growth and sensitization to oxidative damage by overexpression of manganese superoxide dismutase in rat glioma cells. Cell Growth Differ., 7, 1175-1186.

104. Melov,S., Lithgow,G.J., Fischer,D.R., Tedesco,P.M., and Johnson,T.E. (1995) Increased frequency of deletions in the mitochondrial genome with age of Caenorhabditis elegans. Nucleic Acids Res., 23, 1419-1425. 
105. Aleardi,A.M., Benard,G., Augereau,O., Malgat,M., Talbot,J.C., Mazat,J.P., Letellier,T., Dachary-Prigent,J., Solaini,G.C., and Rossignol,R. (2005) Gradual alteration of mitochondrial structure and function by beta-amyloids: importance of membrane viscosity changes, energy deprivation, reactive oxygen species production, and cytochrome c release. J Bioenerg.Biomembr., 37, 207-225.

106. Kontush,A. (2001) Amyloid-beta: an antioxidant that becomes a pro-oxidant and critically contributes to Alzheimer's disease. Free Radic.Biol.Med., 31, 11201131.

107. Calabrese,V., Copani,A., Testa,D., Ravagna,A., Spadaro,F., Tendi,E., Nicoletti,V.G., and Giuffrida Stella,A.M. (2000) Nitric oxide synthase induction in astroglial cell cultures: effect on heat shock protein 70 synthesis and oxidant/antioxidant balance. J Neurosci.Res., 60, 613-622.

108. Thannickal,V.J. and Fanburg,B.L. (2000) Reactive oxygen species in cell signaling. Am.J Physiol Lung Cell Mol.Physiol, 279, L1005-L1028.

109. Mavelli,I., Rigo,A., Federico,R., Ciriolo,M.R., and Rotilio,G. (1982) Superoxide dismutase, glutathione peroxidase and catalase in developing rat brain. Biochem.J, 204, 535-540.

110. Khan,M.A., Van,D.J., Yeung,I.W., and Hill,R.P. (2003) Partial volume rat lung irradiation; assessment of early DNA damage in different lung regions and effect of radical scavengers. Radiother.Oncol., 66, 95-102.

111. Folkerth,R.D., Haynes,R.L., Borenstein,N.S., Belliveau,R.A., Trachtenberg,F., Rosenberg,P.A., Volpe,J.J., and Kinney,H.C. (2004) Developmental lag in superoxide dismutases relative to other antioxidant enzymes in premyelinated human telencephalic white matter. J Neuropathol.Exp.Neurol., 63, 990-999.

112. Manczak,M., Anekonda,T.S., Henson,E., Park,B.S., Quinn,J., and Reddy,P.H. (2006) Mitochondria are a direct site of A beta accumulation in Alzheimer's disease neurons: implications for free radical generation and oxidative damage in disease progression. Hum.Mol.Genet., 15, 1437-1449.

113. Wong-Riley,M.T. (1989) Cytochrome oxidase: an endogenous metabolic marker for neuronal activity. Trends Neurosci., 12, 94-101.

114. Gunter,K.K. and Gunter,T.E. (1994) Transport of calcium by mitochondria. $J$ Bioenerg.Biomembr., 26, 471-485.

115. Cottrell,D.A., Ince,P.G., Blakely,E.L., Johnson,M.A., Chinnery,P.F., Hanna,M., and Turnbull,D.M. (2000) Neuropathological and histochemical changes in a multiple mitochondrial DNA deletion disorder. J Neuropathol.Exp.Neurol., 59, 621-627. 
116. Rahman,S., Hargreaves,I., Clayton,P., and Heales,S. (2001) Neonatal presentation of coenzyme Q10 deficiency. J Pediatr., 139, 456-458.

117. Gunther,C., von,H.K., Muller-Thomsen,T., Alberici,A., Binetti,G., Hock,C., Nitsch,R.M., Stoppe,G., Reiss,J., Gal,A., and Finckh,U. (2004) Possible association of mitochondrial transcription factor A (TFAM) genotype with sporadic Alzheimer disease. Neurosci.Lett., 369, 219-223.

118. Kang,D., Kim,S.H., and Hamasaki,N. (2007) Mitochondrial transcription factor A (TFAM): roles in maintenance of mtDNA and cellular functions. Mitochondrion., 7, 39-44.

119. Roy,D., Cai,Q., Felty,Q., and Narayan,S. (2007) Estrogen-induced generation of reactive oxygen and nitrogen species, gene damage, and estrogen-dependent cancers. J Toxicol.Environ Health B Crit Rev., 10, 235-257.

120. Scarpulla,R.C. (2008) Nuclear control of respiratory chain expression by nuclear respiratory factors and PGC-1-related coactivator. Ann.N.Y.Acad.Sci., 1147, 321334.

121. Taanman,J.W. (1999) The mitochondrial genome: structure, transcription, translation and replication. Biochim.Biophys.Acta, 1410, 103-123.

122. Rasmussen,A.K., Chatterjee,A., Rasmussen,L.J., and Singh,K.K. (2003) Mitochondria-mediated nuclear mutator phenotype in Saccharomyces cerevisiae. Nucleic Acids Res., 31, 3909-3917.

123. Singh,K.K., Kulawiec,M., Still,I., Desouki,M.M., Geradts,J., and Matsui,S. (2005) Inter-genomic cross talk between mitochondria and the nucleus plays an important role in tumorigenesis. Gene, 354, 140-146.

124. Evans,A.R., Limp-Foster,M., and Kelley,M.R. (2000) Going APE over ref-1. Mutat.Res., 461, 83-108.

125. Xanthoudakis,S. and Curran,T. (1996) Redox regulation of AP-1: a link between transcription factor signaling and DNA repair. Adv.Exp.Med.Biol., 387, 69-75.

126. Vasko,M.R., Guo,C., and Kelley,M.R. (2005) The multifunctional DNA repair/redox enzyme Ape1/Ref-1 promotes survival of neurons after oxidative stress. DNA Repair (Amst), 4, 367-379.

127. Ohta,S. (2006) Contribution of somatic mutations in the mitochondrial genome to the development of cancer and tolerance against anticancer drugs. Oncogene, 25, 4768-4776. 
128. Kulawiec,M., Safina,A., Desouki,M.M., Still,I., Matsui,S.I., Bakin,A., and Singh,K.K. (2008) Tumorigenic transformation of human breast epithelial cells induced by mitochondrial DNA depletion. Cancer Biol.Ther., 7.

129. Kurtz,A., Lueth,M., Kluwe,L., Zhang,T., Foster,R., Mautner,V.F., Hartmann,M., Tan,D.J., Martuza,R.L., Friedrich,R.E., Driever,P.H., and Wong,L.J. (2004) Somatic mitochondrial DNA mutations in neurofibromatosis type 1-associated tumors. Mol.Cancer Res, 2, 433-441.

130. Montanini,L., Regna-Gladin,C., Eoli,M., Albarosa,R., Carrara,F., Zeviani,M., Bruzzone,M.G., Broggi,G., Boiardi,A., and Finocchiaro,G. (2005) Instability of mitochondrial DNA and MRI and clinical correlations in malignant gliomas. $J$ Neurooncol., 74, 87-89.

131. Kirches,E., Michael,M., Woy,C., Schneider,T., Warich-Kirches,M., SchneiderStock,R., Winkler,K., Wittig,H., and Dietzmann,K. (1999) Loss of heteroplasmy in the displacement loop of brain mitochondrial DNA in astrocytic tumors. Genes Chromosomes.Cancer, 26, 80-83.

132. Vega,A., Salas,A., Gamborino,E., Sobrido,M.J., Macaulay,V., and Carracedo,A. (2004) mtDNA mutations in tumors of the central nervous system reflect the neutral evolution of mtDNA in populations. Oncogene, 23, 1314-1320.

133. Kiebish,M.A. and Seyfried,T.N. (2005) Absence of pathogenic mitochondrial DNA mutations in mouse brain tumors. BMC.Cancer, 5, 102.

134. Stavrovskaya,I.G. and Kristal,B.S. (2005) The powerhouse takes control of the cell: is the mitochondrial permeability transition a viable therapeutic target against neuronal dysfunction and death? Free Radic.Biol.Med., 38, 687-697.

135. Robertson,J.D., Gogvadze,V., Kropotov,A., Vakifahmetoglu,H., Zhivotovsky,B., and Orrenius,S. (2004) Processed caspase-2 can induce mitochondria-mediated apoptosis independently of its enzymatic activity. EMBO Rep., 5, 643-648.

136. Lee,W.C., Choi,C.H., Cha,S.H., Oh,H.L., and Kim- YK (2005) Role of ERK in hydrogen peroxide-induced cell death of human glioma cells. Neurochem.Res., 30, 263-270.

137. Humphrey,M.L., Cole,M.P., Pendergrass,J.C., and Kiningham,K.K. (2005) Mitochondrial mediated thimerosal-induced apoptosis in a human neuroblastoma cell line (SK-N-SH). Neurotoxicology, 26, 407-416.

138. Gottfried,Y., Voldavsky,E., Yodko,L., Sabo,E., Ben-Itzhak,O., and Larisch,S. (2004) Expression of the pro-apoptotic protein ARTS in astrocytic tumors: correlation with malignancy grade and survival rate. Cancer, 101, 2614-2621. 
139. Raff,M.C., Barres,B.A., Burne,J.F., Coles,H.S., Ishizaki,Y., and Jacobson,M.D. (1993) Programmed cell death and the control of cell survival: lessons from the nervous system. Science, 262, 695-700.

140. Reed,J.C. (1997) Bcl-2 family proteins and the hormonal control of cell life and death in normalcy and neoplasia. Vitam.Horm., 53, 99-138.

141. Ferrer,I., Tortosa,A., Condom,E., Blanco,R., Macaya,A., and Planas,A. (1994) Increased expression of bcl-2 immunoreactivity in the developing cerebral cortex of the rat. Neurosci.Lett., 179, 13-16.

142. Marks,N. and Berg,M.J. (1999) Recent advances on neuronal caspases in development and neurodegeneration. Neurochem.Int., 35, 195-220.

143. Bar,E.E., Chaudhry,A., Farah,M.H., and Eberhart,C.G. (2007) Hedgehog signaling promotes medulloblastoma survival via Bc/II. Am.J Pathol., 170, 347355.

144. Searles,N.S., Mueller,B.A., De Roos,A.J., Viernes,H.M., Farin,F.M., and Checkoway,H. (2005) Risk of brain tumors in children and susceptibility to organophosphorus insecticides: the potential role of paraoxonase (PON1). Environ Health Perspect., 113, 909-913.

145. Rajaraman,P., Stewart,P.A., Samet,J.M., Schwartz,B.S., Linet,M.S., Zahm,S.H., Rothman,N., Yeager,M., Fine,H.A., Black,P.M., Loeffler,J., Shapiro,W.R., Selker,R.G., and Inskip,P.D. (2006) Lead, genetic susceptibility, and risk of adult brain tumors. Cancer Epidemiol Biomarkers Prev., 15, 2514-2520.

146. Schwartzbaum,J.A., Ahlbom,A., Lonn,S., Warholm,M., Rannug,A., Auvinen,A., Christensen,H.C., Henriksson,R., Johansen,C., Lindholm,C., Malmer,B., Salminen,T., Schoemaker,M.J., Swerdlow,A.J., and Feychting,M. (2007) An international case-control study of glutathione transferase and functionally related polymorphisms and risk of primary adult brain tumors. Cancer Epidemiol Biomarkers Prev., 16, 559-565.

147. Ezer,R., Alonso,M., Pereira,E., Kim,M., Allen,J.C., Miller,D.C., and Newcomb,E.W. (2002) Identification of glutathione S-transferase (GST) polymorphisms in brain tumors and association with susceptibility to pediatric astrocytomas. J Neurooncol., 59, 123-134.

148. Barnette,P., Scholl,R., Blandford,M., Ballard,L., Tsodikov,A., Magee,J., Williams,S., Robertson,M., li-Osman,F., Lemons,R., and Keller,C. (2004) Highthroughput detection of glutathione s-transferase polymorphic alleles in a pediatric cancer population. Cancer Epidemiol Biomarkers Prev., 13, 304-313. 
149. Lai,R., Crevier,L., and Thabane,L. (2005) Genetic polymorphisms of glutathione S-transferases and the risk of adult brain tumors: a meta-analysis. Cancer Epidemiol Biomarkers Prev., 14, 1784-1790.

150. Krajinovic,M., Lamothe,S., Labuda,D., Lemieux-Blanchard,E., Theoret,Y., Moghrabi,A., and Sinnett,D. (2004) Role of MTHFR genetic polymorphisms in the susceptibility to childhood acute lymphoblastic leukemia. Blood, 103, 252257.

151. Thompson,J.R., Gerald,P.F., Willoughby,M.L., and Armstrong,B.K. (2001) Maternal folate supplementation in pregnancy and protection against acute lymphoblastic leukaemia in childhood: a case-control study. Lancet, 358, 19351940.

152. Duthie,S.J. and Dobson,V.L. (1999) Dietary flavonoids protect human colonocyte DNA from oxidative attack in vitro. Eur J Nutr., 38, 28-34.

153. Cadieux,B., Ching,T.T., VandenBerg,S.R., and Costello,J.F. (2006) Genome-wide hypomethylation in human glioblastomas associated with specific copy number alteration, methylenetetrahydrofolate reductase allele status, and increased proliferation. Cancer Res, 66, 8469-8476.

154. Sirachainan,N., Wongruangsri,S., Kajanachumpol,S., Pakakasama,S., Visudtibhan,A., Nuchprayoon,I., Lusawat,A., Phudhicharoenrat,S., Shuangshoti,S., and Hongeng,S. (2008) Folate pathway genetic polymorphisms and susceptibility of central nervous system tumors in Thai children. Cancer Detect.Prev., 32, 72-78.

155. Kafadar,A.M., Yilmaz,H., Kafadar,D., Ergen,A., Zeybek,U., Bozkurt,N., Kuday,C., and Isbir,T. (2006) C677T gene polymorphism of methylenetetrahydrofolate reductase (MTHFR) in meningiomas and high-grade gliomas. Anticancer Res, 26, 2445-2449.

156. Pouliquen,D., Olivier,C., Hervouet,E., Pedelaborde,F., Debien,E., Le Cabellec,M.T., Gratas,C., Homma,T., Meflah,K., Vallette,F.M., and Menanteau,J. (2008) Dietary prevention of malignant glioma aggressiveness, implications in oxidant stress and apoptosis. Int J Cancer, 123, 288-295.

157. Tedeschi-Blok,N., Lee,M., Sison,J.D., Miike,R., and Wrensch,M. (2006) Inverse association of antioxidant and phytoestrogen nutrient intake with adult glioma in the San Francisco Bay Area: a case-control study. BMC.Cancer, 6, 148. 
Manuscript 2: Environment, genetic and epigenetic alterations and pediatric central nervous system tumors*

Brian Kunkle, David Sandberg ${ }^{1}$, Prasanna Jayakar ${ }^{2}$, Quentin Felty, Deodutta Roy

Department of Environmental and Occupational Health, Robert Stempel School of Public Health, Florida International University, Miami, Florida 33199; ${ }^{1}$ University of Miami Miller School of Medicine and Miami Children's Hospital; ${ }^{2}$ Neuroscience Program, Miami Children's Brain Institute, Miami, FL 33155

*A version of this manuscript was published in The Encyclopedia of Environmental Health, Five-Volume Set, Jerome Nriagu, Elsevier, New York, 2011.

Keywords: Pediatric central nervous system tumors (pCNSTs), Epigenetics, Geneenvironment interactions, Individual Susceptibility 


\begin{abstract}
Pediatric central nervous system tumors (pCNSTs) are the second most common malignancy among children less than 20 years of age and the most common solid tumor of childhood. The incidence of these tumors has been steadily increasing over the past decades. The etiology as well as the mechanism of the development of a majority of pCNSTs remains elusive. While numerous genetic and epigenetic changes have been identified with both development and outcome of pCNSTs, most of these alterations do not define a majority of tumors. Though ionizing radiation is a risk factor for pCNST development, evidence for the role of other environmental factors such as pesticides, Nnitroso compounds, and viral infections remain debatable. It is probable that the etiology of pediatric brain tumors, as is the case with most cancers, is multifactorial. Interaction of environmental factors with genetic and epigenetic changes may be responsible for the development of the particular type of PCNST in an individual. The assessment of geneenvironment interaction in pCNSTs has been more complex because of the lack of sound molecular epidemiological studies with a more complete picture of individual cancer risk associated with environmental exposure and genetic analysis. The increased susceptibility of the developing fetus and child to environmental insults should also be considered as a part in the developmental of pCNSTs. This review describes the chromosomal, genetic and epigenetic changes found in common pCNSTs, and summarizes the alterations found in pCNSTs that may be influence mitochondrial-nuclear signaling and the basis for interaction between environment and genetic factors.
\end{abstract}




\section{OUTLINE}

I. Introduction

II. Environmental Factors and pCNST

III. Molecular Changes in Different Types of pCNST

IV. Mitochondrial-nuclear signaling in CNST development

V. Gene-environment interaction (GEI) and CNST development

VI. Conclusions

\section{INTRODUCTION}

Pediatric central nervous system tumors (pCNSTs), which may occur in the brain or the spinal cord, are the second most common malignancy among children less than 20 years of age and the most common solid tumor of childhood. The majority of primary pCNSTs arise in the cerebellum and brainstem (infratentorial) from glia and are broadly categorized as gliomas. In contrast, most adult CNSTs (aCNST) originate in the cerebrum (supratentorial), although examples of childhood supratentorial CNSTs exist and vice versa. Glial tumors are usually broken down into more specific subtypes based on their predicted cell type of origin. The most common glial tumors include astrocytoma (from astrocytes), oligodendroglioma (from oligodendrocytes), brain stem glioma (from brain stem cells), and ependymoma (from ependymal cells). Some pCNSTs are composed of primitive or undifferentiated cells, as would be expected given their origin during early life when the nervous system is still developing. These include the primitive neuroectodermal tumors (PNETs) of the brain, notably medulloblastoma (MB), retinoblastoma, ependymoblastoma, and neuroblastoma (NB). Mixed forms of 
brain tumors (displaying a neuronal, as well as a glial component) also exist. Other varieties of primary brain tumors include: tumors of the pineal parenchyma (e.g. pineocytoma, pineoblastoma), choroid plexus tumors, and neuroepithelial tumors of uncertain origin (e.g. gliomatosis cerebri, astroblastoma).

The incidence of these tumors has been steadily increasing since the early 1980s [1;2]. The reason for this is unknown. While some of the heritable genetic risk factors thought to play a part in less than $5-10 \%$ of all pCNSTs are identified, previous studies have failed to produce strong evidence on the genetic alterations that predispose children to the remaining $95 \%$ of sporadic brain tumors. Several cellular pathways important to brain development have been implicated in the development of pCNST, including the Sonic Hedgehog (SHh) pathway, the WNT-wingless (WNT) pathway, and the NOTCH signaling pathway. During normal cerebellar development, these signaling pathways regulate growth and differentiation of granule cell precursors (GCPs) and neural stem cells. Mutations that activate these pathways can cause excessive growth and failure in cell differentiation, and thereby predispose to several types of CNST. However, identified changes in these pathways do not define a majority of pCNSTs. It appears that genetic alterations in pCNST are very subtle. Recent observations implicate a combination of genetic and epigenetic changes induced by environmental factors in the etiology of CNSTs. Therefore, the focus of this paper is on the role of gene mutations, single nucleotide polymorphisms (SNP) of genes, and epigenetic changes in the development of common pCNSTs. Chromosomal, genetic and epigenetic changes found in common pCNSTs, in addition to alterations found in pCNSTs that may be influenced 
by mitochondria signaling are described. Finally, environmental exposures and their interaction with genetic influences in relation to CNST development are discussed.

\section{ENVIRONMENTAL FACTORS AND pCNST}

The etiology of pCNSTs is largely unknown, though several genetic disorders are known risk factors for their development including neurofibromatosis type $1, \mathrm{Li}$ Fraumeni syndrome, basal cell nevus (Gorlin's) syndrome, Turcot syndrome, and ataxia telangiectasia. The role of environment in the etiology and development of pCNSTs is not very clear. Here the environment is defined as everything that surrounds us, i.e., air, water, diet, home, workplace, etc. It is becoming more evident that not only can drugs and environmental stressors interfere with normal fetal development by causing structural malformations, but that exposure to environmental stressors during development can also cause biochemical and functional abnormalities. In utero exposure to several drugs and environmental hazards has been proposed to be a primary cause for the increased incidence of childhood brain cancers, which poses a significant clinical problem. Some suspected in utero carcinogens include benzene, pesticides, trichloroethylene, ethanol, arsenic, cigarette smoke, and infectious biological agents. Early childhood exposures may also influence both aCNST and pCNST development and evidence that pesticides can influence glial development and differentiation well into childhood support this view [3]. Furthermore, many substances, such as 1,3-Butadiene and N-Nitrosomethylurea, have been shown to induce neurogenic tumors in animals, with both the fetus and neonatal animals being at dramatically increased susceptibility to CNST development compared to adults [4]. 
Aside from the extremely rare genetic conditions mentioned above, the only unequivocally identified risk factor is exposure to ionizing radiation, and this explains only a very small fraction of cases. The most consistent link between exposures and pCNST development aside from radiation is that for maternal consumption of cured meats, but whether a dietary component is responsible has not yet been revealed. A majority of epidemiological studies investigating pesticides and cancer risk have reported positive associations, with the risks for children generally higher than adults. While the consistency of results may be affected by type of pesticides being evaluated, exposure circumstances, and tumor classification standards, there is a considerable amount of epidemiological evidence that supports a link between pesticide exposure and pCNSTs. Several viruses have been investigated as causative agents in brain tumors. For instance, $\mathrm{JC}$ virus, a type of polyoma virus, and T-protein, an oncogenic virus product, have been detected at significant levels in PNETs and other tumors [5], though these results are challenged by negative results in other studies [6-10]. The ability of MBs to be induced by $\mathrm{JC}$ virus in mice models has also been demonstrated however [11;12]. Parental exposure to heat and electromagnetic fields, parental occupational exposure to chemicals, tobacco exposure, maternal hair dye use, and exposure to several medications and vitamins have also been investigated as potential etiologic factors, with equivocal results being found. Many of these exposures could certainly play a role in the etiology of pCNST however, as the high rates of cell proliferation and differentiation during development and childhood increases susceptibility of cells to mutagenic and epigenetic alteration. In addition, the blood-brain barrier, which acts as a barrier to potentially harmful substances, is not fully developed in the fetus and can allow harmful substances 
to reach sensitive organs such as the brain. In fact, in utero DNA damage resulting from environmental pollution has been associated with somatic gene mutation in newborns [13]. It appears that exposure to environmental factors may influence the development of pCNSTs, and they likely interact with genetic and epigenetic components.

\section{MOLECULAR CHANGES IN DIFFERENT TYPES OF pCNST}

One of the critical issues involving CNST molecular biology has been the inability to determine the cell of origin of each individual tumor type. The three main cell types from which these tumor precursor cells are thought to arise are neural stem cells, precursor cells, or differentiated cells. Genetic changes in each cell type have been associated with CNST development [14]. It is likely these genetic changes, which may be either inherited or somatic in nature, deregulate normal proliferation and differentiation, and initiate tumor formation. Therefore, most pCNSTs (which are predominantly immature tumors) most likely arise from neural stem cells (which produce both glial and neuronal cells) or progenitor cells in their respective precursor cell type (i.e. neuronal precursor cells for MBs), while most adult tumors probably form from differentiated cell types (i.e. astrocytes in astrocytoma) that have acquired stem cell-like or progenitor cell-like properties [14]. For a complete review of the current information on cell of origin in brain tumors the reader is referred to a 2006 review by Read et al. [14].

Several cellular pathways important to brain development have been implicated in the development of pCNST, including the Sonic Hedgehog (SHh) pathway, the WNTwingless (WNT) pathway, and the NOTCH signaling pathway. During normal cerebellar development, these signaling pathways regulate growth and differentiation of granule cell 
precursors (GCPs) and neural stem cells. Mutations that activate these pathways can cause excessive growth and failure in cell differentiation, and thereby predispose to several types of CNST. Identified changes in these pathways do not define a majority of pCNSTs however, and few other significant genetic changes in these tumors have been established. In fact, tumors arising in different regions of the brain retain distinct patterns of gene expression, though cells in different parts of the brain carry the same genes. This happens because different parts of the brain also contain factors that modify the use of those genes, suppressing some genes and activating others to allow the cells to take on specialized characteristics as the brain matures. Most of molecular and epigenetic changes have been identified in medulloblastoma, astrocytoma and neuroblastoma, and therefore, here, we discuss chromosomal, molecular and epigenetic changes in these three types of CNSTs.

\section{Medulloblastoma $(\mathrm{MB})$}

PNETs are commonly divided by tumor location into infratentorial PNET (iPNET) and supratentorial PNET (sPNET), with iPNET being the more common tumor type. $\mathrm{MB}$, the most common iPNET, is an invasive embryonal tumor that originates in the cerebellum and is most commonly seen in children three to eight years of age. They are the most common non-glial brain tumor, comprising approximately $25 \%$ of all pCNSTs [15]. Additionally, they are the most common malignant brain tumor of childhood [15], though sPNETs are generally considered to be a more aggressive tumor group than MB [16]. The two major subtypes of MB are classic MB (75 to $80 \%$ of all MBs), the most common tumor type which is found predominantly in children, and desmoplastic MB (15 
to $20 \%$ of all MBs), which occurs much less frequently and is more common in adults. Classic MB is usually found in the midline, especially in the posterior vermis, while the desmoplastic subtype arises most commonly in the cerebellar hemispheres. A common variant that exists within these two subtypes is a typically more aggressive tumor type described as large cell/anaplastic (LC/A) MB. For an in-depth review of clinical factors related to medulloblastoma development and survival please see Sarkar et al. 2006 [17]. The most common alterations in pediatric MB are summarized in Table 2-1.

Chromosomal Abnormalities: The most frequent genetic alteration, occurring in $>70 \%$ of $\mathrm{MB}$, is isochromosome $17 \mathrm{q}[\mathrm{i}(17 \mathrm{q})]$, which often occurs in conjunction with partial or complete loss of $17 \mathrm{p}$, found in $30-60 \%$ of cases. Monosomy 17, interstitial deletion and unbalanced translocation have been identified within this chromosome and contribute to these alterations [18-33]. Although loss of $17 \mathrm{p}$ is not specific for $\mathrm{MB}$, it occurs at a higher frequency in MB than in any other tumor. Specific loss at $17 \mathrm{p} 13.3$ has been identified in $38 \%$ of $\mathrm{MB}$ [34]. Attempts to identify genes on $17 \mathrm{p}$ which may be important to tumorigenesis, including p53, have produced negative results $[20 ; 35 ; 36]$. Whether $17 \mathrm{p}$ deletion is associated with poor outcome is debated, with several studies finding these alterations produced poor therapeutic outcome, metastatic disease, and a shorter survival time [18;29;34], while others countered this finding [21;26]. The alterations are more frequent in the more aggressive LC/A MBs compared to classic MBs [37], and are absent in most nodular/desmoplastic MBs [38].

Several other abnormalities occur in most MB, including loss of heterozygosity (LOH) on $7 \mathrm{q}, 8 \mathrm{p}$, and $16 \mathrm{q}$, which have been reported in $60-70 \%$ of cases [33]. $8 \mathrm{p}$ contains a homozygous deletion on 8p22-23.1 and therefore could contain a yet to be identified gene 
Table 2-1. Common susceptibility genes of pediatric medulloblastoma.

\begin{tabular}{|c|c|c|c|c|c|}
\hline Gene Name & $\begin{array}{c}\text { Gene } \\
\text { Symbol }\end{array}$ & Pathway/Function & $\begin{array}{c}\text { Type of } \\
\text { Alteration }\end{array}$ & $\begin{array}{c}\text { Frequency } \\
\text { of Alteration }\end{array}$ & Reference \\
\hline Patched & PTCH & $\begin{array}{l}\text { Sonic Hedgehog } \\
\text { (SHh) Pathway }\end{array}$ & $\begin{array}{l}\text { Somatic } \\
\text { mutation }\end{array}$ & $10 \%$ & $\begin{array}{c}\text { Raffel } 1997 \\
\text { [39]; } \\
\text { Vorechovsky } \\
1997 \text { [40]; } \\
\text { Wolter 1997 } \\
\text { [41] }\end{array}$ \\
\hline Smoothened & $\mathrm{SMO}$ & $\begin{array}{c}\text { Sonic Hedgehog } \\
\text { (SHh) Pathway }\end{array}$ & $\begin{array}{l}\text { Somatic } \\
\text { mutation }\end{array}$ & $10 \%$ & $\begin{array}{c}\text { Taylor } 2002 \\
{[42]}\end{array}$ \\
\hline $\begin{array}{c}\text { Mutated } \\
\text { Suppressor of } \\
\text { Fused }\end{array}$ & SUFU & $\begin{array}{l}\text { Sonic Hedgehog } \\
\text { (SHh) Pathway }\end{array}$ & $\begin{array}{l}\text { Somatic } \\
\text { mutation }\end{array}$ & $5 \%$ & $\begin{array}{c}\text { Reifenberger } \\
1998 \text { [43] }\end{array}$ \\
\hline RENKCTD11 & $\begin{array}{c}\text { RENKCTD } \\
11\end{array}$ & $\begin{array}{l}\text { Suppressor of } \\
\text { Sonic Hedgehog } \\
\text { (SHh) Pathway }\end{array}$ & Allelic Deletion & $39 \%$ & $\begin{array}{c}\text { Di } \\
\text { Marcotullio } \\
2004[25]\end{array}$ \\
\hline $\begin{array}{c}\text { Phosphatase } \\
\text { and tensin }\end{array}$ & PTEN & $\begin{array}{c}\text { Tumor suppressor- } \\
\text { Akt pathway }\end{array}$ & Allelic Loss & $19 \%$ & $\begin{array}{l}\text { Hartmann } \\
2007[44]\end{array}$ \\
\hline $\begin{array}{l}\text { Adenomatous } \\
\text { polyposis coli }\end{array}$ & APC & $\begin{array}{c}\text { WNT-Wingless } \\
\text { Pathway }\end{array}$ & $\begin{array}{l}\text { Somatic } \\
\text { mutation }\end{array}$ & $3-13 \%$ & $\begin{array}{c}\text { Koch } 2001 \\
\text { [45]; Eberhart } \\
\text { 2000 [46]; } \\
\text { Zurawel 2000 } \\
\text { [47] }\end{array}$ \\
\hline $\begin{array}{c}\beta \text {-catenin } \\
\text { (cadherin- } \\
\text { associated } \\
\text { protein) }\end{array}$ & CTNNB1 & $\begin{array}{c}\text { WNT-Wingless } \\
\text { Pathway }\end{array}$ & $\begin{array}{l}\text { Somatic } \\
\text { mutation }\end{array}$ & $6 \%$ & $\begin{array}{c}\text { Zurawel } 1998 \\
\text { [48]; Dahmen } \\
\text { 2001 [49] }\end{array}$ \\
\hline Axin1/Axin2 & $\begin{array}{c}\text { Axin } 1 / A x i \\
n 2\end{array}$ & $\begin{array}{c}\text { WNT-Wingless } \\
\text { Pathway }\end{array}$ & $\begin{array}{c}\text { Point mutation/ } \\
\text { deletion }\end{array}$ & $5 \%$ & $\begin{array}{c}\text { Koch } 2007 \\
\text { [50]; Koch } \\
\text { 2001 [45]; } \\
\text { Dahmen 2001 } \\
\text { [49] }\end{array}$ \\
\hline $\begin{array}{c}\text { v-myc } \\
\text { myelocytom- } \\
\text { atosis viral } \\
\text { oncogene }\end{array}$ & $\begin{array}{l}\text { c-myc or } \\
\text { N-myc }\end{array}$ & Oncogene & Overexpressed & $5-15 \%$ & $\begin{array}{c}\text { Aldorasi } 2002 \\
\text { [51]; Avet- } \\
\text { Loiseau } 1999 \\
\text { [52] }\end{array}$ \\
\hline p53 & p53 & p53-ARF Pathway & $\begin{array}{l}\text { Somatic } \\
\text { mutation }\end{array}$ & $10 \%$ & $\begin{array}{c}\text { Frank } 2004 \\
{[53]}\end{array}$ \\
\hline P14 & $\mathrm{P} 14^{\mathrm{ARF}}$ & p53-ARF Pathway & Methylation & $10 \%$ & $\begin{array}{c}\text { Frank } 2004 \\
{[53]}\end{array}$ \\
\hline $\begin{array}{c}\text { INK4A ARF } \\
(\text { p16) }\end{array}$ & $\begin{array}{l}\mathrm{INK}^{\mathrm{INA}} \mathrm{A}^{\mathrm{ARF}} \\
(\mathrm{p} 16)\end{array}$ & p53-ARF Pathway & Deletion & $10 \%$ & $\begin{array}{c}\text { Frank } 2004 \\
{[53]}\end{array}$ \\
\hline $\begin{array}{l}\text { Neurotrophic } \\
\text { tyrosine } \\
\text { kinase, } \\
\text { receptor, type } \\
3\end{array}$ & TrkC & $\begin{array}{l}\text { Neurotrophin } \\
\text { Pathway }\end{array}$ & Overexpressed & $48-85 \%$ & $\begin{array}{c}\text { Tajima } 1998 \\
{[54] ;} \\
\text { Washiyama } \\
1996[55]\end{array}$ \\
\hline $\begin{array}{l}\text { Platelet- } \\
\text { derived } \\
\text { growth factor } \\
\text { receptor } \alpha\end{array}$ & PDGFR- $\alpha$ & $\begin{array}{l}\text { PDGFR-Ras- } \\
\text { MAPK }\end{array}$ & $\begin{array}{l}\text { Synonymous } \\
\text { Sequence } \\
\text { Variation }\end{array}$ & $7 \%$ & $\begin{array}{l}\text { Gilbertson } \\
2006[56]\end{array}$ \\
\hline
\end{tabular}




\begin{tabular}{|c|c|c|c|c|c|}
\hline Gene Name & $\begin{array}{c}\text { Gene } \\
\text { Symbol }\end{array}$ & Pathway/Function & $\begin{array}{c}\text { Type of } \\
\text { Alteration }\end{array}$ & $\begin{array}{c}\text { Frequency } \\
\text { of Alteration }\end{array}$ & Reference \\
\hline $\begin{array}{c}\text { Forkhead box } \\
\text { G1 }\end{array}$ & FOXG1 & $\begin{array}{c}\text { Theorized } \\
\text { repressor of TGF- } \alpha \\
\text { induced expression } \\
\text { of p21 cip1 and } \\
\text { cellular growth }\end{array}$ & $\begin{array}{c}\text { Copy gain } \\
\text { between } 2 \text { and } \\
21 \text { fold }\end{array}$ & $93 \%$ & $\begin{array}{l}\text { Adeesina } \\
2007[57]\end{array}$ \\
\hline $\begin{array}{c}\text { RAS } \\
\text { association } \\
\text { domain family } \\
\text { 1A }\end{array}$ & RASSF-1A & $\begin{array}{l}\text { Candidate tumor } \\
\text { suppressor }\end{array}$ & $\begin{array}{c}\text { Transcriptionally } \\
\text { silenced }\end{array}$ & $79 \%$ & $\begin{array}{c}\text { Lusher } 2002 \\
{[58]}\end{array}$ \\
\hline $\begin{array}{l}\text { Orthodenticle } \\
\text { homeobox } 2\end{array}$ & OTX2 & Oncogene & Overexpressed & $\begin{array}{l}93 \% \text { of Large } \\
\text { cell/Anaplas- } \\
\text { tic MB }\end{array}$ & $\begin{array}{l}\text { Di Sapio } \\
2005[59]\end{array}$ \\
\hline Paired box 5 & PAX5 & $\begin{array}{l}\text { Developmental } \\
\text { control }\end{array}$ & Overexpressed & $70 \%$ & $\begin{array}{c}\text { Kozmik } 1995 \\
{[60]}\end{array}$ \\
\hline Caspase 8 & Caspase 8 & Apoptosis factor & $\begin{array}{c}\text { Transcriptionally } \\
\text { silenced }\end{array}$ & $62 \%$ & $\begin{array}{c}\text { Gonzalez- } \\
\text { Gomez } 2004 \\
{[61]}\end{array}$ \\
\hline $\begin{array}{l}\text { Hypermethyl- } \\
\text { ated in cancer }\end{array}$ & HIC-1 & $\begin{array}{l}\text { Candidate tumor } \\
\text { suppressor }\end{array}$ & $\begin{array}{c}\text { Transcriptionally } \\
\text { silenced }\end{array}$ & $72 \%$ & $\begin{array}{c}\text { Rood } 2002 \\
{[62]}\end{array}$ \\
\hline $\begin{array}{c}\text { Secretory } \\
\text { granule } \\
\text { neuroendocri } \\
\text { ne protein } 1 \\
\end{array}$ & SGNE1 & $\begin{array}{l}\text { Inhibits } \\
\text { proliferation }\end{array}$ & $\begin{array}{l}\text { Transcriptionally } \\
\text { silenced }\end{array}$ & $50 \%$ & $\begin{array}{c}\text { Waha } 2007 \\
{[63]}\end{array}$ \\
\hline
\end{tabular}

important to MB development [33]. Loss of chromosome $10 \mathrm{q}$ is also frequently seen in MB (40\% of cases) $[33 ; 64]$, as is loss of chromosome 1q $(20 \%$ of cases) $[23 ; 32 ; 64-69]$. The most frequent abnormalities in chromosome 1 include unbalanced translocations, deletions and duplications and rearrangements of chromosome 1 have been shown to result in trisomy $1 \mathrm{q}$ without loss of the $\mathrm{p}$-arm. In addition, deletions in $\mathrm{X}, 1 \mathrm{p}, 3 \mathrm{q}, 6 \mathrm{q}, 8 \mathrm{q}$, $8 \mathrm{p}, 9 \mathrm{q}, 11 \mathrm{p}, 11 \mathrm{q}, 16 \mathrm{q}$, and 18 and gains in $1 \mathrm{p}, 1 \mathrm{q}, 3 \mathrm{q}, 4 \mathrm{p}, 5 \mathrm{p}, 5 \mathrm{q}, 7 \mathrm{q}, 8 \mathrm{q}, 9 \mathrm{p}, 11 \mathrm{p}, 12 \mathrm{q}$ $13 q$, and $14 q$ have been observed at lower rates $[31 ; 32 ; 64 ; 69-72]$, though some are only common in certain subtypes such as gains of $11 p, 13 q$, and $14 q$ in LC/A MBs [71]. Trisomy of chromosome $7[19 ; 24 ; 66 ; 73]$ is also a common chromosomal alteration in $\mathrm{MB}$, though it appears in most tumors with $\mathrm{i}(17 \mathrm{q})$ and thus is most likely a secondary change unimportant to tumor initiation [74]. Loss of $9 \mathrm{q}$, which contains the tumor 
suppressor gene patched (PTCH) at locus 9q22.3, has been linked to poor outcome [75]. Yin et al. 2001 identified the regions 10q25, 11p13-11p15.1 and 16q24.1-24.3 as showing $\mathrm{LOH}$ and being localized to the deleted in malignant brain tumors (DMBT1) gene site [69]. Amplification of N-myc and anonymous oncogenes at 2q12-22 and 17p11 have also been detected in a set of LC/A MBs [71]. Finally, deletion of chromosome 22 has also been reported in approximately $10 \%$ of these tumors $[24 ; 73 ; 76]$, though some reports argue against the overall importance of this change [19;64], and misdiagnosis has been suggested as a possible explanation for this discrepancy [19].

Several more defined chromosomal regions that may contain oncogenes for MB have been identified by comparative genomic hybridization (CGH) and include chromosomal gains of 1q21.3-q23.1, 1q32.1, 2p21, 2p23.1-p25.3, 7, 5p15.3, 8q24, 9q34.13-q34.3, 11q22.3, 17p11.2-q25.3, and 20q13.31-q13.33, and losses of 1q23.3-q24.2, 2q13.12q13.2, 3q26.1, 4q31.23-q32.3, 6q23.1-25.3, 8p22-23.3, 10q24.32-26.2, 12q13.12-q13.2, and 16q23.2-q24.3 [77-79]. Oncogene amplifications that have been identified using CGH in MB include D17S1670 (61.5\% of tumors), PIK3CA (46.2\%), PGY1 (38.5\%), MET (38.5\%), ERBB2 at 17q21.2 (38.5\%), CSE1L (38.5\%), PGY1 at 7q21.1, and MDM2 at 12q14.3-q15 [79].

Gene Alterations: Several inherited genetic diseases predispose affected individuals to MB development, including the autosomal dominant disorder Gorlin's syndrome and Turcot's syndrome. Somatic mutations in the Gorlin's syndrome gene PTCH are found in approximately $10 \%$ of patients with sporadic MB [39-41;80;81]. This inactivation of $\mathrm{PTCH}$, which leads to upregulation of the SHh pathway, appears to be more prevalent in desmoplastic MBs, along with loss of chromosome 9q, while loss of $17 \mathrm{p}$, HIC-1 
inactivation, and myc amplification are more prominent in classic MB $[80 ; 82 ; 83]$. Mouse models for inactivation of PTCH also show development of MB [84;85].

While PTCH is found mutated in sporadic MB at a relatively low frequency, other members of the SHh pathway are also mutated in MB and aberrant activation of this pathway is found in approximately $25 \%$ of cases $[40 ; 86 ; 87]$ Reviewed in [88;89]. The hedgehog signaling pathway is one of the key regulators in brain development as it has been shown to control proliferation and differentiation of granule cell precursors (GCPs). Deregulated proliferation of these progenitor cells through activation of the SHh pathway can result in MB [90;91]. SHh activates patched $(\mathrm{PTCH})$ which then interacts with Smoothened (SMO) and its downstream targets such as Fused (Fu) and Mutated Suppressor of Fused Homolog (SUFU), leading to signaling to Gli proteins to translocate to the nucleus and transcribe target genes [92]. Studies in the brain demonstrate that SHh signaling leads to increased Mycn transcription [93], which as described later, is implicated in CNST development as well. While most SHh mutations are predominantly found in the desmoplastic subtype [40;80;87], they are reported in classic MB as well [39;41]. SUFU is found in approximately $10 \%$ of MB [87] while SMO is mutated in approximately $5 \%$ of tumors [43]. Furthermore, SUFU activation has been reported to result in overactivity of both the SHh and WNT signaling pathways, leading to excessive proliferation and failure in cell differentiation resulting in MB [94]. Along with mutations in SUFU and SMO, gene mutations in PTCH2, a PTCH homolog have also been identified [95]. In contrast to the above results, Chiappa et al. (1999) found no evidence for mutations in genes of the SHh pathway other than PTCH in 27 medulloblastomas. A negative regulator of the SHh pathway, RENKCTD11 (located at 
17p13.2), shows allelic deletion in $39 \%$ of sporadic MBs and is significantly underexpressed in MB [25]. RENKCTD11 has been shown to inhibit MB growth by counteracting the SHh induced nuclear transfer of the transcription factor Gli, which regulates expression of several genes including N-myc, cyclin D, PTCH1, and Gli1 [25;96;97]. Many of these target genes have been shown to exist at elevated levels in both major MB subtypes including PTCH1, Gli1, and N-myc [43;82;98;99].

SHh signaling has also been found to interact with other genes that promote cell cycle progression or cell survival in MB. For instance, hyperactive insulin-like growth factor (IGF) signaling enhances SHh-induced formation of MB [93;100], possibly through cooperative control of N-Myc, as SHh stimulates transcription of N-myc while IGF stabilizes N-myc [101]. MBs frequently overexpress the anti-apoptotic factor Bcl-II [102], and dysregulated apoptosis as a result of Bcl-II overexpression cooperating with SHh-stimulated proliferation appears to transform GCPs to form MBs [103]. SHh pathway target Gli1 is also significantly correlated with Bcl-II expression in MB and both proteins have been shown to be present in regions of decreased apoptosis in desmoplastic MB [104]. Alternatively, phosphatidylinositol 3-kinase (PI3K) signaling may also be an anti-apoptotic factor in SHh transformation of GCPs to aggressive MBs as elevated levels of Akt combined with no upregulated expression of Bcl-II was found in SHh induced MBs [103]. In fact, it appears that dysregulation of PTEN leading to activation of the PI3K/Akt pathway may play a significant part in medulloblastoma pathology [100]. Animal models show that $\mathrm{SHh}$ induced formation of medulloblastomas is significantly enhanced by activation of the PI3K/Akt signaling pathway [93]. Proliferation of medulloblastoma cell lines is dependent on PI3K/AKT signaling, whereas apoptosis is 
not significantly affected [100]. Allelic loss of PTEN has been found in $16 \%$ of the medulloblastoma cases and PTEN mRNA and protein levels are significantly lower in medulloblastomas compared with normal cerebellar tissue of different developmental stages, and reduction of PTEN expression was found associated with PTEN promoter hypermethylation in 50\% of the MB tissue samples [100].

WNT pathway alterations have also been linked to MB (15\% of cases), mostly of the classic MB type [reviewed in [88;89]]. Adenomatous polyposis coli (APC), a gene whose germline mutation is linked to development of Turcot's syndrome, is found mutated in sporadic medulloblastoma (3-13\%) [45;47;48;105-107]. In addition, the Wntwingless pathway partner of APC, $\beta$-catenin (CTNNB1) is also found mutated in a small subset of sporadic MBs $(\sim 6 \%)$ and converts a GSK-3beta phosphorylation site from serine to cysteine [48;49]. Mutations in GSK-3beta itself have not been identified [108]. Finally, mutations in another WNT pathway gene, Axin1/Axin2, including a single somatic point mutation in exon 1 (Pro255Ser) and seven large deletions, have also been detected in $\mathrm{MB}(\sim 5 \%)[45 ; 49 ; 50]$, and their potential to activate oncogenic activity in the Wnt signaling pathway has been established [50]. All of these alterations influence translocation of $\beta$-catenin to the nucleus and activation of its target genes, including myc, in MB. Nuclear accumulation of $\beta$-catenin predicts a favorable outcome in pediatric MB [109].

Amplification of the Myc genes (c-myc and N-myc) is present in 5-15\% of MBs [32;51;71;110-113], and is more common in the aggressive LC/A type [34;114;115]. Myc is activated by various mitogenic signals including those from pathways important to CNST development such as SHh and WNT. Myc target genes in MB are primarily 
involved in cellular growth and metabolism, cell proliferation including rapid expansion of progenitor cells during neurogenesis, cell cycle regulation and differentiation, and stem cell self-renewal [116-119]. While the variations of Myc can perform each other's functions, it appears they function independently as well, modulating the expression of their targets based on cell type and environment $[119 ; 120]$. New research shows that Myc induces $\mathrm{mt}$ gene expression and $\mathrm{mt}$ biogenesis, thereby directly linking Myc's regulatory properties to the production of mitochondrial ROS and the promotion of genomic oxidative damage and instability [121]. Several studies of myc amplification or mRNA overexpression have linked the gene to aggressive clinical behavior in MB [51;75;110;112;122-124]. In addition, low N-myc expression has been related to higher survival rates [125]. Furthermore, c-myc alterations in combination with loss of $17 \mathrm{p}$ appear to produce a more aggressive MB [75].

Defects in the p53-ARF pathway MB including p53 mutation, methylation of P14 ${ }^{\mathrm{ARF}}$ or deletion of INK4A $\mathrm{A}^{\mathrm{ARF}}$ exist in $20 \%$ of MB [53]. These pathway alterations are found more frequently in the LC/A MB tumor type, linking them to a more aggressive tumor type [53]. Mutations in the p53 gene itself, located in the $17 \mathrm{p}$ region at $17 \mathrm{p} 13.1$, are infrequent in $\mathrm{MB}$ however $[20 ; 36 ; 71 ; 126 ; 127]$, though they may reduce survival (Woodburn et al. 2001). Overexpression of Bmi1, which represses the ink4a/Arf tumor suppressor and is located on chromosome 10p, is strongly expressed in proliferating cerebellar precursor cells of mice and humans. It is also coexpressed with the SHh pathway gene PTCH in a significant number of MBs and likely plays an important role in the proliferation of GCP cells [128]. 
Several growth factors and transcription factors involved in neuronal growth, differentiation, survival, and apoptosis have also been investigated in relation to MB development. Several members of the Neurotrophin signaling pathway including the neurothrophins NGF, BDNF, NT3 and the receptors p75, Tyrosine receptor kinase A (TrkA), TrkB, and TrkC are all expressed in MBs. One of these, TrkC, which mediates the functional signals of neurotrophins, is overexpressed in $48-85 \%$ of MBs $[54 ; 55]$ and has been reported to be the single most powerful independent predictor of favorable outcome for MBs [17;123;125;129-132]. Only Gajjar et al. have found no evidence of TrkC affecting clinical presentation [133].

The PDGFR-Ras/MAPK pathway, which is potentially involved in N-nitroso compound (NNC)-induced brain tumors in animals [134], has been shown to be activated in $\mathrm{MB}$, and seems to be particularly important for metastatic MB [135;136]. A gene expression profile study found the platelet derived growth factor receptor alpha (PDGFR$\alpha$ ) and the Ras/mitogen-activated protein (MAP) kinase pathway genes to be related to metastasis in MBs [136]. Known mutational 'hotspots' in PDGFR- $\alpha$, NRas, KRas, HRas, BRAF, and PDGRF- $\beta$ were not found in one MB study on this pathway, with the exception of a synonymous sequence variation in PDGFR- $\alpha$ (CCG to CCA; PRO 567 PRO) that was found in approximately $7 \%$ of tumors ( 2 of 28 tumors studied), suggesting that this mutation may be associated with MB development in certain cases [56]. Wasson et al. also found no amplification in Hras, Kras, or Nras in 20 analyzed MBs [137]. One study did find N-ras mutations of codon 61 in 10\% (3 of 32 cases) of MB however, including a $\mathrm{C}$ to $\mathrm{A}$ mutation at position 1 (leading to a substitution of a glutamine residue for a lysine) and an A to T mutation at position 3 (glutamine-histidine) [138]. A separate 
mutation in pediatric supratentorial PNETs has been found as well. An activating point mutation in KRAS [G to A transition in position 2 of codon 12, substituting aspartate (GAT) for glycine (GGT)] was detected in 1 of 3 sPNETs that developed after prophylactic central nervous system (CNS) treatment for leukemia or lymphoma [139].

ErbB2 (aka HER2/neu) and neuregulin-1b (NRG-1b), part of the ErbB growth factor receptor signaling pathway involved in cerebellar development, appear to play significant roles in MB tumorigenesis also. ErbB2 is expressed in $>80 \%$ of MBs, while NRG- $1 \mathrm{~b}$ is expressed in $87.5 \%$ of MBs [140-144]. Again however, the Gajjar et al. 2004 study disagreed with the consensus as ErbB2 was expressed in only 40\% of tumors [133]. Reduced survival and increased ErbB2 expression has also been associated in several studies $[133 ; 140 ; 142 ; 143 ; 145]$. FOXG1, a theorized repressor of TGF- $\alpha$ induced expression of $\mathrm{p} 21$ cip 1 and cellular growth which interacts with NOTCH signaling, shows copy gain between 2 and 21 fold in 93\% of MB [57]. Finally, several members of a family of transcription factors involved in regulation of neuronal differentiation, the NueroD family, were found to be expressed only in PNETs in a study on a series of different brain tumor types, indicating they may be important to MB development as well [146].

Several other genetic changes, some also involved in neuronal differentiation, have been identified in relation to development of MBs. Amplification of the oncogene OTX2 has been described in 93\% (14 of 15) anaplastic MBs [59]. Inactivation of RASSF-1A, located at 3p21, was found in $79 \%$ of MBs, regardless of pediatric or adult status and/or MB type [58]. The developmental control gene PAX5 is expressed in $70 \%$ of MB and was not found expressed in normal neonatal cerebellum tissue, indicating that PAX5 is 
deregulated in MB [60]. Pomeroy et al. found the GCP transcription factors Zic1 and SSCL1 to be most closely correlated to MBs [82]. Upregulated genes correlated with favorable outcome in this study were involved in cerebellar differentiation [vesicle coat protein $\beta$-NAP, NSC1, Tyrosine receptor kinase $\mathrm{C}(\operatorname{TrkC})$, sodium channels], and genes encoding extracellular matrix proteins [procollagen-lysine-2-oxoglutarate 5-dioxygenase, lysyl hydroxylase, collagen type $\mathrm{V} \alpha-\mathrm{I}$, elastin]. Poor prognosis was correlated with underexpressed cerebellar differentiation genes and overexpressed cell proliferation and metabolism genes [MYBL2, enolase I, LDH, HMG1 (Y), cytochrome C oxidase] and multidrug resistance [sorcin gene]. Other investigators have also found overexpression of GCP related genes in MB, including $\mathrm{p} 75^{\mathrm{NTR}}$, Math1, and the previously mentioned Zic1 [82;147-149], though GCP marker expression tends to be seen more often in the desmoplastic form of MB found predominantly in adults. In contrast, classic MB are associated with expression of markers of non-granule neurons such as calbindin-28k, a major calcium binding protein in the brain located predominantly in the cytosol [150] . Calbindin appears to play a role in reduction of intracellular calcium levels and calcium induced apoptosis in neurons and astrocytes [151;152]. Calbindin-d(28k)-positive MBs show increased aggressiveness, are associated with a high risk of death and recurrence, and are more frequently seen in a patients younger than 15 years old [150].

Other genetic alterations reported include findings of high levels of a stem-cell marker, the glycoprotein CD133, in both MB tumor subtypes, suggesting that stem cells could provide the origin of both MB types [153;154]. Manganese superoxide dismutase (MnSOD) was overexpressed in MB in one study [155] and decreased in another[156], while catalase (CA) and GSH-Px have not been found to be increased in MB [156]. 
Epigenetic Alterations: Several recent studies have identified the tumor suppressor genes RASSF1, Caspase 8, and HIC-1 as being transcriptionally silenced in over $60 \%$ of MB cases [61;62;157-159]. Hypermethylation of HIC-1, which is located at $17 \mathrm{p} 13.3$, has also proven to be a predictor of poor outcome [62]. Recently, Waha et al. 2007 identified a hypermethylated $\mathrm{CpG}$ island which led to silencing of the proliferation inhibiting secretory granule neuroendocrine protein 1 (SGNE1) gene in 50\% of MBs analyzed $(\mathrm{n}=50)$, though no mutations were identified in the SGNE1 (SGNE1 is the human homologue of 7B2 located at 15q11-15). Reports on methylation in MB have also identified $\mathrm{p} 14^{\mathrm{ARF}}, \mathrm{p} 16^{\mathrm{INK} 4 \mathrm{~A}}, \mathrm{TP} 73, \mathrm{TP} 53, \mathrm{RB} 1, \mathrm{RASSF} 1 \mathrm{~A}, \mathrm{HIC1}$, EDNRB, CASP8, DAPK, CDH1, THBS1, TIMP3, GSTP1, MGMT, INK4C (CDKN2C), and MCJ as showing methylation in $\mathrm{MB}$, albeit at a frequency $<20 \%[158 ; 160]$.

\section{Astrocytoma}

Astrocytoma is the most common CNST, comprising $60 \%$ of cases of the disease overall, and $40 \%$ of all pediatric cerebral tumors [15;161]. It is divided into four WHO grades: Grade I pilocytic astrocytoma (aka juvenile pilocytic astrocytoma) predominantly occur as a benign cerebellar and midline structures tumor in children; Grade 2 diffuse astrocytomas (includes fibrillary, protoplasmic, and gemistocytic variants) are benign well-differentiated tumors seen primarily in 20-40 year olds, but also occur frequently in pediatrics, especially in the brain stem; Grade III anaplastic tumors are malignant tumors predominantly affecting the cerebrum of 40 year old patients; and the most common and malignant type overall, Grade IV glioblastoma multiforme (GBM), a necrotic tumor which targets patients in their 50's or 60's, though this is the most common tumor of the 
brain stem in children. In contrast to adults who more often have an aggressive highgrade tumor (Grades III and IV), the low-grade types (Grade I and II) are the most common type of astrocytomas in childhood, though approximately $15-20 \%$ of all pediatric astrocytomas are Grade III and IV astrocytomas [162]. (CBTRUS 2007 Report) A more severe pilocytic astrocytoma subtype, pilomyxoid astrocytoma, also exists and is frequently found in children less than 3 years of age [38]. As with medulloblastoma and all CNST, debate continues as to whether astrocytomas arise from differentiated astrocytes, astroglial progenitor cells, or neural stem cells. In addition, an inherited disease is also associated with development of this brain tumor, as individuals with neurofibromatosis type I (NF1), are at greatly increased risk of developing pilocytic astrocytomas. Table 2-2 summarizes genetic alterations in astrocytoma.

Cytogenetics: Very few studies have evaluated the genetics of pediatric astrocytomas, however most show significant differences in cytogenetic abnormalities between grades of pediatric astrocytomas and between pediatric and adult astrocytomas. While most cytogenetic analysis of pilocytic astrocytoma show normal chromosomal arrangement [163-165], gains of chromosome 7 and 8 are observed in approximately one-third of cases, and loss of $22 \mathrm{q}$ is reported in $20-30 \%$ of cases [166]. These gains were not found in one study of low-grade astrocytomas [166], however another study identified trisomy 7 in this tumor type [167]. Other abnormalities observed in pilocytic tumors include gains of chromosomes 10p, 11 and 12p, losses on chromosomes XY, 1p, 4q, 9p, 11p, 16p, 18, and 19 , and telomeric associations $[165 ; 166 ; 168 ; 169]$. Some authors have also suggested that chromosomal arrangements define two subtypes of pilocytic astrocytoma, mainly one group showing deletions on chromosome 19 and another group showing gains on 19p 
Table 2-2. Common susceptibility genes of pediatric astrocytoma.

\begin{tabular}{|c|c|c|c|c|c|}
\hline Gene Name & $\begin{array}{c}\text { Gene } \\
\text { Symbol } \\
\end{array}$ & Pathway/Function & $\begin{array}{c}\text { Type of } \\
\text { Alteration } \\
\end{array}$ & $\begin{array}{c}\text { Frequency of } \\
\text { Alteration } \\
\end{array}$ & Reference \\
\hline $\begin{array}{l}\text { Neurofibro- } \\
\text { matosis } 1\end{array}$ & NF1 & $\begin{array}{c}\text { Susceptibility } \\
\text { gene for } \\
\text { Neurofibromatosis }\end{array}$ & $\begin{array}{l}\text { Overexpress- } \\
\text { ion/mutation }\end{array}$ & $\begin{array}{l}\text { Common in } \\
\text { pilocytic } \\
\text { astrocytoma }\end{array}$ & Platten 1996 [170] \\
\hline $\begin{array}{c}\text { Epidermal } \\
\text { growth factor } \\
\text { receptor }\end{array}$ & EGFR & $\begin{array}{l}\text { Member of ErbB } \\
\text { family of growth } \\
\text { factors }\end{array}$ & Mutation & $\begin{array}{l}\text { Rare in } \\
\text { pediatric } \\
\text { tumors; } \\
\text { common in } \\
\text { adult tumors }\end{array}$ & $\begin{array}{c}\text { Bredel } 1999 \\
\text { [171]; Cheng } \\
1999 \text { [172]; Sung } \\
2000[173]\end{array}$ \\
\hline $\begin{array}{c}\text { Platelet- } \\
\text { derived growth } \\
\text { factor } \\
\text { receptor- } \alpha\end{array}$ & $\begin{array}{c}\text { PDGFR- } \\
\alpha\end{array}$ & $\begin{array}{l}\text { PDGFR-Ras- } \\
\text { MAPK }\end{array}$ & Mutation & $\begin{array}{l}\text { Rare in } \\
\text { pediatric } \\
\text { tumors; } \\
\text { common in } \\
\text { adult tumors }\end{array}$ & $\begin{array}{c}\text { Bredel } 1999 \\
\text { [171]; Di Sapio } \\
\text { 2002 [174]; } \\
\text { Nakamura 2007 } \\
\text { [175] }\end{array}$ \\
\hline PTEN & PTEN & Tumor Suppressor & $\begin{array}{c}\text { Homozygous } \\
\text { deletion }\end{array}$ & $\begin{array}{l}8 \% \text { in high- } \\
\text { grade } \\
\text { pediatric } \\
\text { astrocytoma }\end{array}$ & $\begin{array}{c}\text { Cheng } 1999 \\
\text { [176]; Raffel } 1999 \\
\text { [177]; Watanabe } \\
1996 \text { [178] }\end{array}$ \\
\hline p53 & p53 & $\begin{array}{c}\text { p53-MDM2- } \\
\text { p14 }\end{array}$ & Mutation & $\begin{array}{l}28-38 \% \text { of } \\
\text { high-grade } \\
\text { pediatric } \\
\text { astrocytoma }\end{array}$ & $\begin{array}{c}\text { Cheng 1999 } \\
\text { [176]; Felix } 1995 \\
\text { [179]; Nakamura } \\
\text { 2007 [175]; } \\
\text { Pollack 1997 } \\
\text { [180]; Pollack } \\
\text { 2001 [181]; } \\
\text { Pollack 2002 } \\
\text { [182]; Sure } 1997 \\
\text { [183] }\end{array}$ \\
\hline MDM2 & MDM2 & $\begin{array}{c}\text { p53-MDM2- } \\
\text { p14 }\end{array}$ & $\begin{array}{l}\text { Overexpressi } \\
\text { on }\end{array}$ & $\begin{array}{c}67 \% \text { of } \\
\text { pediatric } \\
\text { malignant } \\
\text { astrocytoma }\end{array}$ & Sung 2000 [173] \\
\hline $\mathrm{p} 14^{\mathrm{ARF}}$ & $\mathrm{p} 14^{\mathrm{ARF}}$ & $\begin{array}{l}\text { p53-MDM2- } \\
\text { p14 }\end{array}$ & $\begin{array}{l}\text { Homozygous } \\
\text { Deletion }\end{array}$ & $\begin{array}{c}10 \% \text { of } \\
\text { pediatric } \\
\text { glioblastoma }\end{array}$ & $\begin{array}{c}\text { Newcomb } 2000 \\
{[184]}\end{array}$ \\
\hline $\begin{array}{l}\text { Ras-Akt } \\
\text { pathway }\end{array}$ & $\begin{array}{l}\text { Ras-Akt } \\
\text { pathway }\end{array}$ & Ras-Akt pathway & $\begin{array}{c}\text { Pathway } \\
\text { overexpressio } \\
\mathrm{n}\end{array}$ & $\begin{array}{c}100 \% \text { of } \\
\text { sporadic } \\
\text { pilocytic } \\
\text { astrocytomas }\end{array}$ & $\begin{array}{c}\text { Sharma } 2005 \\
{[185]}\end{array}$ \\
\hline Ras & Ras & Ras-Akt pathway & Mutation & Rare & $\begin{array}{c}\text { Sharma 2005 } \\
\text { [185]; Janzarik } \\
\text { 2007 [186]; } \\
\text { Maltzman 1997 } \\
\text { [187]; Sharma } \\
\text { 2005 [185] }\end{array}$ \\
\hline $\begin{array}{c}\text { RB-cyclinD1- } \\
\text { cyclin } \\
\text { dependent } \\
\text { kinase-p16 } \\
\end{array}$ & $\begin{array}{c}\text { RB } \\
\text { cyclinD1 } \\
\text { CDK4 } \\
\text { p16 }\end{array}$ & $\begin{array}{l}\text { RB-cyclinD1- } \\
\text { cyclin dependent } \\
\text { kinase } 4 \text { (CDK4)- } \\
\text { p16 pathway }\end{array}$ & $\begin{array}{l}\text { Inactivation } \\
\text { of pathway }\end{array}$ & $\begin{array}{c}25 \% \text { of } \\
\text { pediatric } \\
\text { high-grade } \\
\text { astrocytoma } \\
\end{array}$ & Sung 2000 [173] \\
\hline
\end{tabular}


and 22q [188]. Cytogenetic abnormalities appear unrelated to pediatric low-grade astrocytoma prognosis [189].

In contrast to the relatively low cytogenetic changes in grade I astrocytoma, pediatric malignant astrocytomas demonstrate a number of chromosomal changes and differ in several respects their adult tumor counterparts, though a few of these tumors have shown normal karyotype at well [190]. In a study on malignant childhood astrocytomas (Grade II-IV) (NOTE: included young adults less than 25 years old), the most common aberrations were loss of $16 \mathrm{p}$ (54\% of cases), 17p (38\%), 19p (38\%), and $22(38 \%)$ and gain on $2 \mathrm{q}(38 \%), 12 \mathrm{q}(38 \%), 13(38 \%), 4 \mathrm{q}(31 \%), 5 \mathrm{q}(31 \%)$, and $8 \mathrm{q}(31 \%)$. Other studies on these tumors have found loss of heterozygosity $(\mathrm{LOH})$ on $1 \mathrm{p} / 19 \mathrm{q}$ and $10 \mathrm{p} / 10 \mathrm{q}$, and gains of $7 p$ and $9 p$ at a lower frequency than adults, however LOH on $22 q$ is comparable in frequency (44\% of diffuse, $40 \%$ of anaplastic, and $61 \%$ of glioblastoma) $[73 ; 175]$. LOH on $19 q$ and $22 q$ was more frequent in children older than six years of age compared to younger children. Rickert et al. 2001 found that compared with adult cases, gain of $1 \mathrm{p}, 2 \mathrm{q}$, and $21 \mathrm{q}$ as well as loss of $6 \mathrm{q}, 11 \mathrm{q}$, and $16 \mathrm{q}$ were more frequent in pediatric malignant astrocytomas [191]. Furthermore, microsatellite instability, which is absent in adult astrocytomas, is seen in $27 \%(12 / 45)$ of pediatric malignant astrocytomas [192]. It also appears that survival is not predicted by cytogenetic changes in pediatric malignant gliomas, in contrast to adult malignant gliomas [193], though this is disputed by a study that showed survival was significantly shorter for pediatric high-grade astrocytomas with amplification of chromosome 1q [191]. Differences in chromosomal aberrations also exist between malignant grades of pediatric astrocytoma. Grade III pediatric tumors show differing cytogenetic changes (gain of 5q; loss of 6q, 9q, 12q, and 
22q) compared to Grade IV pediatric tumors (gain of 1q, 3q, 16q, and loss of 8q and 17p) [191]. Specific regions showing high copy number amplification in pediatric malignant astrocytomas include 8q21-22, 7q22-23, 1p21-22, 2q22, 12q13-pter, 12q15-21, and 13q11-14 [190].

Gene Alterations and Characteristics: NF-1 is caused by a mutation of a gene on chromosome $17 \mathrm{q}$ which encodes a protein known as neurofibromin $(N f 1)$. This mutation also predisposes individuals to development of pilocytic astrocytoma. In contrast to individuals with NF1 who show loss of NF1 expression [194], sporadic pilocytic astrocytomas often have overexpression of NF1 [170;195]. The reason for this discrepancy is currently unknown [38]. Beyond the NF1 gene, many of the other identified mutations found in astrocytomas are important for normal astrocyte development. For instance, alterations in growth factor genes important for glial differentiation from neural stem cells such as mutations in the epidermal growth factor receptor (EGFR) (approximately $30 \%$ to $50 \%$ frequency in grade IV astrocytoma and $15 \%$ of grade III astrocytoma) and overexpression of platelet-derived growth factor alpha (PDGFR- $\alpha$ ) (found in many primary grades and secondary glioblastomas), are common in adult astrocytoma [196-201]. These common adult astrocytic alterations are detected rarely in pediatric low-grade astrocytomas however, and in fact, PDGFR- $\alpha$ amplification has only been observed in one case of one study on these tumors $[137 ; 171 ; 173$ $175 ; 177 ; 180 ; 183]$. Overexpression of EGFR is also rarely observed in pediatric anaplastic astrocytoma and glioblastoma [171-173;176;177], despite them being histologically indistinguishable from adult glioblastoma. Interestingly, a malignant form of pediatric low-grade astrocytoma, disseminated astrocytoma (5-10\% of all pediatric 
low-grade astrocytoma), show a high rate of EGFR amplification and protein expression [202], as do pediatric non-brainstem high-grade tumors ( $80 \%$ show high expression levels though only 2 of 27 show amplification and EGFR changes did not influence outcome) [171]. Thus, it appears EGFR may drive progression of astrocytomas from low to high grade [198].

A common signature of astrocytic tumor progression is angiogenesis and an increasingly hypoxic environment. A report on angiogenic factors in childhood astrocytoma identified the EGFR/FK506-binding protein (FKBP)12/HIF pathway as being significantly overexpressed in childhood glioblastomas compared to low-grade childhood astrocytomas [203]. Peroxisome-proliferator-activated receptor-c coactivator1a (PGC-1a), a key mt-nuclear signaling gene involved in oxidative phosphorylation, mt biogenesis and respiration, is induced by a lack of nutrients and oxygen and is a powerfully regulator of the PDGFR family member vascular endothelial growth factor (VEGF) [204]. VEGF is upregulated in adult astrocytic tumors compared to normal brain [205]. Interleukin-6 (IL-6) upregulates VEGF expression in human glioblastoma cells and the activation of IL-6 is dependent on its interaction with STAT3. This process may play an important role in angiogenesis and its contribution to glioma progression from lower-grade to high-grade GBMs [206]. VEGF, which can be induced by IL-6 and hypoxia [207], can also be upregulated by TNF- $\alpha$ and this process appears to be mediated by Sp-1 in human glioblastoma cells [208]. A role for Hypoxia-inducable factor-1 (HIF1) and its function in a hypoxic environment in the progression of astrocytic tumors to a more aggressive state has also been suggested and is supported by evidence that HIF-1 mediated gene expression is modulated by alterations in genes important to astrocytoma 
development such PTEN, TP53, p16(CDKN2A), p14ARF, EGFR, and PDGFR [209]. Furthermore, recent work shows that loss-of-function mutations in fumarate hydratase (FH) and succinate hydrogenase (SDH) in the mt TCA cycle result in activation of HIF-1. HIF-1 activation can then change the expression of numerous genes important to cellular metabolism, and increase angiogenesis, glucose uptake and glycolosis [210-213]. Additionally, HIF-1 modulated gene expression can be influenced by reactive oxygen species (ROS), a signaling molecule primarily produced in $\mathrm{mt}$ [214]. This work has strengthened the notion that HIF-1 activation could play a role beyond promotion of angiogenesis and actually be involved in initiation of cancer.

PTEN mutations, which occur in $\sim 30 \%$ of adult high-grade astrocytoma, are rare ( $8 \%$ homozygous deletion) in childhood high-grade astrocytoma [176-178;201], and are nonexistent in pediatric pilocytic astrocytoma [215;216]. PTEN protein expression is present in $38 \%$ of pilocytic tumors however [215], and mutations in PTEN predict poor prognosis in pediatric grade III and IV malignant astrocytomas [177]. PTEN interacting with wildtype p53 has been shown to inhibit angiogenesis in malignant astrocytoma cells [217;218], suggesting that mutations in p53 could be important in development of higher grade tumors. Mutations of p53 in astrocytoma are thought to result in decreased apoptosis [219] and cellular transformation [220;221]. In fact, mutations in the p53 pathway (mutation of p53/overexpression of MDM2/deletion of $\mathrm{p} 14^{\mathrm{ARF}}$ ) have been found to be $>95 \%$ in high grade pediatric astrocytomas [173], with mutations in p53 itself occurring in $28-38 \%$ of both childhood and adult high-grade astrocytoma, though these mutations are much lower in children younger than 4 with high-grade astrocytoma [175;176;179-183]. Still, they are the most commonly observed alteration in pediatric 
malignant astrocytomas (Grades II-IV), although some early studies did not find p53 to be a frequent mutation [222-224]. There is also controversy concerning p53 mutation frequency in pilocytic tumors as combination of reports show the frequency to be as low as $1.3 \%$ [215;224-226], while one report showed p35 mutation frequency to be $35 \%$ [227]. Overexpression of MDM2 occurs in $67 \%$ of pediatric malignant astrocytomas [173], while homozygous deletions of CDKN2A/p1 $4^{\mathrm{ARF}}$ at $9 \mathrm{p} 21$ are found in $10 \%$ of pediatric malignant glioblastomas [184]. No MDM2 gene amplification was found in pediatric high-grade and pilocytic astrocytomas in one study however, although this study found p53 mutations to be rare in these tumors as well [224]. As mentioned above, Ink4a is a member of the p53 signaling pathway, being a gene product of p16. Although Ink4a is frequently lost in a large fraction of human GBM samples, mice lacking Ink4a seldom develop spontaneous brain tumors [228]. Aberrant copy numbers of the Ink4a antagonist Bmi1, have been identified in 59\% of gliomas (low and high-grade combined), and increased copy number of Bmil at 10p13 (3-5 copies), while found in all glioma types, are especially elevated in GBMs. In addition, deletions of the Bmi1 locus are found in most types of tumors and are associated with poor prognosis, while increased copy number of the gene locus is not associated with poor outcome [229]. Some authors have suggested two alternative pathways to GBM involving the p53 pathway, one that transforms astrocytes and is Ink4a/Arf dependent and p53 independent, and another that transforms neural stem cells and is p53 dependent [230]. For a more detailed discussion of these mechanisms the reader is referred to Perotin et al. 2006 [230].

Studies in glioma cells have demonstrated the ability of oxidative stress to induce p53 dependent $\mathrm{mt}$ mediated apoptosis through MDM2 degradation promoting p53 
signaling to the $\mathrm{mt}$ followed by cytochrome $\mathrm{c}$ release and nucleosomal fragmentation [231]. This apoptotic pathway involves both pro-apoptotic factors such as bax and Fas, and anti-apoptotic genes such as bcl-II [232]. Glial tumors (46 tumors including astrocytomas, oligodendrogliomas, oligo-astrocytomas, and glioblastomas) show upregulation of the apoptosis-promoting factors bax, Fas, Fas-L, and the apoptotic inhibitor bcl-II but none of these genes correlated with malignancy [233;234]. Bcl-II expression levels have been shown to increase with astrocytic tumor grade in glioma cell studies (included WHO grades I-IV), and an increase in proliferation and decrease in apoptosis accompanies this increased expression in each tumor grade [234]. Furthermore, overexpression of Bax, an antagonist of Bcl-II, has been shown to accelerate apoptosis in rat glioma and human glioblastoma (GBM) cells, while Bcl-II overexpression inhibits apoptosis by repressing neutral sphingomyelinase and the subsequent cascade of ceramide formation, $\mathrm{mt}$ cytochrome c release and caspase activation [235]. Importantly, environmental stimuli such as heat shock, irradiation, and chemotherapeutic drugs [236], have been shown to activate sphingomyleinase mediated apoptosis. Thus, Bcl-II gene over-expression inhibiting apoptosis coupled with gene alterations in other genes promoting cell proliferation may interact with environmental factors to play a significant role in tumor development and progression.

$N F 1$ is a Ras-guanosine triphosphatase-activating protein that, as previously described, contains germline mutations that predispose individuals to development of pilocytic astrocytoma. Ras/Akt pathway overexpression has been reported in $100 \%$ of sporadic pilocytic astrocytomas in one study of 21 tumors [185], in $~ 70 \%$ of aGBM, and in most pGBM and aGBM cell lines [237]. A report by Faury et al. 2007 found that pediatric 
glioblastomas can be divided by subtype based on Ras/Akt pathway activation. In their analysis, the subset defined by Ras and Akt pathway activation had very poor prognosis and exhibited increased expression of genes related to proliferation and to a neural stemcell phenotype (expression of markers of neural stem cells such as nestin, dlx2, CD133, vimentin and ELK). These findings were similar to those of the aggressive adult glioblastoma phenotype they observed. A second subset not showing Ras/Akt pathway activation, showed better prognosis and expressed no markers of a proliferative/stem-cell phenotype, suggesting they may instead originate from astroglial progenitors. [238] Overexpression of $\mathrm{H}-$ or $\mathrm{N}$-ras has been reported in 0,43 , and $71 \%$ of grade I, II, and high-grade astrocytomas respectively [239], though age was not accounted for in this study. Several studies have found Ras mutation, including one which found a somatic G12A Kras mutation in pilocytic astrocytoma [186], one which found a Kras codon 13 mutation in pilocytic astrocytoma [185], and another which found 3 of $25(12 \%)$ of astroglial tumors to have mutation of K-ras-61. As previously mentioned, mutations in Ras are possibly important given that they may be related to development of cancer from environmental exposure [240]. Overall however, mutations in Ras appear to be rare in pediatric astrocytoma, with some studies reporting no mutations of Ras variants in all tumors analyzed [185-187].

Mutations of SHH pathway, which regulates astroglial and oligodendroglial differentiation from their neural progenitor cells, are also found in astrocytomas, though they have been primarily investigated in adult tumors. Three members of the Gli family (Gli1, Gli2, Gli3), which mediate SHh-induced transcriptional activation [241], are reported to be amplified and highly expressed in GBM [242] and Gli1 was found over- 
expressed in several low grade astrocytomas [243]. Levels of GLi1 were not found to correlate with prognosis however, while both PTCH and SMO mRNA expression correlated significantly with malignancy, suggesting their involvement in suppression of astrocytic tumors [244].

Inactivation of the retinoblastoma (RB) tumor suppressor pathway (pRB/cyclinD1/cyclin dependent kinase $4(\mathrm{CDK} 4) / \mathrm{p} 16)$ is found in approximately $25 \%$ of pediatric high grade astrocytoma, compared to over $80 \%$ of high grade adult astrocytomas showing these alterations [173]. Progression from astrocytoma to anaplastic astrocytoma has been shown to involve mutations in other tumor suppressor genes including the retinoblastoma (RB) gene on chromosome 13q. Pilocytic astrocytomas show protein expression of CDK4 in $61 \%$ of cases and protein expression of p16 in $73 \%$ of cases [215], while loss of expression of p16 was found in 11/18 (61\%) of pediatric glioblastomas [183].

A majority of pediatric glioblastomas show overexpression of Y-box-protein-1 (YB1) (38 of $53=72 \%$ ) [238], an RNA-binding protein/transcription factor involved in brain development. This gene may help drive oncogenesis in this tumor as its nuclear localization has been associated with poorer outcome and tumor progression in other cancers [245]. Other findings which point to the importance of precursor cells in tumor development include immunohistochemical studies that have astrocytoma cells express markers of glial progenitor cells such as GFAP, nestin, brain lipid-binding protein, and OLIG-2 [246-248]. PEN5, which is expressed in oligodendrocyte precursor cells (ODPCs), is also observed at a high frequency in pilocytic astrocytomas, suggesting ODPCs may give rise to pilocytic astrocytoma [249;250]. Lastly, as with MB, all grades 
of astrocytoma have been found to harbor CD133 stem cells, providing for more debate on their cell of origin [154;251].

Other genetic findings in pediatric astrocytomas include studies showing MnSOD is strongly expressed in all glioma types (46 tumors including astrocytomas, oligodendrogliomas, oligo-astrocytomas, and glioblastomas) but is not correlated with tumor grade $[155 ; 233]$. Another study found that MnSOD expression was decreased in gliomas however, while catalase (CAT) levels were significantly increased in ascending order in high-grade astrocytoma and low-grade astrocytomas, and GSH-Px was not increased in any astrocytomas [156]. Finally, pilocytic astrocytomas show upregulation of several immune defense-related genes including HLA-DRalpha, HLA-DPA1, HLADPB1, HLA-DQB1, IgG3, IgGK, FCER1G, A2M, FCRN, IFI-56K, DAP12, TIMP1, TIMP2, CDKN1A, and SOCS3 [252].

Epigenetic Alterations: Very few studies have specifically assessed epigenetic changes in pediatric astrocytomas. In one study however, both GSTP1 and p14 ${ }^{\mathrm{ARF}}$ were both found to be unmethylated in pilocytic astrocytomas. This was in comparison to MBs which showed an $18 \%$ methylation rate for GSTP1 and a $45 \%$ rate for $\mathrm{p} 14^{\mathrm{ARF}}$ [253].

Other epigenetic changes have been identified primarily in adult astrocytomas. Grade II gliomas (astrocytomas, oligodendrogliomas, and oligoastrocytomas), grade III astrocytomas, and secondary GBMs commonly display a methylated PTEN promoter. This event is absent in non-tumor brain specimens and rare in primary GBMs [254]. That grade III astrocytomas and secondary GBMs contain methylation of PTEN is consistent with the hypothesis that they arise from progression of grade II gliomas. PTEN promoter methylation also appears to phosphorylate protein kinase B (PKB/Akt) 
and activate the PI3K pathway, which can also be activated by PTEN mutations [254]. Significant global hypomethylation is frequent in adult GBMs and is associated with specific copy number alterations, a low-functioning methylenetetrahydrofolate reductase (MTHFR) allele status, and increased proliferation, suggesting that either low MTHFR levels and increased cell proliferation lead to hypomethylation or decreased MTHFR causes hypomethylation which promotes cell proliferation [255]. Finally, secondary glioblastomas show promoter methylation of RB1, TIMP-3, and HRK [256-258].

\section{Neuroblastoma $(N B)$}

Neuroblastoma, a tumor located in the peripheral neural crest, is the most common extracranial solid tumor in childhood and the most common cancer in infancy, causing 8$10 \%$ of all infant malignancies [259]. Approximately $75 \%$ of cases of neuroblastoma (NB) occur in children under the age of 2 [260]. Table 2-3 summarizes genetic alterations in neuroblastoma.

Table 2-3. Common susceptibility genes of neuroblastoma.

\begin{tabular}{|c|c|c|c|c|c|}
\hline Gene Name & $\begin{array}{c}\text { Gene } \\
\text { Symbol }\end{array}$ & Pathway/Function & $\begin{array}{c}\text { Type of } \\
\text { Alteration }\end{array}$ & $\begin{array}{l}\text { Percent } \\
\text { of Cases }\end{array}$ & Reference \\
\hline $\begin{array}{c}\mathrm{v} \text {-myc } \\
\text { myelocytomat } \\
\text { osis viral } \\
\text { oncogene }\end{array}$ & N-myc & Oncogene & Overexpression & $25-35 \%$ & Park 2008 [261] \\
\hline Ras & Ras & Ras-Akt pathway & Mutation & Rare & Ballas 1988 [262] \\
\hline bcl-II & bcl-II & $\begin{array}{l}\text { Governs mitochondrial } \\
\text { outer membrane } \\
\text { permeabilization }\end{array}$ & Expressed & $\begin{array}{l}\text { Majority } \\
\text { of tumors }\end{array}$ & $\begin{array}{c}\text { Ikegaki } 1995 \\
{[263]}\end{array}$ \\
\hline
\end{tabular}

$\mathrm{N}$-myc protoncogene is amplified in 25 to $35 \%$ of neuroblastomas [261]. It is the key genetic feature used to stratify patients into risk groups [264-266]. As with other CNSTs, 
myc target genes in neuroblastoma are primarily involved in cellular growth and metabolism, cell proliferation, and cell cycle regulation [119]. Phenotype of NB cell lines have been transformed, supporting the oncogenic potential of N-myc [267;268]. Antisense experiments using N-myc have also shown that downregulation of N-Myc result in decreased proliferation and cell growth in NB [269;270]. Finally, mice experiments using $\mathrm{N}$-myc as a target gene have shown its ability to produce NB in vivo [271-273]. The adverse prognostic significance of $N$-myc amplification in NB has been well established and correlates with increased metastases and chemotherapy resistance [264;266;274;275]. Its importance in aggressive NB is also supported by studies showing amplification of N-Myc in NB cell lines exhibit increased proliferation, underexpression of inhibitors of angiogenesis, and increased invasive potential [266;268;276-282].

Ikegaki et al. found that bcl-II is expressed in a majority of NB tumors and cell lines, however it was not correlated with clinical outcome or myc amplification or expression [263]. Phosphatidylinositol 3-kinase (PI3K) inhibition in mice neuroblastoma produces decreased tumor size and decreased N-myc protein levels. In addition knock-down of PI3K in N-myc amplified human neuroblastoma cells causes decreased proliferation and increased apoptosis [283]. Finally, Ras mutations were identified in one study on neuroblastoma [262].

\section{MITOCHONDRIAL-NUCLEAR SIGNALING IN CNST DEVELOPMENT}

Because mitochondria play a large part in brain development and are abundant in brain tissue, their health is critical to the wellbeing of the pediatric brain. Mitochondria in the 
developing brain are very different from those of mature animals and these developmental differences in mitochondria can make the immature brain more vulnerable to environmental factors.

Mt have been shown to play a crucial role in energy metabolism through oxidative phosphorylation, programmed cell death, and the generation of DNA-damaging ROS as side products of their normal function. Mitochondrial DNA (mtDNA) is an easy target for oxidative DNA damage due to its close proximity to ROS production, its lack of protective histone proteins, and its limited repair capabilities. Environmental exposures causing dysregulation of mtDNA and ROS production may contribute to increased nuclear gene mutagenesis. The ability of $\mathrm{mt}$ dysfunction and $\mathrm{mt}$ mutations, to cause cancer has been the subject of intense debate, however. Recent evidence that mtDNA mutations seem to promote tumorigenesis by preventing apoptosis [284] supports a role for $\mathrm{mt}$ dysfunction in cancer. In addition, evidence that mutated nuclear genes that encode subunits of complex II may cause loss of this complex's tumor suppressor role and promote development of hereditary paraganglioma [285;286], suggests that mtnuclear signaling may be important to tumorigenesis as well.

Evidence of mitochondrial changes in CNST: Mitochondrial abnormalities in tumor tissues generally have been considered to be a consequence, rather than the cause of tumorigenesis. However, recent reports argue against this concept and provide support to the idea that mitochondria (mt) may control the growth of cancer tissues [287]. For example, genetic and sporadic cases of brain tumors (paraganglioma and pheochromocytoma) are caused by mutation of a mitochondrial-specific protein, 
succinate dehydrogenase, a Krebs cycle enzyme [285;288;289]. Recently, mutations in another mitochondrial Krebs cycle protein, fumarase, have been associated with the development of uterine fibroids, skin leiomyomata and renal cell cancer [290]. Mutations in these proteins appear to be involved in familial predisposition to benign and malignant tumors, such as malignant phaeochromocytomas and renal cell carcinomas.

Somatic mtDNA mutations have been found in tumors of NF1, an autosomal dominantly inherited disease which predisposes to development of pilocytic astrocytoma. These mutations were all found in the D-loop region [7 of 19 patients with diffuse cutaneous neurofibromas (avg. of 1 mutation per tumor) and 9 of 18 patients with benign plexiform neurofibromas (average of 3 mutations per tumor) had at least 1 somatic mtDNA mutation] and the proportion of mutant mtDNA in the neurofibroma tumors was increased in relation to non-tumor tissues Additionally, the D-loop np 303 to 309 C8 mutation was always dominant in tumors, while the $\mathrm{C} 7$ variant was either reduced or absent in tumors and was dominant in non-tumor tissue [291]. Kiebish and Seyfried 2005 sequenced the entire mitochondrial genome in a series of chemically induced and spontaneous mouse brain tumors with differing metastasis, malignancy, and vascularity. They reported that the tumors showed somatic mtDNA mutations in regions of mononucleotide repeats, which are similar to those found previously in hypervariable regions of the D-loop in human brain tumors. However, none of these mutations were considered pathogenic since they did not change amino acid sequence and therefore could not alter gene function [292].

Mt Changes in Medulloblastoma: Studies have found mitochondrial mutations in MB. One study analyzed the entire mitochondrial genome of 15 cases of $\mathrm{MB}$ and the 
cerebrospinal fluid (CSF) of eight of these 15 cases. $40 \%$ (6 of 15) of the tumors studied had at least one mitochondrial mutation and seven of eight of the CSF samples were found to have mtDNA mutations as well. Three tumors had one somatic mtDNA mutation, 2 had two mutations, and 1 had 11 mutations. The somatic mutations identified in this study, which were located primarily in regions of mononucleotide repeats rather than in respiratory chain related genes, include: three coding region mutations 1) G7521A mutation in tRNA aspartate that changes a GT base pairing to AT base pairing at the amino acyl stem region, 2) the $\mathrm{T} 15904 \mathrm{C}$ mutation in tRNA threonine at the loop region, and 3) the A15937G mutation at the first bp next to the loop, all of which may affect tRNA structure and stability; two missense mutations that can alter mt structure and function: 1) $\mathrm{Y} 496 \mathrm{H}$ in cytochrome c oxidase and 2) L96P in NADH subunit 4, which are involved in the substitution of the hydrophobic aromatic tyrosine with positively charged histidine, and the hydrophobic leucine residue with $\mathrm{x}$ helix destabilizing secondary amino acid proline; and several noncoding region mutations in areas such as transcription factor binding sites and replication primer sites that can affect mtDNA replication, transcription, and expression. 5 (29.4\%) mutations were located in the np 303-315 polyC tract region and $11(61 \%)$ were in the D-loop region. [293]

Mt Changes in Astrocytomas and Other Gliomas: Malignant glioma is the bestcharacterized type of brain tumor with respect to mtDNA alterations. The most frequent observation involves changes in the copy number of mtDNA. A study that examined 45 glioma specimens found that mtDNA was highly amplified in $87 \%$ of the cases. In comparison, a nuclear-encoded reference gene (erb-b) that is frequently amplified in human cancers, increased in only $18 \%$ of the tumor specimens, indicating that mtDNA 
alterations may be much more frequent in gliomas than nuclear-encoded gene alterations [294]. Analysis of 15 low grade gliomas (5 pilocytic astrocytomas, 3 gangliogliomas, 5 low-grade astrocytomas, and 2 neurocytomas) confirmed this finding as all samples analyzed showed evidence of $\mathrm{mt}$ sequence localization within the nucleus [295]. Interestingly, the authors also noted a transfer of mtDNA to the nucleus with nuclear localization of the mtDNA segment significantly correlated to an increase of mtDNA copy numbers. This is significant given that incorporation of mtDNA into the nuclear genome may serve as a mechanism of oncogene activation. In addition, a high frequency of mtDNA copy number changes has been found in comparison to normal control tissue in both low and high grade gliomas [294;295]. Furthermore, the mt content of gliomas is significantly lower than normal rat brain tissue, as is activity levels of cytochrome c oxidase and citrate synthase [296]. This low amount of normally functioning mt has been linked to a hexokinase dependent shift of energy metabolism to glycolysis in gliomas [296].

Astrocytic tumors show high sequence variability, as well as a loss of the heteroplasmy present in a polymorphic D-loop region site of normal cells [297]. Differences in percentage of mtDNA mutations between astrocytic tumor grades has not been found [298]. A recent study of 42 cases of malignant astrocytomas (39 GBMs, two anaplastic astrocytomas, and one anaplastic oligoastrocytoma) showed alterations in $36 \%$ of the cases in the D-loop region, including 16 different somatic alterations (three in the HV1 region and thirteen in the D310 region) [299]. This frequency is comparable to other reports of mtDNA instability in malignant gliomas [297;300]. These alterations do not appear to be associated with increased aggressiveness however [299]. 
Recent work in differential hybridization of GBM tumors revealed decreased expression of seven mt genes. Genes downregulated were mt NADH dehydrogenase subunits 1 and 4 (ND1; ND4); mt cytochrome oxidase subunits I, II, and III (COXI; COXII; COXIII); mt ATP synthase subunit 6 (ATP6); and mt 12S rRNA. The authors noted however, that the reason for this decreased expression could be due to a decrease in mt genome transcription activity, increased mutations in mtDNA, and/or a decrease in number of $\mathrm{mt}$ in GBMs [301]. Others have found hypoxia-tolerant GBM cells to reduce their rate of oxygen consumption in response to oxygen shortage, a defense mechanism that contributes to their survival in this environment. In contrast, hypoxia-sensitive GBM cells maintain their rate of oxygen consumption and show reduced survival [302;303]. This inability of hypoxia-sensitive cells to respond to reduced oxygen may result from an amino acid change in the gene encoding the ND6 subunit of Complex I which may alter Complex I function in hypoxia-sensitive cells [304].

Other reports have noted $\mathrm{mt}$ genome instability in the hypervariable regions in the Dloop of meningiomas, schwannomas, gliomatosis cerebri, low-grade astrocytomas, GBMs, and neurofibromas [291;297;298;300;305] and the presence of 23 separate mtDNA alterations in 4 separate GBM cell lines [304].

Some authors have reported that the mtDNA instabilities (e.g. mutations, polymorphisms, etc.) found in CNST tumors (primarily adult astrocytomas, meningioma, and shwannoma) are simply common human polymorphisms and 'mutational hotspots' [300]. The same authors found no correlation between nuclear mitochondrial instability (nMI) and D-loop changes or mtDNA instability and patient characteristics such as sex, age, tumor size, and clinical outcome [300]. Regardless of their functional significance, 
the above studies clearly show that mtDNA alterations are a frequent event in the development and progression of brain disease pathologies and warrant further investigation. Information on specific mitochondrial-nuclear signaling genes that may play a role in brain disorders can be found in the succeeding section.

\section{GENE-ENVIRONMENT INTERACTION (GEI) AND CNST DEVELOPMENT}

Very few studies to date have investigated GEI in relation to CNST development, especially in pediatric populations. To date, only one epidemiologic study has assessed the effect of environmental interactions with gene mutations on development of pCNST. In this study, two frequent polymorphisms in Paraoxonase (PON1), a gene that metabolizes two residentially used insecticides (chlorpyrifos and diazinon), were investigated in relation to CNST [ $\mathrm{n}=$ astrocytoma (37), PNET (15), other (14)]. A nonsignificantly increased risk of CNST in relation to the inefficient PON1 promoter allele $\left(\mathrm{PON} 1_{-108 \mathrm{~T}}\right.$ allele, relative to $\mathrm{PON} 1_{-108 \mathrm{CC}}$ : odds ratio $(\mathrm{OR})=1.4 ; 95 \%$ confidence interval $(\mathrm{CI}), 1.0-2.2 ; \mathrm{p}$-value for trend $=0.07]$ was found. However, this association was strongest and reached statistical significance among children whose mothers reported chemical treatment of the home for pests during pregnancy or childhood (PON1-108T allele: among exposed, $\mathrm{OR}=2.6 ; 95 \% \mathrm{CI}, 1.2-5.5$; among unexposed, OR $=0.9 ; 95 \%$ CI, 0.5-1.6) and when primitive neuroectodermal tumors were assessed alone (per PON1-108T allele: $\mathrm{OR}=2.4 ; 95 \% \mathrm{CI}, 1.1-5.4)$ [306]. An in vitro study investigating the effect of chlorpyrifos exposure on glioma cells found that the cell signaling interference produced by chlorpyrifos exposure was greater in undifferentiated cells compared to differentiating cells, though effects were still noticed on this cell type as well. However, 
differentiation enhanced ROS production from chlorpyrifos exposure and provoked shortage of the nuclear transcription factor $\mathrm{Sp} 1$, an essential molecule in differentiation [3].

In addition to the above GEI study on pCNST, two studies have assessed GEI in adult glioma. A case-control study on lead exposure, the lead toxicity associated gene $\delta$ aminolevulinic acid dehydratase (ALAD), and risk of brain tumors found increased risk of meningioma with occupational lead exposure. Risk of meningioma, a tumor present mainly in later life, was markedly increased in individuals with the ALAD2 variant allele, for whom risks increased in a dose dependent fashion from $1.1(0.3-4.5)$ to $5.6(0.7-45.5)$ and 12.8 (1.4-120.8) compared to unexposed persons. Risk for glioma was not associated with occupational lead exposure [307]. A second adult GEI study on glutathione transferases (GST) polymorphisms, cigarette smoke exposure, and development of adult glioma failed to find any significant GEI [308]. Several other studies have investigated genes involved in detoxification of carcinogens, and their relation to both pCNST and aCNST development, though no exposure was considered in these studies. Polymorphisms in the carcinogen metabolizing genes GSTM1, GSTP1, and GSTT1 have been investigated for their effect on risk of pCNST. The frequency of the GSTM1 null allele was found to be significantly lower in high-grade pediatric astrocytomas ( $\mathrm{p}<$ 0.002). Additionally, a significant increase in the frequency of the rare GSTP1 variant Val114/Val114 was found in all pediatric astrocytomas combined $(\mathrm{p}<0.002)$ and all pediatric brain tumor types that displayed microsatellite instability (MSI) from mismatch repair (MMR) defects (0.003), suggesting this genotype may define a population susceptible to pCNST development. This same study assessed these polymorphisms in 
relation to aCNST and found no relation of GST polymorphisms to tumor development [309]. Another study found the relative risk of pCNST to be increased 4.9-fold for patients carrying one non-null (GSTM1*A) allele of GSTM1 compared to patients with two null alleles $(95 \%$ confidence interval $1.5-16, \mathrm{P}=0.009)$ [310]. Finally, a metaanalysis on GST polymorphisms and adult brain tumor risk also failed to find any association between GST and tumor development, though the GSTT1 null genotype was associated with meningioma development ( $\mathrm{OR}=1.95 ; 95 \% \mathrm{CI}, 1.02-3.76)$ [311].

Population studies on folate involvement in CNST development have also been performed. Folate is an important micronutrient molecule involved in DNA synthesis and methylation. Studies have linked folate deficiency with both pediatric cancer [312;313] and genomic damage [314]. Disturbances in DNA synthesis, methylation, and repair of this pathway may be involved in CNST development [255]. An investigation of single nucleotide polymorphisms (SNPs) in the folate pathway [methylenetetrahydrofolate reductase (MTHFR) C677Tand A1298C, methionine synthase (MTR) A2756G, thymidylate synthase (TS) 28-bp tandem repeat, and reduced folate carrier (RFC) G80A] and their relation to CNST susceptibility in pediatrics found that the homozygous CC allele of MTHFR A1298C, which reduces MTHFR activity, conferred an increased risk of embryonal CNS tumors (medulloblastoma, pinealoblastoma, and PNETs) (OR: 3.9; 95\% CI: 1.3-11.4, $\mathrm{p}=0.02$ ). SNPs in glial tumors (astrocytoma, oligodendroglioma, and ependymoma) were not related to development of disease [315]. A recent report on folate pathway SNPs in adult meningioma and high grade glioma found that MTHFR C677T and A1298C genotypes associated with increased 5,10 methylenetetrahydrofolate levels elevated disease risk 
while another report on these tumors failed to associate the MTHFR 677T SNP with tumor development [316].

While very few population studies have investigated GEI in CNST, some effects of environmental exposures on CNST development can be seen from cell line and tissue studies such as the aforementioned study on glioma cells exposed to chlorpyrifos. For instance, several studies have investigated manganese toxicity in brain tumor cell lines. Manganese (Mn) exposure in humans is rare but can occur through occupational pathways. Mn targets brain $\mathrm{mt}$ and interferes with energy metabolism in both astrocytoma and neuroblastoma cells through reduction of activity of glycolytic and TCA enzymes such as hexokinase, pyruvate kinase, lactate dehydrogenase, citrate synthase, and malate dehydrogenase [317]. As a result of this metabolic change, Mn exposure may increase oxidative stress via activation of the mitochondrial permeability transition pore, a result found in Mn exposed astrocytes [93]. Manganese-induced cell death in both astrocytoma and neuroblastoma cells is primarily necrotic in nature and is enhanced by glutathione depletion [318]. Interestingly, neuroblastoma cells are more susceptible to Mn toxicity than GBM cells, possibly because of Mn treatments effects on apoptosis in GBM cells. On treatment in GBM cells increases apoptosis and has differential effects on proliferation pathways as it induces down-regulation of MAPK pathway, but does not significantly affect the AKT pathway. Furthermore, Mn reduces levels of c-Jun, c-Fos, and MMP-2 (an extracellular matrix degrading enzyme), which are all associated with invasiveness of GBM [317].

Other in vitro studies include a report which found selenium levels in the cerebrospinal fluid of patients with malignant brain tumors to be lower than those with 
benign tumors. Furthermore, selenium's anticancer effects are seen in its ability to preferentially target human glioma cells for cell death through induction of superoxide and its subsequent disruption of mitochondria [319]. In vivo studies showing environmental exposure effects on CNST include studies in mice that show increased susceptibility to brain mutations for prenatal and neonatal (N-ethyl-N-nitrosourea) ENUexposed mice over adult ENU-exposed mice [320]. Additionally, incidence and degree of aggressiveness of gliomas has been shown to be influenced by dietary supplementation of rats with phytochemicals. Rats fed a diet high in phytochemicals show both reduced incidence and aggressiveness of tumors and was associated with an increase in bcl-II and catalase and a decrease in ki-67, sod-1 and sod-2 transcripts [321]. This result correlates with an epidemiological study on adult glioma which showed reduced risk of glioma for those consuming a diet high in phytoestrogens [322].

\section{CONCLUSIONS}

A growing body of evidence suggesting that there are critical periods of time extending from conception to puberty when the central nervous system in children may be more affected by toxic exposures. While only $1 \%$ of pediatric brain tumors are diagnosed at birth or in the first few months of life, the majority of pCNSTs occurs before age five, strongly suggesting that both prenatal and postnatal exposures may be involved in their etiology. These exposures likely interact with the genome/epigenome of the fetus or young child to produce alterations in their genetic makeup which can predispose to development of disease including pCNSTs (Figure 2-1). Importantly, the ability of environmental exposures to cause micronuclei, chromosomal aberrations, sister 


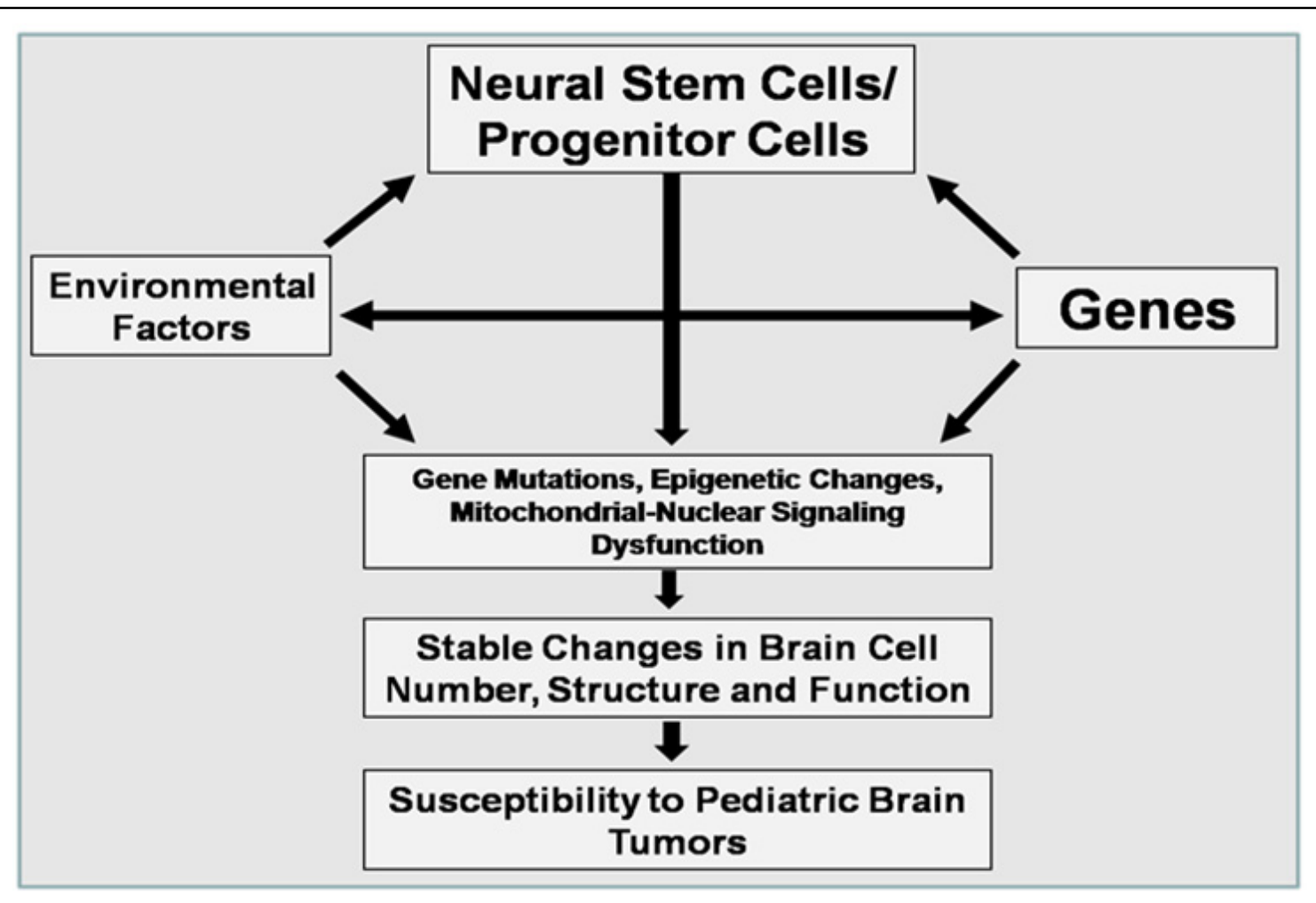

Figure 2-1. A schematic representation of an early life gene-environment interaction model for development of pediatric brain tumors.

chromatic exchanges, DNA adducts, DNA single-strand breaks, and somatic mutations in the DNA of a fetus has been demonstrated. Furthermore, many of these alterations have been shown to predispose to tumor development. These alterations likely play a role in pCNST etiology and so we have discussed the frequent alterations in several common pCNSTs and have reviewed current research on GEI in these tumors. While past research has elucidated several potentially significant environmental, genetic and epigenetic factors in pCNSTs, evidence linking a majority of pCNSTs to specific genetic or environmental exposures is limited. Factors such as the relatively low numbers of accessible tumor tissue for pCNSTs and the heterogeneity of these tumors have contributed to the considerable difficulty involved with determining their etiology. 
Moreover, most past research on these tumors has not considered important factors such as timing of exposure, GEI, and gene-gene interaction within their design. Additionally, the ability to appropriately measure levels of exposure at time of development or predisposition to disease through molecular biomarkers has been limited. Improved research methods and tools, combined with larger studies involving homogenous tumor types, should help answer questions on the etiology of pCNSTs in the future. 


\section{Reference List}

1. Hjalmars,U., Kulldorff,M., Wahlqvist,Y., and Lannering,B. (1999) Increased incidence rates but no space-time clustering of childhood astrocytoma in Sweden, 1973-1992: a population-based study of pediatric brain tumors. Cancer, 85, 2077 2090.

2. McNeil,D.E., Cote,T.R., Clegg,L., and Rorke,L.B. (2002) Incidence and trends in pediatric malignancies medulloblastoma/primitive neuroectodermal tumor: a SEER update. Surveillance Epidemiology and End Results. Med Pediatr.Oncol., 39, 190-194.

3. Garcia,S.J., Seidler,F.J., Crumpton,T.L., and Slotkin,T.A. (2001) Does the developmental neurotoxicity of chlorpyrifos involve glial targets? Macromolecule synthesis, adenylyl cyclase signaling, nuclear transcription factors, and formation of reactive oxygen in C6 glioma cells. Brain Res, 891, 54-68.

4. Rice,J.M. and Wilbourn,J.D. (2000) Tumors of the nervous system in carcinogenic hazard identification. Toxicol.Pathol, 28, 202-214.

5. Khalili,K., Krynska,B., Del,V.L., Katsetos,C.D., and Croul,S. (1999) Medulloblastomas and the human neurotropic polyomavirus JC virus. Lancet, $353,1152-1153$.

6. Huang,H., Reis,R., Yonekawa,Y., Lopes,J.M., Kleihues,P., and Ohgaki,H. (1999) Identification in human brain tumors of DNA sequences specific for SV40 large T antigen. Brain Pathol, 9, 33-42.

7. Kim,J.Y., Koralnik,I.J., LeFave,M., Segal,R.A., Pfister,L.A., and Pomeroy,S.L. (2002) Medulloblastomas and primitive neuroectodermal tumors rarely contain polyomavirus DNA sequences. Neuro.Oncol., 4, 165-170.

8. Okamoto,H., Mineta,T., Ueda,S., Nakahara,Y., Shiraishi,T., Tamiya,T., and Tabuchi,K. (2005) Detection of JC virus DNA sequences in brain tumors in pediatric patients. $J$ Neurosurg., 102, 294-298.

9. Rollison,D.E., Utaipat,U., Ryschkewitsch,C., Hou,J., Goldthwaite,P., Daniel,R., Helzlsouer,K.J., Burger,P.C., Shah,K.V., and Major,E.O. (2005) Investigation of human brain tumors for the presence of polyomavirus genome sequences by two independent laboratories. Int J Cancer, 113, 769-774.

10. Weggen,S., Bayer,T.A., von,D.A., Reifenberger,G., von,S.D., Wiestler,O.D., and Pietsch,T. (2000) Low frequency of SV40, JC and BK polyomavirus sequences in human medulloblastomas, meningiomas and ependymomas. Brain Pathol, 10, 8592. 
11. Nagashima,K., Yasui,K., Kimura,J., Washizu,M., Yamaguchi,K., and Mori,W. (1984) Induction of brain tumors by a newly isolated JC virus (Tokyo-1 strain). Am J Pathol, 116, 455-463.

12. Ohsumi,S., Motoi,M., and Ogawa,K. (1986) Induction of undifferentiated tumors by $\mathrm{JC}$ virus in the cerebrum of rats. Acta Pathol Jpn., 36, 815-825.

13. Perera,F., Hemminki,K., Jedrychowski,W., Whyatt,R., Campbell,U., Hsu,Y., Santella,R., Albertini,R., and O'Neill,J.P. (2002) In utero DNA damage from environmental pollution is associated with somatic gene mutation in newborns. Cancer Epidemiol Biomarkers Prev., 11, 1134-1137.

14. Read,T.A., Hegedus,B., Wechsler-Reya,R., and Gutmann,D.H. (2006) The neurobiology of neurooncology. Ann.Neurol., 60, 3-11.

15. Kleihues,P., Louis,D.N., Scheithauer,B.W., Rorke,L.B., Reifenberger,G., Burger,P.C., and Cavenee,W.K. (2002) The WHO classification of tumors of the nervous system. J Neuropathol.Exp Neurol, 61, 215-225.

16. Jakacki,R.I. (1999) Pineal and nonpineal supratentorial primitive neuroectodermal tumors. Childs Nerv.Syst., 15, 586-591.

17. Sarkar,C., Deb,P., and Sharma,M.C. (2006) Medulloblastomas: new directions in risk stratification. Neurol India, 54, 16-23.

18. Batra,S.K., McLendon,R.E., Koo,J.S., Castelino-Prabhu,S., Fuchs,H.E., Krischer,J.P., Friedman,H.S., Bigner,D.D., and Bigner,S.H. (1995) Prognostic implications of chromosome 17 p deletions in human medulloblastomas. $J$ Neurooncol., 24, 39-45.

19. Biegel,J.A., Rorke,L.B., Packer,R.J., Sutton,L.N., Schut,L., Bonner,K., and Emanuel,B.S. (1989) Isochromosome 17q in primitive neuroectodermal tumors of the central nervous system. Genes Chromosomes.Cancer, 1, 139-147.

20. Biegel,J.A., Burk,C.D., Barr,F.G., and Emanuel,B.S. (1992) Evidence for a 17p tumor related locus distinct from $\mathrm{p} 53$ in pediatric primitive neuroectodermal tumors. Cancer Res, 52, 3391-3395.

21. Biegel,J.A., Janss,A.J., Raffel,C., Sutton,L., Rorke,L.B., Harper,J.M., and Phillips,P.C. (1997) Prognostic significance of chromosome 17p deletions in childhood primitive neuroectodermal tumors (medulloblastomas) of the central nervous system. Clin.Cancer Res, 3, 473-478.

22. Biegel,J.A. and Wentz,E. (1997) No preferential parent of origin for the isochromosome 17q in childhood primitive neuroectodermal tumor (medulloblastoma). Genes Chromosomes.Cancer, 18, 143-146. 
23. Bigner,S.H., Mark,J., Friedman,H.S., Biegel,J.A., and Bigner,D.D. (1988) Structural chromosomal abnormalities in human medulloblastoma. Cancer Genet.Cytogenet., 30, 91-101.

24. Bigner,S.H., McLendon,R.E., Fuchs,H., McKeever,P.E., and Friedman,H.S. (1997) Chromosomal characteristics of childhood brain tumors. Cancer Genet.Cytogenet., 97, 125-134.

25. Di Marcotullio L., Ferretti,E., De,S.E., Argenti,B., Mincione,C., Zazzeroni,F., Gallo,R., Masuelli,L., Napolitano,M., Maroder,M., Modesti,A., Giangaspero,F., Screpanti,I., Alesse,E., and Gulino,A. (2004) REN(KCTD11) is a suppressor of Hedgehog signaling and is deleted in human medulloblastoma. Proc Natl.Acad.Sci.U.S.A, 101, 10833-10838.

26. Emadian,S.M., McDonald,J.D., Gerken,S.C., and Fults,D. (1996) Correlation of chromosome $17 \mathrm{p}$ loss with clinical outcome in medulloblastoma. Clin.Cancer Res, 2, 1559-1564.

27. McDonald,J.D., Daneshvar,L., Willert,J.R., Matsumura,K., Waldman,F., and Cogen,P.H. (1994) Physical mapping of chromosome 17p13.3 in the region of a putative tumor suppressor gene important in medulloblastoma. Genomics, 23, $229-232$.

28. Nicholson,J., Wickramasinghe,C., Ross,F., Crolla,J., and Ellison,D. (2000) Imbalances of chromosome 17 in medulloblastomas determined by comparative genomic hybridisation and fluorescence in situ hybridisation. Mol.Pathol, 53, 313-319.

29. Scheurlen,W.G., Seranski,P., Mincheva,A., Kuhl,J., Sorensen,N., Krauss,J., Lichter,P., Poustka,A., and Wilgenbus,K.K. (1997) High-resolution deletion mapping of chromosome arm $17 \mathrm{p}$ in childhood primitive neuroectodermal tumors reveals a common chromosomal disruption within the Smith-Magenis region, an unstable region in chromosome band 17p11.2. Genes Chromosomes.Cancer, 18, $50-58$.

30. Steichen-Gersdorf,E., Baumgartner,M., Kreczy,A., Maier,H., and Fink,F.M. (1997) Deletion mapping on chromosome 17p in medulloblastoma. Br.J Cancer, $76,1284-1287$.

31. Thomas,G.A. and Raffel,C. (1991) Loss of heterozygosity on 6q, 16q, and 17p in human central nervous system primitive neuroectodermal tumors. Cancer Res, 51, $639-643$.

32. vet-Loiseau,H., Venuat,A.M., Terrier-Lacombe,M.J., Lellouch-Tubiana,A., Zerah,M., and Vassal,G. (1999) Comparative genomic hybridization detects many 
recurrent imbalances in central nervous system primitive neuroectodermal tumours in children. Br.J Cancer, 79, 1843-1847.

33. Yin,X.L., Pang,J.C., and Ng,H.K. (2002) Identification of a region of homozygous deletion on 8p22-23.1 in medulloblastoma. Oncogene, 21, 14611468 .

34. Lamont,J.M., McManamy,C.S., Pearson,A.D., Clifford,S.C., and Ellison,D.W. (2004) Combined histopathological and molecular cytogenetic stratification of medulloblastoma patients. Clin.Cancer Res, 10, 5482-5493.

35. Raffel,C., Thomas,G.A., Tishler,D.M., Lassoff,S., and Allen,J.C. (1993) Absence of p53 mutations in childhood central nervous system primitive neuroectodermal tumors. Neurosurgery, 33, 301-305.

36. Saylors,R.L., III, Sidransky,D., Friedman,H.S., Bigner,S.H., Bigner,D.D., Vogelstein,B., and Brodeur,G.M. (1991) Infrequent p53 gene mutations in medulloblastomas. Cancer Res, 51, 4721-4723.

37. Eberhart,C.G. and Burger,P.C. (2003) Anaplasia and grading in medulloblastomas. Brain Pathol, 13, 376-385.

38. Pietsch,T., Taylor,M.D., and Rutka,J.T. (2004) Molecular pathogenesis of childhood brain tumors. J Neurooncol., 70, 203-215.

39. Raffel,C., Jenkins,R.B., Frederick,L., Hebrink,D., Alderete,B., Fults,D.W., and James, C.D. (1997) Sporadic medulloblastomas contain PTCH mutations. Cancer Res, 57, 842-845.

40. Vorechovsky,I., Tingby,O., Hartman,M., Stromberg,B., Nister,M., Collins,V.P., and Toftgard,R. (1997) Somatic mutations in the human homologue of Drosophila patched in primitive neuroectodermal tumours. Oncogene, 15, 361-366.

41. Wolter,M., Reifenberger,J., Sommer,C., Ruzicka,T., and Reifenberger,G. (1997) Mutations in the human homologue of the Drosophila segment polarity gene patched (PTCH) in sporadic basal cell carcinomas of the skin and primitive neuroectodermal tumors of the central nervous system. Cancer Res., 57, 25812585 .

42. Taylor,M.D., Liu,L., Raffel,C., Hui,C.C., Mainprize,T.G., Zhang,X., Agatep,R., Chiappa,S., Gao,L., Lowrance,A., Hao,A., Goldstein,A.M., Stavrou,T., Scherer,S.W., Dura,W.T., Wainwright,B., Squire,J.A., Rutka,J.T., and Hogg,D. (2002) Mutations in SUFU predispose to medulloblastoma. Nat.Genet., 31, 306310.

43. Reifenberger,J., Wolter,M., Weber,R.G., Megahed,M., Ruzicka,T., Lichter,P., and Reifenberger,G. (1998) Missense mutations in SMOH in sporadic basal cell 
carcinomas of the skin and primitive neuroectodermal tumors of the central nervous system. Cancer Res, 58, 1798-1803.

44. Hartmann,W., Digon-Sontgerath,B., Koch,A., Waha,A., Endl,E., Dani,I., Denkhaus,D., Goodyer,C.G., Sorensen,N., Wiestler,O.D., and Pietsch,T. (2006) Phosphatidylinositol 3'-kinase/AKT signaling is activated in medulloblastoma cell proliferation and is associated with reduced expression of PTEN. Clin.Cancer Res., 12, 3019-3027.

45. Koch,A., Waha,A., Tonn,J.C., Sorensen,N., Berthold,F., Wolter,M., Reifenberger,J., Hartmann,W., Friedl,W., Reifenberger,G., Wiestler,O.D., and Pietsch,T. (2001) Somatic mutations of WNT/wingless signaling pathway components in primitive neuroectodermal tumors. Int J Cancer, 93, 445-449.

46. Eberhart,C.G., Tihan,T., and Burger,P.C. (2000) Nuclear localization and mutation of beta-catenin in medulloblastomas. J Neuropathol.Exp Neurol, 59, 333-337.

47. Zurawel,R.H., Allen,C., Chiappa,S., Cato,W., Biegel,J., Cogen,P., de,S.F., and Raffel,C. (2000) Analysis of PTCH/SMO/SHH pathway genes in medulloblastoma. Genes Chromosomes. Cancer, 27, 44-51.

48. Zurawel,R.H., Chiappa,S.A., Allen,C., and Raffel,C. (1998) Sporadic medulloblastomas contain oncogenic beta-catenin mutations. Cancer Res, 58, 896-899.

49. Dahmen,R.P., Koch,A., Denkhaus,D., Tonn,J.C., Sorensen,N., Berthold,F., Behrens,J., Birchmeier,W., Wiestler,O.D., and Pietsch,T. (2001) Deletions of AXIN1, a component of the WNT/wingless pathway, in sporadic medulloblastomas. Cancer Res, 61, 7039-7043.

50. Koch,A., Hrychyk,A., Hartmann,W., Waha,A., Mikeska,T., Waha,A., Schuller,U., Sorensen,N., Berthold,F., Goodyer,C.G., Wiestler,O.D., Birchmeier,W., Behrens,J., and Pietsch,T. (2007) Mutations of the Wnt antagonist AXIN2 (Conductin) result in TCF-dependent transcription in medulloblastomas. Int $J$ Cancer, 121, 284-291.

51. Aldosari,N., Bigner,S.H., Burger,P.C., Becker,L., Kepner,J.L., Friedman,H.S., and McLendon,R.E. (2002) MYCC and MYCN oncogene amplification in medulloblastoma. A fluorescence in situ hybridization study on paraffin sections from the Children's Oncology Group. Arch Pathol Lab Med, 126, 540-544.

52. Avet-Loiseau,H., Venuat,A.M., Terrier-Lacombe,M.J., Lellouch-Tubiana,A., Zerah,M., and Vassal,G. (1999) Comparative genomic hybridization detects many recurrent imbalances in central nervous system primitive neuroectodermal tumours in children. Br.J.Cancer, 79, 1843-1847. 
53. Frank,A.J., Hernan,R., Hollander,A., Lindsey,J.C., Lusher,M.E., Fuller,C.E., Clifford,S.C., and Gilbertson,R.J. (2004) The TP53-ARF tumor suppressor pathway is frequently disrupted in large/cell anaplastic medulloblastoma. Brain Res.Mol.Brain Res., 121, 137-140.

54. Tajima,Y., Molina,R.P., Jr., Rorke,L.B., Kaplan,D.R., Radeke,M., Feinstein,S.C., Lee,V.M., and Trojanowski,J.Q. (1998) Neurotrophins and neuronal versus glial differentiation in medulloblastomas and other pediatric brain tumors. Acta Neuropathol., 95, 325-332.

55. Washiyama,K., Muragaki,Y., Rorke,L.B., Lee,V.M., Feinstein,S.C., Radeke,M.J., Blumberg,D., Kaplan,D.R., and Trojanowski,J.Q. (1996) Neurotrophin and neurotrophin receptor proteins in medulloblastomas and other primitive neuroectodermal tumors of the pediatric central nervous system. Am J Pathol, $148,929-940$.

56. Gilbertson,R.J., Langdon,J.A., Hollander,A., Hernan,R., Hogg,T.L., Gajjar,A., Fuller,C., and Clifford,S.C. (2006) Mutational analysis of PDGFR-RAS/MAPK pathway activation in childhood medulloblastoma. Eur J Cancer, 42, 646-649.

57. Adesina,A.M., Nguyen,Y., Mehta,V., Takei,H., Stangeby,P., Crabtree,S., Chintagumpala,M., and Gumerlock,M.K. (2007) FOXG1 dysregulation is a frequent event in medulloblastoma. J Neurooncol., 85, 111-122.

58. Lusher,M.E., Lindsey,J.C., Latif,F., Pearson,A.D., Ellison,D.W., and Clifford,S.C. (2002) Biallelic epigenetic inactivation of the RASSF1A tumor suppressor gene in medulloblastoma development. Cancer Res, 62, 5906-5911.

59. Di,C., Liao,S., Adamson,D.C., Parrett,T.J., Broderick,D.K., Shi,Q., Lengauer,C., Cummins,J.M., Velculescu,V.E., Fults,D.W., McLendon,R.E., Bigner,D.D., and Yan,H. (2005) Identification of OTX2 as a medulloblastoma oncogene whose product can be targeted by all-trans retinoic acid. Cancer Res, 65, 919-924.

60. Kozmik,Z., Sure,U., Ruedi,D., Busslinger,M., and Aguzzi,A. (1995) Deregulated expression of PAX5 in medulloblastoma. Proc Natl.Acad.Sci.U.S.A, 92, 57095713.

61. Gonzalez-Gomez,P., Bello,M.J., Inda,M.M., Alonso,M.E., Arjona,D., Aminoso,C., Lopez-Marin,I., de Campos,J.M., Sarasa,J.L., Castresana,J.S., and Rey,J.A. (2004) Deletion and aberrant CpG island methylation of Caspase 8 gene in medulloblastoma. Oncol.Rep., 12, 663-666.

62. Rood,B.R., Zhang,H., Weitman,D.M., and Cogen,P.H. (2002) Hypermethylation of HIC-1 and 17p allelic loss in medulloblastoma. Cancer Res., 62, 3794-3797. 
63. Waha,A., Koch,A., Hartmann,W., Milde,U., Felsberg,J., Hubner,A., Mikeska,T., Goodyer,C.G., Sorensen,N., Lindberg,I., Wiestler,O.D., Pietsch,T., and Waha,A. (2007) SGNE1/7B2 is epigenetically altered and transcriptionally downregulated in human medulloblastomas. Oncogene, 26, 5662-5668.

64. Reardon,D.A., Michalkiewicz,E., Boyett,J.M., Sublett,J.E., Entrekin,R.E., Ragsdale,S.T., Valentine,M.B., Behm,F.G., Li,H., Heideman,R.L., Kun,L.E., Shapiro,D.N., and Look,A.T. (1997) Extensive genomic abnormalities in childhood medulloblastoma by comparative genomic hybridization. Cancer Res, $57,4042-4047$.

65. Blaeker,H., Rasheed,B.K., McLendon,R.E., Friedman,H.S., Batra,S.K., Fuchs,H.E., and Bigner,S.H. (1996) Microsatellite analysis of childhood brain tumors. Genes Chromosomes.Cancer, 15, 54-63.

66. Griffin,C.A., Hawkins,A.L., Packer,R.J., Rorke,L.B., and Emanuel,B.S. (1988) Chromosome abnormalities in pediatric brain tumors. Cancer Res, 48, 175-180.

67. Jenkins,R.B., Kimmel,D.W., Moertel,C.A., Schultz,C.G., Scheithauer,B.W., Kelly,P.J., and Dewald,G.W. (1989) A cytogenetic study of 53 human gliomas. Cancer Genet.Cytogenet., 39, 253-279.

68. Kraus,J.A., Koch,A., Albrecht,S., von,D.A., Wiestler,O.D., and Pietsch,T. (1996) Loss of heterozygosity at locus F13B on chromosome 1q in human medulloblastoma. Int $J$ Cancer, 67, 11-15.

69. Yin,X.L., Pang,J.C., Liu,Y.H., Chong,E.Y., Cheng,Y., Poon,W.S., and Ng,H.K. (2001) Analysis of loss of heterozygosity on chromosomes 10q, 11, and 16 in medulloblastomas. J Neurosurg., 94, 799-805.

70. Koch,A., Tonn,J., Kraus,J.A., Sorensen,N., Albrecht,N.S., Wiestler,O.D., and Pietsch,T. (1996) Molecular analysis of the lissencephaly gene 1 (LIS-1) in medulloblastomas. Neuropathol.Appl.Neurobiol., 22, 233-242.

71. Reardon,D.A., Jenkins,J.J., Sublett,J.E., Burger,P.C., and Kun,L.K. (2000) Multiple genomic alterations including N-myc amplification in a primary large cell medulloblastoma. Pediatr.Neurosurg., 32, 187-191.

72. Tong,Z., Yamaki,T., Harada,K., and Houkin,K. (2004) In vivo quantification of the metabolites in normal brain and brain tumors by proton MR spectroscopy using water as an internal standard. Magn Reson.Imaging, 22, 735-742.

73. Bhattacharjee,M., Hicks,J., Langford,L., Dauser,R., Strother,D., Chintagumpala,M., Horowitz,M., Cooley,L., and Vogel,H. (1997) Central nervous system atypical teratoid/rhabdoid tumors of infancy and childhood. Ultrastruct.Pathol, 21, 369-378. 
74. Biegel,J.A. (1999) Cytogenetics and molecular genetics of childhood brain tumors. Neuro.Oncol., 1, 139-151.

75. Scheurlen,W.G., Schwabe,G.C., Joos,S., Mollenhauer,J., Sorensen,N., and Kuhl,J. (1998) Molecular analysis of childhood primitive neuroectodermal tumors defines markers associated with poor outcome. J Clin.Oncol., 16, 2478-2485.

76. Vagner-Capodano,A.M., Gentet,J.C., Gambarelli,D., Pellissier,J.F., Gouzien,M., Lena,G., Genitori,L., Choux,M., and Raybaud,C. (1992) Cytogenetic studies in 45 pediatric brain tumors. Pediatr.Hematol.Oncol., 9, 223-235.

77. Hui,A.B., Takano,H., Lo,K.W., Kuo,W.L., Lam,C.N., Tong,C.Y., Chang,Q., Gray,J.W., and Ng,H.K. (2005) Identification of a novel homozygous deletion region at $6 \mathrm{q} 23.1$ in medulloblastomas using high-resolution array comparative genomic hybridization analysis. Clin.Cancer Res, 11, 4707-4716.

78. Rossi,M.R., Conroy,J., McQuaid,D., Nowak,N.J., Rutka,J.T., and Cowell,J.K. (2006) Array CGH analysis of pediatric medulloblastomas. Genes Chromosomes.Cancer, 45, 290-303.

79. Tong,C.Y., Hui,A.B., Yin,X.L., Pang,J.C., Zhu,X.L., Poon,W.S., and Ng,H.K. (2004) Detection of oncogene amplifications in medulloblastomas by comparative genomic hybridization and array-based comparative genomic hybridization. $J$ Neurosurg., 100, 187-193.

80. Pietsch,T., Koch,A., and Wiestler,O.D. (1997) Molecular genetic studies in medulloblastomas: evidence for tumor suppressor genes at the chromosomal regions 1q31-32 and 17p13. Klin.Padiatr., 209, 150-155.

81. Xie,J., Johnson,R.L., Zhang,X., Bare,J.W., Waldman,F.M., Cogen,P.H., Menon,A.G., Warren,R.S., Chen,L.C., Scott,M.P., and Epstein,E.H., Jr. (1997) Mutations of the PATCHED gene in several types of sporadic extracutaneous tumors. Cancer Res, 57, 2369-2372.

82. Pomeroy,S.L., Tamayo,P., Gaasenbeek,M., Sturla,L.M., Angelo,M., McLaughlin,M.E., Kim,J.Y., Goumnerova,L.C., Black,P.M., Lau,C., Allen,J.C., Zagzag,D., Olson,J.M., Curran,T., Wetmore,C., Biegel,J.A., Poggio,T., Mukherjee,S., Rifkin,R., Califano,A., Stolovitzky,G., Louis,D.N., Mesirov,J.P., Lander,E.S., and Golub,T.R. (2002) Prediction of central nervous system embryonal tumour outcome based on gene expression. Nature, 415, 436-442.

83. Schofield,D., West,D.C., Anthony,D.C., Marshal,R., and Sklar,J. (1995) Correlation of loss of heterozygosity at chromosome $9 \mathrm{q}$ with histological subtype in medulloblastomas. Am J Pathol, 146, 472-480. 
84. Goodrich,L.V., Milenkovic,L., Higgins,K.M., and Scott,M.P. (1997) Altered neural cell fates and medulloblastoma in mouse patched mutants. Science, 277, 1109-1113.

85. Hahn,H., Wojnowski,L., Specht,K., Kappler,R., Calzada-Wack,J., Potter,D., Zimmer,A., Muller,U., Samson,E., Quintanilla-Martinez,L., and Zimmer,A. (2000) Patched target Igf 2 is indispensable for the formation of medulloblastoma and rhabdomyosarcoma. J Biol.Chem., 275, 28341-28344.

86. Pietsch,T., Waha,A., Koch,A., Kraus,J., Albrecht,S., Tonn,J., Sorensen,N., Berthold,F., Henk,B., Schmandt,N., Wolf,H.K., von,D.A., Wainwright,B., Chenevix-Trench,G., Wiestler,O.D., and Wicking,C. (1997) Medulloblastomas of the desmoplastic variant carry mutations of the human homologue of Drosophila patched. Cancer Res, 57, 2085-2088.

87. Taylor,M.D., Liu,L., Raffel,C., Hui,C.C., Mainprize,T.G., Zhang,X., Agatep,R., Chiappa,S., Gao,L., Lowrance,A., Hao,A., Goldstein,A.M., Stavrou,T., Scherer,S.W., Dura,W.T., Wainwright,B., Squire,J.A., Rutka,J.T., and Hogg,D. (2002) Mutations in SUFU predispose to medulloblastoma. Nat.Genet., 31, 306310.

88. Ellison,D.W., Clifford,S.C., Gajjar,A., and Gilbertson,R.J. (2003) What's new in neuro-oncology? Recent advances in medulloblastoma. Eur J Paediatr.Neurol., 7, 53-66.

89. Gilbertson,R.J. (2004) Medulloblastoma: signalling a change in treatment. Lancet Oncol., 5, 209-218.

90. Dahmane,N. and Altaba,A. (1999) Sonic hedgehog regulates the growth and patterning of the cerebellum. Development, 126, 3089-3100.

91. Wechsler-Reya,R.J. and Scott,M.P. (1999) Control of neuronal precursor proliferation in the cerebellum by Sonic Hedgehog. Neuron, 22, 103-114.

92. Walterhouse,D.O., Yoon,J.W., and Iannaccone,P.M. (1999) Developmental pathways: Sonic hedgehog-Patched-GLI. Environ Health Perspect., 107, 167-171.

93. Rao,G., Pedone,C.A., Del,V.L., Reiss,K., Holland,E.C., and Fults,D.W. (2004) Sonic hedgehog and insulin-like growth factor signaling synergize to induce medulloblastoma formation from nestin-expressing neural progenitors in mice. Oncogene, 23, 6156-6162.

94. Taylor,M.D., Zhang,X., Liu,L., Hui,C.C., Mainprize,T.G., Scherer,S.W., Wainwright,B., Hogg,D., and Rutka,J.T. (2004) Failure of a medulloblastomaderived mutant of SUFU to suppress WNT signaling. Oncogene, 23, 4577-4583. 
95. Smyth,I., Narang,M.A., Evans,T., Heimann,C., Nakamura,Y., ChenevixTrench,G., Pietsch,T., Wicking,C., and Wainwright,B.J. (1999) Isolation and characterization of human patched 2 ( $\mathrm{PTCH} 2)$, a putative tumour suppressor gene inbasal cell carcinoma and medulloblastoma on chromosome $1 \mathrm{p} 32$.

Hum.Mol.Genet., 8, 291-297.

96. Hooper,J.E. and Scott,M.P. (2005) Communicating with Hedgehogs. Nat.Rev.Mol.Cell Biol., 6, 306-317.

97. Lum,L. and Beachy,P.A. (2004) The Hedgehog response network: sensors, switches, and routers. Science, 304, 1755-1759.

98. Hallahan,A.R., Pritchard,J.I., Hansen,S., Benson,M., Stoeck,J., Hatton,B.A., Russell,T.L., Ellenbogen,R.G., Bernstein,I.D., Beachy,P.A., and Olson,J.M. (2004) The SmoA1 mouse model reveals that notch signaling is critical for the growth and survival of sonic hedgehog-induced medulloblastomas. Cancer Res, 64, 7794-7800.

99. Lee,Y., Miller,H.L., Jensen,P., Hernan,R., Connelly,M., Wetmore,C., Zindy,F., Roussel,M.F., Curran,T., Gilbertson,R.J., and McKinnon,P.J. (2003) A molecular fingerprint for medulloblastoma. Cancer Res, 63, 5428-5437.

100. Hartmann,W., Koch,A., Brune,H., Waha,A., Schuller,U., Dani,I., Denkhaus,D., Langmann,W., Bode,U., Wiestler,O.D., Schilling,K., and Pietsch,T. (2005) Insulin-like growth factor II is involved in the proliferation control of medulloblastoma and its cerebellar precursor cells. Am J Pathol, 166, 1153-1162.

101. Browd,S.R., Kenney,A.M., Gottfried,O.N., Yoon,J.W., Walterhouse,D., Pedone,C.A., and Fults,D.W. (2006) N-myc can substitute for insulin-like growth factor signaling in a mouse model of sonic hedgehog-induced medulloblastoma. Cancer Res, 66, 2666-2672.

102. Schuller,U., Schober,F., Kretzschmar,H.A., and Herms,J. (2004) Bcl-2 expression inversely correlates with tumour cell differentiation in medulloblastoma.

Neuropathol.Appl.Neurobiol., 30, 513-521.

103. McCall,T.D., Pedone,C.A., and Fults,D.W. (2007) Apoptosis suppression by somatic cell transfer of Bcl-2 promotes Sonic hedgehog-dependent medulloblastoma formation in mice. Cancer Res, 67, 5179-5185.

104. Bar,E.E., Chaudhry,A., Farah,M.H., and Eberhart,C.G. (2007) Hedgehog signaling promotes medulloblastoma survival via Bc/II. Am J Pathol, 170, 347355. 
105. Hamilton,S.R., Liu,B., Parsons,R.E., Papadopoulos,N., Jen,J., Powell,S.M., Krush,A.J., Berk,T., Cohen,Z., Tetu,B., and . (1995) The molecular basis of Turcot's syndrome. N.Engl.J Med, 332, 839-847.

106. Huang,H., Mahler-Araujo,B.M., Sankila,A., Chimelli,L., Yonekawa,Y., Kleihues,P., and Ohgaki,H. (2000) APC mutations in sporadic medulloblastomas. Am J Pathol, 156, 433-437.

107. Mori,T., Nagase,H., Horii,A., Miyoshi,Y., Shimano,T., Nakatsuru,S., Aoki,T., Arakawa,H., Yanagisawa,A., Ushio,Y., and . (1994) Germ-line and somatic mutations of the APC gene in patients with Turcot syndrome and analysis of APC mutations in brain tumors. Genes Chromosomes.Cancer, 9, 168-172.

108. Raffel,C. (2004) Medulloblastoma: molecular genetics and animal models. Neoplasia., 6, 310-322.

109. Ellison,D.W., Onilude,O.E., Lindsey,J.C., Lusher,M.E., Weston,C.L., Taylor,R.E., Pearson,A.D., and Clifford,S.C. (2005) beta-Catenin status predicts a favorable outcome in childhood medulloblastoma: the United Kingdom Children's Cancer Study Group Brain Tumour Committee. J Clin.Oncol., 23, 7951-7957.

110. Badiali,M., Pession,A., Basso,G., Andreini,L., Rigobello,L., Galassi,E., and Giangaspero,F. (1991) N-myc and c-myc oncogenes amplification in medulloblastomas. Evidence of particularly aggressive behavior of a tumor with c-myc amplification. Tumori, 77, 118-121.

111. Bigner,S.H., Friedman,H.S., Vogelstein,B., Oakes,W.J., and Bigner,D.D. (1990) Amplification of the c-myc gene in human medulloblastoma cell lines and xenografts. Cancer Res, 50, 2347-2350.

112. Herms,J., Neidt,I., Luscher,B., Sommer,A., Schurmann,P., Schroder,T., Bergmann,M., Wilken,B., Probst-Cousin,S., Hernaiz-Driever,P., Behnke,J., Hanefeld,F., Pietsch,T., and Kretzschmar,H.A. (2000) C-MYC expression in medulloblastoma and its prognostic value. Int J Cancer, 89, 395-402.

113. Jay,V., Squire,J., Bayani,J., Alkhani,A.M., Rutka,J.T., and Zielenska,M. (1999) Oncogene amplification in medulloblastoma: analysis of a case by comparative genomic hybridization and fluorescence in situ hybridization. Pathology, 31,337344.

114. Brown,H.G., Kepner,J.L., Perlman,E.J., Friedman,H.S., Strother,D.R., Duffner,P.K., Kun,L.E., Goldthwaite,P.T., and Burger,P.C. (2000) "Large cell/anaplastic" medulloblastomas: a Pediatric Oncology Group Study. $J$ Neuropathol.Exp Neurol, 59, 857-865. 
115. Eberhart,C.G., Kratz,J.E., Schuster,A., Goldthwaite,P., Cohen,K.J., Perlman,E.J., and Burger,P.C. (2002) Comparative genomic hybridization detects an increased number of chromosomal alterations in large cell/anaplastic medulloblastomas. Brain Pathol, 12, 36-44.

116. Huard,J.M., Forster,C.C., Carter,M.L., Sicinski,P., and Ross,M.E. (1999) Cerebellar histogenesis is disturbed in mice lacking cyclin D2. Development, 126, 1927-1935.

117. Kenney,A.M., Cole,M.D., and Rowitch,D.H. (2003) Nmyc upregulation by sonic hedgehog signaling promotes proliferation in developing cerebellar granule neuron precursors. Development, 130, 15-28.

118. Knoepfler,P.S., Cheng,P.F., and Eisenman,R.N. (2002) N-myc is essential during neurogenesis for the rapid expansion of progenitor cell populations and the inhibition of neuronal differentiation. Genes Dev., 16, 2699-2712.

119. Raetz,E.A., Kim,M.K., Moos,P., Carlson,M., Bruggers,C., Hooper,D.K., Foot,L., Liu,T., Seeger,R., and Carroll,W.L. (2003) Identification of genes that are regulated transcriptionally by Myc in childhood tumors. Cancer, 98, 841-853.

120. Malynn,B.A., de,A., I, O'Hagan,R.C., Bronson,R., Davidson,L., DePinho,R.A., and Alt,F.W. (2000) N-myc can functionally replace c-myc in murine development, cellular growth, and differentiation. Genes Dev., 14, 1390-1399.

121. Li,F., Wang,Y., Zeller,K.I., Potter,J.J., Wonsey,D.R., O'Donnell,K.A., Kim,J.W., Yustein,J.T., Lee,L.A., and Dang,C.V. (2005) Myc stimulates nuclearly encoded mitochondrial genes and mitochondrial biogenesis. Mol.Cell Biol., 25, 6225-6234.

122. Bruggers,C.S., Tai,K.F., Murdock,T., Sivak,L., Le,K., Perkins,S.L., Coffin,C.M., and Carroll,W.L. (1998) Expression of the c-Myc protein in childhood medulloblastoma. J Pediatr.Hematol.Oncol., 20, 18-25.

123. Grotzer,M.A., Hogarty,M.D., Janss,A.J., Liu,X., Zhao,H., Eggert,A., Sutton,L.N., Rorke,L.B., Brodeur,G.M., and Phillips,P.C. (2001) MYC messenger RNA expression predicts survival outcome in childhood primitive neuroectodermal tumor/medulloblastoma. Clin.Cancer Res, 7, 2425-2433.

124. Moriuchi,S., Shimizu,K., Miyao,Y., and Hayakawa,T. (1996) An immunohistochemical analysis of medulloblastoma and PNET with emphasis on N-myc protein expression. Anticancer Res, 16, 2687-2692.

125. Eberhart,C.G., Kratz,J., Wang,Y., Summers,K., Stearns,D., Cohen,K., Dang,C.V., and Burger,P.C. (2004) Histopathological and molecular prognostic markers in medulloblastoma: c-myc, N-myc, TrkC, and anaplasia. J Neuropathol.Exp Neurol, 63, 441-449. 
126. Adesina,A.M., Nalbantoglu,J., and Cavenee,W.K. (1994) p53 gene mutation and mdm2 gene amplification are uncommon in medulloblastoma. Cancer Res, 54, 5649-5651.

127. Ohgaki H., Vital A., Kleihues P., and Hainaut P. (2000) Li-Fraumeni syndrome and TP53 germline mutations. In Kleihues P. and Cavenee W.K. (eds.) Pathology and Genetics of Tumours of the Nervous System. IARC Press, Lyon, pp 216-8.

128. Leung C, Lingbeek M, Shakova O, Liu J, Tanger E, Saremaslani P, van Lohuizen $\mathrm{M}$, and Marino S (2004) Bmil is essential for cerebellar development and is overexpressed in human medulloblastomas. Nature, 428, 337-341.

129. Grotzer,M.A., Janss,A.J., Phillips,P.C., and Trojanowski,J.Q. (2000) Neurotrophin receptor TrkC predicts good clinical outcome in medulloblastoma and other primitive neuroectodermal brain tumors. Klin.Padiatr., 212, 196-199.

130. Kim,J.Y., Sutton,M.E., Lu,D.J., Cho,T.A., Goumnerova,L.C., Goritchenko,L., Kaufman,J.R., Lam,K.K., Billet,A.L., Tarbell,N.J., Wu,J., Allen,J.C., Stiles,C.D., Segal,R.A., and Pomeroy,S.L. (1999) Activation of neurotrophin-3 receptor TrkC induces apoptosis in medulloblastomas. Cancer Res, 59, 711-719.

131. Pomeroy,S.L., Sutton,M.E., Goumnerova,L.C., and Segal,R.A. (1997) Neurotrophins in cerebellar granule cell development and medulloblastoma. $J$ Neurooncol., 35, 347-352.

132. Segal,R.A., Goumnerova,L.C., Kwon,Y.K., Stiles,C.D., and Pomeroy,S.L. (1994) Expression of the neurotrophin receptor TrkC is linked to a favorable outcome in medulloblastoma. Proc Natl.Acad.Sci.U.S.A, 91, 12867-12871.

133. Gajjar,A., Hernan,R., Kocak,M., Fuller,C., Lee,Y., McKinnon,P.J., Wallace,D., Lau,C., Chintagumpala,M., Ashley,D.M., Kellie,S.J., Kun,L., and Gilbertson,R.J. (2004) Clinical, histopathologic, and molecular markers of prognosis: toward a new disease risk stratification system for medulloblastoma. J Clin.Oncol., 22, 984-993.

134. Sukumar,S. and Barbacid,M. (1990) Specific patterns of oncogene activation in transplacentally induced tumors. Proc Natl.Acad.Sci.U.S.A, 87, 718-722.

135. Gilbertson,R.J. and Clifford,S.C. (2003) PDGFRB is overexpressed in metastatic medulloblastoma. Nat.Genet., 35, 197-198.

136. MacDonald,T.J., Brown,K.M., LaFleur,B., Peterson,K., Lawlor,C., Chen,Y., Packer,R.J., Cogen,P., and Stephan,D.A. (2001) Expression profiling of medulloblastoma: PDGFRA and the RAS/MAPK pathway as therapeutic targets for metastatic disease. Nat.Genet., 29, 143-152. 
137. Wasson,J.C., Saylors,R.L., III, Zeltzer,P., Friedman,H.S., Bigner,S.H., Burger,P.C., Bigner,D.D., Look,A.T., Douglass,E.C., and Brodeur,G.M. (1990) Oncogene amplification in pediatric brain tumors. Cancer Res, 50, 2987-2990.

138. Iolascon,A., Lania,A., Badiali,M., Pession,A., Saglio,G., Giangaspero,F., Miraglia del,G.E., Perrotta,S., and Cutillo,S. (1991) Analysis of N-ras gene mutations in medulloblastomas by polymerase chain reaction and oligonucleotide probes in formalin-fixed, paraffin-embedded tissues. Med Pediatr.Oncol., 19, 240-245.

139. Brustle,O., Ohgaki,H., Schmitt,H.P., Walter,G.F., Ostertag,H., and Kleihues,P. (1992) Primitive neuroectodermal tumors after prophylactic central nervous system irradiation in children. Association with an activated K-ras gene. Cancer, 69, 2385-2392.

140. Gilbertson,R., Hernan,R., Pietsch,T., Pinto,L., Scotting,P., Allibone,R., Ellison,D., Perry,R., Pearson,A., and Lunec,J. (2001) Novel ERBB4 juxtamembrane splice variants are frequently expressed in childhood medulloblastoma. Genes Chromosomes. Cancer, 31, 288-294.

141. Gilbertson,R.J., Jaros,E.B., Perry,R.H., and Pearson,A.D. (1992) Prognostic factors in medulloblastoma. Lancet, 340, 480.

142. Gilbertson,R.J., Pearson,A.D., Perry,R.H., Jaros,E., and Kelly,P.J. (1995) Prognostic significance of the c-erbB-2 oncogene product in childhood medulloblastoma. Br.J Cancer, 71, 473-477.

143. Gilbertson,R.J., Perry,R.H., Kelly,P.J., Pearson,A.D., and Lunec,J. (1997) Prognostic significance of HER2 and HER4 coexpression in childhood medulloblastoma. Cancer Res, 57, 3272-3280.

144. Gilbertson,R.J., Clifford,S.C., MacMeekin,W., Meekin,W., Wright,C., Perry,R.H., Kelly,P., Pearson,A.D., and Lunec,J. (1998) Expression of the ErbBneuregulin signaling network during human cerebellar development: implications for the biology of medulloblastoma. Cancer Res, 58, 3932-3941.

145. Herms,J.W., Behnke,J., Bergmann,M., Christen,H.J., Kolb,R., Wilkening,M., Markakis,E., Hanefeld,F., and Kretzschmar,H.A. (1997) Potential prognostic value of C-erbB-2 expression in medulloblastomas in very young children. $J$ Pediatr.Hematol.Oncol., 19, 510-515.

146. Rostomily,R.C., Bermingham-McDonogh,O., Berger,M.S., Tapscott,S.J., Reh,T.A., and Olson,J.M. (1997) Expression of neurogenic basic helix-loop-helix genes in primitive neuroectodermal tumors. Cancer Res, 57, 3526-3531.

147. Buhren,J., Christoph,A.H., Buslei,R., Albrecht,S., Wiestler,O.D., and Pietsch,T. (2000) Expression of the neurotrophin receptor p75NTR in medulloblastomas is 
correlated with distinct histological and clinical features: evidence for a medulloblastoma subtype derived from the external granule cell layer. $J$ Neuropathol.Exp Neurol, 59, 229-240.

148. Salsano,E., Pollo,B., Eoli,M., Giordana,M.T., and Finocchiaro,G. (2004) Expression of MATH1, a marker of cerebellar granule cell progenitors, identifies different medulloblastoma sub-types. Neurosci.Lett., 370, 180-185.

149. Yokota,N., Aruga,J., Takai,S., Yamada,K., Hamazaki,M., Iwase,T., Sugimura,H., and Mikoshiba,K. (1996) Predominant expression of human zic in cerebellar granule cell lineage and medulloblastoma. Cancer Res, 56, 377-383.

150. Pelc,K., Vincent,S., Ruchoux,M.M., Kiss,R., Pochet,R., Sariban,E., Decaestecker,C., and Heizmann,C.W. (2002) Calbindin-d(28k): a marker of recurrence for medulloblastomas. Cancer, 95, 410-419.

151. Mattson,M.P., Rychlik,B., Chu,C., and Christakos,S. (1991) Evidence for calcium-reducing and excito-protective roles for the calcium-binding protein calbindin-D28k in cultured hippocampal neurons. Neuron, 6, 41-51.

152. Wernyj,R.P., Mattson,M.P., and Christakos,S. (1999) Expression of calbindinD28k in C6 glial cells stabilizes intracellular calcium levels and protects against apoptosis induced by calcium ionophore and amyloid beta-peptide. Brain Res Mol.Brain Res, 64, 69-79.

153. Hemmati,H.D., Nakano,I., Lazareff,J.A., Masterman-Smith,M., Geschwind,D.H., Bronner-Fraser,M., and Kornblum,H.I. (2003) Cancerous stem cells can arise from pediatric brain tumors. Proc.Natl.Acad.Sci.U.S.A, 100, 15178-15183.

154. Singh,S.K., Hawkins,C., Clarke,I.D., Squire,J.A., Bayani,J., Hide,T., Henkelman,R.M., Cusimano,M.D., and Dirks,P.B. (2004) Identification of human brain tumour initiating cells. Nature, 432, 396-401.

155. Cobbs,C.S., Levi,D.S., Aldape,K., and Israel,M.A. (1996) Manganese superoxide dismutase expression in human central nervous system tumors. Cancer Res, 56, 3192-3195.

156. Pu,P.Y., Lan,J., Shan,S.B., Huang,E.Q., Bai,Y., Guo,Y., and Jiang,D.H. (1996) Study of the antioxidant enzymes in human brain tumors. J Neurooncol., 29, 121128.

157. Fruhwald,M.C., O'Dorisio,M.S., Dai,Z., Tanner,S.M., Balster,D.A., Gao,X., Wright,F.A., and Plass,C. (2001) Aberrant promoter methylation of previously unidentified target genes is a common abnormality in medulloblastomas-implications for tumor biology and potential clinical utility. Oncogene, 20, 50335042. 
158. Lindsey,J.C., Anderton,J.A., Lusher,M.E., and Clifford,S.C. (2005) Epigenetic events in medulloblastoma development. Neurosurg.Focus., 19, E10.

159. Waha,A., Waha,A., Koch,A., Meyer-Puttlitz,B., Weggen,S., Sorensen,N., Tonn,J.C., Albrecht,S., Goodyer,C.G., Berthold,F., Wiestler,O.D., and Pietsch,T. (2003) Epigenetic silencing of the HIC-1 gene in human medulloblastomas. $J$ Neuropathol.Exp.Neurol., 62, 1192-1201.

160. Uziel,T., Zindy,F., Sherr,C.J., and Roussel,M.F. (2006) The CDK inhibitor p18Ink4c is a tumor suppressor in medulloblastoma. Cell Cycle, 5, 363-365.

161. Kaatsch,P., Rickert,C.H., Kuhl,J., Schuz,J., and Michaelis,J. (2001) Populationbased epidemiologic data on brain tumors in German children. Cancer, 92, 31553164.

162. Packer,R.J. (1999) Brain tumors in children. Arch Neurol, 56, 421-425.

163. Sanoudou,D., Tingby,O., Ferguson-Smith,M.A., Collins,V.P., and Coleman,N. (2000) Analysis of pilocytic astrocytoma by comparative genomic hybridization. Br.J Cancer, 82, 1218-1222.

164. Schrock,E., Blume,C., Meffert,M.C., du,M.S., Bersch,W., Kiessling,M., Lozanowa,T., Thiel,G., Witkowski,R., Ried,T., and Cremer,T. (1996) Recurrent gain of chromosome arm 7q in low-grade astrocytic tumors studied by comparative genomic hybridization. Genes Chromosomes.Cancer, 15, 199-205.

165. Zattara-Cannoni,H., Gambarelli,D., Lena,G., Dufour,H., Choux,M., Grisoli,F., and Vagner-Capodano,A.M. (1998) Are juvenile pilocytic astrocytomas benign tumors? A cytogenetic study in 24 cases. Cancer Genet.Cytogenet., 104, 157-160.

166. White,F.V., Anthony,D.C., Yunis,E.J., Tarbell,N.J., Scott,R.M., and Schofield,D.E. (1995) Nonrandom chromosomal gains in pilocytic astrocytomas of childhood. Hum.Pathol, 26, 979-986.

167. Neumann,E., Kalousek,D.K., Norman,M.G., Steinbok,P., Cochrane,D.D., and Goddard,K. (1993) Cytogenetic analysis of 109 pediatric central nervous system tumors. Cancer Genet.Cytogenet., 71, 40-49.

168. Roberts,P., Chumas,P.D., Picton,S., Bridges,L., Livingstone,J.H., and Sheridan,E. (2001) A review of the cytogenetics of 58 pediatric brain tumors. Cancer Genet.Cytogenet., 131, 1-12.

169. Thiel,G., Lozanova,T., Vogel,S., Kintzel,D., Janisch,W., and Witkowski,R. (1993) Age-related nonrandom chromosomal abnormalities in human low-grade astrocytomas. Hum.Genet., 91, 547-550. 
170. Platten,M., Giordano,M.J., Dirven,C.M., Gutmann,D.H., and Louis,D.N. (1996)

Up-regulation of specific NF 1 gene transcripts in sporadic pilocytic astrocytomas. Am J Pathol, 149, 621-627.

171. Bredel,M., Pollack,I.F., Hamilton,R.L., and James,C.D. (1999) Epidermal growth factor receptor expression and gene amplification in high-grade non-brainstem gliomas of childhood. Clin.Cancer Res., 5, 1786-1792.

172. Cheng,Y., Ng,H.K., Ding,M., Zhang,S.F., Pang,J.C., and Lo,K.W. (1999) Molecular analysis of microdissected de novo glioblastomas and paired astrocytic tumors. J Neuropathol.Exp Neurol, 58, 120-128.

173. Sung,T., Miller,D.C., Hayes,R.L., Alonso,M., Yee,H., and Newcomb,E.W. (2000) Preferential inactivation of the p53 tumor suppressor pathway and lack of EGFR amplification distinguish de novo high grade pediatric astrocytomas from de novo adult astrocytomas. Brain Pathol, 10, 249-259.

174. Di,S.A., Morra,I., Pradotto,L., Guido,M., Schiffer,D., and Mauro,A. (2002) Molecular genetic changes in a series of neuroepithelial tumors of childhood. J.Neurooncol., 59, 117-122.

175. Nakamura,M., Shimada,K., Ishida,E., Higuchi,T., Nakase,H., Sakaki,T., and Konishi,N. (2007) Molecular pathogenesis of pediatric astrocytic tumors. Neuro.Oncol., 9, 113-123.

176. Cheng,Y., Ng,H.K., Zhang,S.F., Ding,M., Pang,J.C., Zheng,J., and Poon,W.S. (1999) Genetic alterations in pediatric high-grade astrocytomas. Hum.Pathol., 30, 1284-1290.

177. Raffel,C., Frederick,L., O'Fallon,J.R., therton-Skaff,P., Perry,A., Jenkins,R.B., and James,C.D. (1999) Analysis of oncogene and tumor suppressor gene alterations in pediatric malignant astrocytomas reveals reduced survival for patients with PTEN mutations. Clin.Cancer Res, 5, 4085-4090.

178. Watanabe,K., Tachibana,O., Sata,K., Yonekawa,Y., Kleihues,P., and Ohgaki,H. (1996) Overexpression of the EGF receptor and p53 mutations are mutually exclusive in the evolution of primary and secondary glioblastomas. Brain Pathol., 6, 217-223.

179. Felix,C.A., Slavc,I., Dunn,M., Strauss,E.A., Phillips,P.C., Rorke,L.B., Sutton,L., Bunin,G.R., and Biegel,J.A. (1995) p53 gene mutations in pediatric brain tumors. Med Pediatr.Oncol., 25, 431-436.

180. Pollack,I.F., Hamilton,R.L., Finkelstein,S.D., Campbell,J.W., Martinez,A.J., Sherwin,R.N., Bozik,M.E., and Gollin,S.M. (1997) The relationship between TP53 mutations and overexpression of p53 and prognosis in malignant gliomas of childhood. Cancer Res, 57, 304-309. 
181. Pollack,I.F., Finkelstein,S.D., Burnham,J., Holmes,E.J., Hamilton,R.L., Yates,A.J., Finlay,J.L., and Sposto,R. (2001) Age and TP53 mutation frequency in childhood malignant gliomas: results in a multi-institutional cohort. Cancer Res, 61, 7404-7407.

182. Pollack,I.F., Finkelstein,S.D., Woods,J., Burnham,J., Holmes,E.J., Hamilton,R.L., Yates,A.J., Boyett,J.M., Finlay,J.L., and Sposto,R. (2002) Expression of p53 and prognosis in children with malignant gliomas. N.Engl.J Med, 346, 420-427.

183. Sure,U., Ruedi,D., Tachibana,O., Yonekawa,Y., Ohgaki,H., Kleihues,P., and Hegi,M.E. (1997) Determination of p53 mutations, EGFR overexpression, and loss of p16 expression in pediatric glioblastomas. J Neuropathol.Exp Neurol, 56, 782-789.

184. Newcomb,E.W., Alonso,M., Sung,T., and Miller,D.C. (2000) Incidence of p14ARF gene deletion in high-grade adult and pediatric astrocytomas.

Hum.Pathol, 31, 115-119.

185. Sharma,M.K., Zehnbauer,B.A., Watson,M.A., and Gutmann,D.H. (2005) RAS pathway activation and an oncogenic RAS mutation in sporadic pilocytic astrocytoma. Neurology, 65, 1335-1336.

186. Janzarik,W.G., Kratz,C.P., Loges,N.T., Olbrich,H., Klein,C., Schafer,T., Scheurlen,W., Roggendorf,W., Weiller,C., Niemeyer,C., Korinthenberg,R., Pfister,S., and Omran,H. (2007) Further evidence for a somatic KRAS mutation in a pilocytic astrocytoma. Neuropediatrics, 38, 61-63.

187. Maltzman,T.H., Mueller,B.A., Schroeder,J., Rutledge,J.C., Patterson,K., PrestonMartin,S., and Faustman,E.M. (1997) Ras oncogene mutations in childhood brain tumors. Cancer Epidemiol Biomarkers Prev., 6, 239-243.

188. Szymas J, Wolf G, Peterson S, Schleuns K, Nowak S, and Peterson I (2000) Comparative Genomic Hybridization Indicating Two Distinct Subgroups of Pilocytic Astrocytomas. Neurosurgical Focus, 8.

189. Orr,L.C., Fleitz,J., McGavran,L., Wyatt-Ashmead,J., Handler,M., and Foreman,N.K. (2002) Cytogenetics in pediatric low-grade astrocytomas. Med Pediatr.Oncol., 38, 173-177.

190. Warr,T., Ward,S., Burrows,J., Harding,B., Wilkins,P., Harkness,W., Hayward,R., Darling,J., and Thomas,D. (2001) Identification of extensive genomic loss and gain by comparative genomic hybridisation in malignant astrocytoma in children and young adults. Genes Chromosomes.Cancer, 31, 15-22. 
191. Rickert,C.H., Strater,R., Kaatsch,P., Wassmann,H., Jurgens,H., DockhornDworniczak,B., and Paulus,W. (2001) Pediatric high-grade astrocytomas show chromosomal imbalances distinct from adult cases. Am J Pathol, 158, 1525-1532.

192. Alonso,M., Hamelin,R., Kim,M., Porwancher,K., Sung,T., Parhar,P., Miller,D.C., and Newcomb,E.W. (2001) Microsatellite instability occurs in distinct subtypes of pediatric but not adult central nervous system tumors. Cancer Res, 61, 2124-2128.

193. Pollack,I.F., Finkelstein,S.D., Burnham,J., Hamilton,R.L., Yates,A.J., Holmes,E.J., Boyett,J.M., and Finlay,J.L. (2003) Association between chromosome $1 \mathrm{p}$ and $19 \mathrm{q}$ loss and outcome in pediatric malignant gliomas: results from the CCG-945 cohort. Pediatr.Neurosurg., 39, 114-121.

194. Gutmann,D.H., Donahoe,J., Brown,T., James,C.D., and Perry,A. (2000) Loss of neurofibromatosis 1 (NF1) gene expression in NF1-associated pilocytic astrocytomas. Neuropathol.Appl.Neurobiol., 26, 361-367.

195. Wimmer,K., Eckart,M., Meyer-Puttlitz,B., Fonatsch,C., and Pietsch,T. (2002) Mutational and expression analysis of the NF1 gene argues against a role as tumor suppressor in sporadic pilocytic astrocytomas. J Neuropathol.Exp Neurol, 61, 896-902.

196. Board,R. and Jayson,G.C. (2005) Platelet-derived growth factor receptor (PDGFR): a target for anticancer therapeutics. Drug Resist.Updat., 8, 75-83.

197. Friedman,H.S. and Bigner,D.D. (2005) Glioblastoma multiforme and the epidermal growth factor receptor. N.Engl.J Med, 353, 1997-1999.

198. Hlobilkova,A., Ehrmann,J., Sedlakova,E., Krejci,V., Knizetova,P., Fiuraskova,M., Kala,M., Kalita,O., and Kolar,Z. (2007) Could changes in the regulation of the $\mathrm{PI} 3 \mathrm{~K} / \mathrm{PKB} / \mathrm{Akt}$ signaling pathway and cell cycle be involved in astrocytic tumor pathogenesis and progression? Neoplasma, 54, 334-341.

199. Kleihues,P. and Ohgaki,H. (2000) Phenotype vs genotype in the evolution of astrocytic brain tumors. Toxicol.Pathol, 28, 164-170.

200. Lang,F.F., Miller,D.C., Koslow,M., and Newcomb,E.W. (1994) Pathways leading to glioblastoma multiforme: a molecular analysis of genetic alterations in 65 astrocytic tumors. $J$ Neurosurg., 81, 427-436.

201. von,D.A., Louis,D.N., Menon,A.G., von,A.K., Petersen,I., Ellison,D., Wiestler,O.D., and Seizinger,B.R. (1993) Deletions on the long arm of chromosome 17 in pilocytic astrocytoma. Acta Neuropathol., 86, 81-85.

202. Tabori,U., Rienstein,S., Dromi,Y., Leider-Trejo,L., Constantini,S., Burstein,Y., Dvir,R., Amariglio,N., Toren,A., Rechavi,G., Izraeli,S., and Aviram,A. (2005) 
Epidermal growth factor receptor gene amplification and expression in disseminated pediatric low-grade gliomas. J Neurosurg., 103, 357-361.

203. Khatua,S., Peterson,K.M., Brown,K.M., Lawlor,C., Santi,M.R., LaFleur,B., Dressman,D., Stephan,D.A., and MacDonald,T.J. (2003) Overexpression of the EGFR/FKBP12/HIF-2alpha pathway identified in childhood astrocytomas by angiogenesis gene profiling. Cancer Res, 63, 1865-1870.

204. Arany,Z., Foo,S.Y., Ma,Y., Ruas,J.L., Bommi-Reddy,A., Girnun,G., Cooper,M., Laznik,D., Chinsomboon,J., Rangwala,S.M., Baek,K.H., Rosenzweig,A., and Spiegelman,B.M. (2008) HIF-independent regulation of VEGF and angiogenesis by the transcriptional coactivator PGC-1alpha. Nature, 451, 1008-1012.

205. Berkman,R.A., Merrill,M.J., Reinhold,W.C., Monacci,W.T., Saxena,A., Clark,W.C., Robertson,J.T., Ali,I.U., and Oldfield,E.H. (1993) Expression of the vascular permeability factor/vascular endothelial growth factor gene in central nervous system neoplasms. J Clin.Invest, 91, 153-159.

206. Loeffler,S., Fayard,B., Weis,J., and Weissenberger,J. (2005) Interleukin-6 induces transcriptional activation of vascular endothelial growth factor (VEGF) in astrocytes in vivo and regulates VEGF promoter activity in glioblastoma cells via direct interaction between STAT3 and Sp1. Int J Cancer, 115, 202-213.

207. Gollmer,J.C., Ladoux,A., Gioanni,J., Paquis,P., Dubreuil,A., Chatel,M., and Frelin,C. (2000) Expression of vascular endothelial growth factor-b in human astrocytoma. Neuro.Oncol., 2, 80-86.

208. Ryuto,M., Ono,M., Izumi,H., Yoshida,S., Weich,H.A., Kohno,K., and Kuwano,M. (1996) Induction of vascular endothelial growth factor by tumor necrosis factor alpha in human glioma cells. Possible roles of SP-1. J Biol.Chem., $271,28220-28228$.

209. Brat,D.J. and Mapstone,T.B. (2003) Malignant glioma physiology: cellular response to hypoxia and its role in tumor progression. Ann.Intern.Med., 138, 659668.

210. Esteban,M.A. and Maxwell,P.H. (2005) HIF, a missing link between metabolism and cancer. Nat.Med., 11, 1047-1048.

211. Isaacs,J.S., Jung,Y.J., Mole,D.R., Lee,S., Torres-Cabala,C., Chung,Y.L., Merino,M., Trepel,J., Zbar,B., Toro,J., Ratcliffe,P.J., Linehan,W.M., and Neckers,L. (2005) HIF overexpression correlates with biallelic loss of fumarate hydratase in renal cancer: novel role of fumarate in regulation of HIF stability. Cancer Cell, 8, 143-153. 
212. Pollard,P.J., Briere,J.J., Alam,N.A., Barwell,J., Barclay,E., Wortham,N.C., Hunt,T., Mitchell,M., Olpin,S., Moat,S.J., Hargreaves,I.P., Heales,S.J., Chung,Y.L., Griffiths,J.R., Dalgleish,A., McGrath,J.A., Gleeson,M.J., Hodgson,S.V., Poulsom,R., Rustin,P., and Tomlinson,I.P. (2005) Accumulation of Krebs cycle intermediates and over-expression of HIF1alpha in tumours which result from germline FH and SDH mutations. Hum.Mol.Genet., 14, 2231-2239.

213. Selak,M.A., Armour,S.M., MacKenzie,E.D., Boulahbel,H., Watson,D.G., Mansfield,K.D., Pan,Y., Simon,M.C., Thompson,C.B., and Gottlieb,E. (2005) Succinate links TCA cycle dysfunction to oncogenesis by inhibiting HIF-alpha prolyl hydroxylase. Cancer Cell, 7, 77-85.

214. Kietzmann,T. and Gorlach,A. (2005) Reactive oxygen species in the control of hypoxia-inducible factor-mediated gene expression. Semin.Cell Dev.Biol., 16, 474-486.

215. Cheng,Y., Pang,J.C., Ng,H.K., Ding,M., Zhang,S.F., Zheng,J., Liu,D.G., and Poon,W.S. (2000) Pilocytic astrocytomas do not show most of the genetic changes commonly seen in diffuse astrocytomas. Histopathology, 37, 437-444.

216. Duerr,E.M., Rollbrocker,B., Hayashi,Y., Peters,N., Meyer-Puttlitz,B., Louis,D.N., Schramm,J., Wiestler,O.D., Parsons,R., Eng,C., and von,D.A. (1998) PTEN mutations in gliomas and glioneuronal tumors. Oncogene, 16, 2259-2264.

217. Van Meir,E.G., Kikuchi,T., Tada,M., Li,H., Diserens,A.C., Wojcik,B.E., Huang,H.J., Friedmann,T., de,T.N., and Cavenee,W.K. (1994) Analysis of the p53 gene and its expression in human glioblastoma cells. Cancer Res., 54, 649652.

218. Wen,S., Stolarov,J., Myers,M.P., Su,J.D., Wigler,M.H., Tonks,N.K., and Durden,D.L. (2001) PTEN controls tumor-induced angiogenesis. Proc.Natl.Acad.Sci.U.S.A, 98, 4622-4627.

219. Graeber,T.G., Osmanian,C., Jacks,T., Housman,D.E., Koch,C.J., Lowe,S.W., and Giaccia,A.J. (1996) Hypoxia-mediated selection of cells with diminished apoptotic potential in solid tumours. Nature, 379, 88-91.

220. Bogler,O., Huang,H.J., and Cavenee,W.K. (1995) Loss of wild-type p53 bestows a growth advantage on primary cortical astrocytes and facilitates their in vitro transformation. Cancer Res., 55, 2746-2751.

221. Yahanda,A.M., Bruner,J.M., Donehower,L.A., and Morrison,R.S. (1995) Astrocytes derived from $\mathrm{p} 53$-deficient mice provide a multistep in vitro model for development of malignant gliomas. Mol.Cell Biol., 15, 4249-4259. 
222. Lang,F.F., Miller,D.C., Pisharody,S., Koslow,M., and Newcomb,E.W. (1994) High frequency of p53 protein accumulation without p53 gene mutation in human juvenile pilocytic, low grade and anaplastic astrocytomas. Oncogene, 9, 949-954.

223. Litofsky,N.S., Hinton,D., and Raffel,C. (1994) The lack of a role for p53 in astrocytomas in pediatric patients. Neurosurgery, 34, 967-972.

224. Willert,J.R., Daneshvar,L., Sheffield,V.C., and Cogen,P.H. (1995) Deletion of chromosome arm 17p DNA sequences in pediatric high-grade and juvenile pilocytic astrocytomas. Genes Chromosomes.Cancer, 12, 165-172.

225. Ishii,N., Sawamura,Y., Tada,M., Daub,D.M., Janzer,R.C., MeagherVillemure,M., de,T.N., and Van Meir,E.G. (1998) Absence of p53 gene mutations in a tumor panel representative of pilocytic astrocytoma diversity using a p53 functional assay. Int $J$ Cancer, 76, 797-800.

226. Patt,S., Gries,H., Giraldo,M., Cervos-Navarro,J., Martin,H., Janisch,W., and Brockmoller,J. (1996) p53 gene mutations in human astrocytic brain tumors including pilocytic astrocytomas. Hum.Pathol, 27, 586-589.

227. Hayes,V.M., Dirven,C.M., Dam,A., Verlind,E., Molenaar,W.M., Mooij,J.J., Hofstra,R.M., and Buys,C.H. (1999) High frequency of TP53 mutations in juvenile pilocytic astrocytomas indicates role of TP53 in the development of these tumors. Brain Pathol, 9, 463-467.

228. Dirks,P. (2007) Bmil and cell of origin determinants of brain tumor phenotype. Cancer Cell, 12, 295-297.

229. Hayry,V., Tanner,M., Blom,T., Tynninen,O., Roselli,A., Ollikainen,M., Sariola,H., Wartiovaara,K., and Nupponen,N.N. (2008) Copy number alterations of the polycomb gene BMI1 in gliomas. Acta Neuropathol., 116, 97-102.

230. Gil-Perotin,S., Marin-Husstege,M., Li,J., Soriano-Navarro,M., Zindy,F., Roussel,M.F., Garcia-Verdugo,J.M., and Casaccia-Bonnefil,P. (2006) Loss of p53 induces changes in the behavior of subventricular zone cells: implication for the genesis of glial tumors. J Neurosci., 26, 1107-1116.

231. Bonini,P., Cicconi,S., Cardinale,A., Vitale,C., Serafino,A.L., Ciotti,M.T., and Marlier,L.N. (2004) Oxidative stress induces p53-mediated apoptosis in glia: p53 transcription-independent way to die. J Neurosci.Res, 75, 83-95.

232. Yang,H., Deng,C., Shen,S., Zhang,D., and Yu,Y. (2006) Expression and significance of Bcl-2, Bax, Fas and caspase-3 in different phases of human hemangioma. J Huazhong. Univ Sci.Technolog.Med Sci., 26, 402-404.

233. Tews,D.S. (1999) Cell death and oxidative stress in gliomas. Neuropathol.Appl.Neurobiol., 25, 272-284. 
234. Yu,S., Pu,P., Jiang,D., An,T., Guan,X., and Yang,L. (2000) [Relationship of bcl-2 gene expression with cell proliferation and apoptosis in human gliomas].

Zhonghua Bing.Li Xue.Za Zhi., 29, 12-15.

235. Sawada,M., Nakashima,S., Banno,Y., Yamakawa,H., Takenaka,K., Shinoda,J., Nishimura,Y., Sakai,N., and Nozawa,Y. (2000) Influence of Bax or Bcl-2 overexpression on the ceramide-dependent apoptotic pathway in glioma cells. Oncogene, 19, 3508-3520.

236. Santana,P., Pena,L.A., Haimovitz-Friedman,A., Martin,S., Green,D., McLoughlin,M., Cordon-Cardo,C., Schuchman,E.H., Fuks,Z., and Kolesnick,R. (1996) Acid sphingomyelinase-deficient human lymphoblasts and mice are defective in radiation-induced apoptosis. Cell, 86, 189-199.

237. Rajasekhar,V.K., Viale,A., Socci,N.D., Wiedmann,M., Hu,X., and Holland,E.C. (2003) Oncogenic Ras and Akt signaling contribute to glioblastoma formation by differential recruitment of existing mRNAs to polysomes. Mol.Cell, 12, 889-901.

238. Faury,D., Nantel,A., Dunn,S.E., Guiot,M.C., Haque,T., Hauser,P., Garami,M., Bognar,L., Hanzely,Z., Liberski,P.P., Lopez-Aguilar,E., Valera,E.T., Tone,L.G., Carret,A.S., Del Maestro,R.F., Gleave,M., Montes,J.L., Pietsch,T., Albrecht,S., and Jabado,N. (2007) Molecular profiling identifies prognostic subgroups of pediatric glioblastoma and shows increased YB-1 expression in tumors. $J$ Clin.Oncol., 25, 1196-1208.

239. Orian,J.M., Vasilopoulos,K., Yoshida,S., Kaye,A.H., Chow,C.W., and Gonzales,M.F. (1992) Overexpression of multiple oncogenes related to histological grade of astrocytic glioma. Br.J Cancer, 66, 106-112.

240. Bos,J.L. (1989) ras oncogenes in human cancer: a review. Cancer Res, 49, 46824689.

241. Lee,J., Platt,K.A., Censullo,P., and Altaba,A. (1997) Gli1 is a target of Sonic hedgehog that induces ventral neural tube development. Development, 124, 2537 2552 .

242. Kinzler,K.W., Bigner,S.H., Bigner,D.D., Trent,J.M., Law,M.L., O'Brien,S.J., Wong,A.J., and Vogelstein,B. (1987) Identification of an amplified, highly expressed gene in a human glioma. Science, 236, 70-73.

243. Dahmane,N., Sanchez,P., Gitton,Y., Palma,V., Sun,T., Beyna,M., Weiner,H., and Altaba,A. (2001) The Sonic Hedgehog-Gli pathway regulates dorsal brain growth and tumorigenesis. Development, 128, 5201-5212.

244. Katayam,M., Yoshida,K., Ishimori,H., Katayama,M., Kawase,T., Motoyama,J., and Kamiguchi,H. (2002) Patched and smoothened mRNA expression in human 
astrocytic tumors inversely correlates with histological malignancy. $J$ Neurooncol., 59, 107-115.

245. Kuwano,M., Uchiumi,T., Hayakawa,H., Ono,M., Wada,M., Izumi,H., and Kohno,K. (2003) The basic and clinical implications of ABC transporters, Y-boxbinding protein-1 (YB-1) and angiogenesis-related factors in human malignancies. Cancer Sci., 94, 9-14.

246. Godbout,R., Bisgrove,D.A., Shkolny,D., and Day,R.S., III (1998) Correlation of B-FABP and GFAP expression in malignant glioma. Oncogene, 16, 1955-1962.

247. Ligon,K.L., Alberta,J.A., Kho,A.T., Weiss,J., Kwaan,M.R., Nutt,C.L., Louis,D.N., Stiles,C.D., and Rowitch,D.H. (2004) The oligodendroglial lineage marker OLIG2 is universally expressed in diffuse gliomas. $J$ Neuropathol.Exp Neurol, 63, 499-509.

248. Lu,Q.R., Park,J.K., Noll,E., Chan,J.A., Alberta,J., Yuk,D., Alzamora,M.G., Louis,D.N., Stiles,C.D., Rowitch,D.H., and Black,P.M. (2001) Oligodendrocyte lineage genes (OLIG) as molecular markers for human glial brain tumors. Proc Natl.Acad.Sci.U.S.A, 98, 10851-10856.

249. Figarella-Branger,D., Daniel,L., Andre,P., Guia,S., Renaud,W., Monti,G., Vivier,E., and Rougon,G. (1999) The PEN5 epitope identifies an oligodendrocyte precursor cell population and pilocytic astrocytomas. Am J Pathol, 155, 12611269.

250. Shoshan,Y., Nishiyama,A., Chang,A., Mork,S., Barnett,G.H., Cowell,J.K., Trapp,B.D., and Staugaitis,S.M. (1999) Expression of oligodendrocyte progenitor cell antigens by gliomas: implications for the histogenesis of brain tumors. Proc Natl.Acad.Sci.U.S.A, 96, 10361-10366.

251. Galli,R., Binda,E., Orfanelli,U., Cipelletti,B., Gritti,A., De,V.S., Fiocco,R., Foroni,C., Dimeco,F., and Vescovi,A. (2004) Isolation and characterization of tumorigenic, stem-like neural precursors from human glioblastoma. Cancer Res, 64, 7011-7021.

252. Huang,H., Hara,A., Homma,T., Yonekawa,Y., and Ohgaki,H. (2005) Altered expression of immune defense genes in pilocytic astrocytomas. $J$ Neuropathol.Exp Neurol, 64, 891-901.

253. Gonzalez-Gomez,P., Bello,M.J., Lomas,J., Arjona,D., Alonso,M.E., Aminoso,C., de Campos,J.M., Vaquero,J., Sarasa,J.L., Casartelli,C., and Rey,J.A. (2003) Epigenetic changes in pilocytic astrocytomas and medulloblastomas. Int $J$ Mol.Med., 11, 655-660. 
254. Wiencke,J.K., Zheng,S., Jelluma,N., Tihan,T., Vandenberg,S., Tamguney,T., Baumber,R., Parsons,R., Lamborn,K.R., Berger,M.S., Wrensch,M.R., HaasKogan,D.A., and Stokoe,D. (2007) Methylation of the PTEN promoter defines low-grade gliomas and secondary glioblastoma. Neuro.Oncol., 9, 271-279.

255. Cadieux,B., Ching,T.T., VandenBerg,S.R., and Costello,J.F. (2006) Genome-wide hypomethylation in human glioblastomas associated with specific copy number alteration, methylenetetrahydrofolate reductase allele status, and increased proliferation. Cancer Res, 66, 8469-8476.

256. Nakamura,M., Yonekawa,Y., Kleihues,P., and Ohgaki,H. (2001) Promoter hypermethylation of the RB1 gene in glioblastomas. Lab Invest, 81, 77-82.

257. Nakamura,M., Ishida,E., Shimada,K., Nakase,H., Sakaki,T., and Konishi,N. (2005) Frequent HRK inactivation associated with low apoptotic index in secondary glioblastomas. Acta Neuropathol., 110, 402-410.

258. Nakamura,M., Ishida,E., Shimada,K., Kishi,M., Nakase,H., Sakaki,T., and Konishi,N. (2005) Frequent LOH on 22q12.3 and TIMP-3 inactivation occur in the progression to secondary glioblastomas. Lab Invest, 85, 165-175.

259. Brodeur,G.M. (2003) Neuroblastoma: biological insights into a clinical enigma. Nat.Rev.Cancer, 3, 203-216.

260. Goodman MT, Gurney JG, Smith MA, and Olshan AF (1999) Sympathetic Nervous System Tumors. SEER Pediatric Monograph. NCI SEER Pediatric Monograph 1975-1995,65-72.

261. Park,J.R., Eggert,A., and Caron,H. (2008) Neuroblastoma: biology, prognosis, and treatment. Pediatr.Clin.North Am, 55, 97-120, x.

262. Ballas,K., Lyons,J., Janssen,J.W., and Bartram,C.R. (1988) Incidence of ras gene mutations in neuroblastoma. Eur J Pediatr., 147, 313-314.

263. Ikegaki,N., Katsumata,M., Tsujimoto,Y., Nakagawara,A., and Brodeur,G.M. (1995) Relationship between bcl-2 and myc gene expression in human neuroblastoma. Cancer Lett., 91, 161-168.

264. Brodeur,G.M., Seeger,R.C., Schwab,M., Varmus,H.E., and Bishop,J.M. (1984) Amplification of N-myc in untreated human neuroblastomas correlates with advanced disease stage. Science, 224, 1121-1124.

265. Rubie,H., Hartmann,O., Michon,J., Frappaz,D., Coze,C., Chastagner,P., Baranzelli,M.C., Plantaz,D., vet-Loiseau,H., Benard,J., Delattre,O., Favrot,M., Peyroulet,M.C., Thyss,A., Perel,Y., Bergeron,C., Courbon-Collet,B., Vannier,J.P., Lemerle,J., and Sommelet,D. (1997) N-Myc gene amplification is a major prognostic factor in localized neuroblastoma: results of the French NBL 90 
study. Neuroblastoma Study Group of the Societe Francaise d'Oncologie Pediatrique. J Clin.Oncol., 15, 1171-1182.

266. Seeger,R.C., Brodeur,G.M., Sather,H., Dalton,A., Siegel,S.E., Wong,K.Y., and Hammond,D. (1985) Association of multiple copies of the N-myc oncogene with rapid progression of neuroblastomas. N.Engl.J Med, 313, 1111-1116.

267. Gross,N., Miescher,G., Beck,D., Favre,S., and Beretta,C. (1994) Altered growth and phenotype in clonal mycN transfectants of the SK-N-SH neuroblastoma cell line. Int J Cancer, 59, 141-148.

268. Schweigerer,L., Breit,S., Wenzel,A., Tsunamoto,K., Ludwig,R., and Schwab,M. (1990) Augmented MYCN expression advances the malignant phenotype of human neuroblastoma cells: evidence for induction of autocrine growth factor activity. Cancer Res, 50, 4411-4416.

269. Negroni,A., Scarpa,S., Romeo,A., Ferrari,S., Modesti,A., and Raschella,G. (1991) Decrease of proliferation rate and induction of differentiation by a MYN antisense DNA oligomer in a human neuroblastoma cell line. Cell Growth Differ., 2, 511-518.

270. Schmidt,M.L., Salwen,H.R., Manohar,C.F., Ikegaki,N., and Cohn,S.L. (1994) The biological effects of antisense N-myc expression in human neuroblastoma. Cell Growth Differ., 5, 171-178.

271. Hackett,C.S., Hodgson,J.G., Law,M.E., Fridlyand,J., Osoegawa,K., de Jong,P.J., Nowak,N.J., Pinkel,D., Albertson,D.G., Jain,A., Jenkins,R., Gray,J.W., and Weiss,W.A. (2003) Genome-wide array CGH analysis of murine neuroblastoma reveals distinct genomic aberrations which parallel those in human tumors.

Cancer Res, 63, 5266-5273.

272. Weiss,W.A., Aldape,K., Mohapatra,G., Feuerstein,B.G., and Bishop,J.M. (1997) Targeted expression of MYCN causes neuroblastoma in transgenic mice. EMBO $J, 16,2985-2995$.

273. Weiss,W.A., Godfrey,T., Francisco,C., and Bishop,J.M. (2000) Genome-wide screen for allelic imbalance in a mouse model for neuroblastoma. Cancer Res, 60, 2483-2487.

274. DuBois,S.G., Kalika,Y., Lukens,J.N., Brodeur,G.M., Seeger,R.C., Atkinson,J.B., Haase,G.M., Black,C.T., Perez,C., Shimada,H., Gerbing,R., Stram,D.O., and Matthay,K.K. (1999) Metastatic sites in stage IV and IVS neuroblastoma correlate with age, tumor biology, and survival. J Pediatr.Hematol.Oncol., 21, 181-189. 
275. Norris,M.D., Bordow,S.B., Marshall,G.M., Haber,P.S., Cohn,S.L., and Haber,M. (1996) Expression of the gene for multidrug-resistance-associated protein and outcome in patients with neuroblastoma. N.Engl.J Med, 334, 231-238.

276. Breit,S., Ashman,K., Wilting,J., Rossler,J., Hatzi,E., Fotsis,T., and Schweigerer,L. (2000) The N-myc oncogene in human neuroblastoma cells: down-regulation of an angiogenesis inhibitor identified as activin A. Cancer Res, $60,4596-4601$.

277. Brodeur,G.M., Seeger,R.C., Schwab,M., Varmus,H.E., and Bishop,J.M. (1985) Amplification of N-myc sequences in primary human neuroblastomas: correlation with advanced disease stage. Prog.Clin.Biol.Res, 175, 105-113.

278. Goodman,L.A., Liu,B.C., Thiele,C.J., Schmidt,M.L., Cohn,S.L., Yamashiro,J.M., Pai,D.S., Ikegaki,N., and Wada,R.K. (1997) Modulation of N-myc expression alters the invasiveness of neuroblastoma. Clin.Exp Metastasis, 15, 130-139.

279. Hatzi,E., Breit,S., Zoephel,A., Ashman,K., Tontsch,U., Ahorn,H., Murphy,C., Schweigerer,L., and Fotsis,T. (2000) MYCN oncogene and angiogenesis: downregulation of endothelial growth inhibitors in human neuroblastoma cells. Purification, structural, and functional characterization. Adv.Exp Med Biol., 476, 239-248.

280. Meitar,D., Crawford,S.E., Rademaker,A.W., and Cohn,S.L. (1996) Tumor angiogenesis correlates with metastatic disease, $\mathrm{N}$-myc amplification, and poor outcome in human neuroblastoma. J Clin.Oncol., 14, 405-414.

281. Schweigerer,L., Scheurich,P., and Fotsis,T. (1990) Enhanced MYCN oncogene expression in human neuroblastoma cells results in increased susceptibility to growth inhibition by TNF alpha. Biochem.Biophys.Res Commun., 170, 13011307.

282. Thiele,C.J., Reynolds,C.P., and Israel,M.A. (1985) Decreased expression of Nmyc precedes retinoic acid-induced morphological differentiation of human neuroblastoma. Nature, 313, 404-406.

283. Chesler,L., Schlieve,C., Goldenberg,D.D., Kenney,A., Kim,G., McMillan,A., Matthay,K.K., Rowitch,D., and Weiss,W.A. (2006) Inhibition of phosphatidylinositol 3-kinase destabilizes Mycn protein and blocks malignant progression in neuroblastoma. Cancer Res, 66, 8139-8146.

284. Shidara,Y., Yamagata,K., Kanamori,T., Nakano,K., Kwong,J.Q., Manfredi,G., Oda,H., and Ohta,S. (2005) Positive contribution of pathogenic mutations in the mitochondrial genome to the promotion of cancer by prevention from apoptosis. Cancer Res, 65, 1655-1663. 
285. Niemann,S. and Muller,U. (2000) Mutations in SDHC cause autosomal dominant paraganglioma, type 3. Nat.Genet., 26, 268-270.

286. Shoubridge,E.A. (2001) Nuclear gene defects in respiratory chain disorders. Semin.Neurol, 21, 261-267.

287. Roy,D., Cai,Q., Felty,Q., and Narayan,S. (2007) Estrogen-induced generation of reactive oxygen and nitrogen species, gene damage, and estrogen-dependent cancers. J Toxicol.Environ Health B Crit Rev., 10, 235-257.

288. Astuti,D., Latif,F., Dallol,A., Dahia,P.L., Douglas,F., George,E., Skoldberg,F., Husebye,E.S., Eng,C., and Maher,E.R. (2001) Gene mutations in the succinate dehydrogenase subunit SDHB cause susceptibility to familial pheochromocytoma and to familial paraganglioma. Am J Hum.Genet., 69, 49-54.

289. Baysal,B.E., Ferrell,R.E., Willett-Brozick,J.E., Lawrence,E.C., Myssiorek,D., Bosch,A., van der,M.A., Taschner,P.E., Rubinstein,W.S., Myers,E.N., Richard,C.W., III, Cornelisse,C.J., Devilee,P., and Devlin,B. (2000) Mutations in SDHD, a mitochondrial complex II gene, in hereditary paraganglioma. Science, $287,848-851$.

290. Tomlinson,I.P., Alam,N.A., Rowan,A.J., Barclay,E., Jaeger,E.E., Kelsell,D., Leigh,I., Gorman,P., Lamlum,H., Rahman,S., Roylance,R.R., Olpin,S., Bevan,S., Barker,K., Hearle,N., Houlston,R.S., Kiuru,M., Lehtonen,R., Karhu,A., Vilkki,S., Laiho,P., Eklund,C., Vierimaa,O., Aittomaki,K., Hietala,M., Sistonen,P., Paetau,A., Salovaara,R., Herva,R., Launonen,V., and Aaltonen,L.A. (2002) Germline mutations in FH predispose to dominantly inherited uterine fibroids, skin leiomyomata and papillary renal cell cancer. Nat.Genet., 30, 406-410.

291. Kurtz,A., Lueth,M., Kluwe,L., Zhang,T., Foster,R., Mautner,V.F., Hartmann,M., Tan,D.J., Martuza,R.L., Friedrich,R.E., Driever,P.H., and Wong,L.J. (2004) Somatic mitochondrial DNA mutations in neurofibromatosis type 1-associated tumors. Mol.Cancer Res, 2, 433-441.

292. Kiebish,M.A. and Seyfried,T.N. (2005) Absence of pathogenic mitochondrial DNA mutations in mouse brain tumors. BMC.Cancer, 5, 102.

293. Wong,L.J., Lueth,M., Li,X.N., Lau,C.C., and Vogel,H. (2003) Detection of mitochondrial DNA mutations in the tumor and cerebrospinal fluid of medulloblastoma patients. Cancer Res, 63, 3866-3871.

294. Liang,B.C. and Hays,L. (1996) Mitochondrial DNA copy number changes in human gliomas. Cancer Lett., 105, 167-173. 
295. Liang,B.C. (1996) Evidence for association of mitochondrial DNA sequence amplification and nuclear localization in human low-grade gliomas. Mutat.Res, 354, 27-33.

296. Oudard,S., Boitier,E., Miccoli,L., Rousset,S., Dutrillaux,B., and Poupon,M.F. (1997) Gliomas are driven by glycolysis: putative roles of hexokinase, oxidative phosphorylation and mitochondrial ultrastructure. Anticancer Res, 17, 1903-1911.

297. Kirches,E., Michael,M., Woy,C., Schneider,T., Warich-Kirches,M., SchneiderStock,R., Winkler,K., Wittig,H., and Dietzmann,K. (1999) Loss of heteroplasmy in the displacement loop of brain mitochondrial DNA in astrocytic tumors. Genes Chromosomes.Cancer, 26, 80-83.

298. Kirches,E., Krause,G., Weis,S., Mawrin,C., and Dietzmann,K. (2002) Comparison between mitochondrial DNA sequences in low grade astrocytomas and corresponding blood samples. Mol.Pathol, 55, 204-206.

299. Montanini,L., Regna-Gladin,C., Eoli,M., Albarosa,R., Carrara,F., Zeviani,M., Bruzzone,M.G., Broggi,G., Boiardi,A., and Finocchiaro,G. (2005) Instability of mitochondrial DNA and MRI and clinical correlations in malignant gliomas. $J$ Neurooncol., 74, 87-89.

300. Vega,A., Salas,A., Gamborino,E., Sobrido,M.J., Macaulay,V., and Carracedo,A. (2004) mtDNA mutations in tumors of the central nervous system reflect the neutral evolution of mtDNA in populations. Oncogene, 23, 1314-1320.

301. Dmitrenko,V., Shostak,K., Boyko,O., Khomenko,O., Rozumenko,V., Malisheva,T., Shamayev,M., Zozulya,Y., and Kavsan,V. (2005) Reduction of the transcription level of the mitochondrial genome in human glioblastoma. Cancer Lett., 218, 99-107.

302. lalunis-Turner,M.J., Franko,A.J., and Parliament,M.B. (1999) Modulation of oxygen consumption rate and vascular endothelial growth factor mRNA expression in human malignant glioma cells by hypoxia. Br.J Cancer, 80, 104109.

303. Turcotte,M.L., Parliament,M., Franko,A., and lalunis-Turner,J. (2002) Variation in mitochondrial function in hypoxia-sensitive and hypoxia-tolerant human glioma cells. Br.J Cancer, 86, 619-624.

304. DeHaan,C., Habibi-Nazhad,B., Yan,E., Salloum,N., Parliament,M., and lalunisTurner,J. (2004) Mutation in mitochondrial complex I ND6 subunit is associated with defective response to hypoxia in human glioma cells. Mol.Cancer, 3, 19.

305. Kirches,E., Krause,G., Warich-Kirches,M., Weis,S., Schneider,T., MeyerPuttlitz,B., Mawrin,C., and Dietzmann,K. (2001) High frequency of 
mitochondrial DNA mutations in glioblastoma multiforme identified by direct sequence comparison to blood samples. Int J Cancer, 93, 534-538.

306. Searles,N.S., Mueller,B.A., De Roos,A.J., Viernes,H.M., Farin,F.M., and Checkoway,H. (2005) Risk of brain tumors in children and susceptibility to organophosphorus insecticides: the potential role of paraoxonase (PON1). Environ Health Perspect., 113, 909-913.

307. Rajaraman,P., Stewart,P.A., Samet,J.M., Schwartz,B.S., Linet,M.S., Zahm,S.H., Rothman,N., Yeager,M., Fine,H.A., Black,P.M., Loeffler,J., Shapiro,W.R., Selker,R.G., and Inskip,P.D. (2006) Lead, genetic susceptibility, and risk of adult brain tumors. Cancer Epidemiol Biomarkers Prev., 15, 2514-2520.

308. Schwartzbaum,J.A., Ahlbom,A., Lonn,S., Warholm,M., Rannug,A., Auvinen,A., Christensen,H.C., Henriksson,R., Johansen,C., Lindholm,C., Malmer,B., Salminen,T., Schoemaker,M.J., Swerdlow,A.J., and Feychting,M. (2007) An international case-control study of glutathione transferase and functionally related polymorphisms and risk of primary adult brain tumors. Cancer Epidemiol Biomarkers Prev., 16, 559-565.

309. Ezer,R., Alonso,M., Pereira,E., Kim,M., Allen,J.C., Miller,D.C., and Newcomb,E.W. (2002) Identification of glutathione S-transferase (GST) polymorphisms in brain tumors and association with susceptibility to pediatric astrocytomas. J Neurooncol., 59, 123-134.

310. Barnette,P., Scholl,R., Blandford,M., Ballard,L., Tsodikov,A., Magee,J., Williams,S., Robertson,M., li-Osman,F., Lemons,R., and Keller,C. (2004) Highthroughput detection of glutathione s-transferase polymorphic alleles in a pediatric cancer population. Cancer Epidemiol Biomarkers Prev., 13, 304-313.

311. Lai,R., Crevier,L., and Thabane,L. (2005) Genetic polymorphisms of glutathione S-transferases and the risk of adult brain tumors: a meta-analysis. Cancer Epidemiol Biomarkers Prev., 14, 1784-1790.

312. Krajinovic,M., Lamothe,S., Labuda,D., Lemieux-Blanchard,E., Theoret,Y., Moghrabi,A., and Sinnett,D. (2004) Role of MTHFR genetic polymorphisms in the susceptibility to childhood acute lymphoblastic leukemia. Blood, 103, 252257.

313. Thompson,J.R., Gerald,P.F., Willoughby,M.L., and Armstrong,B.K. (2001) Maternal folate supplementation in pregnancy and protection against acute lymphoblastic leukaemia in childhood: a case-control study. Lancet, 358, 1935 1940 .

314. Duthie,S.J. and Dobson,V.L. (1999) Dietary flavonoids protect human colonocyte DNA from oxidative attack in vitro. Eur J Nutr., 38, 28-34. 
315. Sirachainan,N., Wongruangsri,S., Kajanachumpol,S., Pakakasama,S., Visudtibhan,A., Nuchprayoon,I., Lusawat,A., Phudhicharoenrat,S., Shuangshoti,S., and Hongeng,S. (2008) Folate pathway genetic polymorphisms and susceptibility of central nervous system tumors in Thai children. Cancer Detect.Prev., 32, 72-78.

316. Kafadar,A.M., Yilmaz,H., Kafadar,D., Ergen,A., Zeybek,U., Bozkurt,N., Kuday,C., and Isbir,T. (2006) C677T gene polymorphism of methylenetetrahydrofolate reductase (MTHFR) in meningiomas and high-grade gliomas. Anticancer Res, 26, 2445-2449.

317. Malthankar,G.V., White,B.K., Bhushan,A., Daniels,C.K., Rodnick,K.J., and Lai,J.C. (2004) Differential lowering by manganese treatment of activities of glycolytic and tricarboxylic acid (TCA) cycle enzymes investigated in neuroblastoma and astrocytoma cells is associated with manganese-induced cell death. Neurochem.Res, 29, 709-717.

318. Dukhande,V.V., Malthankar-Phatak,G.H., Hugus,J.J., Daniels,C.K., and Lai,J.C. (2006) Manganese-induced neurotoxicity is differentially enhanced by glutathione depletion in astrocytoma and neuroblastoma cells. Neurochem.Res, 31, 13491357.

319. Kim,E.H., Sohn,S., Kwon,H.J., Kim,S.U., Kim,M.J., Lee,S.J., and Choi,K.S. (2007) Sodium selenite induces superoxide-mediated mitochondrial damage and subsequent autophagic cell death in malignant glioma cells. Cancer Res, 67, 6314-6324.

320. Slikker,W., III, Mei,N., and Chen,T. (2004) N-ethyl-N-nitrosourea (ENU) increased brain mutations in prenatal and neonatal mice but not in the adults. Toxicol.Sci., 81, 112-120.

321. Pouliquen,D., Olivier,C., Hervouet,E., Pedelaborde,F., Debien,E., Le Cabellec,M.T., Gratas,C., Homma,T., Meflah,K., Vallette,F.M., and Menanteau,J. (2008) Dietary prevention of malignant glioma aggressiveness, implications in oxidant stress and apoptosis. Int J Cancer, 123, 288-295.

322. Tedeschi-Blok,N., Lee,M., Sison,J.D., Miike,R., and Wrensch,M. (2006) Inverse association of antioxidant and phytoestrogen nutrient intake with adult glioma in the San Francisco Bay Area: a case-control study. BMC.Cancer, 6, 148. 


\section{HYPOTHESIS AND SPECIFIC AIMS}

Hypothesis: In utero environmental exposures are hypothesized to produce genetic and epigenetic changes in mitochondrial-nuclear signaling genes, such as, PGC1, mtTFA, NRF-1. These changes, in turn, may be involved in the development of pediatric central nervous system tumors (pCNTSs).

Specific Aim 1: To evaluate activation and/or expression of genetic and epigenetic components of the mt-nuclear signaling pathway in brain tumors.

Specific Aim 2: To estimate pre- and postnatal environmental risk factors (organic solvents, pesticides, illicit drugs, infections, etc.) for childhood brain cancer. Correlations of these risk factors to our genetic and epigenetic changes of interest will be determined to establish whether there is any evidence of gene-environment interactions (GEI) between our genes and/or epigenes of interest and in utero and early life exposures.

Specific Aim 3: To identify how many genetic and/or epigenetic changes are required for the development of pCNST. 


\title{
RESEARCH MANUSCRIPTS
}

Manuscript 3: Early life exposure of the brain to pesticides and development of childhood brain cancer: A Meta-analysis*

\author{
Kunkle B, Roy D.
}

Department of Environmental and Occupational Health, Robert Stempel School of Public Health, Florida International University, Miami, Florida 33199

*Presented as a an Oral Presentation at 19th Conference of the International Society for Environmental Epidemiology, Mexico City, Mexico 


\section{ABSTRACT}

Objective: Relatively little is known about the etiology of childhood brain tumors (CBT). While there are several studies which link pesticide exposure to increased risk of CBT, findings have been inconsistent. A meta-analysis of 17 published epidemiological studies was performed to test the concept that imprinting as a result of in utero exposure to pesticides is involved in the development of brain cancer in children.

Material and methods: Meta-analysis was performed using the general variance-based method and homogeneity was tested by means of the Q statistic. Summary relative risk (RR) estimates were calculated for risk of childhood brain cancer and 1) paternal exposure to pesticides prior to conception, 2) both maternal and paternal exposure to pesticides during pregnancy, 3) maternal exposure during pregnancy to a. agricultural and b. non-agricultural activities, and 4) childhood exposure to a. agricultural and b. nonagricultural activities up to date of diagnosis with CBT.

Results: Results reveal a significantly increased risk of CBT among children whose mothers had farm-related exposures during pregnancy $(\mathrm{RR}=1.48,95 \% \mathrm{CI}=1.18-1.84)$. A dose response is recognized when this risk estimate is compared to those for risk of CBT from maternal exposure to non-agricultural pesticides (e.g. home extermination, pest strips) during pregnancy $(\mathrm{RR}=1.36,1.10-1.68)$, and risk of CBT among children exposed to agricultural activities $(\mathrm{RR}=1.32,1.04-1.67)$.

Conclusions: Our findings suggest that in utero imprinting of brain development by pesticides may be involved in the etiology of CBT. 


\section{INTRODUCTION}

Links between pesticide exposure and childhood tumors were first noted in case reports in the 1970s [1-3]. Since then, numerous studies have been published that support a role for pesticides in childhood brain tumor (CBT) etiology. To date, three separate reviews of pesticide exposure and CBTs have been published [4-6]. In 1997, Daniels et al. found that the studies to date showed that 1) farm residence was associated with CBT and 2) pesticide use in the home was fairly consistently associated with CBT despite the small sample sizes of studies. However, they concluded that "it remains unclear whether a specific time window of exposure may be of greater importance in studying the effects of home pesticide use." Zahm and Ward's 1998 review noted that nine of the 17 studies through 1998 had reported increased risk of CBT from pesticide exposure, five additional studies found a positive relationship that was not statistically significant, and only three studies reported no excess risk associated with pesticide exposure. Finally, Jurewics and Hanke 2006 reported that most studies since 1998 found associations between CBT and both agricultural employment and home use of pesticides. In addition, they commented on new positive associations being found with prenatal and preconception time periods of exposure.

Most studies on the relation between pesticide exposure and CBT have used small sample sizes and to date no meta-analysis of these studies has been published. While not a pediatric study, a meta-analysis of adult BT and farming did find an increased RR of 1.30 (95\% CI: $1.09-1.56)$ [7]. By conducting a meta-analysis of the studies on CBT and pesticides we aim to synthesize past information on this topic and produce more robust risk estimates of any relations that may exist. Questions that we attempted to answer 
with this study include: 1) Does exposure to pesticides increase risk of CBT?; 2) Are maternal and paternal exposures both important in CBT etiology and if so, does one increase risk more than the other?; 3) Are certain exposure time periods important for etiology of CBT?; and, 4) Is there a difference in risk for agricultural and non-agricultural pesticides exposures?

\section{BACKGROUND}

Several mechanisms for CBT development from pesticide exposure have been suggested, occurring at three separate time periods:

(1) exposure during preconception resulting in genetic alterations;

(2) in utero exposure causing genetic or teratogenic effects; and

(3) postnatal exposure via the mother's breast milk or direct exposure to the child (e.g. diet, childhood play habits, etc.).

While occupational exposure is an established pathway for significant pesticide exposure, contact through home use of pesticides has been of less concern. However, substantial pesticide exposure to children can occur in and around the home, with those being used outdoors being tracked into the home on shoes and by pets. $82 \%$ of United States households use pesticides with an average of 3 to 4 different pesticide products being used per home [8]. These exposures can become long-lasting as the pesticide residues can remain in carpets, furniture, and toys without being degraded by processes that exist outdoors (e.g., rain and sun) [6]. Furthermore, Whyatt et al. 2003 examined pesticide levels in plasma of $230 \mathrm{NYC}$ mothers and infant pairs, finding that 7 pesticides were detected in up to $83 \%$ of the plasma sample. Maternal plasma levels were 
correlated with cord blood levels, indicating placental transfer from pregnant mother to fetus [9].

\section{METHODS}

A PubMed search was conducted to identify studies of the association between CBT and pesticides. This search included articles published from 1966 until December 17, 2010. Search terms used in various combinations were brain, cancer, tumor, childhood, adolescent, in utero, pregnancy, central nervous system, pesticides, farming, and agriculture. References cited in the studies identified by this search were also reviewed for inclusion in the meta-analyses.

Inclusion criteria for initial search were: 1) Published in English language peerreviewed journals between 1966 and 2006; 2) Provided sufficient data to determine an estimator of risk for CBT and its confidence interval (CI); and, 3) Study evaluated pesticide and/or farm exposure and CBT. Exclusion criteria for initial search were: 1) Did not report original results (reviews, comments, letters, etc.); 2) Results already reported in another study or in a more comprehensive study; 3) Geographic studies using GIS, etc.; 4) Study had less than 4 cases in subgroup of interest; and, 5) Study did not report timing of exposure. For timing of exposure a study was excluded if the exposure period was not specific to one of our identified time periods. For example, Kristensen et al. 1997 used a 5 year period of exposure and was thus excluded from the final analyses [10].

CBT was defined as any child diagnosed with CBT until age 19. This conformed to the standard SEER (Surveillance, Epidemiology, and End Results) childhood cancer 
classification. CBT included all central nervous system tumors including brain tumors such as astrocytoma and primitive neuroectodermal tumor (PNET) and other central nervous system tumors such as neuroblastoma. Pesticide exposures were defined as either agricultural or non-agricultural in nature. Agricultural pesticide exposures were defined as exposures to pesticides from farming, farm related activities, living on a farm, mixing and preparing agricultural pesticides, horticulture, nursery work, and professional gardening. Non-agricultural pesticide exposures were those that occurred during home use such as flea/tick pesticide use, garden pesticide use, yard treatment, pest strip use, and home extermination.

The data were stratified three separate ways and several separate meta-analyses were performed among these groups. Stratification methods included 1) exposure categories separated into maternal exposures, paternal exposures, and child exposures; 2) exposure time period separated into preconception, pregnancy, and childhood; and 3) type of exposure split into agricultural pesticide exposures and non-agricultural pesticides exposures.

A general variance-based method using confidence intervals developed independently by Prentice and Thomas [11] and Greenland [12] was used to calculate odds ratio risk estimates. This method requires only information on each study's estimate of risk and its $95 \%$ confidence interval, reducing the amount of studies excluded from the analysis because of missing data. The weight given to each study is chosen to be the inverse of the variance of the effect estimate, meaning that larger studies with smaller standard errors are given more weight than smaller studies that have larger standard errors. In addition, because adjusted rate ratios and confidence intervals are used in the analysis, 
the method takes confounding into consideration, unlike other meta-analyses methods which may not include confounding in their estimates. Analysis was completed using Comprehensive Meta-Analysis Version 2.2.046 from Biostat, Inc. which can be downloaded at www.Meta-Analysis.com [13].

Risk estimates were combined following several pre-determined rules. For studies that reported risk estimates for different types of CBT separately without reporting a summary estimate for all CBT, we calculated a summary risk estimate for use in our meta-analyses. For example, one summary risk estimate was calculated by combing the odds ratio for risk of astrocytoma and PNET reported by Bunin et al. 1994. In addition, when a study reported more than one risk estimate for different pesticide exposure types or situations, the general exposure category was used for the meta-analyses calculations. Finally, the studies that reported home exposure/use of pesticides during pregnancy without specifying it as either maternal or paternal specifically were included in the maternal exposure during pregnancy category. This was based on the concept that the mother is the ultimate exposure during this period.

\section{RESULTS}

The initial literature search produced 33 studies that fit the inclusion criteria. 17 studies were rejected by the exclusion criteria, leaving 16 studies for the final meta-analyses calculations. Table 3-1 lists the characteristics of these 16 studies, including their design, case and control totals, and tumor types analyzed. Of the 16 studies, 15 were case-control studies and one was a cohort study. Results of the meta-analyses performed can be found in Table 3-2, organized by time period and exposure category. 
Table 3-1. Characteristics of studies included in the meta-analyses of parental pesticide exposure and risk of childhood brain tumor development.

\begin{tabular}{|c|c|c|c|}
\hline $\begin{array}{l}\text { Study First } \\
\text { Author } \\
\text { and Year }\end{array}$ & $\begin{array}{l}\text { Study } \\
\text { Design }\end{array}$ & Study Subjects (n) & Tumor Type(s) \\
\hline $\begin{array}{l}\text { Feychting } 2001 \\
{[14]}\end{array}$ & Cohort & $\begin{array}{l}152 \text { cases; } 11 \text { exposed cases; } \\
235,635 \text { cohort size }\end{array}$ & Nervous System Tumor \\
\hline $\begin{array}{l}\text { Kuijten } 1992 \\
\text { [15] }\end{array}$ & $\begin{array}{l}\text { Case- } \\
\text { control }\end{array}$ & $\begin{array}{l}163 \text { cases and control } \\
\text { mothers; } \\
158 \text { cases and control fathers }\end{array}$ & Astrocytoma \\
\hline $\begin{array}{l}\text { Wilkins } 1990 \\
{[16]}\end{array}$ & $\begin{array}{l}\text { Case- } \\
\text { control }\end{array}$ & 110 cases; 193 controls & Brain Cancer \\
\hline Efird 2003 [17] & $\begin{array}{l}\text { Case- } \\
\text { control }\end{array}$ & 1218 cases; 2223 controls & Astroglial, PNET, Other Glial, Other \\
\hline Kerr 2000 [18] & $\begin{array}{l}\text { Case- } \\
\text { control }\end{array}$ & 183 cases; 372 controls & Neuroblastoma \\
\hline $\begin{array}{l}\text { Holly } 1998 \\
{[19]^{*}}\end{array}$ & $\begin{array}{l}\text { Case- } \\
\text { control }\end{array}$ & 540 cases; 801 controls & Astroglial, PNET, Other Glial \\
\hline Bunin 1994 [20] & $\begin{array}{l}\text { Case } \\
\text { control }\end{array}$ & 322 cases; 321 controls & Astrocytoma, PNET \\
\hline $\begin{array}{l}\text { McCredie } 1994 \\
{[21]}\end{array}$ & $\begin{array}{l}\text { Case- } \\
\text { control }\end{array}$ & 82 cases; 164 controls & Brain and cranial nerve tumors \\
\hline $\begin{array}{l}\text { Daniels } 2001 \\
{[22]}\end{array}$ & $\begin{array}{l}\text { Case- } \\
\text { control }\end{array}$ & $\begin{array}{l}538 \text { cases and } 504 \text { control } \\
\text { mothers; } 405 \text { cases and } 304 \\
\text { control fathers }\end{array}$ & Neuroblastoma \\
\hline $\begin{array}{l}\text { Pogoda } 2001 \\
{[23]}\end{array}$ & $\begin{array}{l}\text { Case- } \\
\text { control }\end{array}$ & 224 cases; 218 controls & $\begin{array}{l}\text { Brain, cranial nerve, and cranial meninges } \\
\text { tumors }\end{array}$ \\
\hline Leiss 1995 [24] & $\begin{array}{l}\text { Case- } \\
\text { control }\end{array}$ & 17 cases; 118 controls & Brain Cancer \\
\hline Davis 1993 [25] & $\begin{array}{l}\text { Case- } \\
\text { control }\end{array}$ & $\begin{array}{l}45 \text { cases; } 85 \text { no disease } \\
\text { controls; } 108 \text { cancer controls }\end{array}$ & Astrocytoma, Medulloblastoma, Other \\
\hline $\begin{array}{l}\text { Preston-Martin } \\
1982 \text { [26] }\end{array}$ & $\begin{array}{l}\text { Case- } \\
\text { control }\end{array}$ & 209 cases; 209 controls & $\begin{array}{l}\text { Astrocytoma, medulloblastoma, } \\
\text { ependymoma, other glioma, meningioma, } \\
\text { neuroma, other }\end{array}$ \\
\hline $\begin{array}{l}\text { McKean- } \\
\text { Cowdin } 1998 \\
{[27]^{*}}\end{array}$ & $\begin{array}{l}\text { Case- } \\
\text { control }\end{array}$ & 540 cases; 801 controls & Astroglial, PNET, Other Glial, Other \\
\hline $\begin{array}{l}\text { Wilkins } 1988 \\
{[28]}\end{array}$ & $\begin{array}{l}\text { Case- } \\
\text { control }\end{array}$ & 30 cases; 19 controls & Brain Cancer \\
\hline Gold 1982 [29] & $\begin{array}{l}\text { Case- } \\
\text { control }\end{array}$ & 70 cases & Brain Cancer \\
\hline
\end{tabular}

*These manuscripts used the same study population. However, different exposure analyses results were reported in each study and therefore, both manuscripts were included in our meta-analyses. 
Table 3-2. Summary of results of meta-analyses of the association between pesticides and childhood brain tumors.

\begin{tabular}{|c|c|c|c|}
\hline Time Period & Exposure Category & $\begin{array}{l}\text { Studies in } \\
\text { Estimate }\end{array}$ & $\begin{array}{c}\text { Summary Risk Estimate } \\
\text { Odds Ratio (95\% CI) }\end{array}$ \\
\hline \multirow{2}{*}{ Pre-conception } & Maternal Exposures & 1 & $0.87(0.29-2.60)$ \\
\hline & Paternal Exposures & 3 & $2.29(1.39-3.78)$ \\
\hline \multirow{3}{*}{ Pregnancy } & $\begin{array}{l}\text { Maternal Exposures } \\
\text { (Agricultural) }\end{array}$ & 5 & $1.48(1.18-1.84)$ \\
\hline & $\begin{array}{l}\text { Maternal Exposures } \\
\text { (Non-agricultural) }\end{array}$ & 7 & $1.36(1.10-1.68)$ \\
\hline & Paternal Exposures & 5 & $1.63(1.16-2.31)$ \\
\hline \multirow{2}{*}{ Childhood } & Agricultural Exposures & 4 & $1.35(1.08-1.70)$ \\
\hline & Non-agricultural Exposures & 5 & $1.32(1.04-1.67)$ \\
\hline
\end{tabular}

Exposure during Pre-conception

No meta-analysis was performed on maternal exposure to pesticides during preconception as only one study fit the criteria for this grouping. This study, McKeanCowdin et al. 1998, reported no increased risk for CBT from maternal exposure to pesticides during preconception (OR: 0.87, 95\% Confidence Interval (CI): 0.29 - 2.6) [27]. Three studies were combined for the paternal exposure to pesticides during preconception, producing a calculated summary risk estimate of odds ratio $(\mathrm{OR})=2.29$ (95\% CI: $1.39-3.78)$ (Figure 3-1).

\section{Exposures during Pregnancy}

All three summary risk estimates for exposure during pregnancy showed a significant association between pesticide exposure and CBT. A combination of 5 studies for maternal exposure to agricultural pesticides during pregnancy generated an increased risk of $\mathrm{OR}=1.48(95 \% \mathrm{CI}: 1.18-1.84)($ Figure $3-2)$. 


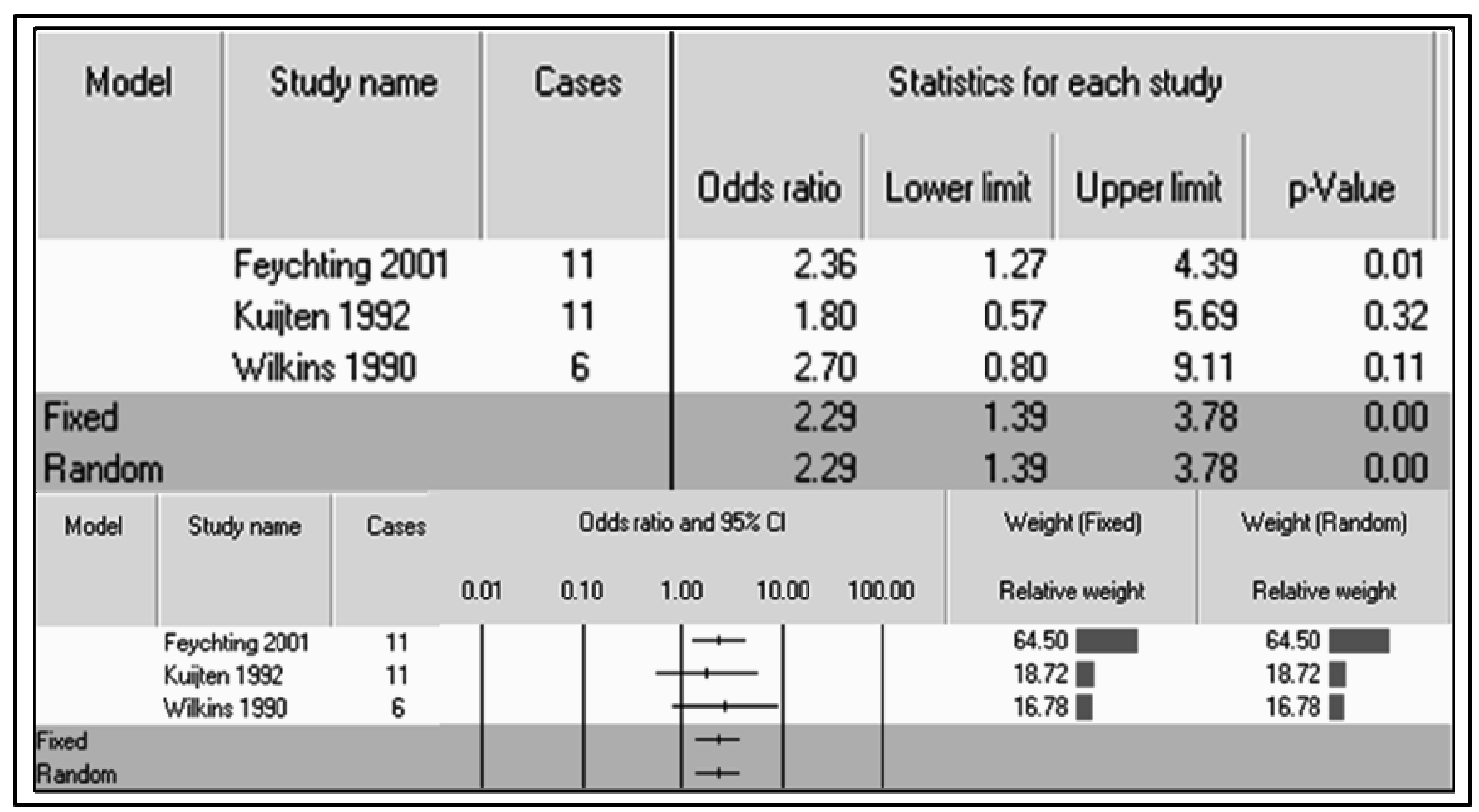

Figure 3-1. Meta-analysis results for paternal exposure to pesticides during preconception.

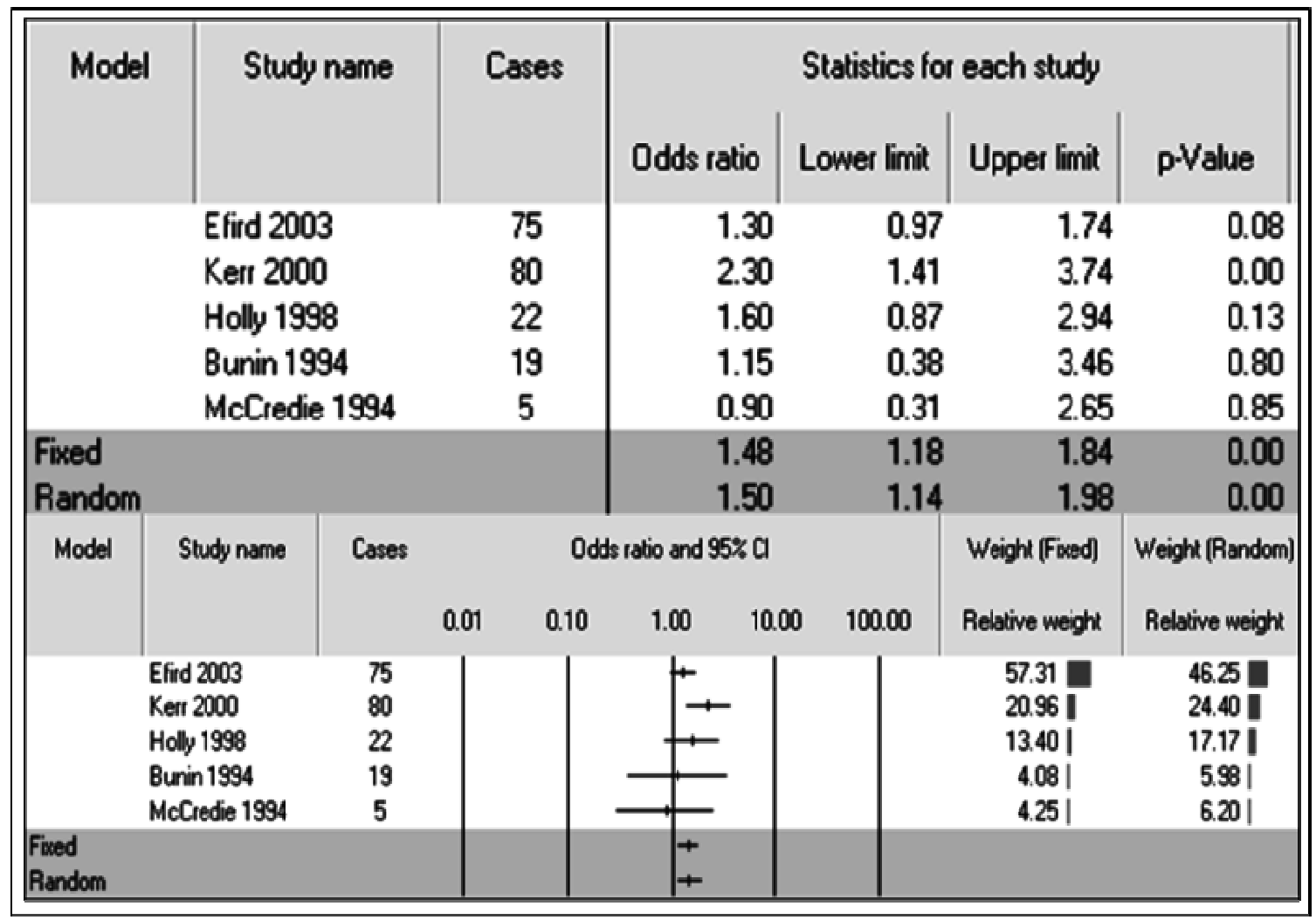

Figure 3-2. Meta-analysis results for maternal exposure to pesticides during pregnancy (agricultural/work exposures only). 
Seven studies of maternal exposure to non-agricultural pesticides during pregnancy produced a summary risk estimate of $\mathrm{OR}=1.36(95 \% \mathrm{CI}: 1.10-1.68)$ (Figure 3-3). Finally, the paternal exposure to pesticides during pregnancy meta-analysis grouped five studies for a final calculated summary risk estimate of $\mathrm{OR}=1.63(95 \%$ CI: $1.16-2.31)$ (Figure 3-4).

\section{Exposures during Childhood}

Combining four studies of childhood exposure to agricultural pesticides produced a summary risk estimate of $\mathrm{OR}=1.35(95 \%$ CI: $1.08-1.70)$ (Figure 3-5). Nonagricultural pesticide exposures during childhood were also found to be significantly associated with development of CBT as a meta-analysis of five studies found an increased risk of $\mathrm{OR}=1.32(95 \% \mathrm{CI}: 1.04-1.67)($ Figure 3-6).

\section{DISCUSSION}

Our meta-analyses produced several estimates of increased risk of CBT from exposure to pesticides. Comparing results from our categories of exposure, pre-conception and pregnancy exposure estimates were slightly higher than childhood exposure estimates, paternal exposures produced slightly higher risk estimates compared to maternal exposures, and agricultural exposures produced slightly higher risk estimates compared to non-agricultural exposures.

Evidence supporting a possible role for paternal exposure to pesticides during preconception and increased risk of CBT is limited but does exist. Tomatis et al. 1981 reported male rats given a single dose of ethylnitrosourea prior to mating with untreated 


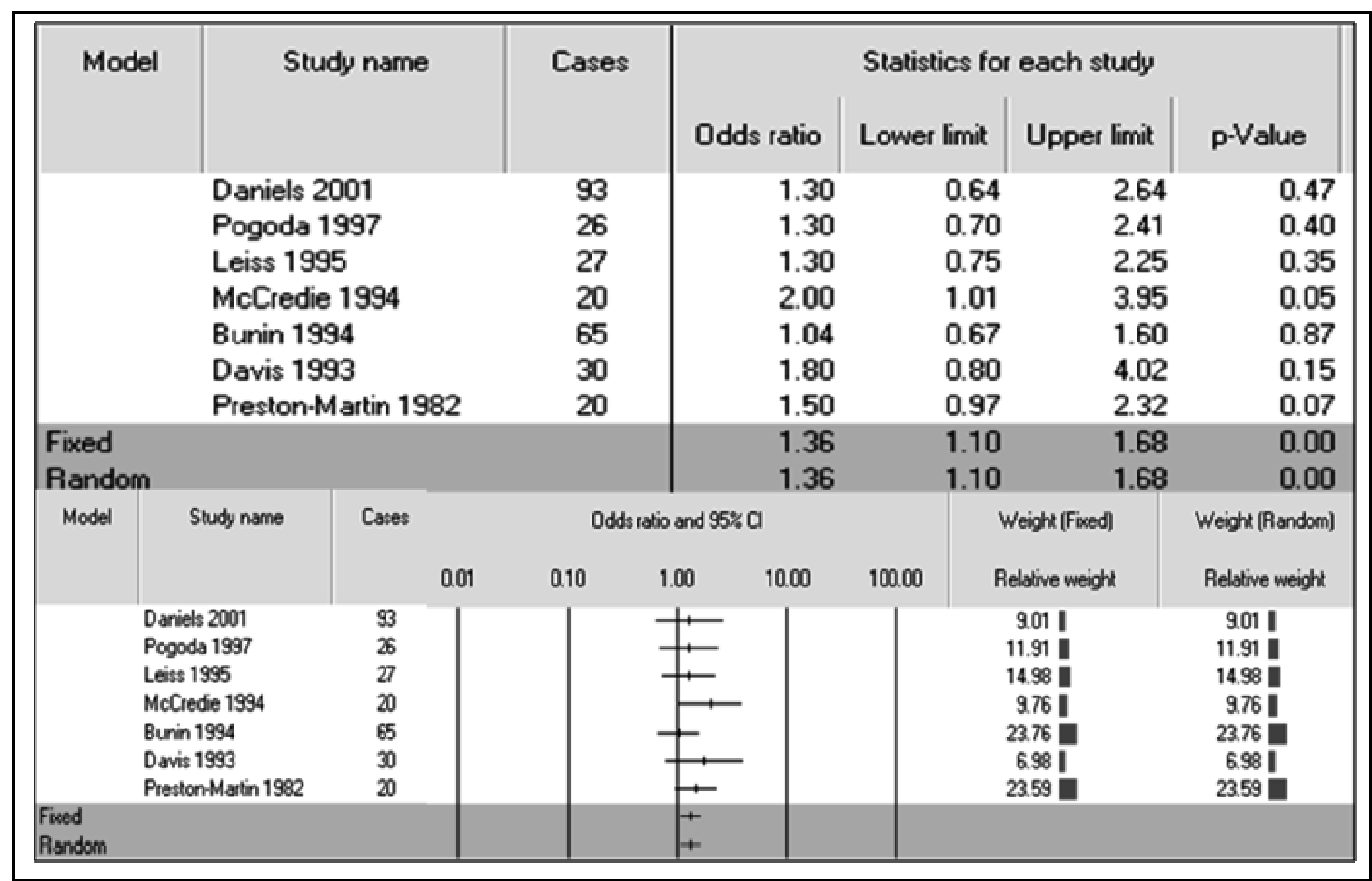

Figure 3-3. Meta-analysis results for maternal exposure to pesticides during pregnancy (non-agricultural exposures only).

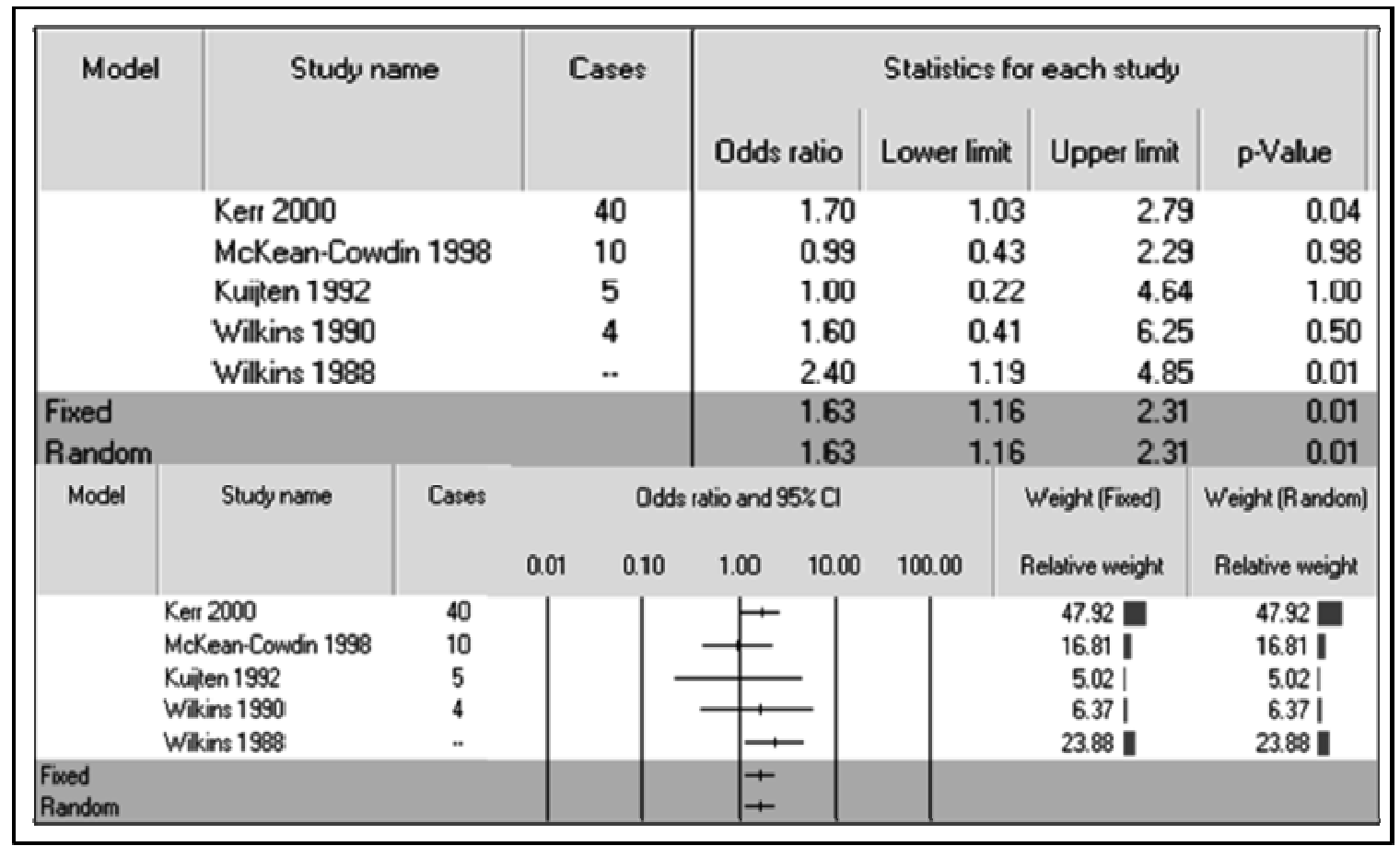

Figure 3-4. Meta-analysis results for paternal exposure to pesticides during pregnancy (agricultural/work exposures only). 


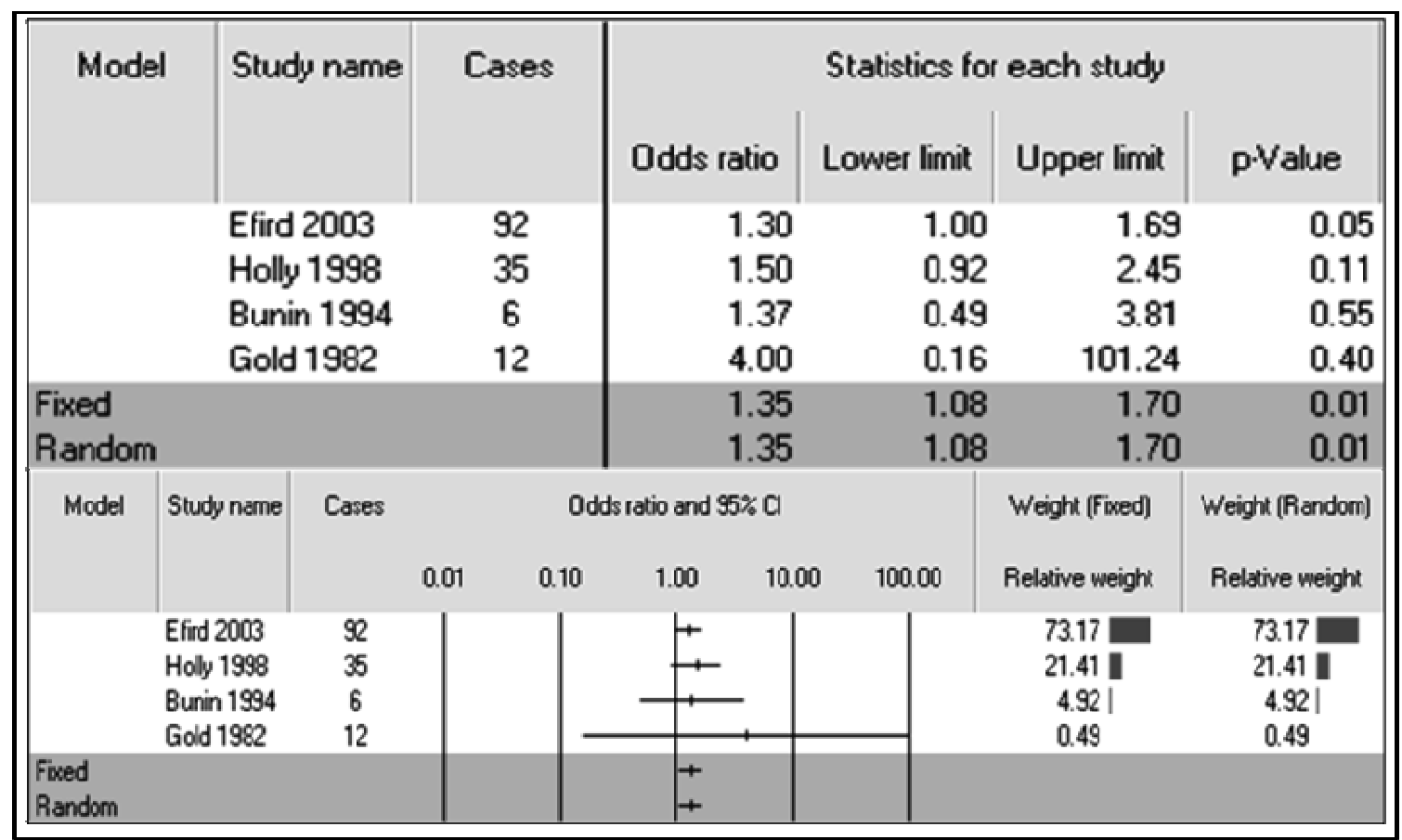

Figure 3-5. Meta-analysis results for childhood exposure to agricultural pesticides.

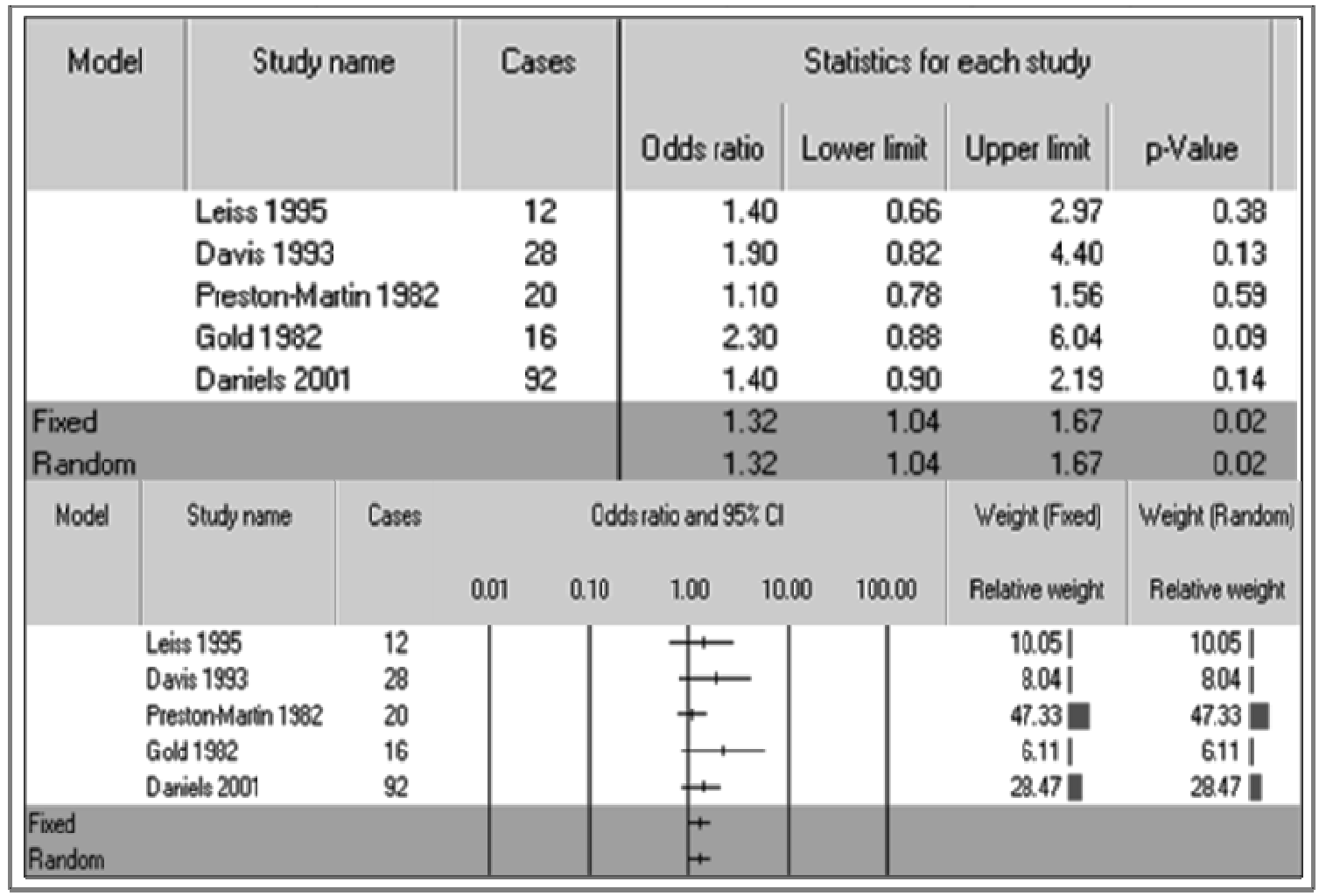

Figure 3-6. Meta-analysis results for childhood exposure to non-agricultural pesticides. 
females produced offspring at increased risk for CNS tumors (5.6\% compared to $1.9 \%$ controls; $p=0.08$ ) [30]. Yu et al. 1999 found that offspring of male mice treated with chromium two weeks before conception were at increased risk of tumors. This study also reported that methylation changes were noted in the sperm and could have altered parental imprinting [31]. Lastly, a population study by Infante-Rivard et al. 1999 found increased risk of leukemia in children whose fathers were exposed to pesticides during preconception [32].

There are several strengths of this meta-analysis. As mentioned earlier, the use of the general variance based method gave more weight to larger studies, considered confounding, and limited the number of studies excluded because of missing data. Most studies used interview data to assess exposure, providing a more direct accounting of exposure. Finally, the combining of similar exposure time periods and splitting of maternal/paternal and agricultural/non-agricultural exposures allowed for assessment of the range of possible external etiological factors involved in CBT development.

Limitations of the study include those typical of the epidemiological studies combined in meta-analyses such as publication bias, recall bias and exposure misclassification. Also, pesticide and CBT type, along with individual practices of participants, were not distinguished in most studies. Lastly, a few studies had correlations for exposures across three time periods, thus limiting our ability to evaluate fully the independent effects of pesticide exposure during specific time periods.

Based on the collective results of these meta-analyses it appears pesticide exposure does increase risk of $\mathrm{CBT}$, with preconception and prenatal exposures being especially important factors in increasing risk of its development. Interestingly, paternal exposure 
may be as important, if not more important than maternal exposures, particularly during the preconception period. Whether this is a result of paternal exposures being more prevalent than maternal exposures or the consequence of a biological process, is a question that deserves further attention in future investigations of CBT etiology. The need for CBT exposure studies with better exposure time period characterization, including the division of pregnancy exposures into trimester, is also apparent. 


\section{Reference List}

1. Infante,P.F. and Newton,W.A., Jr. (1975) Letter: Prenatal chlordane exposure and neuroblastoma. N.Engl.J.Med., 293, 308.

2. Infante,P.F. and Freeman,C. (1987) Cancer mortality among workers exposed to chlordane. J.Occup.Med., 29, 908-911.

3. Pratt,C.B., Rivera,G., Shanks,E., Johnson,W.W., Howarth,C., Terrell,W., and Kumar,A.P. (1977) Colorectal carcinoma in adolescents implications regarding etiology. Cancer, 40, 2464-2472.

4. Daniels,J.L., Olshan,A.F., and Savitz,D.A. (1997) Pesticides and childhood cancers. Environ.Health Perspect., 105, 1068-1077.

5. Jurewicz,J., Hanke,W., Johansson,C., Lundqvist,C., Ceccatelli,S., van den Hazel,P., Saunders,M., and Zetterstrom,R. (2006) Adverse health effects of children's exposure to pesticides: what do we really know and what can be done about it. Acta Paediatr. Suppl, 95, 71-80.

6. Zahm,S.H. and Ward,M.H. (1998) Pesticides and childhood cancer. Environ.Health Perspect., 106 Suppl 3, 893-908.

7. Khuder,S.A., Mutgi,A.B., and Schaub,E.A. (1998) Meta-analyses of brain cancer and farming. Am.J.Ind.Med., 34, 252-260.

8. U.S.Environmental Protection Agency. US EPA National Home and Garden Pesticide Use Survey. 1990. Washington, DC.

9. Whyatt,R.M., Barr,D.B., Camann,D.E., Kinney,P.L., Barr,J.R., Andrews,H.F., Hoepner,L.A., Garfinkel,R., Hazi,Y., Reyes,A., Ramirez,J., Cosme,Y., and Perera,F.P. (2003) Contemporary-use pesticides in personal air samples during pregnancy and blood samples at delivery among urban minority mothers and newborns. Environ.Health Perspect., 111, 749-756.

10. Kristensen,P., Irgens,L.M., Andersen,A., Bye,A.S., and Sundheim,L. (1997) Birth defects among offspring of Norwegian farmers, 1967-1991. Epidemiology, 8, 537-544.

11. Prentice,R.L. and Thomas,D.B. (1987) On the epidemiology of oral contraceptives and disease. Adv.Cancer Res., 49, 285-401.

12. Greenland,S., Schlesselman,J.J., and Criqui,M.H. (1986) The fallacy of employing standardized regression coefficients and correlations as measures of effect. Am.J.Epidemiol., 123, 203-208. 
13. Borenstein M, Hedges L, Higgins J, and Rothstein H. Comprehensive Metaanalysis Version 2. 2005. Englewood NJ, Biostat.

14. Feychting,M., Plato,N., Nise,G., and Ahlbom,A. (2001) Paternal occupational exposures and childhood cancer. Environ Health Perspect., 109, 193-196.

15. Kuijten,R.R., Bunin,G.R., Nass,C.C., and Meadows,A.T. (1992) Parental occupation and childhood astrocytoma: results of a case-control study. Cancer Res., 52, 782-786.

16. Wilkins,J.R., III and Sinks,T. (1990) Parental occupation and intracranial neoplasms of childhood: results of a case-control interview study. Am.J.Epidemiol., 132, 275-292.

17. Efird,J.T., Holly,E.A., Preston-Martin,S., Mueller,B.A., Lubin,F., Filippini,G., Peris-Bonet,R., McCredie,M., Cordier,S., Arslan,A., and Bracci,P.M. (2003) Farm-related exposures and childhood brain tumours in seven countries: results from the SEARCH International Brain Tumour Study. Paediatr.Perinat.Epidemiol., 17, 201-211.

18. Kerr,M.A., Nasca,P.C., Mundt,K.A., Michalek,A.M., Baptiste,M.S., and Mahoney,M.C. (2000) Parental occupational exposures and risk of neuroblastoma: a case-control study (United States). Cancer Causes Control, 11, 635-643.

19. Holly,E.A., Bracci,P.M., Mueller,B.A., and Preston-Martin,S. (1998) Farm and animal exposures and pediatric brain tumors: results from the United States West Coast Childhood Brain Tumor Study. Cancer Epidemiol.Biomarkers Prev., 7, 797-802.

20. Bunin,G.R., Buckley,J.D., Boesel,C.P., Rorke,L.B., and Meadows,A.T. (1994) Risk factors for astrocytic glioma and primitive neuroectodermal tumor of the brain in young children: a report from the Children's Cancer Group. Cancer Epidemiol.Biomarkers Prev., 3, 197-204.

21. McCredie,M., Maisonneuve,P., and Boyle,P. (1994) Perinatal and early postnatal risk factors for malignant brain tumours in New South Wales children. Int.J.Cancer, 56, 11-15.

22. Daniels,J.L., Olshan,A.F., Teschke,K., Hertz-Picciotto,I., Savitz,D.A., Blatt,J., Bondy,M.L., Neglia,J.P., Pollock,B.H., Cohn,S.L., Look,A.T., Seeger,R.C., and Castleberry,R.P. (2001) Residential pesticide exposure and neuroblastoma. Epidemiology, 12, 20-27.

23. Pogoda,J.M. and Preston-Martin,S. (1997) Household pesticides and risk of pediatric brain tumors. Environ.Health Perspect., 105, 1214-1220. 
24. Leiss,J.K. and Savitz,D.A. (1995) Home pesticide use and childhood cancer: a case-control study. Am.J.Public Health, 85, 249-252.

25. Davis,J.R., Brownson,R.C., Garcia,R., Bentz,B.J., and Turner,A. (1993) Family pesticide use and childhood brain cancer. Arch.Environ.Contam Toxicol., 24, 8792.

26. Preston-Martin,S., Yu,M.C., Benton,B., and Henderson,B.E. (1982) N-Nitroso compounds and childhood brain tumors: a case-control study. Cancer Res., 42, $5240-5245$.

27. McKean-Cowdin,R., Preston-Martin,S., Pogoda,J.M., Holly,E.A., Mueller,B.A., and Davis,R.L. (1998) Parental occupation and childhood brain tumors: astroglial and primitive neuroectodermal tumors. J Occup.Environ Med., 40, 332-340.

28. Wilkins,J.R., III and Koutras,R.A. (1988) Paternal occupation and brain cancer in offspring: a mortality-based case-control study. Am J Ind.Med., 14, 299-318.

29. Gold,E.B., Diener,M.D., and Szklo,M. (1982) Parental occupations and cancer in children--a case-control study and review of the methodologic issues. $J$ Occup.Med., 24, 578-584.

30. Tomatis,L., Cabral,J.R., Likhachev,A.J., and Ponomarkov,V. (1981) Increased cancer incidence in the progeny of male rats exposed to ethylnitrosourea before mating. Int.J Cancer, 28, 475-478.

31. Yu,W., Sipowicz,M.A., Haines,D.C., Birely,L., Diwan,B.A., Riggs,C.W., Kasprzak,K.S., and Anderson,L.M. (1999) Preconception urethane or chromium(III) treatment of male mice: multiple neoplastic and non-neoplastic changes in offspring. Toxicol.Appl.Pharmacol., 158, 161-176.

32. Infante-Rivard,C., Labuda,D., Krajinovic,M., and Sinnett,D. (1999) Risk of childhood leukemia associated with exposure to pesticides and with gene polymorphisms. Epidemiology, 10, 481-487. 
Manuscript 4: Identifying gene alterations required for the development of astrocytoma

Brian Kunkle, Changwon Yoo ${ }^{1}$, Quentin Felty, and Deodutta Roy

Departments of Environmental and Occupational Health and ${ }^{1}$ Epidemiology and

Biostatistics, Florida International University, Miami, FL 33199 


\section{ABSTRACT}

Astrocytomas are neoplasms of the brain that originate in a type of glial cell called an astrocyte. Recent advances in high-throughput microarrays have produced a wealth of information concerning molecular biology of glioma. In particular, microarrays have been used to obtain genetic and epigenetic changes between normal non-tumor tissue and glioma tissue. Due to the relative rarity of gliomas, microarray data for these tumors is often the product of small studies, and thus pooling this data becomes desirable. Additionally, analysis of microarray data has been an evolving field as techniques such as cluster analysis, networking analysis and principal components analysis have been used in order to tease biologically relevant information from the large amount of data produced from microarrays. We chose to combine these analytic approaches through first combining available microarray data on gliomas using a meta-analysis approach, and then conducting gene pathway networking analysis on results of this meta-analysis. Our goal in this study was to identify key genes and/or pathways that are critical in the development of astrocytic tumors. We also aim to identify genes and/or pathways that may further the understanding of the differences between low and high grade astrocytic tumors. Several steps were involved in our analysis, including: 1) identification of a significant set of over- and under-expressed genes through meta-analysis of several astrocytoma microarray studies; 2) enrichment analysis of the set of significant genes; 3) network analysis of the set of significant genes; and 4) investigation and validation of the network analysis. Through meta-analysis of 12 sub-studies which compared normal tissue to astrocytomas, we were able to identify a list of 554 genes which were differentially expressed in the majority of these studies. Many of the genes have in fact 
been implicated in development of astrocytoma, including EGFR, HIF-1 $\alpha$, c-Myc, WNT5A, and IDH3A. We then performed reverse engineering of our gene list using Bayesian network analysis. Four networks of genes were produced, one for each grade of Astrocytoma (Grade I-IV). Genes most influential to the highest grade of astrocytoma, Glioblastoma (Grade IV) were: COL4A1, EGFR, BTF3, MPP2, RAB31, CDK4, CD99, ANXA2, TOP2A, and SERBP1. This study was able to identify a set of key genes significantly dysregulated during the development of astrocytoma. Our results suggest that alterations in the expression of eight to ten key genes may be required for the development of astrocytomas. 


\section{BACKGROUND}

Astrocytomas are neoplasms of the brain that originate in a type of glial cell called an astrocyte. They are the most common glioma and their most aggressive form, glioblastoma multiforme, has a median survival of less than one year. While recent studies have characterized much of their basic biology, the major mechanisms behind the development of these tumors still remain unknown. Importantly, while some glioblastomas are thought to evolve from lower grade astrocytomas (secondary glioblastomas), most are thought to arise de novo (primary glioblastomas). Identifying genetic differences between the typically benign lower grade astrocytomas (Grade I-II) malignant higher grade astrocytomas (Grade III-IV) could be an important step in better characterization of these highly malignant tumors (Figure 4-1). In addition, determination of the main pathways and genes involved in their development could provide for better therapies in the future.

Recent advances in high-throughput microarrays have produced a wealth of information concerning glioma biology. In particular, microarrays have been used to obtain differences in gene expression between normal non-tumor tissue and glioma tissue. Due to the relative rarity of gliomas, microarray data for these tumors is often the product of small studies, and thus pooling this data becomes desirable. Additionally, analysis of microarray data has been an evolving field as techniques such as cluster analysis, networking analysis and principal components analysis have been used in order to tease biologically relevant information from the large amount of data produced from microarrays. We chose to combine these analytic approaches through first combining available microarray data on gliomas using a meta-analysis approach, and then 
conducting Bayesian analysis on results of this meta-analysis. Our goal in this approach was to identify key genes and/or pathways that are critical in the development of astrocytic tumors. Our results point to the involvement of several key genes in the development and progression of astrocytoma ( $8-18$ genes depending on the grade of tumor).

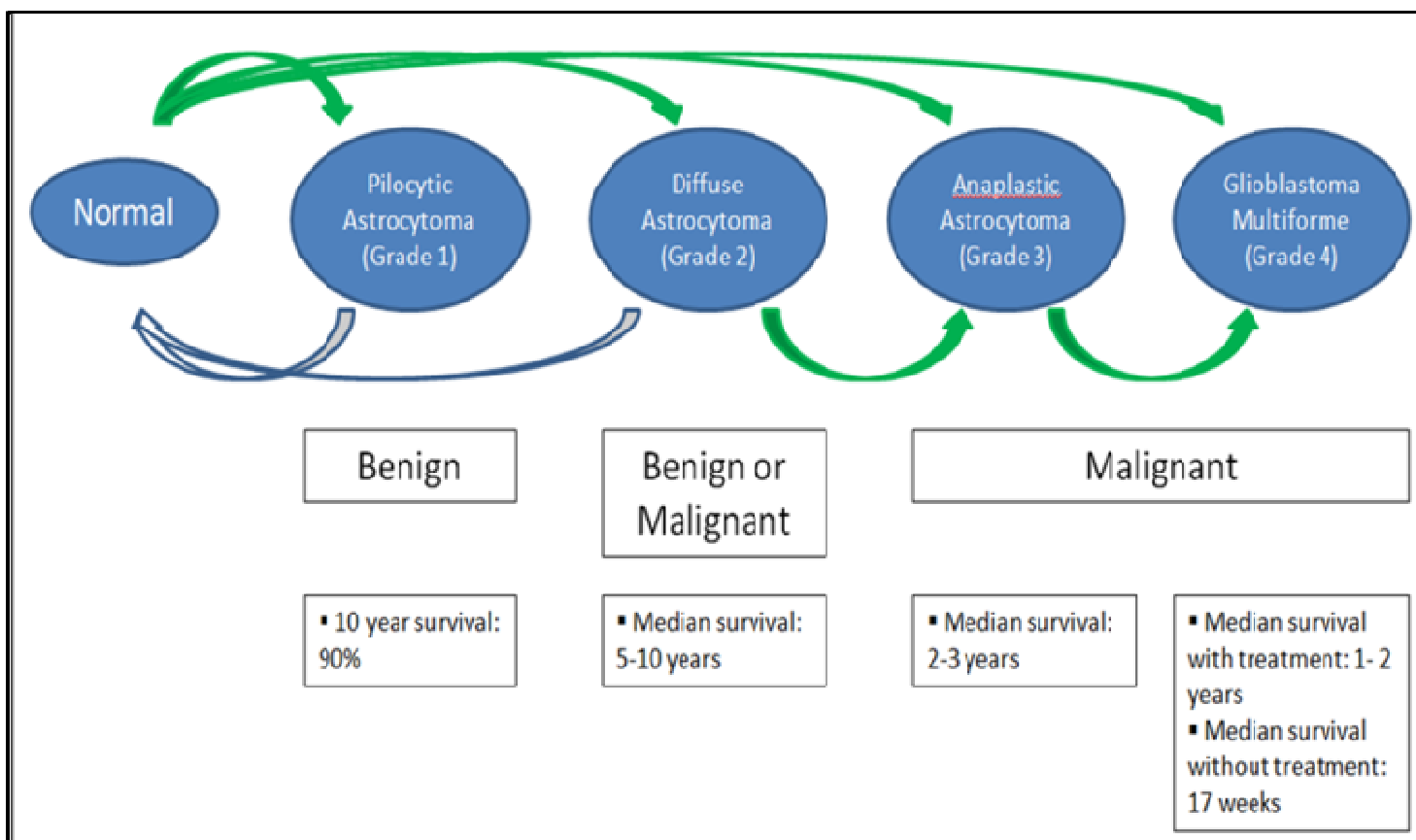

Figure 4-1. Characteristics of progression of Astrocytoma from Grade 1 to Grade 4.

\section{METHODS}

Several steps were involved in our analysis, including: 1) identification of a significant set of over- and under-expressed genes through meta-analysis of several astrocytoma microarray studies; 2) enrichment analysis of the set of significant genes; 3) network analysis of the set of significant genes; and 4) investigation and validation of the network analysis. A more detailed description of these steps follows. 
Meta-analysis of Microarray Datasets: Oncomine (Compendia Bioscience, Ann Arbor, MI), a web-based cancer microarray database, was used to perform meta-analysis of cancer vs. normal studies in Astrocytoma [1]. The goal of this analysis was to identify a set of significantly over-and under-expressed genes in Astrocytoma for further investigation. An Oncomine query for 'Differential Analysis - Cancer vs. Normal Analysis' and 'Cancer Type - Brain and CNS Cancer' was performed to identify studies that compared Astrocytoma to normal tissue. Pilocytic Astrocytoma (WHO Grade I), Diffuse Astrocytoma (WHO Grade II), Anaplastic Astrocytoma (WHO Grade III), and Primary and Secondary Glioblastoma Multiforme (WHO Grade IV) 'sub-studies' were chosen. Only studies analyzing microarray mRNA expression were used for the analysis. For purposes of this paper, 'sub-studies' are defined as studies on brain tumor sub-types within a larger overall study on brain tumors. Studies from our query that compared Astrocytic tumors to normal tissue were then selected for the meta-analysis. Oncomine ranks genes within each individual study based on a gene's p-value compared to all other genes within the study. In meta-analysis, two heat-maps are returned: one for top overexpressed genes and one for top under-expressed genes. Genes in these heat-maps ordered based on their median rank across the selected individual analyses. For our study, the top 600 significantly under-expressed and the top 600 significantly overexpressed genes from meta-analysis were narrowed to our 'significant gene list' by discarding all genes from these 1200 over- and under-expressed genes that were identified in 6 or less of the sub-studies. Thus, a gene was included in our final list of significant genes if it was identified as over- or under-expressed in at least 7 of the 10 
sub-studies. This final set of genes was then subjected to enrichment and pathway analysis with several different tools.

Gene Set Enrichment Analysis: FuncAssociate (Roth Laboratory, Harvard) and Ingenuity Pathway Analysis (IPA) (Redwood City, California) were used to identify pathways and other systems biology characteristics of our top set of genes. FuncAssociate is a web-based tool which performs a Fisher's Exact Test to determine a list of Gene Ontology (GO) attributes that are over- (or under-) represented among a set of genes entered by the user [2]. GO Terms, curated by the Gene Ontology Consortium, identify significant cellular components (e.g. rough endoplasmic reticulum, ribosome), biological processes (e.g. signal transduction, pyrimidine metabolic process), and molecular functions (e.g. catalytic activity, binding, adenylate cyclase activity) of a set of genes [3]. Our significant gene list from Oncomine was entered into FuncAssociate for analysis. Settings were species: Homo sapiens; namespace: HGNC_Symbol; mode: ordered; simulations: 1000; over/under: both; and p-value cutoff: 0.05 . The HGNC Symbol namespace setting resulted in our choosing the entire known human genome as our universe of comparison genes for the enrichment analyses.

IPA was also used to analyze our Oncomine gene list. This web-based program uses a manually curated database of findings from the scientific literature, along with data obtained from the Kyoto Encyclopedia of Genes and Genomes (KEGG), to analyze connections between genes, proteins, and other molecules. It also uses its own terminology for functional classifications of these molecules that is similar but not exact to the terminology used by GO. Enrichment analysis was performed using IPA's "Core Analysis" function. Whereas GO Terms do not relate significant pathways of a set of 
genes, IPA Core Analysis does have this ability and therefore was used both to identify significant biological processes/molecular functions and to identify any pathways that were more commonly activated or inactivated in our set of genes. Significance of the identified processes and pathways is given by the right-tailed Fisher exact test p-value, meaning only overrepresented attributes are returned by IPA. The IPA default reference set of molecules, which includes all functionally-characterized molecules in IPA, was used as the universe of comparison genes. Several groups of processes are identified, including: biological functions ('Bio Functions'), toxicological functions ('Tox Functions'), and established pathways ('Canonical Pathways'). The number of molecules from a set of data found to be in a pathway, divided by the total number of molecules in the identified canonical pathway is given.

Reverse Engineering Bayesian Network Analysis: Bayesian networks have been widely used and accepted in modeling molecular networks from microarray data $[4 ; 5]$. These networks are probabilistic graphical models that produce directed acyclic graphs (DAG) that represent a set of random variables and their conditional dependencies. Nodes of the DAG represent genes or other variables such as disease and are assumed to be conditionally independent of each other. The structures produced by Bayesian network analysis naturally represent causal hypotheses.

We used the software application Banjo (Duke University, NC) for probabilistic structure learning of static Bayesian networks from our steady state expression data from Oncomine [6]. Banjo performs structure inference using a local search strategy termed Bayesian Dirichlet equivalence (BDe) scoring metric for discrete variables. This strategy 
makes incremental changes in the structure aimed at improving the score of the structure. A score for the 'best network', influence scores for the edges of the best network, and a dot graphical layout file are returned as results of the search. The dot file is a DAG indicating regulation among genes and their possible influence on disease outcome.

The goal of this Bayesian analysis was to identify what may be the most critical genes for development of astrocytoma from our significant set of meta-analysis genes. This was accomplished by identifying a Markov blanket of each network output chosen as the 'best network' for each grade of astrocytoma. In a Bayesian network, the Markov blanket of any node $A$ is its set of neighboring nodes composed of a nodes parents, children, and the parents of its children. This defined set of neighboring nodes shields node $A$ from the rest of the network, and thus the Markov blanket of node $A$ is the only knowledge needed to predict the behavior of node $A$.

Though its sensitivity is low, Banjo has been shown to have a very high positive predictive value for 100 plus case sets (regardless of the number of genes) composed of the type of 'global', steady-state gene data we analyzed [7]. For an overview of Bayesian network probability structures the reader is referred to Charniak 1991 [8]. Several other papers provide more detailed information on their construction and examples of their use with molecular modeling [5;9-12].

To perform the analysis on our data, expression values for our significant set of genes were downloaded from Oncomine and loaded into Microsoft Excel. The top 100 overexpressed genes and top 100 under-expressed genes were then considered for analysis in Banjo. In order to increase our sample size, missing cases imputation was performed on cases with missing expression data for a particular gene using average of all expression 
values across the gene as the imputation. Cases without Grade identification and/or identified as non-tissue cases (i.e. cell lines) were excluded from the analysis. Studies from our meta-analysis with missing data for a large amount of genes were also excluded. The expression data for the remaining genes was then separated by Grade, discretized per study (due to Oncomine normalizing expression values per study), and combined for analysis in Banjo. Discretization of the data into three tiers expression (under-, median-, and over-expressed) was performed using the programming software tool Perl. Assuming normally distributed data, the three tiers were selected based on a one standard deviation confidence interval (i.e. $\sim 68 \%$ of the values will have 'median-expression', with $\sim 16 \%$ of the values under-expressed and $\sim 16 \%$ of the values over-expressed). Discretized files were then run in Banjo for four separate analyses: 1) Normal Tissue vs. Grade I Pilocytic Astrocytoma cases, 2) Normal Tissue vs. Grade II Diffuse Astrocytoma cases, 3) Normal Tissue vs. Grade III Anaplastic Astrocytoma, and 4) Normal Tissue vs. Grade IV Glioblastoma Multiforme cases. Analyses was performed on the four Grades three separate times (three hours in length for each network search), with the 'best network' from these three runs being chosen as our 'final best network' for each Grade. Best network score significance was calculated using a log calculation of all three network scores, with a percent of the total score returned for each network.

Investigation of Bayesian Network Results: Several methods were used to investigate and validate both the prediction capabilities and the biological plausibility of our Markov network genes. They included literature and biological database searches, prediction analysis and clustering analysis, and curated gene and pathway analysis. The literature 
and database search of our Markov genes gathered information on gene cellular localization and function, and published research supporting the genes involvement in tumor formation by searching biological databases such The Human Gene Compendium's GeneCards (www.genecards.org), PubMed (www.pubmed.com), the Information Hyperlinked over Proteins (iHOP) Database (www.ihop-net.org), and the Glioblastoma Multiforme Database (GBMBase) (www.gbmbase.org).

To assess the ability of our Markov genes to distinguish between normal and tumor samples in our analysis, we performed several prediction analyses including receiver operating characteristic (ROC) curve analysis representing the Bayesian network discretized results; and linear regression, logistic regression, cross validation and support vector machine (SVM) analysis to assess the predictability of both the discretized and raw expression values of our Markov genes. Hierarchical Clustering was also performed on each set of Markov genes in order to further explore how these genes separated our set of non-tumor and tumor patients. These analyses were performed using both IBM SPSS Statistics 19.0 and Multi-Experiment Viewer $(\mathrm{MeV})$ version 4.7.1.

Genie, a software tool for analyzing Bayesian networks developed by the University of Pittsburgh [13], was used to predict the probability of developing Astrocytoma given certain expression states for its gene network. In Bayesian network analysis this is done by learning the parameters of a given DAG structure. To accomplish this task, the discretized results files for each Grade of astrocytoma were loaded into the Genie software. Additionally, the Banjo network structure results were recreated in Genie. Genie's 'learn parameters' function was then used to predict probabilities of outcomes for certain network structures. Given our small sample sizes, we did not allow a probability 
of 0 to be assigned to any result, choosing instead to use 0.01 for any probability calculated as 0 . This allowed us to perform parameter assessment under the assumption that a low probability case may still have a very small chance of occurring in our data. Once our network parameters were established in Genie, we analyzed the probability of developing each grade of astrocytoma given differentially expressed states of the Markov genes of each grade. This was done assuming the 2005-2007 Surveillance, Epidemiology and End Results (SEER) calculated lifetime probability of diagnosis of cancer of the brain and other nervous system of $0.61 \%$ [14]. (NOTE: This analysis was performed for Grade IV Astrocytoma only).

In order to investigate existing literature and ontology based connections between our Markov gene lists we used programs in both IPA and PathJam [15]. The goal of these analyses was to investigate a) the quality of our network analysis findings in Banjo and Genie, and b) the biological relationships of our Markov genes from these analyses. The initial investigation was done using the Path Explorer feature of IPA. Path Explorer uses curated literature and experimental evidence of biochemical interactions to produce networks of existing connections between a set of user imputed genes. This function was used to search for any existing connections among the Grade IV Astrocytoma Markov Genes.

IPA's Core Analysis was then performed on these same Grade IV Astrocytoma Markov Genes in order to produce connections for a set of genes independent of their established pathways. This analysis generated gene networks produced by including genes in pathways of the inputted gene list. Networks are ordered in importance by an IPA-defined significance score. Settings for this analysis were Direct and Indirect 
Relationships, All Data Sources, All Species, and All Tissues \& Cell Lines. The Human Genome U133 Plus 2.0 Array (19,079 genes) was selected as our reference universe of genes as it contained the largest gene set from our meta-analysis and was used in 2 of the 5 meta-analysis studies used for our Banjo analysis. The top identified network from the Core Analysis was compared to our Banjo/Genie generated results. Complementary to this Core Analysis's production of top biological and disease related functions was our investigation of our Markov genes using PathJam [15]. This public server-based tool allows for interpretation of gene lists by integrating pathwayrelated annotations from several public sources including Reactome, KEGG, NCBI Pathway Interaction Database, and Biocarta. Using this tool we were able to produce interactive graphs linking all four Astroctyoma Markov gene lists with pathway annotations, allowing for graphical pathway investigation into our gene lists.

\section{RESULTS}

Meta-analysis of Microarray Datasets: A total of 12 studies (with 27 sub-studies) conducting cancer vs. normal analysis on 'Brain and CNS Cancer' were identified in Oncomine. Non-astrocytic tumor studies and studies analyzing DNA (i.e. acCGH arrays) were then discarded, leaving seven studies (10 sub-studies) on astrocytoma for the metaanalysis. These 10 sub-studies are listed in Table 4-1.

The top 600 significantly over-expressed and top 600 significantly under-expressed genes were identified from a total of 10 'sub-studies'. The narrowing of the initial list of 1200 genes produced a total of 646 genes for further analysis (372 significantly overexpressed genes and 274 significantly under-expressed genes). A list of these genes can 
be found in Table 1 and Table 2 of the Appendix. It should be noted that Primary and Secondary Glioblastomas were separated within only one of the nine studies identified as Astrocytoma in Oncomine (Bredel: 27 Primary vs. 2 Secondary Glioblastomas). Therefore, separation of these subtypes of Glioblastomas was not considered in our study.

Table 4-1. List of Oncomine studies in meta-analysis of Astrocytoma vs. Normal Studies.

\begin{tabular}{lcc}
\hline Oncomine Study ID, Publication Journal, Date & Study Astrocytoma Type* & $\begin{array}{c}\text { n } \\
\text { (tumor/normal) }\end{array}$ \\
\hline Bredel Brain 2, Cancer Res, 2005 [16] & Glioblastoma & $27 / 4$ \\
Gutmann Brain, Cancer Res, 2002 [17] & Pilocytic Astrocytoma & $8 / 3$ \\
Lee Brain, Cancer Cell, 2006 [18] & Glioblastoma & $22 / 3$ \\
Liang Brain, Proc Natl Acad Sci USA, 2005 [19] & Glioblastoma & $30 / 3$ \\
Rickman Brain, Cancer Res, 2001 [20] & Astrocytoma & $45 / 6$ \\
Shai Brain, Oncogene, 2003 [21] & Astrocytoma & $5 / 7$ \\
Shai Brain, Oncogene, 2003 [21] & Glioblastoma & $27 / 7$ \\
Sun Brain, Cancer Cell, $2006[\mathbf{2 2}]$ & Anaplastic Astrocytoma & $19 / 23$ \\
Sun Brain, Cancer Cell, 2006 [22] & Diffuse Astrocytoma & $7 / 23$ \\
Sun Brain, Cancer Cell, 2006 [22] & Glioblastoma & $81 / 23$ \\
\hline
\end{tabular}

* All studies are Astrocytoma tissue type vs. normal tissue.

Gene Set Enrichment Analysis: In order to identify significant biological processes, molecular functions, and pathways of the final set of 646 genes, we conducted enrichment analysis on this set of genes. As described in the methods, two separate programs were used for this analysis: FuncAssociate and IPA.

FuncAssociate Results: FuncAssociate identified 60 GO Terms as being overrepresented and $1 \mathrm{GO}$ Term as being under-represented among our set of 314 overexpressed genes (Table 4-2 and Table 4-3). Several significant processes were related to nervous system processes (axon part, postsynaptic density, synapse part, synaptic transmission, neuron projection), developmental processes (cell part morphogenesis, cellular component morphogenesis, regulation of anatomical structure morphogenesis, 
anatomical structure morphogenesis, regulation of developmental process, anatomical structure development, development process), and several cellular processes associated with cancer (cell adhesion, biological adhesion, regulation of cell proliferation, regulation of apoptosis). Several genes involved in developmental processes have been linked to brain tumor development. 147 genes of our list of 646, in fact, were categorized in the GO developmental process terms listed above. Several of these genes, including MYC, EGFR, HIF1A, HGF, APOE, TIMP3, and WNT5A have been identified as being important to development of astrocytoma.

Table 4-2. Significant over-represented GO Terms for differentially expressed genes in Astrocytoma.

\begin{tabular}{|c|c|c|c|}
\hline Rank & p-adjusted & GO ID & GO Name \\
\hline 1 & 0.006 & GO:0019829 & Cation-transporting ATPase activity \\
\hline 2 & 0.036 & GO:0033267 & Axon part \\
\hline 3 & 0.04 & GO:0005938 & Cell cortex \\
\hline 4 & 0.04 & GO:0014069 & Postsynaptic density \\
\hline 5 & 0.013 & GO:0044420 & Extracellular matrix part \\
\hline 6 & 0.019 & GO:0032990 & Cell part morphogenesis \\
\hline 7 & 0 & GO:0032989 & Cellular component morphogenesis \\
\hline 8 & 0 & GO:0019900 & Kinase binding \\
\hline 9 & 0 & GO:0044456 & Synapse part \\
\hline 10 & 0.011 & GO:0019901 & Protein kinase binding \\
\hline 11 & 0.001 & GO:0010035 & Response to inorganic substance \\
\hline 12 & 0.002 & GO:0007268 & Synaptic transmission \\
\hline 13 & 0 & GO:0043005 & Neuron projection \\
\hline 14 & 0 & GO:0044419 & Interspecies interaction between organisms \\
\hline 15 & 0.002 & GO:0044057 & Regulation of system process \\
\hline 16 & 0.013 & GO:0022603 & Regulation of anatomical structure morphogenesis \\
\hline 17 & 0 & GO:0019899 & Enzyme binding \\
\hline 18 & 0 & GO:0008092 & Cytoskeletal protein binding \\
\hline 19 & 0 & GO:0007155 & Cell adhesion \\
\hline 20 & 0 & GO:0022610 & Biological adhesion \\
\hline 21 & 0 & GO:0042127 & Regulation of cell proliferation \\
\hline 22 & 0 & GO:0042995 & Cell projection \\
\hline 23 & 0 & GO:0005515 & Protein binding \\
\hline 24 & 0.007 & GO:0005509 & Calcium binding \\
\hline 25 & 0 & GO:0008150 & Biological process \\
\hline 26 & 0.001 & GO:0010033 & Response to organic substance \\
\hline 27 & 0 & GO:0023034 & Intracellular signaling pathway \\
\hline 28 & 0 & GO:0044459 & Plasmamembrane part \\
\hline 29 & 0.013 & GO:0045907 & Intracellular transport \\
\hline 30 & 0.001 & GO:0009653 & Anatomical structure morphogenesis \\
\hline 31 & 0.011 & GO:0050793 & Regulation of developmental process \\
\hline
\end{tabular}




\begin{tabular}{cccl}
\hline Rank & p-adjusted & GO ID & GO Name \\
\hline $\mathbf{3 2}$ & 0.011 & GO:0051239 & Regulation of multicellular organismal process \\
\hline $\mathbf{3 3}$ & 0.016 & GO:0010646 & Regulation of cell communication \\
$\mathbf{3 4}$ & 0.013 & GO:0035466 & Regulation of signaling pathway \\
$\mathbf{3 5}$ & 0.035 & GO:0045184 & Establishment of protein localization \\
$\mathbf{3 6}$ & 0.035 & GO:0042981 & Regulation of apoptosis \\
$\mathbf{3 7}$ & 0 & GO:0005488 & Binding \\
\hline $\mathbf{3 8}$ & 0.033 & GO:0050790 & Regulation of catalytic activity \\
$\mathbf{3 9}$ & 0.015 & GO:0065009 & Regulation of molecular function \\
$\mathbf{4 0}$ & 0.03 & GO:0031226 & Intrinsic to plasma membrane \\
$\mathbf{4 1}$ & 0 & GO:0048518 & Positive regulation of biological process \\
$\mathbf{4 2}$ & 0.006 & GO:0042221 & Response to chemical stimulus \\
$\mathbf{4 3}$ & 0 & GO:0048522 & Positive regulation of cellular process \\
$\mathbf{4 4}$ & 0.015 & GO:0065008 & Regulation of biological quality \\
$\mathbf{4 5}$ & 0 & GO:0043234 & Protein complex \\
$\mathbf{4 6}$ & 0.001 & GO:0048519 & Negative regulation of biological process \\
$\mathbf{4 7}$ & 0 & GO:0009987 & Cellular process \\
$\mathbf{4 8}$ & 0.016 & GO: 0048856 & Anatomical stucture development \\
$\mathbf{4 9}$ & 0.011 & GO:0048523 & Negative regulation of cellular process \\
$\mathbf{5 0}$ & 0 & GO:0005737 & Cytoplasm \\
$\mathbf{5 1}$ & 0 & GO: 0032502 & Developmental process \\
\hline $\mathbf{5 2}$ & 0.002 & GO:0005886 & Plasma membrane \\
$\mathbf{5 3}$ & 0.007 & GO:0016043 & Cellular component organization \\
$\mathbf{5 4}$ & 0.005 & GO:0023052 & Signaling \\
$\mathbf{5 5}$ & 0 & GO:0044444 & Cytoplasmic part \\
\hline $\mathbf{5 6}$ & 0.006 & GO:0032991 & Mactromolecular complex \\
$\mathbf{5 7}$ & 0 & GO:0065007 & Biological regulation \\
$\mathbf{5 8}$ & 0.002 & GO:0050789 & Regulation of biological process \\
$\mathbf{5 9}$ & 0.005 & GO:0050794 & Regulation of cellular process \\
$\mathbf{6 0}$ & 0.013 & GO:0044424 & Intracellular part \\
\hline & & & \\
\hline
\end{tabular}

Table 4-3. Significant under-represented GO Terms for differentially expressed genes in Astrocytoma.

\begin{tabular}{cccl}
\hline Rank & p-adjusted & GO ID & GO Name \\
\hline $\mathbf{1}$ & 0.006 & GO: 0004984 & Olfactory receptor activity \\
\hline
\end{tabular}

Ingenuity Pathway Analysis Results: IPA produced similar and contrasting results to the above analysis using FuncAssociate. Top Canonical Pathways identified for the overexpressed gene list include: ‘Synaptic Long Term Potentiation' (p-value: 6.25E-07; Ratio of molecules in pathway from user list/total molecules in pathway: 16/113), 'IL-8 Signaling' (p-value: 7.41E-07; Ratio: 20/186), 'G Beta Gamma Signaling' (p-value: 9.48E-07; Ratio: 15/119), 'CXCR4 Signaling' (p-value: 1.1E-06; Ratio: 19/167), and 
'Cholecystokinin/Gastrin-mediated Signaling' (p-value: 1.39E-06; Ratio: 15/104) (Figure 4-2). Several pathways known to be important to glioma development were also at the top of the significant canonical pathways list, including 'WNT/beta-Catenin Signaling' (CD44, CDH2, DVL3, LRP1, MYC, SOX4, SOX9, SOX13, TCF3, TCF4, TLE3, WNT5A) and 'mTOR Signaling' (EIF3B, EIF3E, EIF3F, EIF4A1, HIF1A, PRKD1, RHOC, RND2, RND3). Confirming our gene list as involved with brain tumor development, 'Glioma Invasiveness Signaling' (CD44, F2R, ITGAV, MMP9, RHOC, RND2, RND3, TIMP3, TIMP4) and 'Glioblastoma Multiforme Signaling' (CDK6, CDKN1A, EGFR, ITPR2, MYC, RHOC, RND2, RND3, TCF3, WNT5A) were returned as significant pathways as well.

IPA Core Analysis also returns what are termed 'Top Bio Functions', grouped into three categories: Diseases and Disorders, Molecular and Cellular Functions, and Physiological System Development and Function. Significant functions are returned with their associated p-value and \# of input molecules in the function. The top 5 Disease and Disorders for our list of 554 astrocytoma differentially expressed genes were: 'Neurological Disease' (p-value: 1.17E-25 - 4.98E-04; 270 molecules from our list), 'Cancer' (3.83E-24 - 5.61E-04; 240 molecules), 'Skeletal and Muscular Disorders' (2.32E-19 - 4.42E-04; 206 molecules), ‘Genetic Disorder’ (3.04E-17 - 5.27E-04; 354 molecules), and 'Inflammatory Disease' (2.20E-16 - 4.92E-04; 195 molecules). The top 5 Molecular and Cellular Functions were 'Cell Death' (1.36E-21 - 5.81E-04; 205 molecules), 'Cellular Growth and Proliferation' (1.23E-14 - 4.48E-04; 203 molecules), 'Cell Morphology' (2.51E-14 - 4.82E-04; 99 molecules), 'Cellular Movement' (1.08E-11 - 4.58E-04; 116 molecules), and 'Cell Cycle' (5.83E-11 - 5.61E-04; 91 molecules). 


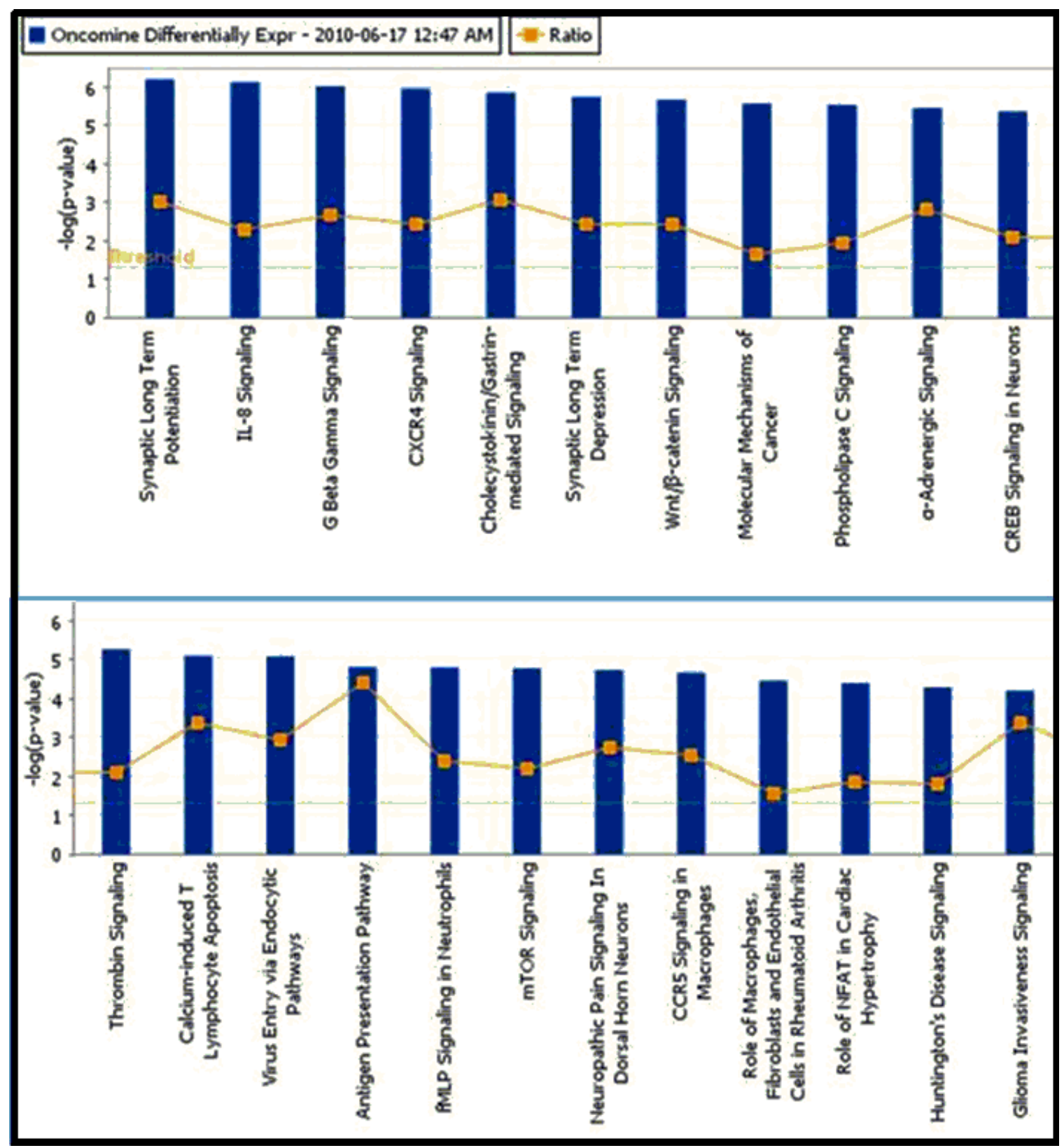

Figure 4-2. Top Canonical Pathways for Astrocytoma differentially expressed genes. The threshold line denotes the cutoff for significance ( $p$-value $=0.05$ ). Ratio is the number of molecules in the input list vs. the total number of molecules in the function.

The top 5 Physiological System Development and Functions were 'Tissue Development' (1.65E-09 - 5.79E-04; 105 molecules), 'Skeletal and Muscular System Development and Function' (1.67E-09 - 2.96E-04; 54 molecules), 'Tissue Morphology' 
(7.04E-08 - 1.35E-04; 78 molecules), 'Nervous System Development and Function' (1.48E-07E - 3.65E-04; 96 molecules), and 'Behavior' (1.67E-07 - 3.09E-04; 47 molecules). Figure 4-3 shows these top Bio Functions in order of significance. When interpreting these results, it is important to keep in mind that the p-values refer to the High Level Functions rather than to individual Lower-Level Functions, and therefore, if a High Level Function contains two or more specific Lower-Level Functions, a range of significances is displayed.

Core Analysis also produces Top Toxicity Profiles. The Top 5 profiles for our 554 differentially expressed genes were 'Hepatic Fibrosis' (p-value: 3.59E-06; Ratio of molecules: 13/85), 'Hepatic Cholestasis' (p-value: 4.77E-03; Ratio: 11/135), 'G1/S Transition of the Cell Cycle' (p-value: 5.02E-03; Ratio: 6/49), 'Oxidative Stress' (pvalue: 1.05E-02; Ratio: 6/57), and 'VDR/RXR Activation' (p-value: 1.28E-02; Ratio: 7/77) (Figure 4-4). 


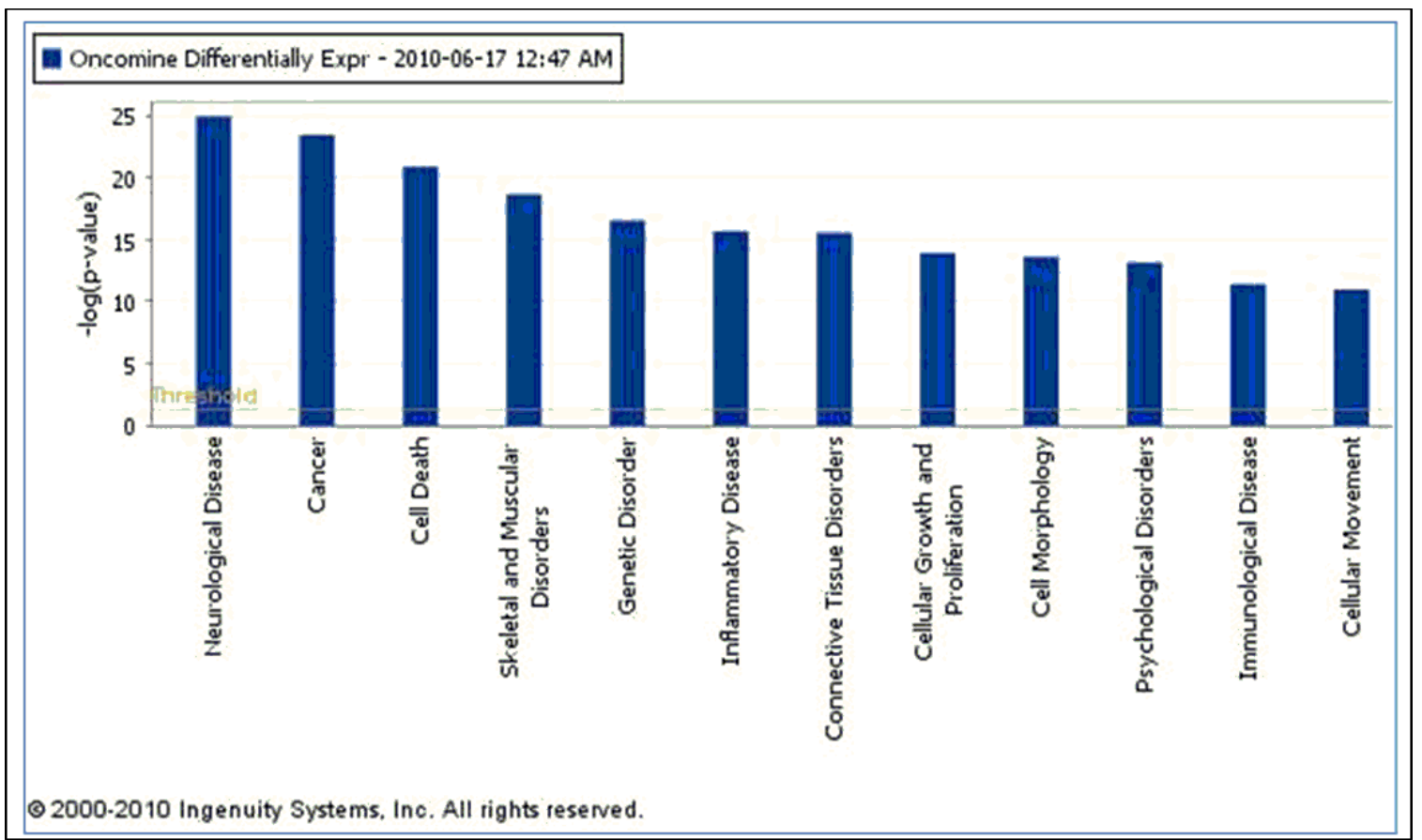

Figure 4-3. Top Biological Functions for Astrocytoma differentially expressed genes. The threshold line denotes the cutoff for significance $(p$-value $=0.05)$.

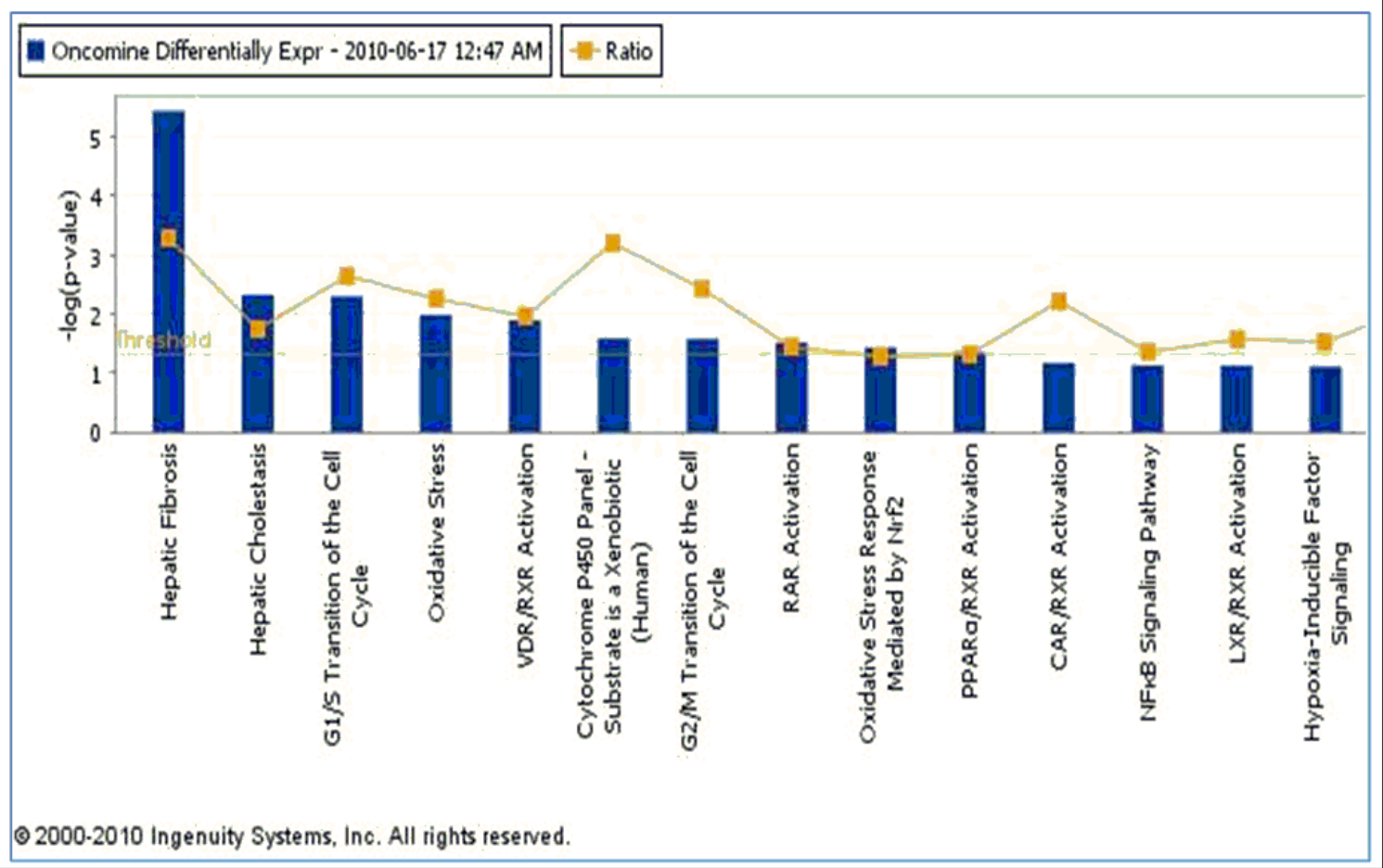

Figure 4-4. Top Toxicological Functions for Astrocytoma differentially expressed genes. The threshold line denotes the cutoff for significance ( $p$-value $=0.05$ ). Ratio is the number of molecules in the input list vs. the total number of molecules in the function. 
Reverse Engineering Bayesian Network Analysis: Four separate analyses were run in Banjo in order to search for genes critical for Grade I, II, III and IV Astrocytoma development. As discussed in the methods, studies and/or genes with missing expression data were excluded from the network analysis. Studies removed for both analyses were Bredel 2005, Liang 2005, and Rickman 2001. Additionally, Gutmann 2002 was removed from the Grade IV analyses as it did not contain Grade IV tumors. Genes were removed from our top 200 genes list (100 over- and 100 under-expressed genes) for each analyses based on availability per Grade. 77 genes were removed for Grade 1, 68 for Grade 2, and 23 each for Grades 3 and 4. Please see Table 4-4 for sample size and search score results for each grade of tumor. Markov blanket genes identified for each grade were as follows:

- Grade I Pilocytic Astrocytoma: IGFB5, TIMP4, SSR2, LPL, DUSP7, GABRA5, SH3GL3, C1S, WNT10B, SRPX, ANK3, HLAA, EIF4A1, PTGER3, CCND2

- Grade II Diffuse Astrocytoma: FN1, MARCKS, PRDX4, NONO, SPARC, WNT5A, CD44, EIF4A1, CD99, CALCRL, EMP1, VCAN, CDH11, VAMP1, RAB3B, DUSP7, PPP2R2B, SERINC3

- Grade III Anaplastic Astrocytoma: LPL, MARCKS, SERBP1, DPYSL3, SNRPE, EIF4A1, ANXA1, MCM3, BTN3A3, MTHFD2, DAB2, RCAN2, RUSC2, TPPP, MAST3, CNTN2

- Grade IV Glioblastoma Multiforme: COL4A1, EGFR, BTF3, MPP2, RAB31, CDK4, CD99, ANXA2, TOP2A, SERBP1

DAG structures for these Markov genes can be seen in Figures 4-5, 4-6, 4-7, and 4-8. A comparison of these Markov genes across each grade of Astrocytoma can be found in Appendix Table 3. 
Table 4-4. Sample statistics and significance of search score results of Bayesian network analysis.

\begin{tabular}{|c|c|c|c|c|c|c|c|}
\hline & \multirow{2}{*}{$\begin{array}{l}\text { Studies in } \\
\text { Analysis }\end{array}$} & \multirow{2}{*}{ Normal } & \multirow{2}{*}{ Tumor } & \multirow{2}{*}{$\begin{array}{c}\text { Genes } \\
\text { Analyzed } \\
\text { for Network }\end{array}$} & \multicolumn{3}{|c|}{$\begin{array}{c}\text { Bayesian Analysis Network Score } \\
\text { Significance* }\end{array}$} \\
\hline & & & & & Search 1 & Search 2 & Search 3 \\
\hline $\begin{array}{l}\text { Normal vs. } \\
\text { Grade } 1\end{array}$ & $\begin{array}{c}\text { Bredel, } \\
\text { Gutmann, } \\
\text { Rickman }\end{array}$ & 13 & 30 & 122 & $1.37 \%$ & $98.16 \%$ & $0.46 \%$ \\
\hline $\begin{array}{l}\text { Normal vs. } \\
\text { Grade II }\end{array}$ & $\begin{array}{l}\text { Rickman, } \\
\text { Shai, Sun }\end{array}$ & 36 & 14 & 131 & $9.11 \%$ & $6.62 \%$ & $84.62 \%$ \\
\hline $\begin{array}{l}\text { Normal vs. } \\
\text { Grade III }\end{array}$ & $\begin{array}{l}\text { Bredel, } \\
\text { Shai, Sun }\end{array}$ & 34 & 23 & 176 & $1.98 \%$ & $0.04 \%$ & $99.95 \%$ \\
\hline $\begin{array}{l}\text { Normal vs. } \\
\text { Grade IV }\end{array}$ & $\begin{array}{l}\text { Bredel, } \\
\text { Shai, Sun }\end{array}$ & 34 & 137 & 176 & $0.00 \%$ & $0.00 \%$ & $99.99 \%$ \\
\hline
\end{tabular}

*Significance score for each network equals percent of total score for all three networks combined.

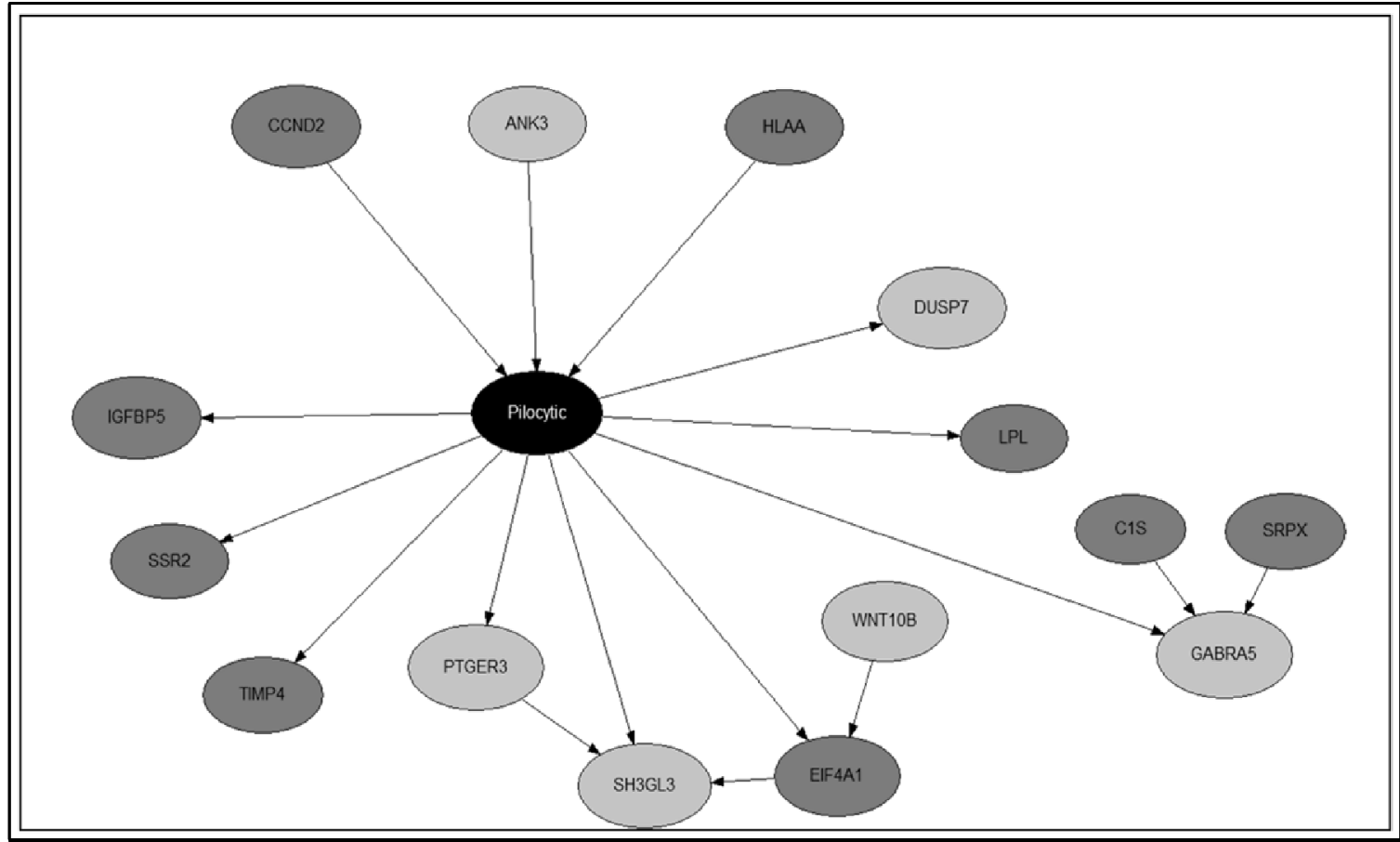

Figure 4-5. Markov blanket genes for Bayesian network of Pilocytic Astrocytoma. Darker shade genes are overexpressed genes and lighter shade genes are underexpressed genes from the Oncomine meta-analysis. 


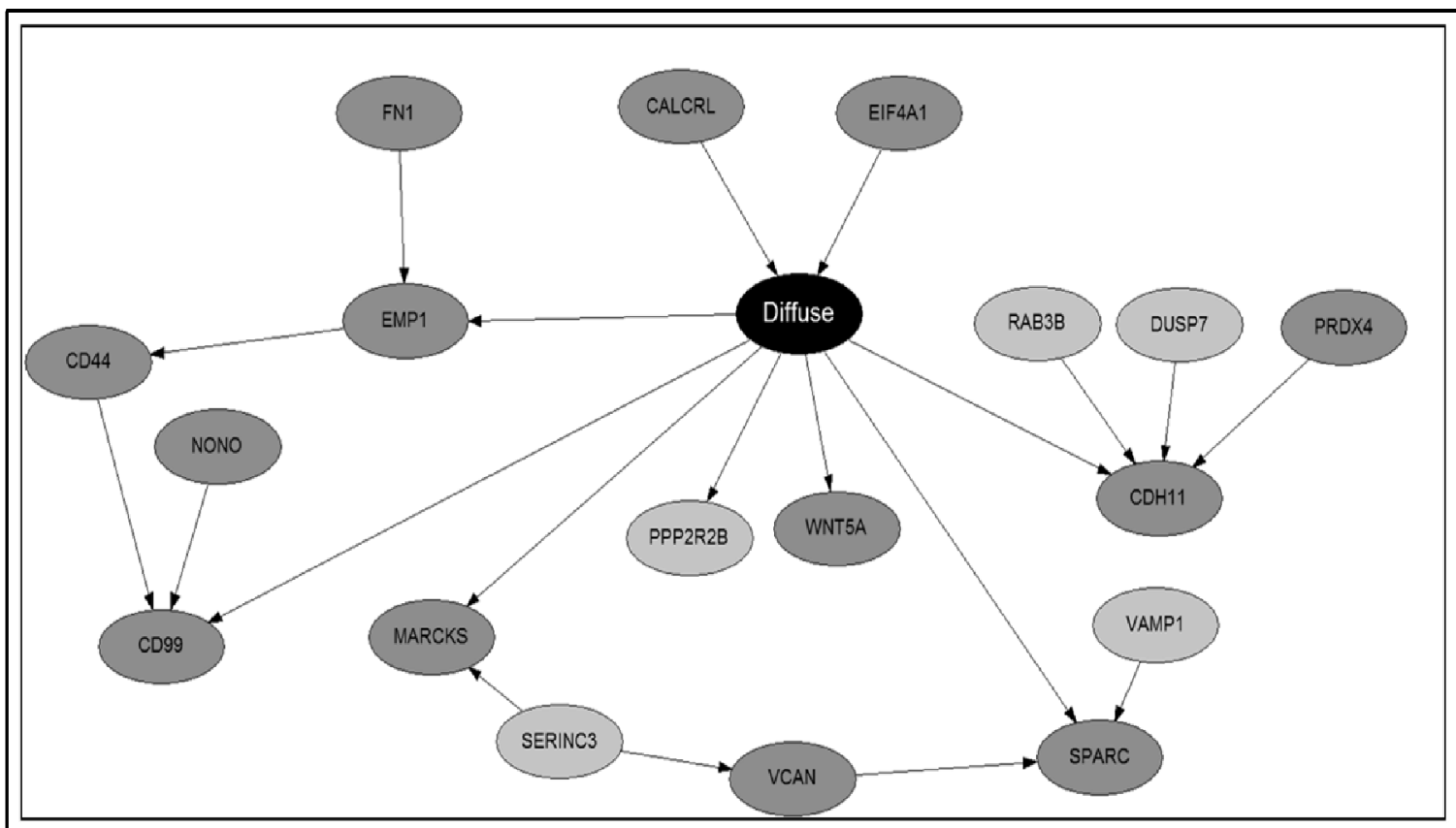

Figure 4-6. Markov blanket genes for Bayesian network of Diffuse Astrocytoma. Darker shade genes are overexpressed genes and lighter shade genes are underexpressed genes from the Oncomine meta-analysis.

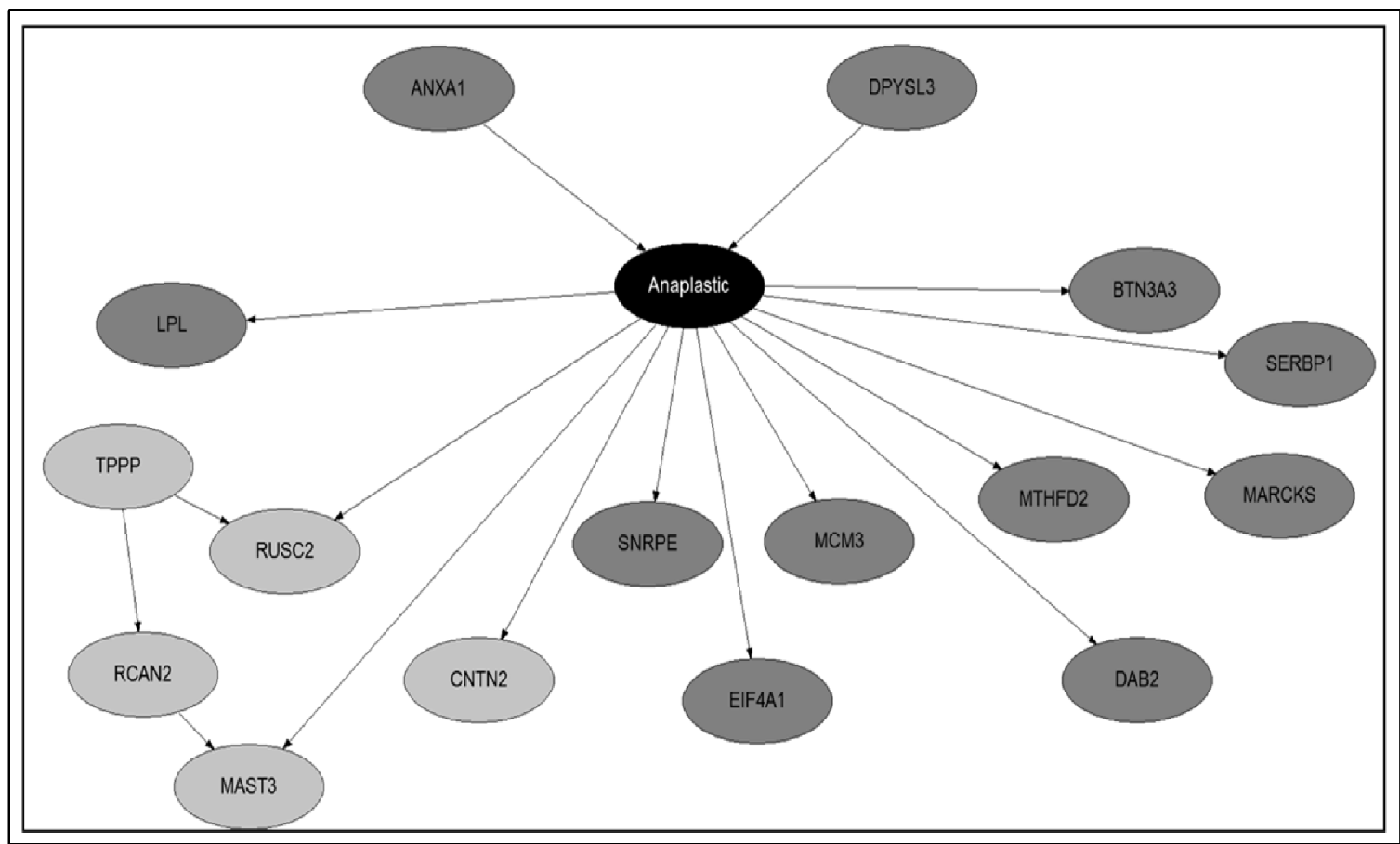

Figure 4-7. Markov blanket genes for Bayesian network of Anaplastic Astrocytoma. Darker shade genes are overexpressed genes and lighter shade genes are underexpressed genes from the Oncomine meta-analysis. 


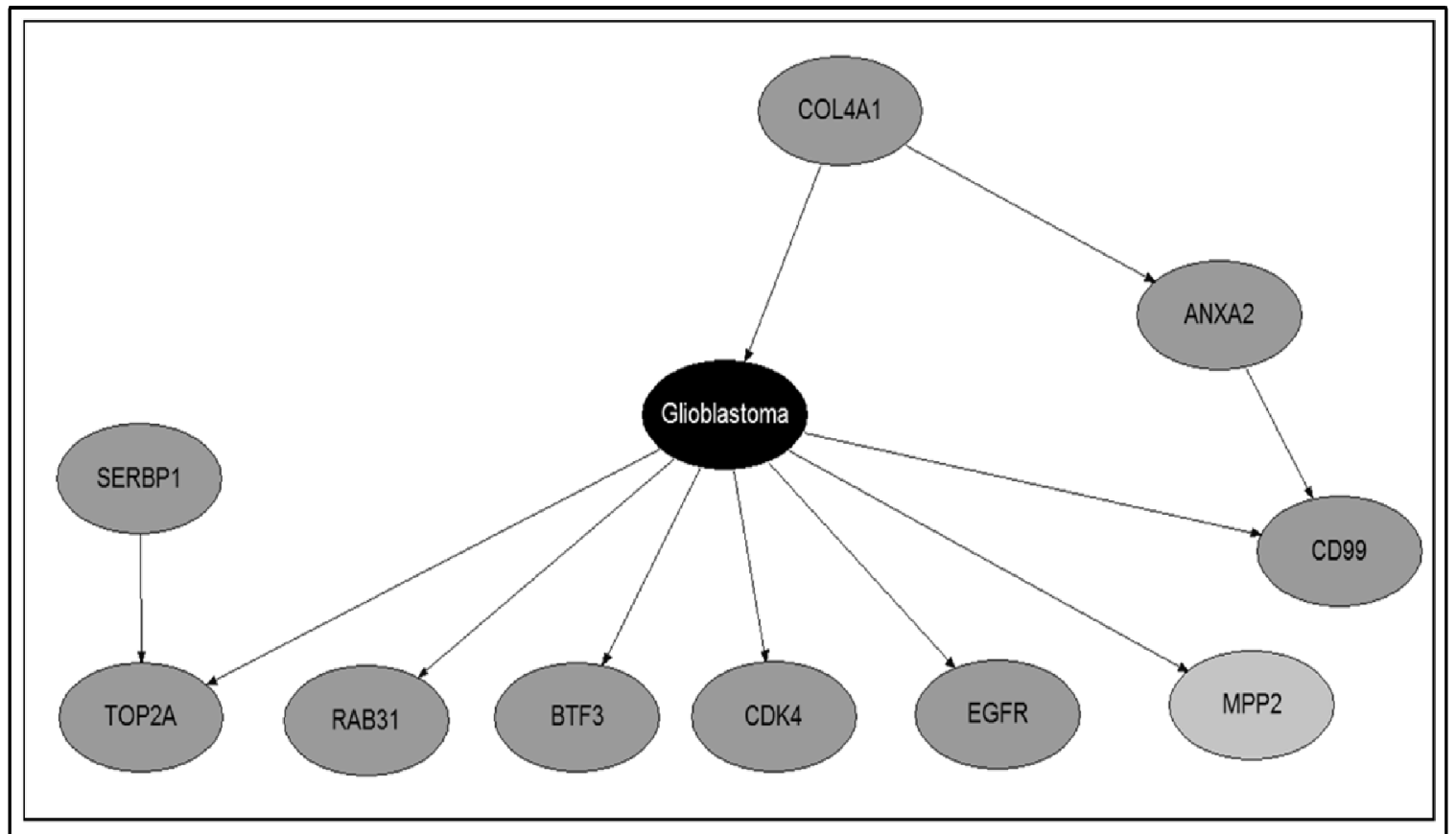

Figure 4-8. Markov blanket genes for Bayesian network of Glioblastoma Multiforme. Darker shade genes are overexpressed genes and lighter shade genes are underexpressed genes from the Oncomine meta-analysis.

Analysis of Bayesian Network Results

Normal Tissue vs. Grade I Astrocytoma: Prediction analysis of the 15 Grade I Markov genes showed that the 15 gene set we identified as important for Pilocytic Astrocytoma development was able to predict tumor status consistently in each analysis type (Table 4-5). Results of hierarchical clustering using expression data from our Markov genes can be found in Figure 4-9. Results of the PathJam analysis can be found in Appendix Figure 1. 


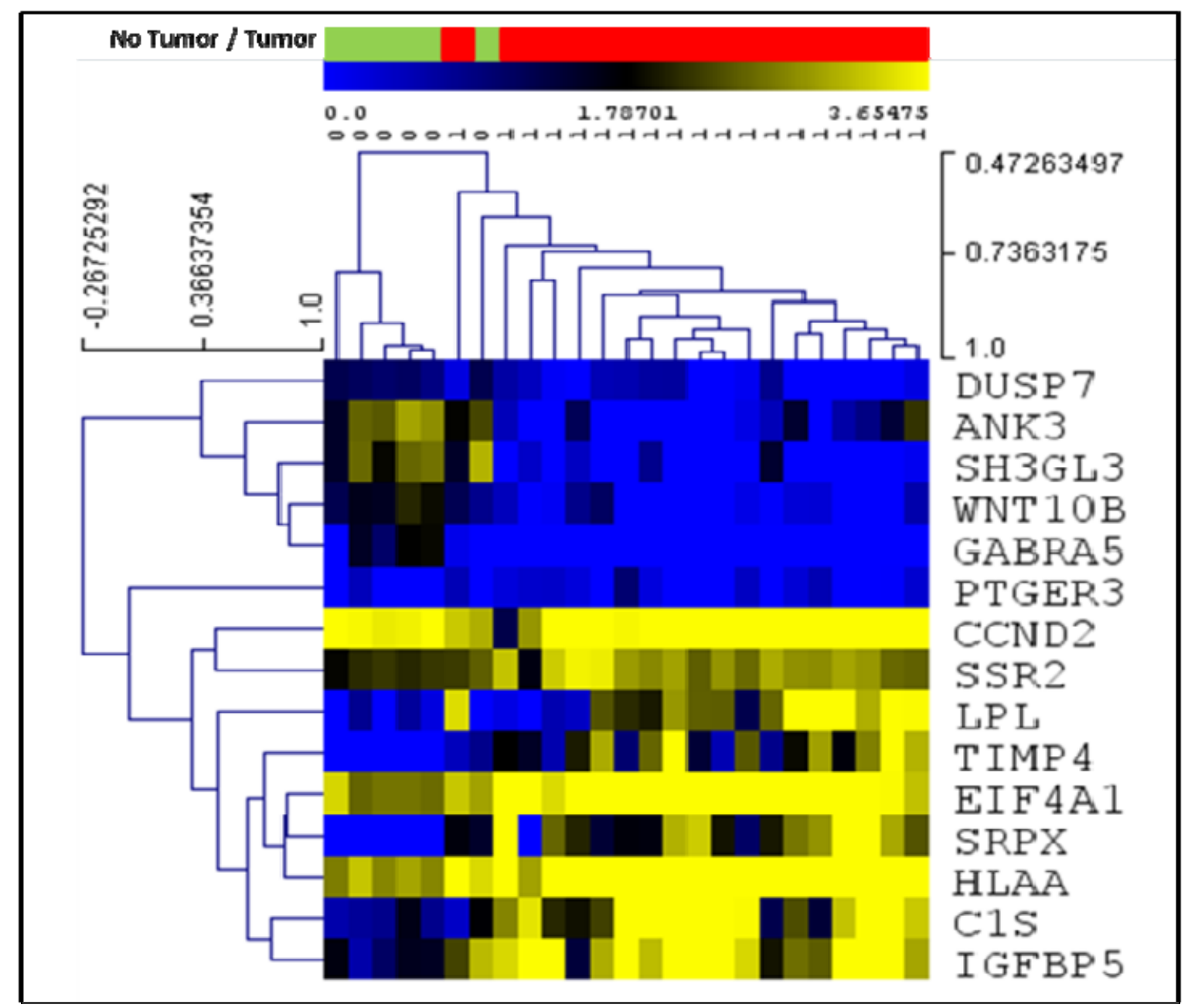

Figure 4-9. Hierarchical clustering of Pilocytic Astrocytoma Markov genes using raw expression values of Rickman study only. No Tumor/Tumor Bar: Red bar areas represent samples without tumors and green bar areas represent tumor cases. Expression: Blue squares represent underexpression; yellow squares represent overexpression.

Table 4-5. Pilocytic Astrocytoma prediction analysis summary. 15 total Markov genes were used in the analysis, except in linear stepwise regression, which used only 10 significant predictor genes in the analysis.

\begin{tabular}{lcc}
\hline Type of Prediction Analysis & $\begin{array}{c}\text { Case Counts } \\
\text { (No Tumor/Tumor) }\end{array}$ & Predictability \\
\hline Bayesian Network Results using ROC Curve & $13 / 30$ & 1.000 AUC (.000 sig.) \\
Linear Regression (15 genes together) & $13 / 30$ & .873 (aR square) (.000 sig.) \\
Linear Regression (stepwise) (10 gene model) & $13 / 30$ & .880 (aR square) (.000 sig.) \\
Logistic Regression (discretized expression) & $13 / 30$ & Error: Perfect fit detected \\
Logistic Regression (raw expression) & $6 / 19$ & Error: Perfect fit detected \\
Cross Validation (discretized expression) & $13 / 30$ & $79.1 \%$ \\
Cross Validation (raw expression) & $6 / 19$ & $88 \%$ \\
Support Vector Machine (SVM) & $6 / 19$ & $100 \%$ \\
\hline
\end{tabular}


Normal Tissue vs. Grade II Astrocytoma: Prediction analysis of the 18 Grade II Markov genes showed that our set of 18 genes was able to predict tumor status consistently when using logistic regression, cross validation and SVM analysis. Linear regression seemed to predict that a signature of 10 genes would predict tumor status just as well as our 18 total genes, though each gene set only predicted approximately $21 \%$ of the tumor status's variability in either case (Table 4-6). Results of hierarchical clustering using expression data from our Markov genes can be found in Figure 4-10. Results of the PathJam analysis can be found in Appendix Figure 2.

Normal Tissue vs. Grade III Astrocytoma: Prediction analysis of the 18 Grade III Markov genes showed that our set of 18 genes was able to predict tumor status, especially when using logistic regression, raw expression in cross validation, and the SVM analysis. Linear regression seemed to again predict that a signature of much less than the total genes (10 of 18) would predict tumor status (Table 4-7). Results of hierarchical clustering using expression data from our Markov genes can be found in Figure 4-11. Results of the PathJam analysis can be found in Appendix Figure 3.

Table 4-6. Diffuse Astrocytoma prediction analysis summary. 18 total Markov genes were used in the analysis, except in linear stepwise regression, which used only 10 significant predictor genes in the analysis.

\begin{tabular}{lcc}
\hline Type of Prediction Analysis & $\begin{array}{c}\text { Case Counts } \\
\text { (No Tumor/Tumor) }\end{array}$ & Predictability \\
\hline Bayesian Network Results using ROC Curve & $36 / 14$ & 1.000 AUC (.000 sig.) \\
Linear Regression (18 genes together) & $36 / 14$ & .207 (aR square) (.092 sig.) \\
Linear Regression (stepwise) (10 gene model) & $36 / 14$ & .880 (aR square) (.028 sig.) \\
Logistic Regression (discretized expression) & $36 / 14$ & $88 \%$ (1.000 sig.) \\
Logistic Regression (raw expression) & $23 / 8$ & Error: Perfect fit detected \\
Cross Validation (discretized expression) & $36 / 14$ & $70 \%$ \\
Cross Validation (raw expression) & $23 / 7$ & $80 \%$ \\
Support Vector Machine (SVM) & $23 / 7$ & $100 \%$ \\
\hline
\end{tabular}




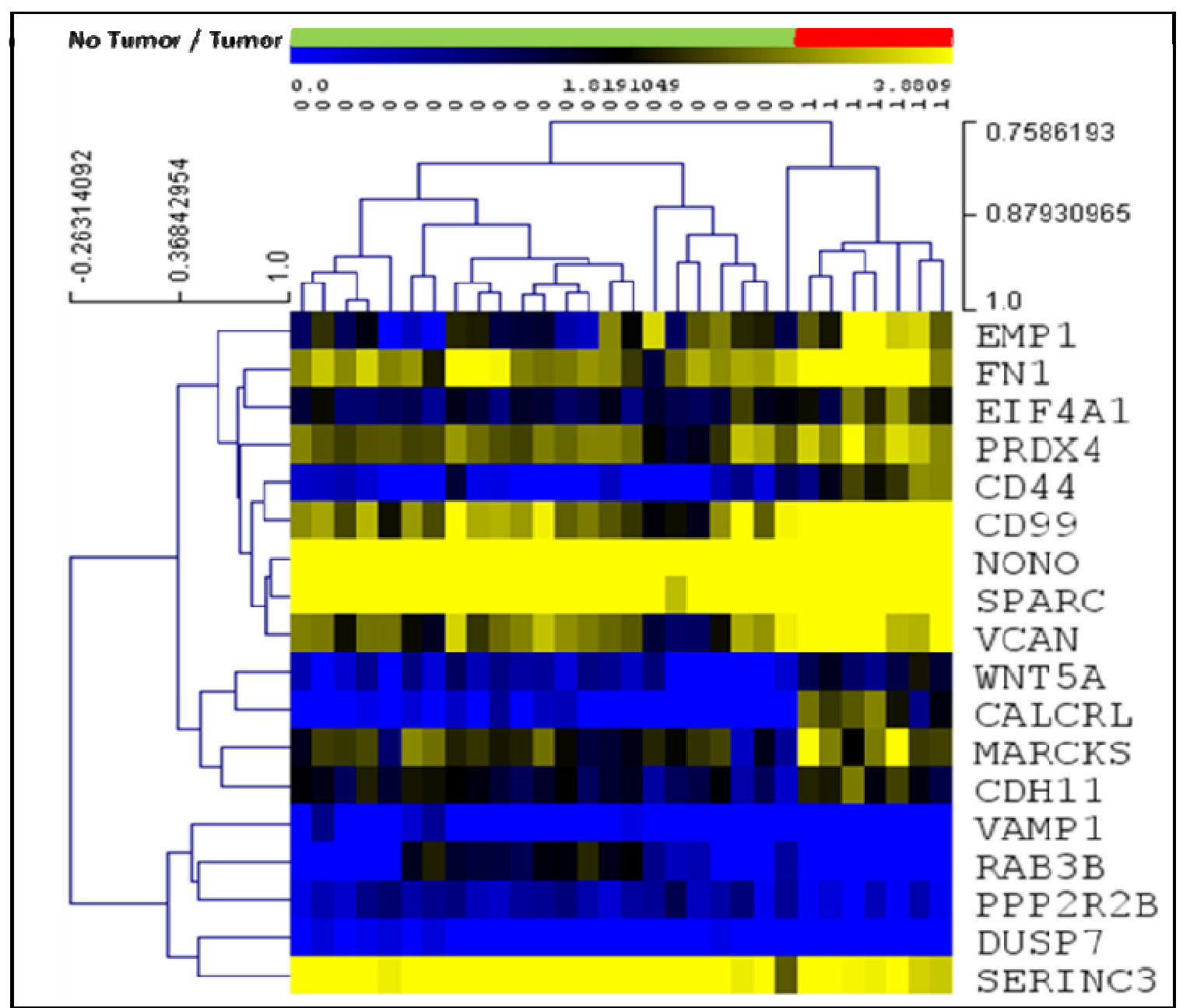

Figure 4-10. Hierarchical clustering of Diffuse Astrocytoma Markov genes using raw expression values of Sun Study Only. No Tumor /Tumor Bar: Green bar areas represent samples without tumors and red bar areas represent tumor cases. Expression: Blue squares represent underexpression; yellow squares represent overexpression.

Table 4-7. Anaplastic Astrocytoma prediction analysis summary. 18 total Markov genes were used in the analysis, except in linear stepwise regression, which used only 11 significant predictor genes in the analysis.

\begin{tabular}{lcc}
\hline Type of Prediction Analysis & $\begin{array}{c}\text { Case Counts } \\
\text { (No Tumor/Tumor) }\end{array}$ & $\begin{array}{c}\text { Predictability } \\
\text { Bayesian Network Results using ROC Curve }\end{array}$ \\
Linear Regression (18 genes together) & $34 / 23$ & 1.000 AUC (.000 sig.) \\
Linear Regression (stepwise) (11 gene model) & $34 / 23$ & .631 (aR square) (.000 sig.) \\
Logistic Regression (discretized expression) & $34 / 23$ & .645 (aR square) (.000 sig.) \\
Logistic Regression (raw expression) & $23 / 19$ & $96.5 \%(1.000$ sig.) \\
Cross Validation (discretized expression) & $34 / 23$ & Error: Perfect fit detected \\
Cross Validation (raw expression) & $23 / 19$ & $84.2 \%$ \\
Support Vector Machine (SVM) & $23 / 19$ & $100 \%$ \\
\hline
\end{tabular}




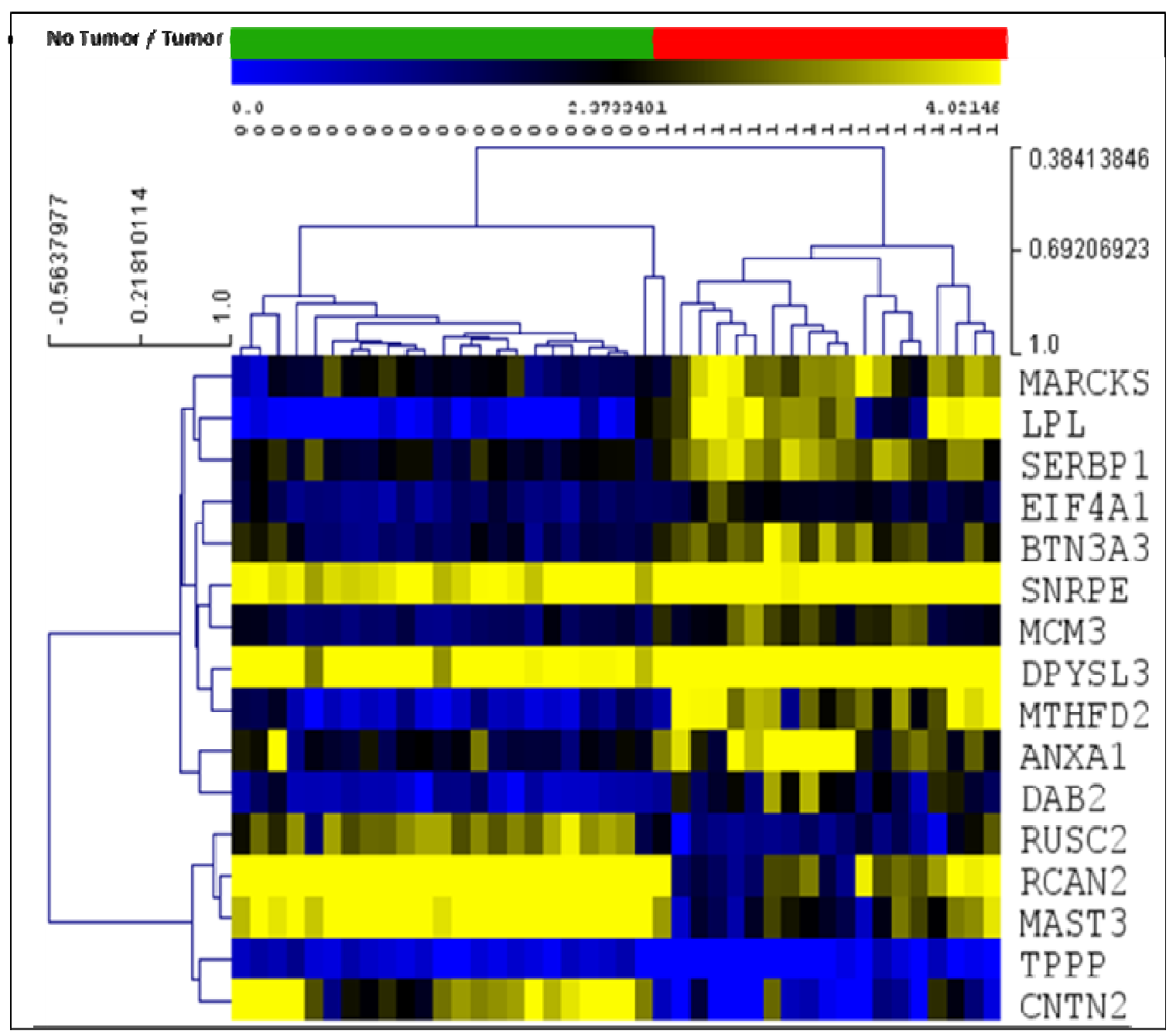

Figure 4-11. Hierarchical clustering of Anaplastic Astrocytoma Markov genes using raw expression values of Sun study only. No Tumor/Tumor Bar: Green bar areas represent samples without tumors and red bar areas represent tumor cases. Expression: Blue squares represent underexpression; Yellow squares represent overexpression.

Normal Tissue vs. Grade IV Astrocytoma: Prediction analysis of the 10 Grade IV Markov genes showed that our set of 10 genes was again able to consistently predict between non-tumor and tumor cases with all analysis (Table 4-8). Please see Appendix Table 4 for results of the biological database and literature search. Research supporting the potential involvement and importance of all 10 genes in development of glioblastoma was found in the literature. Results of hierarchical clustering using expression data from 
our Markov genes can be found in Figure 4-12. Assessment of increased lifetime risk of development of development of astrocytoma due to deregulation of our Markov genes showed that differential expression of all 10 of our genes at once increased your lifetime risk of brain tumor development to $85.90 \%$. In contrast, differential expression of two separate sets of 10 genes found outside the Markov blanket in our Bayesian network increased lifetime risk of brain tumor development to $2.61 \%$ and $0.98 \%$ respectively (Table 4-9).

Results of the IPA and PathJam analysis can be found in Appendix Figures 4 through 6. The investigation using IPA's Path Explorer produced a network of genes showing empirical evidence of interaction among our 10 Glioblastoma Markov blanket genes. IPA Core Analysis of these same Markov genes added genes and molecules such as NFkB, ERK, MAPK, Vegf, growth hormone and collagen to produce a network whose top biological functions are cancer, neurological disease, and cellular movement (Appendix Figure 6). Our analysis of these same Markov genes using PathJam found that three of the 10 genes in particular seemed to be potential 'hubs of activity' and had functions that they shared. These genes, EGFR, COL4A1, and CDK4 all shared the 'pathways to cancer' annotation; and EGFR and COL4A1 were shown to be involved specific cancers such as glioma, melanoma, lung cancer, bladder cancer, and pancreatic cancer. Additionally, COL4A1 and EGFR shared involvement in axon guidance and focal adhesion. For a full list of the biological pathways and gene ontology terms associated with each gene please see Appendix Figure 4. 
Table 4-8. Glioblastoma Multiforme prediction analysis summary. 10 total Markov genes were used in the analysis, except in linear stepwise regression, which used only 6 significant predictor genes in the analysis.

\begin{tabular}{lcc}
\hline Type of Prediction Analysis & $\begin{array}{c}\text { Case Counts } \\
\text { (No Tumor/Tumor) }\end{array}$ & Predictability \\
\hline Bayesian Network Results using ROC Curve & $34 / 23$ & 1.000 AUC (.000 sig.) \\
Linear Regression (18 genes together) & $34 / 23$ & .631 (aR square) (.000 sig.) \\
Linear Regression (stepwise) (11 gene model) & $34 / 23$ & .645 (aR square) (.000 sig.) \\
Logistic Regression (discretized expression) & $34 / 23$ & $96.5 \%(1.000$ sig.) \\
Logistic Regression (raw expression) & $23 / 19$ & Error: Perfect fit detected \\
Cross Validation (discretized expression) & $34 / 23$ & $84.2 \%$ \\
Cross Validation (raw expression) & $23 / 19$ & $100 \%$ \\
Support Vector Machine (SVM) & $23 / 19$ & $100 \%$ \\
\hline
\end{tabular}

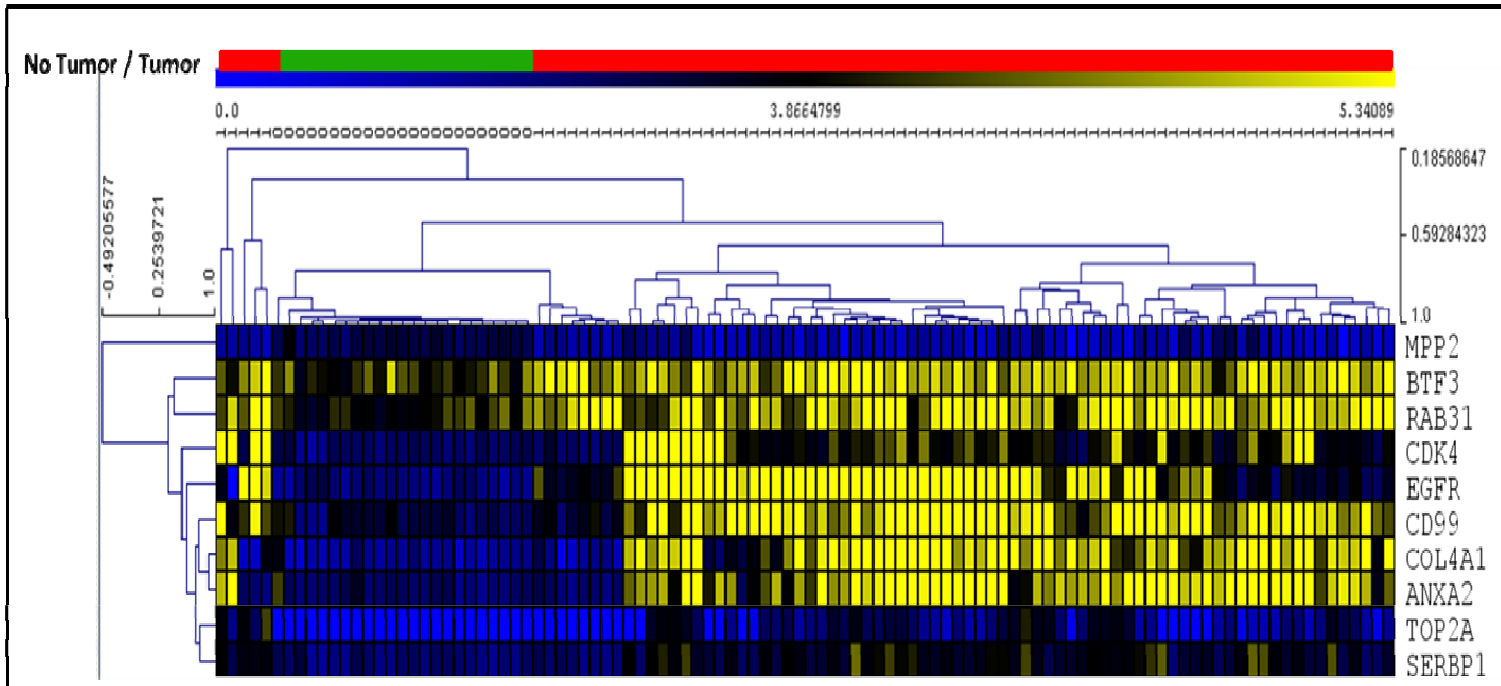

Figure 4-12. Hierarchical clustering of Glioblastoma Multiforme genes using raw expression values of Sun study only. No Tumor/Tumor Bar: Green bar areas represent samples without tumors and red bar areas represent tumor cases. Expression: Darker squares represent underexpression; Lighter squares represent overexpression.

Table 4-9. Risk associated with Markov genes vs. non-Markov genes in Glioblastoma Multiforme. Normal Gene Set Risk represents the SEER calculated $0.61 \%$ chance of a person developing a brain tumor in their lifetime.

\begin{tabular}{lc}
\hline Gene Set & Risk \\
\hline Normal Gene Set & 0.61 \\
$\begin{array}{l}\text { Markov Differentially Expressed (COL4A1, CD99, ANXA2, MPP2, EGFR, CDK4, } \\
\text { BTF3, RAB31, TOP2A, SERBP1) }\end{array}$ & 85.90 \\
$\begin{array}{l}\text { D-Connected Differentially Expressed (KIF5C, PALLD, S100A10, TPPP, PCNA, } \\
\text { FN1, IGFBP2, CDH11, LYPLA1) }\end{array}$ & 2.61 \\
$\begin{array}{l}\text { D-Separated Differentially Expressed (PKP4, SYNCRIP, CALCRL, GABRA5, } \\
\text { MOBP, PLOD2, WNT5A, C1S, RPS2, FCHO1) }\end{array}$ & 0.98 \\
\hline
\end{tabular}




\section{DISCUSSION}

This study produced several major findings including identification of a list of top over- and under-expressed genes among 10 sub-studies on astrocytoma, identification of several genes important to development of both low and high grade astrocytomas, identification of important signaling pathways in astrocytic tumors, and identification of possible mechanisms which explain the genes and pathways identified as important to development of astrocytoma.

Through meta-analysis of 10 sub-studies which compared normal tissue to astrocytomas, a list of 646 genes which were differentially expressed in the majority of these studies was identified. Many of the genes identified through this meta-analysis have in fact been implicated in development of astrocytoma including EGFR (amplification occurs in $\sim 40 \%$ of primary glioblastomas [23;24]), HIF-1 $\alpha$, c-Myc, WNT5A, and IDH3A. Enrichment analysis of the 646 genes using FuncAssociate identified several processes associated with these genes, many of which are related to nervous system, developmental, and tumor promoting processes. Ingenuity Pathway Analysis also produced a list of processes that are significantly associated with these genes, including two pathways which have previously been linked to development of astrocytomas [1. 'WNT/beta-Catenin Signaling' (Genes from our set in pathway: CD44, CDH2, DVL3, LRP1, MYC, SOX4, SOX9, SOX13, TCF3, TCF4, TLE3, WNT5A) and 2. 'mTOR Signaling' (Genes: EIF3B, EIF3E, EIF3F, EIF4A1, HIF1A, PRKD1, RHOC, RND2, RND3)] and two pathways associated with brain tumor development [1. 'Glioma Invasiveness Signaling' (Genes: CD44, F2R, ITGAV, MMP9, RHOC, RND2, RND3, 
TIMP3, TIMP4) and 'Glioblastoma Multiforme Signaling' (Genes: CDK6, CDKN1A, EGFR, ITPR2, MYC, RHOC, RND2, RND3, TCF3, WNT5A)].

In order narrow our large set of genes down into a few genes which could be most influential to development of astrocytomas, we performed reverse engineering of our gene list using Bayesian network analysis. Four networks of genes were produced, one for each grade of Astrocytoma.

To investigate the biological mechanisms of our set of significant Grade IV network genes we used biological databases such as The Human Gene Conpendium's GeneCards, PubMed, the Information Hyperlinked over Proteins (iHOP) Database, and the Glioblastoma Multiforme Database (GBMBase). Results of this investigation can be found in Table 4. Much of the biology described in this table was considered in the context of current knowledge on signaling pathways of astrocytoma. Major patterns in these tumors have been described [25], and include components of the Ras-MAPK and PI3K-AKT-mTOR signaling pathways being affected in the plurality $(88 \% ; 80$ of 91$)$ of malignant gliomas and disruption of the p53 and RB tumor suppressor networks also occurring in a high proportion of glioblastomas: $87 \%$ (79 of 91) and $78 \%$ (71 of 91), respectively [25].

There are several strengths and limitations involved with our analyses. Several characteristics of microarray expression studies must be considered. First, expression levels of many genes differ among individuals and thus gene expression can be analyzed like other quantitative phenotypes such as height and blood glucose levels. This allowed us to separate each gene into expression categories of over-, median, and underexpression. Expression changes can also reflect many types of alterations significant to 
tumor development, including chromosomal translocations and epigenetic alterations. Additionally, several studies have established causal links between differential gene expression and complex disease risk and thus identification of over- and under-expressed genes in tumor tissue compared to normal tissue could provide important clues to the development of tumors. Furthermore, it has also been shown that genes with similar expression patterns form complexes and/or pathways that are part of regulatory circuits that may lead to tumors and other diseases, lending support to the validity of our pathway analyses. Our meta-analysis, which took the top 600 over- and top 600 under-expressed genes from a set of studies, should also have produced the most important differentially expressed genes across all astrocytic tumors. Analysis that shows 143 genes in GBM are expressed on average at 10-fold higher levels than normal tissue confirms that the most highly expressed genes in GBM were considered in our analysis [26].

There are also several limitations of expression values. Foremost are the discrepancies between protein and mRNA levels in studies correlating their expression, a clear sign that interactions outside the classical DNA to mRNA to protein pathway are taking place inside the cell. Additionally, it has been shown that known genes may not necessarily be differentially expressed in diseases due to the ability of mutations in the coding regions of genes and post-translational modifications affecting gene function without affecting its expression level. However, our approach of meta-analysis and focusing on networks of genes rather than single genes may lessen the effect of missing important genes (i.e. while one gene in a pathway may not be expressed, another may). Finally, only looking at mean expression changes of genes could lead to incorrect conclusions about the 
involvement of a pathway in a disease condition, and so as suggested by de la Fuente 2010, co-expression of genes should also be considered [27].

Limitations of enrichment analysis in general apply [28] to our analysis, including: a) incomplete annotation databases as a result of only a subset of known genes being functionally annotated; b) annotation databases may not be completely updated with all literature results; c) some annotation assignments may be erroneous, especially those which are electronically inferred; d) singling out the most important processes for genes involved in several biological processes is limited. This can be overcome by looking at the gene in context of other over- and/or under-expressed genes however; and e) annotation bias due to some biological processes being studied in more detail than others (e.g. proliferation).

Another limitation of our approach is that because our set of significant genes was chosen through meta-analysis of micro-array studies that used differing platforms and differing gene totals per study, we were unable to input a set of genes as for our 'total gene universe' in our gene enrichment analyses. This limited us to choosing the entire genome as our universe of comparison genes for the enrichment analyses. However, 4 of the 9 studies contained $18,800+$ genes and one other study contained 14,584 genes, making it likely that most of our selected significant genes represent most of the appropriate over- and/or under-expressed genes in astrocytoma.

Reverse network engineering methods have evolved greatly over the past decade, with recent reports lending credibility to their ability to correctly predict biological interactions $[29 ; 30]$. However, limitations associated with their use must be considered. In particular, static Bayesian networks cannot contain feedback loops, due to the steady 
state nature of the data. Thus, a characteristic common to biological systems was not considered in our network. Also, because Bayesian networks model probabilistic dependencies among variables and not causality, we cannot conclusively say that the parents of a node are direct causes of its behavior [4]. A causal link can be inferred however, if the Causal Markov Condition holds true. Simply, this condition states that any node in a Bayesian network is conditionally independent of its non-descendants, given its parents; and, a node is conditionally independent of the entire network, given its Markov blanket. A strength of our approach is the exploration of gene networks in tumors without a priori genetic interaction networks being assumed. This has been mentioned as a limitation of previous work on gene networks in gliomas [31]. Incorporation of biological evidence that directs our Bayesian network search could serve to strengthen our approach in the future however.

Finally, limitations concerning the data used in our study must be considered. For example, our inability to separate pediatric astrocytomas from adult astrocytomas, secondary glioblastomas from secondary glioblastomas, and male vs. female cases does limit the extent to which we can draw conclusions from our data. The possibility that 'a fraction of GBMs designated as primary tumors may follow a sequence of genetic events similar to that of secondary lesions but not come to clinical attention until malignant progression to a GBM has occurred', lessens the concern of dividing types of glioblastomas however. Additionally, our method could be considered non-biased in this respect, as it does not pre-condition results based on priors, thus allowing for a search which may provide key genes across all hypothesized glioblastoma subtypes. 
This research was able to identify several genes and pathways that are associated in the development of astrocytoma. Though these molecules could be causally linked to astrocytoma, further detailed analysis is necessary. Experiments involving system perturbations of these genes (e.g. gene knockout experiments) are needed to establish directionality in our network and to provide validity of our findings. 


\section{Reference List}

1. Rhodes,D.R., Kalyana-Sundaram,S., Mahavisno,V., Varambally,R., Yu,J., Briggs,B.B., Barrette,T.R., Anstet,M.J., Kincead-Beal,C., Kulkarni,P., Varambally,S., Ghosh,D., and Chinnaiyan,A.M. (2007) Oncomine 3.0: genes, pathways, and networks in a collection of 18,000 cancer gene expression profiles. Neoplasia., 9, 166-180.

2. Berriz,G.F., Beaver,J.E., Cenik,C., Tasan,M., and Roth,F.P. (2009) Next generation software for functional trend analysis. Bioinformatics., 25, 3043-3044.

3. Ashburner,M., Ball,C.A., Blake,J.A., Botstein,D., Butler,H., Cherry,J.M., Davis,A.P., Dolinski,K., Dwight,S.S., Eppig,J.T., Harris,M.A., Hill,D.P., IsselTarver,L., Kasarskis,A., Lewis,S., Matese,J.C., Richardson,J.E., Ringwald,M., Rubin,G.M., and Sherlock,G. (2000) Gene ontology: tool for the unification of biology. The Gene Ontology Consortium. Nat.Genet., 25, 25-29.

4. Friedman,N., Linial,M., Nachman,I., and Pe'er,D. (2000) Using Bayesian networks to analyze expression data. J.Comput.Biol., 7, 601-620.

5. Yoo,C., Thorsson,V., and Cooper,G.F. (2002) Discovery of causal relationships in a gene-regulation pathway from a mixture of experimental and observational DNA microarray data. Pac.Symp.Biocomput.,498-509.

6. Banjo: Bayesian Network Inference with Java Objects. http://www.cs.duke.edu/ amink/software/banjo/.

7. Bansal,M. and di,B.D. (2007) Inference of gene networks from temporal gene expression profiles. IET.Syst.Biol., 1, 306-312.

8. Charniak, E. (1991) Bayesian Networks without Tears. AI Magazine, 50-62.

9. Hartemink,A.J. (2005) Reverse engineering gene regulatory networks. Nat.Biotechnol., 23, 554-555.

10. Yoo,C. and Brilz,E.M. (2009) The five-gene-network data analysis with local causal discovery algorithm using causal Bayesian networks. Ann.N.Y.Acad.Sci., $1158,93-101$.

11. Pe'er,D., Regev,A., Elidan,G., and Friedman,N. (2001) Inferring subnetworks from perturbed expression profiles. Bioinformatics., 17 Suppl 1, S215-S224.

12. Zhu,J., Zhang,B., Smith,E.N., Drees,B., Brem,R.B., Kruglyak,L., Bumgarner,R.E., and Schadt,E.E. (2008) Integrating large-scale functional genomic data to dissect the complexity of yeast regulatory networks. Nat.Genet., $40,854-861$. 
13. Druzdzel MJ. SMILE: Structural modeling, inference, and learning engine and GeNIe: A development environment for graphical decision-theoretic models. Sixteenth national conference on artificial intelligence , 902-903. 1999. Menlo Park, CA, AAAI Press/The MIT Press.

14. Howlader N, Noone AM, Krapcho M, Neyman N, Aminou R, Waldron W, Altekruse SF, Kosary CL, Ruhl J, Tatalovich Z, Cho H, Eisner MP, Lewis DR, Chen HS, Feuer EJ, Cronin KA, and Edwards BK (eds). SEER Cancer Statistics Review, 1975-2008, National Cancer Institute. 2011. Bethesda, MD.

15. Glez-Pena,D., Reboiro-Jato,M., Dominguez,R., Gomez-Lopez,G., Pisano,D.G., and Fdez-Riverola,F. (2010) PathJam: a new service for integrating biological pathway information. J.Integr.Bioinform., 7.

16. Bredel,M., Bredel,C., Juric,D., Harsh,G.R., Vogel,H., Recht,L.D., and Sikic,B.I. (2005) High-resolution genome-wide mapping of genetic alterations in human glial brain tumors. Cancer Res., 65, 4088-4096.

17. Gutmann,D.H., Hedrick,N.M., Li,J., Nagarajan,R., Perry,A., and Watson,M.A. (2002) Comparative gene expression profile analysis of neurofibromatosis 1associated and sporadic pilocytic astrocytomas. Cancer Res., 62, 2085-2091.

18. Lee,J., Kotliarova,S., Kotliarov,Y., Li,A., Su,Q., Donin,N.M., Pastorino,S., Purow,B.W., Christopher,N., Zhang,W., Park,J.K., and Fine,H.A. (2006) Tumor stem cells derived from glioblastomas cultured in bFGF and EGF more closely mirror the phenotype and genotype of primary tumors than do serum-cultured cell lines. Cancer Cell, 9, 391-403.

19. Liang,Y., Diehn,M., Watson,N., Bollen,A.W., Aldape,K.D., Nicholas,M.K., Lamborn,K.R., Berger,M.S., Botstein,D., Brown,P.O., and Israel,M.A. (2005) Gene expression profiling reveals molecularly and clinically distinct subtypes of glioblastoma multiforme. Proc.Natl.Acad.Sci.U.S.A, 102, 5814-5819.

20. Rickman,D.S., Bobek,M.P., Misek,D.E., Kuick,R., Blaivas,M., Kurnit,D.M., Taylor,J., and Hanash,S.M. (2001) Distinctive molecular profiles of high-grade and low-grade gliomas based on oligonucleotide microarray analysis. Cancer Res., 61, 6885-6891.

21. Shai,R., Shi,T., Kremen,T.J., Horvath,S., Liau,L.M., Cloughesy,T.F., Mischel,P.S., and Nelson,S.F. (2003) Gene expression profiling identifies molecular subtypes of gliomas. Oncogene, 22, 4918-4923.

22. Sun,L., Hui,A.M., Su,Q., Vortmeyer,A., Kotliarov,Y., Pastorino,S., Passaniti,A., Menon,J., Walling,J., Bailey,R., Rosenblum,M., Mikkelsen,T., and Fine,H.A. (2006) Neuronal and glioma-derived stem cell factor induces angiogenesis within the brain. Cancer Cell, 9, 287-300. 
23. Ohgaki,H., Dessen,P., Jourde,B., Horstmann,S., Nishikawa,T., Di Patre,P.L., Burkhard,C., Schuler,D., Probst-Hensch,N.M., Maiorka,P.C., Baeza,N., Pisani,P., Yonekawa,Y., Yasargil,M.G., Lutolf,U.M., and Kleihues,P. (2004) Genetic pathways to glioblastoma: a population-based study. Cancer Res., 64, 6892-6899.

24. Watanabe,K., Tachibana,O., Sata,K., Yonekawa,Y., Kleihues,P., and Ohgaki,H. (1996) Overexpression of the EGF receptor and p53 mutations are mutually exclusive in the evolution of primary and secondary glioblastomas. Brain Pathol., $6,217-223$.

25. Huse,J.T. and Holland,E.C. (2010) Targeting brain cancer: advances in the molecular pathology of malignant glioma and medulloblastoma. Nat.Rev.Cancer, 10, 319-331.

26. Parsons,D.W., Jones,S., Zhang,X., Lin,J.C., Leary,R.J., Angenendt,P., Mankoo,P., Carter,H., Siu,I.M., Gallia,G.L., Olivi,A., McLendon,R., Rasheed,B.A., Keir,S., Nikolskaya,T., Nikolsky,Y., Busam,D.A., Tekleab,H., Diaz,L.A., Jr., Hartigan,J., Smith,D.R., Strausberg,R.L., Marie,S.K., Shinjo,S.M., Yan,H., Riggins,G.J., Bigner,D.D., Karchin,R., Papadopoulos,N., Parmigiani,G., Vogelstein,B., Velculescu,V.E., and Kinzler,K.W. (2008) An integrated genomic analysis of human glioblastoma multiforme. Science, 321, 1807-1812.

27. de la Fuente,A. (2010) From 'differential expression' to 'differential networking' identification of dysfunctional regulatory networks in diseases. Trends Genet., 26, 326-333.

28. Khatri,P. and Draghici,S. (2005) Ontological analysis of gene expression data: current tools, limitations, and open problems. Bioinformatics., 21, 3587-3595.

29. Basso,K., Margolin,A.A., Stolovitzky,G., Klein,U., Dalla-Favera,R., and Califano,A. (2005) Reverse engineering of regulatory networks in human B cells. Nat.Genet., 37, 382-390.

30. Yu, J, Smith, V. A., Wang, P. P., Hartemink, A. J., and Jarvis, E. D. Using Bayesian Network Inference Algorithms to Recover Molecular Genetic Regulatory Networks. 3rd International Conference on Systems Biology . 2002. Stockholm, Sweden, Karolinska Institute.

31. Bredel,M., Scholtens,D.M., Harsh,G.R., Bredel,C., Chandler,J.P., Renfrow,J.J., Yadav,A.K., Vogel,H., Scheck,A.C., Tibshirani,R., and Sikic,B.I. (2009) A network model of a cooperative genetic landscape in brain tumors. JAMA, 302, 261-275.

32. Liu,Y., Carson-Walter,E.B., Cooper,A., Winans,B.N., Johnson,M.D., and Walter,K.A. (2010) Vascular gene expression patterns are conserved in primary and metastatic brain tumors. J.Neurooncol., 99, 13-24. 
33. Huse,J.T. and Holland,E.C. (2010) Targeting brain cancer: advances in the molecular pathology of malignant glioma and medulloblastoma. Nat.Rev.Cancer, 10, 319-331.

34. Guillamo,J.S., de,B.S., Valable,S., Marteau,L., Leuraud,P., Marie,Y., Poupon,M.F., Parienti,J.J., Raymond,E., and Peschanski,M. (2009) Molecular mechanisms underlying effects of epidermal growth factor receptor inhibition on invasion, proliferation, and angiogenesis in experimental glioma. Clin.Cancer Res., 15, 3697-3704.

35. Mukherjee,B., McEllin,B., Camacho,C.V., Tomimatsu,N., Sirasanagandala,S., Nannepaga,S., Hatanpaa,K.J., Mickey,B., Madden,C., Maher,E., Boothman,D.A., Furnari,F., Cavenee,W.K., Bachoo,R.M., and Burma,S. (2009) EGFRvIII and DNA double-strand break repair: a molecular mechanism for radioresistance in glioblastoma. Cancer Res., 69, 4252-4259.

36. Idbaih,A., Aimard,J., Boisselier,B., Marie,Y., Paris,S., Criniere,E., Carvalho,S.R., Laigle-Donadey,F., Rousseau,A., Mokhtari,K., Thillet,J., Sanson,M., HoangXuan,K., and Delattre,J.Y. (2009) Epidermal growth factor receptor extracellular domain mutations in primary glioblastoma. Neuropathol.Appl.Neurobiol., 35, 208-213.

37. Ruano,Y., Ribalta,T., de Lope,A.R., Campos-Martin,Y., Fiano,C., PerezMagan,E., Hernandez-Moneo,J.L., Mollejo,M., and Melendez,B. (2009) Worse outcome in primary glioblastoma multiforme with concurrent epidermal growth factor receptor and p53 alteration. Am.J.Clin.Pathol., 131, 257-263.

38. Odreman,F., Vindigni,M., Gonzales,M.L., Niccolini,B., Candiano,G., Zanotti,B., Skrap,M., Pizzolitto,S., Stanta,G., and Vindigni,A. (2005) Proteomic studies on low- and high-grade human brain astrocytomas. J.Proteome.Res., 4, 698-708.

39. Kusumawidjaja,G., Kayed,H., Giese,N., Bauer,A., Erkan,M., Giese,T., Hoheise,J.D., Friess,H., and Kleeff,J. (2007) Basic transcription factor 3 (BTF3) regulates transcription of tumor-associated genes in pancreatic cancer cells. Cancer Biol.Ther., 6, 367-376.

40. Guerreiro,A.S., Fattet,S., Kulesza,D.W., Atamer,A., Elsing,A.N., Shalaby,T., Jackson,S.P., Schoenwaelder,S.M., Grotzer,M.A., Delattre,O., and Arcaro,A. (2011) A sensitized RNA interference screen identifies a novel role for the PI3K p110gamma isoform in medulloblastoma cell proliferation and chemoresistance. Mol.Cancer Res., 9, 925-935.

41. Ng,E.L., Ng,J.J., Liang,F., and Tang,B.L. (2009) Rab22B is expressed in the CNS astroglia lineage and plays a role in epidermal growth factor receptor trafficking in A431 cells. J.Cell Physiol, 221, 716-728. 
42. Serao,N.V., Delfino,K.R., Southey,B.R., Beever,J.E., and Rodriguez-Zas,S.L. (2011) Cell cycle and aging, morphogenesis, and response to stimuli genes are individualized biomarkers of glioblastoma progression and survival. BMC.Med.Genomics, 4, 49.

43. Wiedemeyer,W.R., Dunn,I.F., Quayle,S.N., Zhang,J., Chheda,M.G., Dunn,G.P., Zhuang,L., Rosenbluh,J., Chen,S., Xiao,Y., Shapiro,G.I., Hahn,W.C., and Chin,L. (2010) Pattern of retinoblastoma pathway inactivation dictates response to CDK4/6 inhibition in GBM. Proc.Natl.Acad.Sci.U.S.A, 107, 11501-11506.

44. Nobusawa,S., Lachuer,J., Wierinckx,A., Kim,Y.H., Huang,J., Legras,C., Kleihues,P., and Ohgaki,H. (2010) Intratumoral patterns of genomic imbalance in glioblastomas. Brain Pathol., 20, 936-944.

45. Ishizawa,K., Komori,T., Shimada,S., and Hirose,T. (2008) Olig2 and CD99 are useful negative markers for the diagnosis of brain tumors. Clin.Neuropathol., 27, 118-128.

46. An,J.H., Lee,S.Y., Jeon,J.Y., Cho,K.G., Kim,S.U., and Lee,M.A. (2009) Identification of gliotropic factors that induce human stem cell migration to malignant tumor. J.Proteome.Res., 8, 2873-2881.

47. Tatenhorst,L., Rescher,U., Gerke,V., and Paulus,W. (2006) Knockdown of annexin 2 decreases migration of human glioma cells in vitro. Neuropathol.Appl.Neurobiol., 32, 271-277.

48. Dawany,N.B., Dampier,W.N., and Tozeren,A. (2011) Large-scale integration of microarray data reveals genes and pathways common to multiple cancer types. Int.J.Cancer, 128, 2881-2891.

49. Ladha,J., Donakonda,S., Agrawal,S., Thota,B., Srividya,M.R., Sridevi,S., Arivazhagan,A., Thennarasu,K., Balasubramaniam,A., Chandramouli,B.A., Hegde,A.S., Kondaiah,P., Somasundaram,K., Santosh,V., and Rao,S.M. (2010) Glioblastoma-specific protein interaction network identifies PP1A and CSK21 as connecting molecules between cell cycle-associated genes. Cancer Res., 70, 6437-6447.

50. Nakahara,Y., Shiraishi,T., Okamoto,H., Mineta,T., Oishi,T., Sasaki,K., and Tabuchi,K. (2004) Detrended fluctuation analysis of genome-wide copy number profiles of glioblastomas using array-based comparative genomic hybridization. Neuro.Oncol., 6, 281-289.

51. Koensgen,D., Mustea,A., Klaman,I., Sun,P., Zafrakas,M., Lichtenegger,W., Denkert,C., Dahl,E., and Sehouli,J. (2007) Expression analysis and RNA localization of PAI-RBP1 (SERBP1) in epithelial ovarian cancer: association with tumor progression. Gynecol.Oncol., 107, 266-273. 
Manuscript 5: Modeling gene-environment interaction in Glioblastoma Multiforme via an integrated bioinformatics approach

Brian Kunkle, Changwon Yoo ${ }^{1}$, Quentin Felty, and Deodutta Roy

Departments of Environmental and Occupational Health and ${ }^{1}$ Epidemiology and

Biostatistics, Florida International University, Miami, FL 33199 


\begin{abstract}
Recent developments in bioinformatics, including integration of large amounts of diverse biological and environmental data, allow for investigation of gene-gene and geneenvironment interactions. Bioinformatics resources were used to develop hypotheses for investigation of GEI in the development of glioblastoma multiforme (GBM), the most common and aggressive type of human brain tumor. Genes responsive to environmental exposures were identified using the Environmental Genome Project, Comparative Toxicology, and Seattle SNPs databases. These genes were then compared to a curated list of genes altered in GBM. The list of genes responsive to the environment and important to GBM was then further investigated using gene networking tools such as RSpider and Cytoscape. A total of 173 environmentally responsive genes were found to be altered in GBM. The main biological functions of these genes included Signaling by Nerve Growth Factor (NGF), DNA Repair, Integrin Cell Surface Interactions, Biological Oxidations, Apoptosis, Synaptic Transmission, Cell Cycle Checkpoints, and Arachidonic Acid Metabolism. Importantly, NGF, a protein essential to axonal growth and differentiation, and maintenance and survival of its targeted nerve cells, has been implicated in development of several cancers, including GBM. Generation of GEI data relevant to GBM etiology through this bioinformatics method, can provide highly useful information for hypothesis generation.
\end{abstract}




\section{INTRODUCTION}

The etiology of brain tumors is mainly unknown. Aside from extremely rare genetic conditions, such as neurofibromatosis and tuberous sclerosis, the only unequivocally identified risk factor is exposure to ionizing radiation, and this explains only a very small fraction of cases. Research over the past few decades does point to the relevancy of a few environmental exposures in brain tumor etiology however. A number of these exposures, including pesticides, $\mathrm{N}$-nitroso compounds, non-ionizing radiation from longterm cell phone use, and infection with polyomavirus, have been positively linked to brain tumors, although findings are inconclusive. Several work-related exposures have been convincingly linked to brain tumors however, including nuclear workers exposed to radiation, pathologists and embalmers exposed to formaldehyde, plastic workers exposed to vinyl chloride, and textile and plastic workers exposed to acrylonitrile [1].

Very few epidemiological studies to date have investigated gene-environment interactions (GEI) in relation to brain tumor development. To date, two studies have assessed GEI in adult glioma. A case-control study on lead exposure, the lead toxicity associated gene $\delta$-aminolevulinic acid dehydratase (ALAD), and risk of brain tumors found increased risk of meningioma with occupational lead exposure. Risk of meningioma, a tumor present mainly in later life, was markedly increased in individuals with the ALAD2 variant allele, for whom risks increased in a dose dependent fashion from $1.1(0.3-4.5)$ to $5.6(0.7-45.5)$ and $12.8(1.4-120.8)$ compared to unexposed persons. Risk for glioma was not associated with occupational lead exposure [2]. A second adult GEI study on glutathione transferases (GST) polymorphisms, cigarette smoke exposure, and development of adult glioma failed to find any significant GEI [3]. While few GEI 
studies in glioblastoma exist, computational modeling of 600 adults with glioma has shown that a polygenic-environment-interactive model best explained the pattern of occurrence of brain tumors [4].

Recent developments in bioinformatics such as tools that allow for the assessment of pathway and gene relationships, text mining of published literature, and integration of large amounts of diverse biological and environmental data allow for hypothesis driven investigations of gene-gene and gene-environment interactions. Methods that exploit these tools have been applied to modeling of gene-environment interactions in depression and alcohol use [5], and bipolar disorder and its interaction with both tobacco use [6] and lithium treatment [7]. Integration of toxicological and pharmacological databases such as the Comparative Toxicological Database (CTD) [8] and Environmental Genome Projects (EGP) [9] with data on genetic alterations has also proven useful in developing hypothesis for research into GEI related diseases [10;11]. We chose to use these environmental bioinformatics resources to develop hypotheses for investigation of geneenvironment interactions in the development of glioblastoma multiforme (GBM), the most common and aggressive type of human brain tumor.

\section{BACKGROUND ON GENE ALTERATIONS AND ENVIRONMENTAL EXPOSURES}

Alterations in genes that interact with environmental influences are thought to play a large part in this variable response and its subsequent risk for disease. The genetic alterations that result from environmental exposures can occur at several levels, including in single nucleotides, small stretches of DNA (microsatellites), whole genes, structural 
components of chromosomes, or complete chromosomes. In principle, complex diseases such as cancer might be more susceptible to the lower levels, or 'softer' forms, of variation such as variation in noncoding sequences and copy number, which alter gene dose without abolishing gene function. Thus, variability in responsiveness of these altered genes to environmental influences may be directly related to disease susceptibility.

Among rearrangements frequently involved in tumor progression is DNA amplification, which drastically modifies gene dosage in cancer cells [12;13] and has been linked to glioma development through growth factors such as EGFR [14]. Amplification of a gene refers to existence of at least five copies of a DNA segment (or deletion of a segment for loss of copies) that is less than 20 megabases in length, whereas a low $(<5)$ copy number increase or decrease (also referred to as gain or loss), is directed towards intact chromosomes, entire chromosome arms, or larger chromosomal regions with only one intra-chromosomal breakpoint. Mechanisms of gene amplification have been reviewed in detail by Myllykangas and Knuutila [15]. In this review, the authors cite a 0.440 amplification frequency per case of GBM (268 amplifications in 609 reviewed cases) vs. 0.047 amplification per case of astrocytoma (43 amplifications in 920 reviewed cases). This difference may be due to the more progressed solid tumor nature of GBM compared to astrocytoma. For the purposes of this paper, amplification or deletion, and gain or loss of gene copy number will be referred to as copy number variation $(\mathrm{CNV})$.

A recent study of gene expression variation sought to determine the fraction of gene expression 'traits' associated with either SNPs or CNVs in complex phenotypes. SNP 
genotypes and CNV measurements were associated with $83 \%$ and $18 \%$ of those gene expression traits for which statistically significant associations were found [16]. While CNVs accounted for a small role, this study may still underestimate the role of CNVs, given the greater completeness and accuracy with which SNPs can be queried at present. Regardless, the import of both SNPs and CNVs to variation in phenotype and disease susceptibility is becoming clearer. Recent research is also finding that, surprisingly, most of the SNP variations associated with disease are not in the region of DNA that codes for a protein. Instead, they are usually in the large non-coding regions on the chromosome between genes, or in the intron sequences that are edited out of the DNA sequence when proteins are processed. These are presumably sequences of DNA that control other genes, but usually, their protein function is not known [17].

Evidence of environmental exposures causing $\mathrm{CNV}$ is still developing, while the environments ability to cause SNP mutations is quite established [18;19]. Although evidence suggests that most common copy number variants are inherited and therefore caused by ancestral structural mutations [20], there is growing evidence that many or most normal and sporadic, nonrecurring CNVs, which account for the majority of disease-associated CNVs in humans and those in cancers, arise via mechanisms coupled to aberrant DNA replication and/or non-homologous repair of DNA damage [21]. This suggests an unexpected mitotic, rather than meiotic, cell origin for many CNVs and has a number of important implications for the role of environmental exposures in their formation. This evidence has led some to hypothesize that the two types of environmental agents most likely to be associated with CNV formation are: 1) agents that lead to replication stress, which might lead to CNVs through secondary breakage or 
replicative template switching, and 2) agents that directly induce DNA double-strand breaks (DNA DSBs), which might lead to CNVs through inappropriate joining of broken ends. Moreover, the ability of environmental agents to cause CNVs and induce epigenetic transgenerational effects in the sperm epigenome separate from methylation effects has recently been established [22].

In an attempt to identify genes potentially important in environmentally related alterations in GBM, we apply a method similar to the bioinformatics methods of Herbert et al. in their research on identifying potential environmentally-related autism genes [23]. We have modified and extended this method to include a search for specific genechemical observations important for our 'environmentally responsive genes', and develop a gene network using these genes and alterations in GBM.

\section{METHODS}

A summary of the methodology and workflow outline for this research can be seen in Figure 5-1. Briefly, significant copy number alterations and SNP mutations in GBM were curated from published literature and the COSMIC database [24]. Gene lists from six studies on GBM were used for this curation (Table 5-1) [24-30]. Design of study, analysis platform, sample size and region of genome analyzed were criteria used to select studies to include in our alteration results.

Gene lists from three environmental databases were used for the compilation of possible environmentally important genes in GBM. These databases were: 
a. The Environmental Genome Project (EGP) located at: http://egp.gs.washington.edu/finished_genes.html. The National Institute of Environmental Health Sciences (NIEHS) EGP is a database which identifies and genotypes genes with functions related to cell cycle, cell division, cell signaling, cell structure, DNA repair, gene expression, homeostasis, metabolism, immune and inflammatory response, hormone metabolism, nutrition, oxidative metabolism and stress, membrane pumps and/or drug resistance, and signal transduction [9]. All genes from this database were included in our environmentally responsive genes list.

b. Seattle SNPs located at: http://pga.gs.washington.edu/finished_genes.html. The Seattle SNP database is a National Heart Lung and Blood Institute (NHLBI) funded project focused on identifying, genotyping, and modeling associations between SNPs in candidate genes and pathways that underlie inflammatory responses in humans. All genes from this database were included in our inflammatory genes list.

c. The Comparative Toxicogenomics Database (CTD) located at: http://www.mdibl.org/research/ctd.shtml. The CTD, operated by the Mount Desert Island Biological Laboratory (MDIBL) with support from the National Institutes of Health (NIH), collects gene-environment-disease interactions information from published literature. It is searchable by several methods including disease, gene, chemicals and gene-chemical interactions. We searched GBM to obtain a list of genes found to be modulated by chemical exposures. 
Table 5-1. List of Glioblastoma studies used for compilation of alterations list.

\begin{tabular}{|c|c|c|c|c|c|c|c|c|}
\hline \multirow[b]{2}{*}{$\begin{array}{c}\text { Alteration } \\
\text { Type }\end{array}$} & \multicolumn{7}{|c|}{ Study Author and Year } & \multirow[b]{2}{*}{ Total } \\
\hline & $\begin{array}{c}\text { TCGA } \\
2008 \\
{[25]} \\
\end{array}$ & $\begin{array}{c}\text { Korshunov } \\
2006 \\
{[28]}\end{array}$ & $\begin{array}{c}\text { Freire } \\
2008 \\
{[27]} \\
\end{array}$ & $\begin{array}{c}\text { Margareto } \\
2009 \\
{[29]} \\
\end{array}$ & $\begin{array}{c}\text { Parson } \\
2008 \\
{[30]}\end{array}$ & $\begin{array}{c}\text { Carter } \\
2009 \\
{[26]}\end{array}$ & $\begin{array}{c}\text { COSMIC } \\
{[24]}\end{array}$ & \\
\hline Amplifications & 15 & 35 & 98 & $\mathrm{x}$ & 69 & $\mathrm{x}$ & $\mathrm{x}$ & 217 \\
\hline Deletions & 12 & $\mathrm{x}$ & 44 & $\mathrm{x}$ & 77 & $\mathrm{x}$ & $\mathrm{x}$ & 350 \\
\hline Copy Gains & 158 & 34 & $\mathrm{x}$ & 22 & $\mathrm{x}$ & $\mathrm{x}$ & $\mathrm{x}$ & 214 \\
\hline Copy Losses & 126 & 34 & $\mathrm{x}$ & 1 & $\mathrm{x}$ & $\mathrm{x}$ & $\mathrm{x}$ & 161 \\
\hline $\begin{array}{l}\text { SNP Mutated } \\
\text { Genes }\end{array}$ & 222 & $\mathrm{x}$ & $\mathrm{x}$ & $\mathrm{x}$ & 42 & 17 & 2129 & 2410 \\
\hline $\begin{array}{c}\text { Driver } \\
\text { Mutations }\end{array}$ & $\mathrm{x}$ & $\mathrm{x}$ & $\mathrm{x}$ & $\mathrm{x}$ & 42 & 17 & $\mathrm{x}$ & 59 \\
\hline
\end{tabular}

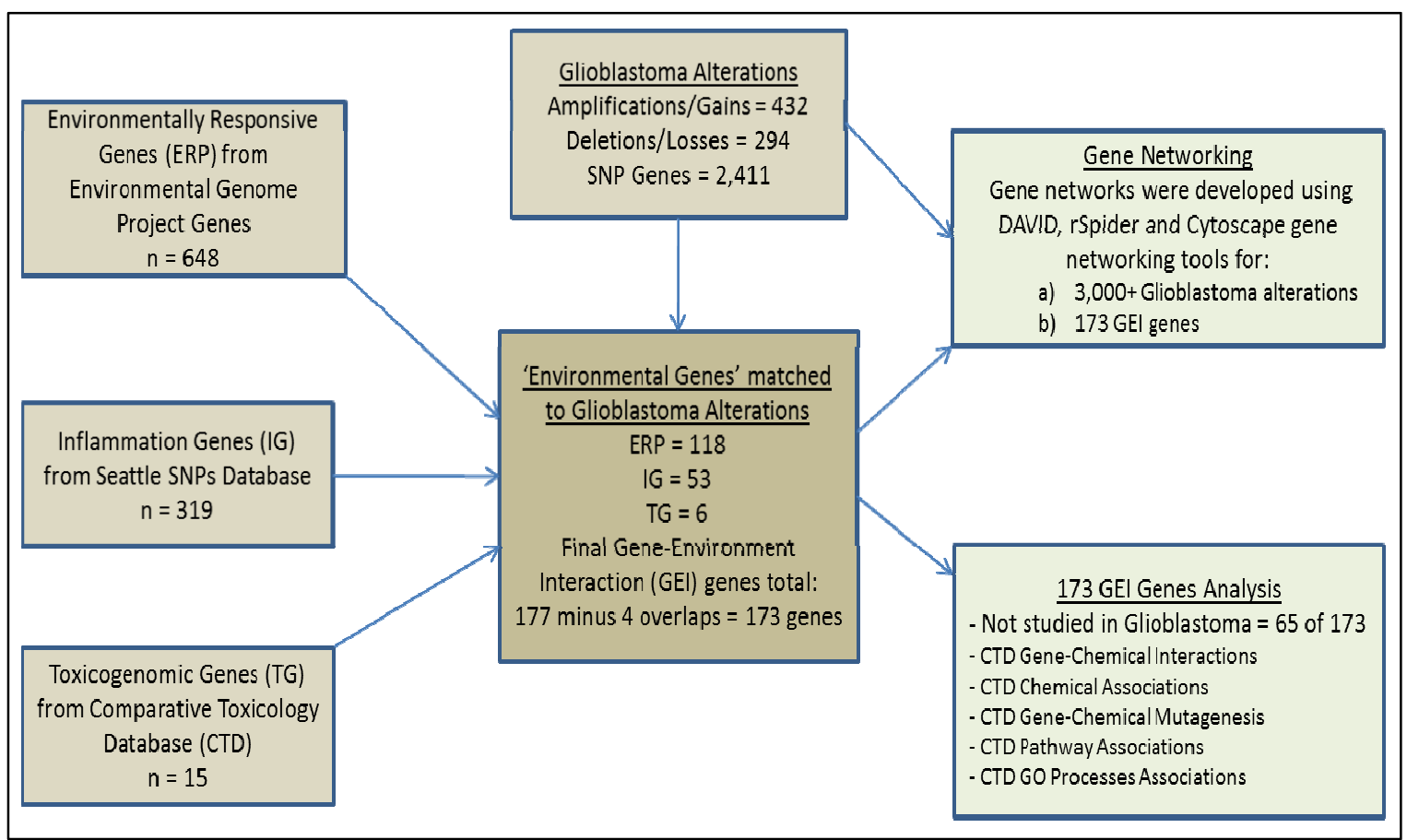

Figure 5-1. Bioinformatics methodology. This flowchart illustrates steps outlined in the methods section by which we identified interactions between three environmentally relevant genomics databases and Glioblastoma alterations.

The gene lists from the glioblastoma alterations search and our environmental genes database search were then inputted into the GeneVenn program [31] to assess their overlap. Gene overlaps between the three environmental gene databases and our 
glioblastoma alterations list were determined. Overlapping genes, referred to as the 'GEI gene list' from this point forward, were used for further analysis including:

1. Pubmatrix (http://pubmatrix.grc.nia.nih.gov), an NIH tool which allows cross referencing of gene lists with search terms, was used to assess whether overlapping genes had been previously studied in relation to glioblastoma.

2. The GEI gene list was searched in the Comparative Toxicology Database for relevant gene-chemical interactions and chemical associations.

3. Both the GEI gene list and the entire Glioblastoma alterations list were subjected to gene networking analysis using the bioinformatics tools RSpider [32] and DAVID [33]. RSpider results were visualized using Cytoscape [34].

\section{RESULTS}

A total of 217 amplified genes, 214 copy number gain genes, 350 deleted genes, 161 copy number loss genes, and 2410 SNP mutated genes were found in the 6 total studies and 1 database we searched (Table 5-1). According to the COSMIC database, 2,129 genes have been found to be mutated in glioblastoma, while 15,733 genes have been sequenced in glioblastoma where no mutation has been found. The top 20 mutated GBM genes in our COSMIC search, with the percentage of mutated genes per tumors analyzed, can be seen in Figure 5-2. In a GeneVenn comparison of our alterations lists, 67 amplified/gain genes and 45 deleted/loss genes were shown to also be mutated in our gene sets, while 6 amplified/gain genes also have copy number deletion or loss in GBM (Figure 5-3). 


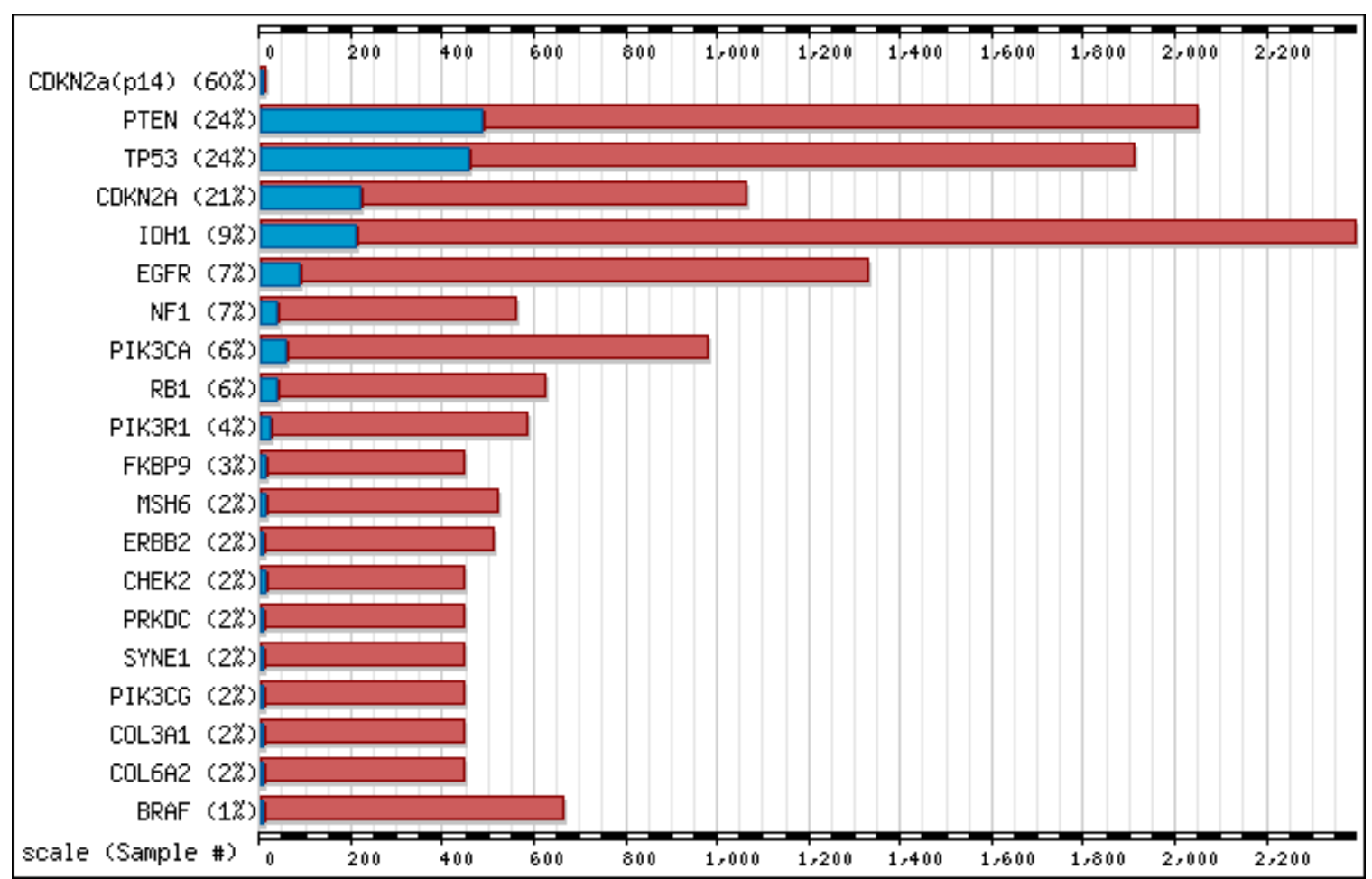

Figure 5-2. Top 20 genes mutated in Glioblastoma according to COSMIC database search. Blue bars represent tissue samples with mutations; Red bars represent all tissue samples.

The search of the environmental databases returned 648 Environmental Genome Project (EGP) genes (environmentally responsive genes), 319 Seattle SNP (SSNP) genes (inflammatory genes), and 15 Comparative Toxicology Database (CTD) genes (toxicogenomic genes). Very little overlap existed between these gene sets (4 between EGP and CTD, 3 between SSNP and CTD, 8 between EGP and SSNP, and 1 between all three databases). Overlapping of our final list of GBM alterations with the environmental genes found 173 genes that have an environmental exposure link and are altered in glioblastoma. These genes are listed in Appendix Table 5 with their gene symbol, gene name, and whether they have ever been previously studied in glioblastoma. Of these 173 genes, a Pubmatrix search found that 65 of our overlapping genes had not been previously assessed in glioblastoma research. The list of 173 genes potentially important 


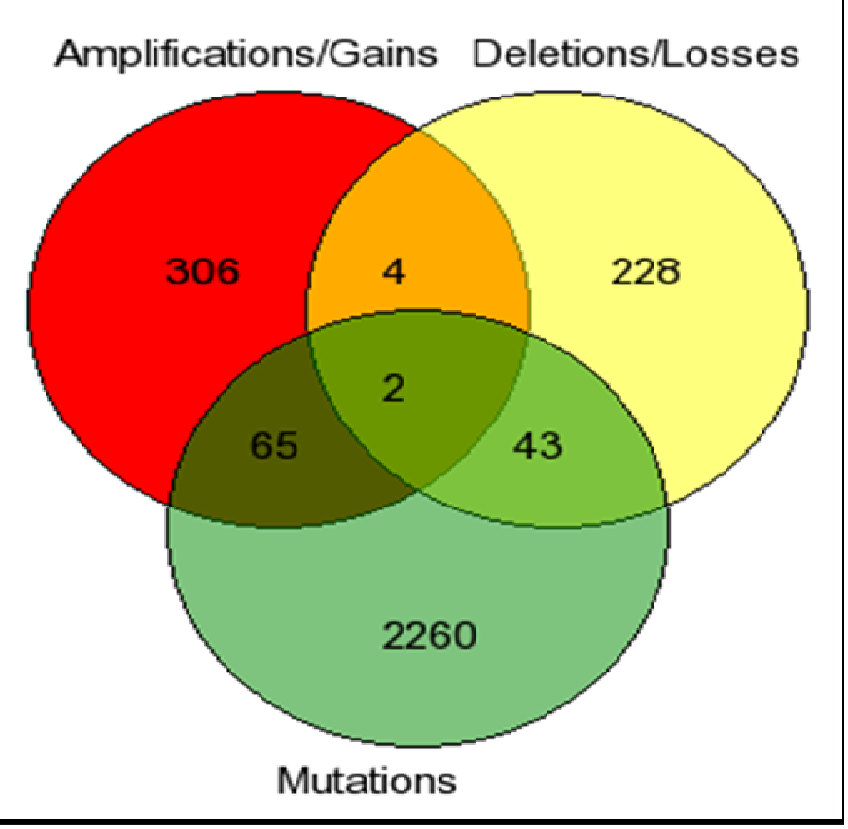

Figure 5-3. Overlap between our Glioblastoma amplified/gain genes, deleted/loss genes, and SNP mutated genes. in GEI in glioblastoma formation was then subjected to analysis in the Comparative Toxicology Database. Results indicate substantial potential for chemical interaction with these set of genes including interactions with chemicals such as arsenic and pesticides such as chlorpyrifos for gene $\mathrm{ABCB} 1$, benzene and bisphenol A for EGFR, and estradiol for MDM2 and NCOA1. In total, our list of 173 genes produced 30,983 genechemical interactions and showed 13,779 chemical associations. A specific search for chemical-gene interactions producing mutagenesis in our genes found 68 results. A list of these genes accompanied their interacting chemical and a brief description of their interaction effect can be found in Appendix Table 6.

The final section of our analysis involved the development of a gene network for our 173 potentially environmentally important GBM genes and a second network for our entire list of over 3,000 GBM alterations. These networks were produced using R spider, a web-based tool for that develops biological networks from user-inputted gene lists by querying the core pathways and reactions contained in the Reactome and KEGG databases. These databases, which use data extracted from biomedical experiments and literature, are currently two of the most complete and best-curated pathway databases. 
RSpider and Cytoscape analysis of our list of 173 GEI GBM genes produced a network with main biological functions of Signaling by Nerve Growth Factor (NGF), DNA Repair, Integrin Cell Surface Interactions, Biological Oxidations, Apoptosis, HIV Infection, Synaptic Transmission, Metabolism of Amino Acids and Derivatives, Signaling by Insulin Receptor, Cell Cycle Checkpoints, and Arachidonic Acid Metabolism. The RSpider/Cytoscape network for the list of GBM alterations again found Signaling by NGF to be the top biological function. Other functions for this gene list were Integrin Cell Surface Interactions, Cell Cycle Checkpoints, Signaling by PDGF, Synaptic Transmission, Signaling by Rho GTPases, Signaling by Insulin Receptor, DNA Repair, Apoptosis, Inositol Phosphate Metabolism, and Metabolism of Carbohydrates. Genes from our list of 173 GEI genes involved in NGF signaling, according to our search of the CTD database include AKT2, BRAF, CASP9, MDM2, NRAS, PTEN, and STAT3.

Analysis by DAVID of the 173 GEI GBM genes found 35 KEGG ontologies significantly represented in the gene list (Table 5-2). The top ontology was 'Pathways in cancer' which contained 42 of the 173 GEI genes. The ontology 'Glioma' was also significant as 13 of the $173 \mathrm{GEI}$ are known glioma genes according to the KEGG database. The top KEGG ontology for the Glioblastoma alterations list according to DAVID analyses was also 'Pathways in Cancer', as 123 genes from the list were in this ontology. A total of $62 \mathrm{KEGG}$ ontologies were significantly represented in this list of over 3,000 mutated genes. Gene ontology results for this list of alterations provide a broad overall picture of pathways potentially affected by or effecting Glioblastoma development. Representations of the 'Pathways in Cancer' and 'Glioma' KEGG 
pathways/ontologies with genes contained in the GEI gene list and GBM gene list highlighted are presented in the Appendix (Appendix Figures 7-10).

\section{DISCUSSION}

Our review of current research on GBM found very few studies that assessed the potential role of gene-environment interaction in their development. Several plausible environmental exposures have been linked to their development however, and therefore the possible biological mechanisms involved need more investigation. Most research on GBM biology to date has focused on a few mechanisms and pathways in their development, including those promoting cell cycle dysregulation and enhanced glioma cell proliferation. These mechanisms include the Rb pathway, the p53 pathway, mitogenic signaling pathways (MAPK, PI3K, PTEN, AKT) and receptor tyrosine kinase signaling molecules (EGFR and PDGFR) [35]. Our bioinformatics investigation found 173 genes with the potential to be involved in GEI in GBM. 65 of these environmentally responsive genes have not been investigated with regards to Glioblastoma, and several of them were shown to have significant potential for response to chemicals and subsequent disease related actions. For example, Chlorpyrifos, an organophosphate insecticide associated with development of neurological disorders [36;37], was shown to bind to ABCB1 gene in our CTD search. While this gene has been studied in Glioblastoma treatment [38], to our knowledge, its potential for involvement in development of GBM through GEI has not been assessed. In fact, 174 of our 176 Glioblastoma altered genes with GEI potential had evidence of gene-chemical relationships in our CTD search, including many with mutagenic relationships (Appendix Table 6). We have shown that 
Table 5-2. KEGG Gene Ontology Results produced by DAVID analysis of 173 GEI Glioblastoma gene list.

\begin{tabular}{|c|c|c|c|c|}
\hline KEGG Gene Ontology & $\begin{array}{l}\text { Gene } \\
\text { Count }\end{array}$ & $\begin{array}{c}\text { \% of } \\
\text { Genes in } \\
\text { Ontology }\end{array}$ & P-Value & Genes in KEGG Gene Ontology Category \\
\hline hsa05200:Pathways in cancer & 42 & 24.4186 & $1.38 \mathrm{E}-20$ & $\begin{array}{l}\text { FGFR2, FGFR1, FGFR3, PTGS2, ERBB2, MLH1, CDH1, PTEN, } \\
\text { MMP2, SHH, CTNNB1, ARNT, IGF1R, CDKN2A, CDKN2B, CASP9, } \\
\text { BCL2, CSF3R, EGF, MYC, FGF2, AKT2, EGFR, MSH6, IL6, BRAF, } \\
\text { MSH2, TGFBR2, TP53, BRCA2, CDK6, RB1, HGF, STAT1, CDK4, } \\
\text { STAT3, NRAS, BAX, MDM2, MAPK9, PTCH2, ABL1 }\end{array}$ \\
\hline hsa05218:Melanoma & 17 & 9.883721 & $2.78 \mathrm{E}-12$ & $\begin{array}{l}\text { EGFR, FGFR1, BRAF, TP53, CDK6, CDH1, RB1, HGF, CDK4, PTEN, } \\
\text { NRAS, IGF1R, CDKN2A, MDM2, EGF, FGF2, AKT2 }\end{array}$ \\
\hline hsa05219:Bladder cancer & 14 & 8.139535 & $4.20 \mathrm{E}-12$ & $\begin{array}{c}\text { EGFR, FGFR3, BRAF, ERBB2, TP53, CDH1, RB1, CDK4, MMP2, } \\
\text { NRAS, CDKN2A, MDM2, EGF, MYC }\end{array}$ \\
\hline hsa05212:Pancreatic cancer & 16 & 9.302326 & $4.73 \mathrm{E}-11$ & $\begin{array}{c}\text { EGFR, BRAF, ERBB2, TGFBR2, TP53, BRCA2, CDK6, RB1, STAT1, } \\
\text { CDK4, STAT3, CDKN2A, CASP9, MAPK9, EGF, AKT2 }\end{array}$ \\
\hline hsa05215:Prostate cancer & 17 & 9.883721 & $1.08 \mathrm{E}-10$ & $\begin{array}{l}\text { EGFR, FGFR2, FGFR1, BRAF, ERBB2, TP53, IGF2, RB1, PTEN, } \\
\text { CTNNB1, NRAS, IGF1R, CASP9, BCL2, MDM2, EGF, AKT2 }\end{array}$ \\
\hline hsa04115:p53 signaling pathway & 15 & 8.72093 & $2.59 \mathrm{E}-10$ & $\begin{array}{l}\text { TP53, CDK6, CHEK1, CHEK2, CDK4, PTEN, ATM, CDKN2A, } \\
\text { CASP9, CCND2, BAX, SERPINE1, GADD45G, MDM2, MDM4 }\end{array}$ \\
\hline hsa05213:Endometrial cancer & 13 & 7.55814 & 1.31E-09 & $\begin{array}{l}\text { EGFR, BRAF, ERBB2, TP53, MLH1, CDH1, PTEN, CTNNB1, NRAS, } \\
\text { CASP9, EGF, MYC, AKT2 }\end{array}$ \\
\hline hsa04110:Cell cycle & 18 & 10.46512 & $2.54 \mathrm{E}-09$ & $\begin{array}{l}\text { CDC7, E2F4, TP53, PRKDC, CDK6, CHEK1, RB1, CHEK2, CDK4, } \\
\text { ATM, CDKN2A, CDKN2B, CCND2, CDKN2C, GADD45G, MDM2, } \\
\text { ABL1, MYC }\end{array}$ \\
\hline hsa05210:Colorectal cancer & 15 & 8.72093 & 4.89E-09 & $\begin{array}{l}\text { EGFR, MSH6, BRAF, MSH2, TGFBR2, TP53, MLH1, CTNNB1, } \\
\text { IGF1R, CASP9, BAX, BCL2, MAPK9, MYC, AKT2 }\end{array}$ \\
\hline hsa05214:Glioma & 13 & 7.55814 & $1.37 \mathrm{E}-08$ & $\begin{array}{c}\text { EGFR, BRAF, TP53, CDK6, RB1, CDK4, PTEN, NRAS, IGF1R, } \\
\text { CDKN2A, MDM2, EGF, AKT2 }\end{array}$ \\
\hline
\end{tabular}




\begin{tabular}{|c|c|c|c|c|}
\hline KEGG Gene Ontology & $\begin{array}{l}\text { Gene } \\
\text { Count }\end{array}$ & $\begin{array}{c}\text { \% of } \\
\text { Genes in } \\
\text { Ontology }\end{array}$ & P-Value & Genes in KEGG Gene Ontology Category \\
\hline hsa05223:Non-small cell lung cancer & 12 & 6.976744 & $2.71 \mathrm{E}-08$ & $\begin{array}{c}\text { EGFR, NRAS, CDKN2A, CASP9, BRAF, ERBB2, TP53, CDK6, RB1, } \\
\text { EGF, CDK4, AKT2 }\end{array}$ \\
\hline hsa05220:Chronic myeloid leukemia & 12 & 6.976744 & $9.21 \mathrm{E}-07$ & $\begin{array}{l}\text { NRAS, CDKN2A, BRAF, TGFBR2, TP53, MDM2, CDK6, RB1, } \\
\text { ABL1, CDK4, MYC, AKT2 }\end{array}$ \\
\hline hsa05222:Small cell lung cancer & 11 & 6.395349 & $2.01 \mathrm{E}-05$ & $\begin{array}{l}\text { PTGS2, CASP9, CDKN2B, BCL2, TP53, CDK6, RB1, CDK4, MYC, } \\
\text { PTEN, AKT2 }\end{array}$ \\
\hline hsa04010:MAPK signaling pathway & 19 & 11.04651 & $3.50 \mathrm{E}-05$ & $\begin{array}{l}\text { EGFR, FGFR2, FGFR1, FGFR3, BRAF, NF1, TGFBR2, TP53, DDIT3, } \\
\text { NRAS, TNFRSF1A, MAP3K8, GADD45G, MAPK9, RAP1B, EGF, } \\
\text { FGF2, MYC, AKT2 }\end{array}$ \\
\hline hsa03430:Mismatch repair & 6 & 3.488372 & $1.49 \mathrm{E}-04$ & MSH6, RFC2, MSH2, POLD1, MLH1, PMS2 \\
\hline hsa04012:ErbB signaling pathway & 10 & 5.813953 & $1.61 \mathrm{E}-04$ & $\begin{array}{l}\text { EGFR, NRAS, BRAF, ERBB2, MAPK9, EGF, ABL1, ABL2, MYC, } \\
\text { AKT2 }\end{array}$ \\
\hline $\begin{array}{l}\text { hsa04060: Cytokine-cytokine receptor } \\
\text { interaction }\end{array}$ & 17 & 9.883721 & $3.14 \mathrm{E}-04$ & $\begin{array}{l}\text { EGFR, IL3, IL6, TNFRSF25, TGFBR2, TNFRSF8, HGF, IFNAR1, } \\
\text { TNFRSF1A, TNFRSF9, IFNA1, TNFRSF1B, TNFRSF11B, IL17B, } \\
\text { IL4R, CSF3R, EGF }\end{array}$ \\
\hline hsa05216:Thyroid cancer & 6 & 3.488372 & 4.70E-04 & NRAS, BRAF, TP53, CDH1, MYC, CTNNB1 \\
\hline hsa04510:Focal adhesion & 14 & 8.139535 & $6.96 \mathrm{E}-04$ & $\begin{array}{l}\text { EGFR, BRAF, ERBB2, HGF, PTEN, CTNNB1, VWF, IGF1R, CCND2, } \\
\text { BCL2, MAPK9, RAP1B, EGF, AKT2 }\end{array}$ \\
\hline $\begin{array}{l}\text { hsa04722: Neurotrophin signaling } \\
\text { pathway }\end{array}$ & 10 & 5.813953 & 0.002176 & $\begin{array}{l}\text { NRAS, BRAF, BCL2, BAX, TP53, MAPK9, RAP1B, ABL1, CSK, } \\
\text { AKT2 }\end{array}$ \\
\hline hsa04630:Jak-STAT signaling pathway & 11 & 6.395349 & 0.002988 & $\begin{array}{l}\text { IL3, IFNA1, IL6, CCND2, IL4R, CSF3R, STAT1, MYC, STAT3, } \\
\text { IFNAR1, AKT2 }\end{array}$ \\
\hline hsa04210:Apoptosis & 8 & 4.651163 & 0.003823 & TNFRSF1A, IL3, CASP9, BCL2, BAX, TP53, ATM, AKT2 \\
\hline $\begin{array}{l}\text { hsa05014:Amyotrophic lateral sclerosis } \\
\text { (ALS) }\end{array}$ & 6 & 3.488372 & 0.007297 & TNFRSF1A, TNFRSF1B, CASP9, BCL2, BAX, TP53 \\
\hline hsa04520:Adherens junction & 7 & 4.069767 & 0.00853 & EGFR, IGF1R, FGFR1, ERBB2, TGFBR2, CDH1, CTNNB1 \\
\hline
\end{tabular}




\begin{tabular}{|c|c|c|c|c|}
\hline KEGG Gene Ontology & $\begin{array}{c}\text { Gene } \\
\text { Count }\end{array}$ & $\begin{array}{c}\% \text { of } \\
\text { Genes in } \\
\text { Ontology }\end{array}$ & P-Value & Genes in KEGG Gene Ontology Category \\
\hline $\begin{array}{l}\text { hsa04620: Toll-like receptor signaling } \\
\text { pathway }\end{array}$ & 8 & 4.651163 & 0.008628 & IKBKE, IFNA1, IL6, MAP3K8, MAPK9, STAT1, IFNAR1, AKT2 \\
\hline hsa03420: Nucleotide excision repair & 5 & 2.906977 & 0.018309 & ERCC5, RFC2, DDB1, POLD1, POLE \\
\hline $\begin{array}{l}\text { hsa04920:Adipocytokine signaling } \\
\text { pathway }\end{array}$ & 6 & 3.488372 & 0.019018 & TNFRSF1A, PPARA, TNFRSF1B, MAPK9, STAT3, AKT2 \\
\hline $\begin{array}{l}\text { hsa04610: Complement and coagulation } \\
\text { cascades }\end{array}$ & 6 & 3.488372 & 0.021341 & F13B, VWF, F3, F13A1, SERPINE1, SERPING1 \\
\hline hsa05211: Renal cell carcinoma & 6 & 3.488372 & 0.022569 & NRAS, BRAF, RAP1B, HGF, ARNT, AKT2 \\
\hline $\begin{array}{l}\text { hsa04810: Regulation of actin } \\
\text { cytoskeleton }\end{array}$ & 11 & 6.395349 & 0.026801 & $\begin{array}{l}\text { EGFR, FGFR2, FGFR1, NRAS, ITGAL, FGFR3, BRAF, IGF2, EGF, } \\
\text { CSK, FGF2 }\end{array}$ \\
\hline hsa05221: Acute myeloid leukemia & 5 & 2.906977 & 0.044768 & NRAS, BRAF, MYC, STAT3, AKT2 \\
\hline $\begin{array}{l}\text { hsa04914:Progesterone-mediated oocyte } \\
\text { maturation }\end{array}$ & 6 & 3.488372 & 0.048636 & PGR, IGF1R, BRAF, MAPK9, IGF2, AKT2 \\
\hline $\begin{array}{l}\text { hsa00980: Metabolism of xenobiotics by } \\
\text { cytochrome P450 }\end{array}$ & 5 & 2.906977 & 0.049693 & CYP3A4, CYP1B1, CYP2C19, CYP2E1, UGT1A1 \\
\hline hsa04370:VEGF signaling pathway & 5 & 2.906977 & 0.095568 & NRAS, PTGS2, CASP9, NOS3, AKT2 \\
\hline
\end{tabular}


many of these genes have not been studied in Glioblastoma, and therefore their potential for involvement in GBM should be assessed in future investigations into the etiology of GBM.

Through gene network and gene ontology analysis, we were able to obtain significant biological functions involved in our set of GEI and GBM alteration genes lists. The top function in both gene sets involved NGF, a small secreted protein important in axonal growth and integral in the differentiation, maintenance and survival of its targeted nerve cells. NGF has been implicated in several cancers including liver cancer [39], oral cancer [40], breast cancer [41], and several brain cancers [42-44], including glioblastoma [45;46]. The survival and proliferation of breast cancer cells are in fact, strongly stimulated by NGF [47], and NGF, through direction of downstream signaling of PI3K, ERK, and VEGF, may be an important stimulator of breast cancer angiogenesis [48]. Furthermore, the potential importance of NGF on the development of tumors through shifting proapoptotic signals in cancer cells has been shown in GBM cells [45]. Importantly, environmental factors such as PCBs are believed to have the ability to influence the NGF neurotrophic system [49]. One mechanism for the influence of NGF to environmental factors may be through $\mathrm{Nrf}$, a redox-sensitive transcription factor that has been shown to direct expression of cytoprotective phase 2 genes such as thioredoxin reductase 1 (TXNRD1) in GBM cells [50]. There are obvious limitations to this type of bioinformatics analyses of course. While this analysis provides numerous hypotheses for potential GEI interactions, it can only suggest possibilities, and therefore further research in a lab setting is necessary to validate their involvement in GBM. Another limitation is the nonrandom choice of our set of GBM alterations. While we did choose studies and 
databases we felt would provide a comprehensive set of alterations, we did not assess the entire set of literature on GBM alterations, and therefore may have missed some potential alterations in our analysis. Furthermore, we have not included epigenetic genes in our analysis and therefore may have missed other potential GEI pathways to GBM through these mechanisms. While these are shortcomings of this type of research, the clear benefit of this study in particular, is the production of a list of genes with potential to contribute to GBM that have not previously been studied. Furthermore, generation of GEI data relevant to GBM etiology through this bioinformatics method provides highly use information for hypothesis generation. 


\section{Reference List}

1. National Institutes of Health. What you need to know about brain tumors. National Cancer Institute. NIH Publication No. 02-1558. 2002.

2. Rajaraman,P., Stewart,P.A., Samet,J.M., Schwartz,B.S., Linet,M.S., Zahm,S.H., Rothman,N., Yeager,M., Fine,H.A., Black,P.M., Loeffler,J., Shapiro,W.R., Selker,R.G., and Inskip,P.D. (2006) Lead, genetic susceptibility, and risk of adult brain tumors. Cancer Epidemiol Biomarkers Prev., 15, 2514-2520.

3. Schwartzbaum,J.A., Ahlbom,A., Lonn,S., Warholm,M., Rannug,A., Auvinen,A., Christensen,H.C., Henriksson,R., Johansen,C., Lindholm,C., Malmer,B., Salminen,T., Schoemaker,M.J., Swerdlow,A.J., and Feychting,M. (2007) An international case-control study of glutathione transferase and functionally related polymorphisms and risk of primary adult brain tumors. Cancer Epidemiol Biomarkers Prev., 16, 559-565.

4. de,A.M., Barnholtz,J.S., Amos,C.I., Adatto,P., Spencer,C., and Bondy,M.L. (2001) Segregation analysis of cancer in families of glioma patients. Genet.Epidemiol., 20, 258-270.

5. McEachin,R.C., Keller,B.J., Saunders,E.F., and McInnis,M.G. (2008) Modeling gene-by-environment interaction in comorbid depression with alcohol use disorders via an integrated bioinformatics approach. BioData.Min, 1, 2.

6. McEachin,R.C., Saccone,N.L., Saccone,S.F., Kleyman-Smith,Y.D., Kar,T., Kare,R.K., Ade,A.S., Sartor,M.A., Cavalcoli,J.D., and McInnis,M.G. (2010) Modeling complex genetic and environmental influences on comorbid bipolar disorder with tobacco use disorder. BMC.Med.Genet., 11, 14.

7. McEachin,R.C., Chen,H., Sartor,M.A., Saccone,S.F., Keller,B.J., Prossin,A.R., Cavalcoli,J.D., and McInnis,M.G. (2010) A genetic network model of cellular responses to lithium treatment and cocaine abuse in bipolar disorder. BMC.Syst.Biol., 4, 158.

8. Davis,A.P., Murphy,C.G., Saraceni-Richards,C.A., Rosenstein,M.C., Wiegers,T.C., and Mattingly,C.J. (2009) Comparative Toxicogenomics Database: a knowledgebase and discovery tool for chemical-gene-disease networks. Nucleic Acids Res., 37, D786-D792.

9. Rieder,M.J., Livingston,R.J., Stanaway,I.B., and Nickerson,D.A. (2008) The environmental genome project: reference polymorphisms for drug metabolism genes and genome-wide association studies. Drug Metab Rev., 40, 241-261. 
10. Bauer-Mehren,A., Bundschus,M., Rautschka,M., Mayer,M.A., Sanz,F., and Furlong,L.I. (2011) Gene-disease network analysis reveals functional modules in mendelian, complex and environmental diseases. PLoS.One., 6, e20284.

11. Herbert,M.R., Russo,J.P., Yang,S., Roohi,J., Blaxill,M., Kahler,S.G., Cremer,L., and Hatchwell,E. (2006) Autism and environmental genomics. Neurotoxicology, 27, 671-684.

12. Myllykangas,S., Tikka,J., Bohling,T., Knuutila,S., and Hollmen,J. (2008) Classification of human cancers based on DNA copy number amplification modeling. BMC.Med.Genomics, 1, 15.

13. Santarius,T., Shipley,J., Brewer,D., Stratton,M.R., and Cooper,C.S. (2010) A census of amplified and overexpressed human cancer genes. Nat.Rev.Cancer, 10, 59-64.

14. Vogt,N., Lefevre,S.H., Apiou,F., Dutrillaux,A.M., Cor,A., Leuraud,P., Poupon,M.F., Dutrillaux,B., Debatisse,M., and Malfoy,B. (2004) Molecular structure of double-minute chromosomes bearing amplified copies of the epidermal growth factor receptor gene in gliomas. Proc.Natl.Acad.Sci.U.S.A, 101, 11368-11373.

15. Myllykangas,S. and Knuutila,S. (2006) Manifestation, mechanisms and mysteries of gene amplifications. Cancer Lett., 232, 79-89.

16. Stranger,B.E., Forrest,M.S., Dunning,M., Ingle,C.E., Beazley,C., Thorne,N., Redon,R., Bird,C.P., de,G.A., Lee,C., Tyler-Smith,C., Carter,N., Scherer,S.W., Tavare,S., Deloukas,P., Hurles,M.E., and Dermitzakis,E.T. (2007) Relative impact of nucleotide and copy number variation on gene expression phenotypes. Science, 315, 848-853.

17. Manolio,T.A. (2010) Genomewide association studies and assessment of the risk of disease. N.Engl.J.Med., 363, 166-176.

18. Wang,X., Tomso,D.J., Liu,X., and Bell,D.A. (2005) Single nucleotide polymorphism in transcriptional regulatory regions and expression of environmentally responsive genes. Toxicol.Appl.Pharmacol., 207, 84-90.

19. Erichsen,H.C. and Chanock,S.J. (2004) SNPs in cancer research and treatment. Br.J.Cancer, 90, 747-751.

20. McCarroll,S.A., Kuruvilla,F.G., Korn,J.M., Cawley,S., Nemesh,J., Wysoker,A., Shapero,M.H., de Bakker,P.I., Maller,J.B., Kirby,A., Elliott,A.L., Parkin,M., Hubbell,E., Webster,T., Mei,R., Veitch,J., Collins,P.J., Handsaker,R., Lincoln,S., Nizzari,M., Blume,J., Jones,K.W., Rava,R., Daly,M.J., Gabriel,S.B., and 
Altshuler,D. (2008) Integrated detection and population-genetic analysis of SNPs and copy number variation. Nat.Genet., 40, 1166-1174.

21. Arlt,M.F., Ozdemir,A.C., Birkeland,S.R., Lyons,R.H., Jr., Glover,T.W., and Wilson,T.E. (2011) Comparison of constitutional and replication stress-induced genome structural variation by SNP array and mate-pair sequencing. Genetics, $187,675-683$.

22. Guerrero-Bosagna,C., Settles,M., Lucker,B., and Skinner,M.K. (2010) Epigenetic transgenerational actions of vinclozolin on promoter regions of the sperm epigenome. PLoS.One., 5.

23. Herbert,M.R., Russo,J.P., Yang,S., Roohi,J., Blaxill,M., Kahler,S.G., Cremer,L., and Hatchwell,E. (2006) Autism and environmental genomics. Neurotoxicology, 27, 671-684.

24. Forbes,S.A., Bindal,N., Bamford,S., Cole,C., Kok,C.Y., Beare,D., Jia,M., Shepherd,R., Leung,K., Menzies,A., Teague,J.W., Campbell,P.J., Stratton,M.R., and Futreal,P.A. (2011) COSMIC: mining complete cancer genomes in the Catalogue of Somatic Mutations in Cancer. Nucleic Acids Res., 39, D945-D950.

25. The Cancer Genome Atlas. (2008) Comprehensive genomic characterization defines human glioblastoma genes and core pathways. Nature, 455, 1061-1068.

26. Carter,H., Chen,S., Isik,L., Tyekucheva,S., Velculescu,V.E., Kinzler,K.W., Vogelstein,B., and Karchin,R. (2009) Cancer-specific high-throughput annotation of somatic mutations: computational prediction of driver missense mutations. Cancer Res., 69, 6660-6667.

27. Freire,P., Vilela,M., Deus,H., Kim,Y.W., Koul,D., Colman,H., Aldape,K.D., Bogler,O., Yung,W.K., Coombes,K., Mills,G.B., Vasconcelos,A.T., and Almeida,J.S. (2008) Exploratory analysis of the copy number alterations in glioblastoma multiforme. PLoS.One., 3, e4076.

28. Korshunov,A., Sycheva,R., and Golanov,A. (2006) Genetically distinct and clinically relevant subtypes of glioblastoma defined by array-based comparative genomic hybridization (array-CGH). Acta Neuropathol., 111, 465-474.

29. Margareto,J., Leis,O., Larrarte,E., Pomposo,I.C., Garibi,J.M., and Lafuente,J.V. (2009) DNA copy number variation and gene expression analyses reveal the implication of specific oncogenes and genes in GBM. Cancer Invest, 27, 541-548.

30. Parsons,D.W., Jones,S., Zhang,X., Lin,J.C., Leary,R.J., Angenendt,P., Mankoo,P., Carter,H., Siu,I.M., Gallia,G.L., Olivi,A., McLendon,R., Rasheed,B.A., Keir,S., Nikolskaya,T., Nikolsky,Y., Busam,D.A., Tekleab,H., Diaz,L.A., Jr., Hartigan,J., Smith,D.R., Strausberg,R.L., Marie,S.K., Shinjo,S.M., Yan,H., Riggins,G.J., 
Bigner,D.D., Karchin,R., Papadopoulos,N., Parmigiani,G., Vogelstein,B., Velculescu,V.E., and Kinzler,K.W. (2008) An integrated genomic analysis of human glioblastoma multiforme. Science, 321, 1807-1812.

31. Pirooznia,M., Nagarajan,V., and Deng,Y. (2007) GeneVenn - A web application for comparing gene lists using Venn diagrams. Bioinformation., 1, 420-422.

32. Antonov,A.V., Schmidt,E.E., Dietmann,S., Krestyaninova,M., and Hermjakob,H. (2010) R spider: a network-based analysis of gene lists by combining signaling and metabolic pathways from Reactome and KEGG databases. Nucleic Acids Res., 38, W78-W83.

33. Huang,d.W., Sherman,B.T., and Lempicki,R.A. (2009) Systematic and integrative analysis of large gene lists using DAVID bioinformatics resources. Nat.Protoc., 4 , 44-57.

34. Shannon,P., Markiel,A., Ozier,O., Baliga,N.S., Wang,J.T., Ramage,D., Amin,N., Schwikowski,B., and Ideker,T. (2003) Cytoscape: a software environment for integrated models of biomolecular interaction networks. Genome Res., 13, 24982504 .

35. Furnari,F.B., Fenton,T., Bachoo,R.M., Mukasa,A., Stommel,J.M., Stegh,A., Hahn,W.C., Ligon,K.L., Louis,D.N., Brennan,C., Chin,L., DePinho,R.A., and Cavenee,W.K. (2007) Malignant astrocytic glioma: genetics, biology, and paths to treatment. Genes Dev., 21, 2683-2710.

36. Cao,J., Varnell,A.L., and Cooper,D.C. (2011) Gulf War Syndrome: A role for organophosphate induced plasticity of locus coeruleus neurons. Nature Precedings.

37. Rauh,V.A., Garfinkel,R., Perera,F.P., Andrews,H.F., Hoepner,L., Barr,D.B., Whitehead,R., Tang,D., and Whyatt,R.W. (2006) Impact of prenatal chlorpyrifos exposure on neurodevelopment in the first 3 years of life among inner-city children. Pediatrics, 118, e1845-e1859.

38. Schaich,M., Kestel,L., Pfirrmann,M., Robel,K., Illmer,T., Kramer,M., Dill,C., Ehninger,G., Schackert,G., and Krex,D. (2009) A MDR1 (ABCB1) gene single nucleotide polymorphism predicts outcome of temozolomide treatment in glioblastoma patients. Annals of Oncology, 20, 175-181.

39. Rasi,G., Serafino,A., Bellis,L., Lonardo,M.T., Andreola,F., Zonfrillo,M., Vennarecci,G., Pierimarchi,P., Sinibaldi,V.P., Ettorre,G.M., Santoro,E., and Puoti,C. (2007) Nerve growth factor involvement in liver cirrhosis and hepatocellular carcinoma. World J.Gastroenterol., 13, 4986-4995. 
40. Ye,Y., Dang,D., Zhang,J., Viet,C.T., Lam,D.K., Dolan,J., Gibbs,J., and Schmidt,B.L. (2011) Nerve growth factor links oral cancer progression, pain, and cachexia. Mol.Cancer Ther..

41. Dolle,L., El Yazidi-Belkoura,I., Adriaenssens,E., Nurcombe,V., and Hondermarck,H. (2003) Nerve growth factor overexpression and autocrine loop in breast cancer cells. Oncogene, 22, 5592-5601.

42. Holub,J.L., Qiu,Y.Y., Chu,F., and Madonna,M.B. (2011) The role of nerve growth factor in caspase-dependent apoptosis in human $\mathrm{BE}(2) \mathrm{C}$ neuroblastoma. J.Pediatr.Surg., 46, 1191-1196.

43. Marchetti,D., Mrak,R.E., Paulsen,D.D., and Sinnappah-Kang,N.D. (2007) Neurotrophin receptors and heparanase: a functional axis in human medulloblastoma invasion. J.Exp.Clin.Cancer Res., 26, 5-23.

44. Weiner,H.L. (1995) The role of growth factor receptors in central nervous system development and neoplasia. Neurosurgery, 37, 179-193.

45. Brown,M.C., Staniszewska,I., Lazarovici,P., Tuszynski,G.P., Del,V.L., and Marcinkiewicz,C. (2008) Regulatory effect of nerve growth factor in alpha9beta1 integrin-dependent progression of glioblastoma. Neuro.Oncol., 10, 968-980.

46. Giraud,S., Loum,E., Bessette,B., Mathonnet,M., and Lalloue,F. (2011) P75 neurotrophin receptor is sequestered in the Golgi apparatus of the U-87 MG human glioblastoma cell line. Int.J.Oncol., 38, 391-399.

47. Dolle,L., Adriaenssens,E., El Yazidi-Belkoura,I., Le,B., X, Nurcombe,V., and Hondermarck,H. (2004) Nerve growth factor receptors and signaling in breast cancer. Curr.Cancer Drug Targets., 4, 463-470.

48. Romon,R., Adriaenssens,E., Lagadec,C., Germain,E., Hondermarck,H., and Le,B., X (2010) Nerve growth factor promotes breast cancer angiogenesis by activating multiple pathways. Mol.Cancer, 9, 157.

49. Angus,W.G. and Contreras,M.L. (1994) The effects of Aroclor 1254 on undifferentiated and NGF-stimulated differentiating PC12 cells. Neurotoxicology, $15,809-817$.

50. Mimura,J., Kosaka,K., Maruyama,A., Satoh,T., Harada,N., Yoshida,H., Satoh,K., Yamamoto,M., and Itoh,K. (2011) Nrf2 regulates NGF mRNA induction by carnosic acid in $\mathrm{T} 98 \mathrm{G}$ glioblastoma cells and normal human astrocytes. J.Biochem., 150, 209-217. 
APPENDIX 
Appendix Table 1. Significantly over-expressed gene list from Oncomine metaanalysis of normal vs. astrocytoma studies. *Genes are ranked by significance in Oncomine. ${ }^{* *}$ Genes were considered significant in the meta-analysis, and chosen for further analysis, if they were found in at least in at least 7 of 10 meta-analyzed studies.

\begin{tabular}{|c|c|c|c|c|c|}
\hline $\begin{array}{c}\text { Gene Significance } \\
\text { Rank* }\end{array}$ & Gene Symbol & $\begin{array}{l}\text { Studies } \\
\text { (of 10)** }\end{array}$ & $\begin{array}{c}\text { Gene Significance } \\
\text { Rank* }\end{array}$ & Gene Symbol & $\begin{array}{l}\text { Studies } \\
\text { (of 10)** }\end{array}$ \\
\hline 1 & SYNCRIP & 9 & 187 & PLAU & 10 \\
\hline 2 & RAB31 & 10 & 188 & HLA-DRB1 & 10 \\
\hline 3 & HLA-G & 8 & 189 & SERPING1 & 10 \\
\hline 4 & FN1 & 10 & 190 & RB1 & 8 \\
\hline 5 & HLA-J & 7 & 191 & NFKB1A & 10 \\
\hline 6 & SOX4 & 10 & 192 & PTTG1IP & 10 \\
\hline 7 & $\mathrm{C} 1 \mathrm{R}$ & 10 & 193 & RPL12 & 9 \\
\hline 8 & SNRPG & 9 & 194 & CXCR4 & 9 \\
\hline 9 & NAMPT & 9 & 195 & FYB & 10 \\
\hline 10 & TIMP3 & 10 & 196 & ITGAV & 10 \\
\hline 11 & GNB2L1 & 10 & 197 & ISG15 & 10 \\
\hline 12 & IGFBP7 & 9 & 198 & GALNT1 & 10 \\
\hline 13 & HIF1A & 10 & 199 & SEC11A & 8 \\
\hline 14 & RPLP0 & 9 & 200 & EMP3 & 10 \\
\hline 15 & ANXA2 & 10 & 201 & IFI44 & 8 \\
\hline 16 & LPL & 10 & 202 & CAV1 & 10 \\
\hline 17 & ID3 & 7 & 203 & RIT1 & 10 \\
\hline 18 & PRPF40A & 9 & 204 & ATP6V0E1 & 9 \\
\hline 19 & MARCKS & 10 & 205 & RBMS1 & 9 \\
\hline 20 & P4HB & 10 & 206 & SMAD1 & 10 \\
\hline 21 & PALLD & 8 & 207 & LPCAT1 & 8 \\
\hline 22 & COL4A1 & 10 & 208 & FOXD1 & 9 \\
\hline 23 & PRDX4 & 10 & 209 & EIF4A3 & 10 \\
\hline 24 & SERBP1 & 9 & 210 & AEBP1 & 10 \\
\hline 25 & IFI16 & 10 & 211 & MYCBP & 10 \\
\hline 26 & PROS1 & 10 & 212 & DDX39 & 8 \\
\hline 27 & DPYSL3 & 10 & 213 & CTSO & 10 \\
\hline 28 & IDH1 & 8 & 214 & IL13RA1 & 10 \\
\hline 29 & DYNLT1 & 9 & 215 & CFI & 9 \\
\hline 30 & NONO & 10 & 216 & TFPI & 10 \\
\hline 31 & SOD2 & 10 & 217 & G3BP1 & 10 \\
\hline 32 & SPARC & 10 & 218 & DAG1 & 10 \\
\hline 33 & TIMP4 & 10 & 219 & CKS2 & 10 \\
\hline 34 & DBI & 9 & 220 & PABPC1 & 10 \\
\hline 35 & CD151 & 10 & 221 & AK2 & 9 \\
\hline
\end{tabular}




\begin{tabular}{|c|c|c|c|c|c|}
\hline $\begin{array}{c}\text { Gene Significance } \\
\text { Rank* }\end{array}$ & Gene Symbol & $\begin{array}{c}\text { Studies } \\
(\text { of 10)** }\end{array}$ & $\begin{array}{c}\text { Gene Significance } \\
\text { Rank* }\end{array}$ & Gene Symbol & $\begin{array}{c}\text { Studies } \\
\text { (of 10)*** }\end{array}$ \\
\hline 36 & SNRPE & 9 & 222 & PTPN12 & 10 \\
\hline 37 & LYPLA1 & 9 & 223 & ILF2 & 10 \\
\hline 38 & ZFP36L2 & 10 & 224 & SP3 & 10 \\
\hline 39 & HLA-F & 10 & 225 & SSR4 & 10 \\
\hline 40 & HLA-B & 8 & 226 & SOX6 & 7 \\
\hline 41 & PTBP1 & 9 & 227 & LAPTM4B & 9 \\
\hline 42 & PCNA & 10 & 228 & CDKN2C & 9 \\
\hline 43 & COL1A2 & 10 & 229 & F13A1 & 10 \\
\hline 44 & BTF3 & 9 & 230 & SP110 & 7 \\
\hline 45 & WNT5A & 10 & 231 & TOP1 & 10 \\
\hline 46 & CCND2 & 10 & 232 & ANXA5 & 10 \\
\hline 47 & CD44 & 10 & 233 & MUC1 & 10 \\
\hline 48 & EIF4A1 & 10 & 234 & VAT1 & 10 \\
\hline 49 & CSDA & 10 & 235 & UBE2J1 & 9 \\
\hline 50 & PDLIM5 & 9 & 236 & KCTD12 & 7 \\
\hline 51 & HLA-E & 9 & 237 & INPPL1 & 10 \\
\hline 52 & NNMT & 10 & 238 & TAP1 & 10 \\
\hline 53 & CD99 & 10 & 239 & STAT1 & 10 \\
\hline 54 & IGFBP5 & 10 & 240 & GBP1 & 10 \\
\hline 55 & ANXA1 & 10 & 241 & PHLDA1 & 10 \\
\hline 56 & CALCRL & 10 & 242 & COPB2 & 10 \\
\hline 57 & IGFBP2 & 9 & 243 & DECR1 & 10 \\
\hline 58 & EMP1 & 8 & 244 & COL4A2 & 10 \\
\hline 59 & BTG1 & 10 & 245 & SNRNP200 & 8 \\
\hline 60 & SRPX & 10 & 246 & SOX9 & 10 \\
\hline 61 & SSR2 & 9 & 247 & KIF14 & 10 \\
\hline 62 & PRRX1 & 8 & 248 & ACBD3 & 9 \\
\hline 63 & TRAF3IP2 & 9 & 249 & DARS & 10 \\
\hline 64 & CDK4 & 10 & 250 & TAPBP & 9 \\
\hline 65 & EGFR & 10 & 251 & LYN & 10 \\
\hline 66 & TOP2A & 10 & 252 & CHI3L2 & 10 \\
\hline 67 & PTPRZ1 & 10 & 253 & BCL6 & 10 \\
\hline 68 & SAT1 & 10 & 254 & ILF3 & 10 \\
\hline 69 & $\mathrm{ABCC} 3$ & 9 & 255 & LMNB1 & 9 \\
\hline 70 & WEE1 & 10 & 256 & TGIF1 & 10 \\
\hline 71 & TAGN2 & 9 & 257 & NID1 & 10 \\
\hline 72 & S100A10 & 10 & 258 & PPP4C & 10 \\
\hline 73 & MCM3 & 10 & 259 & CANX & 10 \\
\hline 74 & STAT3 & 10 & 260 & NMI & 10 \\
\hline 75 & RPS2 & 9 & 261 & COL1A1 & 7 \\
\hline
\end{tabular}




\begin{tabular}{|c|c|c|c|c|c|}
\hline $\begin{array}{c}\text { Gene Significance } \\
\text { Rank* }\end{array}$ & Gene Symbol & $\begin{array}{c}\text { Studies } \\
(\text { of 10)** }\end{array}$ & $\begin{array}{c}\text { Gene Significance } \\
\text { Rank* }\end{array}$ & Gene Symbol & $\begin{array}{c}\text { Studies } \\
\text { (of 10)*** }\end{array}$ \\
\hline 76 & BTN3A3 & 9 & 262 & SEC61G & 9 \\
\hline 77 & MTHFD2 & 10 & 263 & TRIO & 10 \\
\hline 78 & RPS19 & 10 & 264 & DNALI1 & 9 \\
\hline 79 & VCAN & 10 & 265 & $\mathrm{~F} 2 \mathrm{R}$ & 10 \\
\hline 80 & IRAK1 & 10 & 266 & PSMB9 & 9 \\
\hline 81 & CDH11 & 10 & 267 & C1orf61 & 10 \\
\hline 82 & RPL18A & 9 & 268 & CEBPD & 9 \\
\hline 83 & DAB2 & 10 & 269 & SLC2A5 & 10 \\
\hline 84 & TMX1 & 9 & 270 & TCF4 & 10 \\
\hline 85 & PSMB8 & 7 & 271 & LSM7 & 8 \\
\hline 86 & HLA-A & 10 & 272 & EDNRA & 10 \\
\hline 87 & CD63 & 8 & 273 & PLXNB2 & 8 \\
\hline 88 & HSD17B10 & 10 & 274 & SSR1 & 10 \\
\hline 89 & DAP & 10 & 275 & SCP2 & 10 \\
\hline 90 & UBE2L6 & 9 & 276 & SUPR1 & 9 \\
\hline 91 & DFNA5 & 7 & 277 & PXDN & 10 \\
\hline 92 & TGFB1 & 10 & 278 & OSMR & 9 \\
\hline 93 & YBX1 & 8 & 279 & RNASE6 & 10 \\
\hline 94 & $\mathrm{C} 1 \mathrm{~S}$ & 10 & 280 & IL1RAP & 9 \\
\hline 95 & FCGBP & 10 & 281 & GLB1 & 10 \\
\hline 96 & PYGL & 10 & 282 & SON & 10 \\
\hline 97 & SHMT2 & 10 & 283 & LIMS1 & 10 \\
\hline 98 & PLOD2 & 10 & 284 & NEDD4 & 10 \\
\hline 99 & ODC1 & 10 & 285 & ZNF22 & 10 \\
\hline 100 & VIM & 10 & 286 & WTAP & 10 \\
\hline 101 & PSMA2 & 10 & 287 & RPL29 & 10 \\
\hline 102 & LTF & 7 & 288 & EIF3B & 10 \\
\hline 103 & IGFBP3 & 10 & 289 & TM9SF1 & 10 \\
\hline 104 & $\mathrm{ABCA} 1$ & 8 & 290 & EIF3E & 10 \\
\hline 105 & WDR1 & 8 & 291 & CD14 & 10 \\
\hline 106 & NCK1 & 10 & 292 & TNX8 & 7 \\
\hline 107 & B2M & 10 & 293 & ENTPD1 & 10 \\
\hline 108 & KDELR2 & 10 & 294 & RBBP4 & 10 \\
\hline 109 & CTSC & 10 & 295 & GPR56 & 8 \\
\hline 110 & GNAS & 10 & 296 & STAB1 & 8 \\
\hline 111 & CHI3L1 & 10 & 297 & BUD31 & 10 \\
\hline 112 & SFRS3 & 10 & 298 & DTYMK & 10 \\
\hline 113 & RAB13 & 8 & 299 & LRP10 & 8 \\
\hline 114 & ADAM9 & 10 & 300 & TRIB2 & 10 \\
\hline 115 & TNC & 10 & 301 & GNA12 & 9 \\
\hline
\end{tabular}




\begin{tabular}{|c|c|c|c|c|c|}
\hline $\begin{array}{c}\text { Gene Significance } \\
\text { Rank* }\end{array}$ & Gene Symbol & $\begin{array}{c}\text { Studies } \\
(\text { of 10)** }\end{array}$ & $\begin{array}{c}\text { Gene Significance } \\
\text { Rank* }\end{array}$ & Gene Symbol & $\begin{array}{c}\text { Studies } \\
\text { (of 10)*** }\end{array}$ \\
\hline 116 & HNMT & 9 & 302 & RBMX & 10 \\
\hline 117 & CALD1 & 10 & 303 & HEBP2 & 9 \\
\hline 118 & APOC1 & 10 & 304 & SFRS1 & 9 \\
\hline 119 & PSME2 & 10 & 305 & ARHGDIB & 10 \\
\hline 120 & MCL1 & 10 & 306 & FLNA & 10 \\
\hline 121 & PHB2 & 10 & 307 & VCAM1 & 10 \\
\hline 122 & MYC & 10 & 308 & CSNK1A1 & 10 \\
\hline 123 & RELA & 9 & 309 & PSMF1 & 10 \\
\hline 124 & PLTP & 8 & 310 & PDIA6 & 9 \\
\hline 125 & SOAT1 & 7 & 311 & GNS & 10 \\
\hline 126 & NME4 & 10 & 312 & RUNX1 & 10 \\
\hline 127 & RHOC & 10 & 313 & RPL17 & 8 \\
\hline 128 & HLA-C & 7 & 314 & SMC5 & 9 \\
\hline 129 & ZC3HAV1 & 9 & 315 & ETV1 & 10 \\
\hline 130 & JAG1 & 10 & 316 & LAMC1 & 10 \\
\hline 131 & CSRP2 & 10 & 317 & PCOLCE & 10 \\
\hline 132 & BARD1 & 10 & 318 & RECQL & 10 \\
\hline 133 & LAMA4 & 9 & 319 & VAMP8 & 8 \\
\hline 134 & PRCP & 9 & 320 & ARHGEF6 & 10 \\
\hline 135 & TIMP1 & 10 & 321 & BNIP2 & 10 \\
\hline 136 & CBX3 & 10 & 322 & FADD & 10 \\
\hline 137 & NME2 & 7 & 323 & HLA-DRA & 10 \\
\hline 138 & CPNE3 & 8 & 324 & MDK & 9 \\
\hline 139 & CD163 & 10 & 325 & GALNT10 & 9 \\
\hline 140 & POLR2J & 10 & 326 & TNPO1 & 10 \\
\hline 141 & CKAP4 & 10 & 327 & HMGN1 & 9 \\
\hline 142 & PTN & 9 & 328 & EIF4EBP1 & 8 \\
\hline 143 & LYPD1 & 9 & 329 & BTN3A2 & 9 \\
\hline 144 & DLG5 & 9 & 330 & TMCO1 & 9 \\
\hline 145 & LAPTM4A & 9 & 331 & KARS & 10 \\
\hline 146 & ID4 & 10 & 332 & POSTN & 10 \\
\hline 147 & WWTR1 & 9 & 333 & ELF1 & 10 \\
\hline 148 & CALU & 9 & 334 & TPM2 & 10 \\
\hline 149 & GBE1 & 10 & 335 & GTF3C2 & 10 \\
\hline 150 & FYN & 10 & 336 & GBP2 & 9 \\
\hline 151 & ERGIC3 & 9 & 337 & TP53 & 9 \\
\hline 152 & BACH1 & 8 & 338 & GAS1 & 10 \\
\hline 153 & SERPINE1 & 10 & 339 & CYFIP1 & 10 \\
\hline 154 & POLD2 & 10 & 340 & JUN & 10 \\
\hline 155 & AIF1 & 10 & 341 & $\mathrm{RCN} 1$ & 10 \\
\hline
\end{tabular}




\begin{tabular}{|c|c|c|c|c|c|}
\hline $\begin{array}{c}\text { Gene Significance } \\
\text { Rank* }\end{array}$ & Gene Symbol & $\begin{array}{c}\text { Studies } \\
(\text { of 10)** }\end{array}$ & $\begin{array}{c}\text { Gene Significance } \\
\text { Rank* }\end{array}$ & Gene Symbol & $\begin{array}{c}\text { Studies } \\
\text { (of 10)** }\end{array}$ \\
\hline 156 & FCGRT & 10 & 342 & HNRNPUL1 & 9 \\
\hline 157 & H19 & 8 & 343 & HAT1 & 9 \\
\hline 158 & $\mathrm{H} 2 \mathrm{AFV}$ & 9 & 344 & MAPK7 & 10 \\
\hline 159 & MAPRE1 & 10 & 345 & TRIM14 & 10 \\
\hline 160 & KIAA0040 & 7 & 346 & UBE2C & 10 \\
\hline 161 & TPR & 10 & 347 & MAPKAPK2 & 10 \\
\hline 162 & RPL23 & 10 & 348 & SP100 & 10 \\
\hline 163 & COL3A1 & 10 & 349 & SFPQ & 10 \\
\hline 164 & DPY19L1 & 9 & 350 & FKBP5 & 10 \\
\hline 165 & APOE & 10 & 351 & HLA-DMA & 10 \\
\hline 166 & PDPN & 9 & 352 & $\mathrm{H} 3 \mathrm{~F} 3 \mathrm{~A}$ & 10 \\
\hline 167 & GNG5 & 9 & 353 & NPM1 & 7 \\
\hline 168 & NUP205 & 10 & 354 & NAGA & 7 \\
\hline 169 & SSRP1 & 10 & 355 & CTGF & 10 \\
\hline 170 & HLA-DQB1 & 10 & 356 & GUSB & 10 \\
\hline 171 & LAMB2 & 10 & 357 & RPA1 & 10 \\
\hline 172 & LHFPL2 & 10 & 358 & MPZL1 & 9 \\
\hline 173 & BAT1 & 8 & 359 & LY96 & 8 \\
\hline 174 & OBSL1 & 9 & 360 & HLA-DPB1 & 10 \\
\hline 175 & CNN3 & 10 & 361 & AIMP2 & 9 \\
\hline 176 & PPIB & 10 & 362 & ARPC1B & 10 \\
\hline 177 & STK17A & 9 & 363 & EEF1G & 10 \\
\hline 178 & ACLY & 10 & 364 & SH3BP2 & 10 \\
\hline 179 & FCGR1A & 9 & 365 & UBA7 & 10 \\
\hline 180 & COL6A1 & 10 & 366 & PTK7 & 10 \\
\hline 181 & RPL7A & 7 & 367 & FHL1 & 10 \\
\hline 182 & ZNF207 & 9 & 368 & CLEC2B & 10 \\
\hline 183 & TLE3 & 10 & 369 & CCBL2 & 9 \\
\hline 184 & NMB & 9 & 370 & VEGFA & 10 \\
\hline 185 & SRI & 10 & 371 & CLIC1 & 7 \\
\hline 186 & PAICS & 10 & 372 & SEPT9 & 8 \\
\hline
\end{tabular}


Appendix Table 2. Significantly under-expressed gene list from Oncomine metaanalysis of normal vs. astrocytoma studies. *Genes are ranked by significance in Oncomine. ${ }^{* *}$ Genes were considered significant in the meta-analysis, and chosen for further analysis, if they were found in at least in at least 7 of 10 meta-analyzed studies.

\begin{tabular}{|c|c|c|c|c|c|}
\hline $\begin{array}{l}\text { Gene Significance } \\
\text { Rank* }\end{array}$ & Gene Symbol & $\begin{array}{c}\text { Studies } \\
\text { (of 10)** }\end{array}$ & $\begin{array}{c}\text { Gene Significance } \\
\text { Rank* }\end{array}$ & Gene Symbol & $\begin{array}{c}\text { Studies } \\
\text { (of 10)** }\end{array}$ \\
\hline 1 & ANK3 & 10 & 139 & RAB11FIP2 & 9 \\
\hline 2 & DCNTN1 & 7 & 140 & DLGAP2 & 9 \\
\hline 3 & BCL2L2 & 10 & 141 & MADD & 10 \\
\hline 4 & WDR7 & 9 & 142 & TNK1 & 9 \\
\hline 5 & PLEKHB2 & 9 & 143 & CD200 & 10 \\
\hline 6 & PRKCZ & 10 & 144 & SORBS2 & 9 \\
\hline 7 & GRM3 & 10 & 145 & RAP1GAP & 10 \\
\hline 8 & OPA1 & 9 & 146 & NR1D1 & 10 \\
\hline 9 & USP12 & 9 & 147 & IDI1 & 10 \\
\hline 10 & ATP6V0A1 & 10 & 148 & MAL & 10 \\
\hline 11 & VAMP1 & 8 & 149 & ELMO1 & 10 \\
\hline 12 & EPB41L3 & 9 & 150 & PURA & 10 \\
\hline 13 & IDH3A & 10 & 151 & KRT17 & 10 \\
\hline 14 & MAPRE2 & 10 & 152 & $\mathrm{CD} 47$ & 10 \\
\hline 15 & SH3GL3 & 10 & 153 & RUFY3 & 9 \\
\hline 16 & PTGER3 & 10 & 154 & COX7A1 & 9 \\
\hline 17 & ATP6V1E1 & 9 & 155 & MPHOSPH8 & 9 \\
\hline 18 & RCAN2 & 10 & 156 & BIN1 & 10 \\
\hline 19 & SBF1 & 7 & 157 & C5orf30 & 9 \\
\hline 20 & TSPYL1 & 9 & 158 & CAMTA1 & 9 \\
\hline 21 & RANGAP1 & 9 & 159 & PRDM2 & 10 \\
\hline 22 & ZNF365 & 7 & 160 & GSTM5 & 10 \\
\hline 23 & SNCG & 9 & 161 & EDIL3 & 9 \\
\hline 24 & STAU2 & 9 & 162 & NEFM & 10 \\
\hline 25 & ASPHD1 & 7 & 163 & SYT5 & 10 \\
\hline 26 & PTAFR & 10 & 164 & PRSS3 & 9 \\
\hline 27 & RAB3B & 10 & 165 & LARGE & 9 \\
\hline 28 & PRKCB & 10 & 166 & STK39 & 8 \\
\hline 29 & STMN1 & 10 & 167 & SV2B & 9 \\
\hline 30 & CNNM2 & 9 & 168 & XK & 10 \\
\hline 31 & CACNA1B & 8 & 169 & CLCN4 & 10 \\
\hline 32 & CHIC1 & 7 & 170 & MEG3 & 9 \\
\hline 33 & VAMP2 & 10 & 171 & NECAB3 & 7 \\
\hline 34 & WNT10B & 9 & 172 & YWHAZ & 10 \\
\hline 35 & DUSP7 & 10 & 173 & C22orf9 & 8 \\
\hline
\end{tabular}




\begin{tabular}{|c|c|c|c|c|c|}
\hline $\begin{array}{c}\text { Gene Significance } \\
\text { Rank* }\end{array}$ & Gene Symbol & $\begin{array}{c}\text { Studies } \\
(\text { of 10)** }\end{array}$ & $\begin{array}{c}\text { Gene Significance } \\
\text { Rank* }\end{array}$ & Gene Symbol & $\begin{array}{c}\text { Studies } \\
\text { (of 10)** }\end{array}$ \\
\hline 36 & GRIN2C & 10 & 174 & INPP5F & 9 \\
\hline 37 & RUSC2 & 9 & 175 & RAB3A & 10 \\
\hline 38 & MAPK8IP2 & 7 & 176 & DBP & 10 \\
\hline 39 & SSX2IP & 9 & 177 & KCNAB2 & 10 \\
\hline 40 & TPM3 & 9 & 178 & GABRB2 & 8 \\
\hline 41 & ТРРP & 9 & 179 & SLC17A7 & 9 \\
\hline 42 & PICK1 & 8 & 180 & AMPH & 10 \\
\hline 43 & APLP1 & 10 & 181 & PDE1A & 10 \\
\hline 44 & GABRA5 & 9 & 182 & QDPR & 10 \\
\hline 45 & SOCS7 & 9 & 183 & FOXO4 & 10 \\
\hline 46 & PPP1R16B & 9 & 184 & KCNMA1 & 10 \\
\hline 47 & TSPAN5 & 9 & 185 & MYH10 & 10 \\
\hline 48 & MAPT & 10 & 186 & CYP26A1 & 9 \\
\hline 49 & MAGI1 & 10 & 187 & RAB40B & 10 \\
\hline 50 & RASGRF1 & 10 & 188 & SEMA4D & 10 \\
\hline 51 & MAST3 & 9 & 189 & NCKIPSD & 9 \\
\hline 52 & CNTN2 & 10 & 190 & PRR4 & 10 \\
\hline 53 & SERPINI1 & 10 & 191 & DCLK1 & 9 \\
\hline 54 & PKP4 & 10 & 192 & UROS & 9 \\
\hline 55 & CACNB1 & 10 & 193 & PDE2A & 9 \\
\hline 56 & NUAK1 & 9 & 194 & KIAA0232 & 10 \\
\hline 57 & SNCA & 10 & 195 & TRIM3 & 8 \\
\hline 58 & KIF17 & 7 & 196 & ARHGEF4 & 8 \\
\hline 59 & GABRA2 & 10 & 197 & SYNPO & 9 \\
\hline 60 & TTBK2 & 7 & 198 & MBOAT7 & 10 \\
\hline 61 & BTRC & 8 & 199 & RIMS2 & 9 \\
\hline 62 & DYNC1I1 & 9 & 200 & TERF2IP & 9 \\
\hline 63 & PRKCG & 10 & 201 & PSD3 & 9 \\
\hline 64 & ZBTB7A & 9 & 202 & STX1A & 10 \\
\hline 65 & LMTK2 & 9 & 203 & ATP6V1C1 & 10 \\
\hline 66 & RYBP & 9 & 204 & FXR2 & 10 \\
\hline 67 & KIF5C & 9 & 205 & RAB40C & 9 \\
\hline 68 & AGTPBP1 & 9 & 206 & KIT & 10 \\
\hline 69 & RYR2 & 10 & 207 & UBE3A & 10 \\
\hline 70 & LDOC1 & 8 & 208 & ZC3H13 & 9 \\
\hline 71 & TPD52 & 10 & 209 & CLASP2 & 9 \\
\hline 72 & MOBP & 10 & 210 & MAN1A2 & 9 \\
\hline 73 & TUBB4 & 10 & 211 & HLF & 10 \\
\hline 74 & LDB3 & 8 & 212 & SYN2 & 10 \\
\hline 75 & CACNA1A & 9 & 213 & NEBL & 9 \\
\hline
\end{tabular}




\begin{tabular}{|c|c|c|c|c|c|}
\hline $\begin{array}{c}\text { Gene Significance } \\
\text { Rank* }\end{array}$ & Gene Symbol & $\begin{array}{c}\text { Studies } \\
(\text { of 10)** }\end{array}$ & $\begin{array}{c}\text { Gene Significance } \\
\text { Rank* }\end{array}$ & Gene Symbol & $\begin{array}{c}\text { Studies } \\
\text { (of 10)** }\end{array}$ \\
\hline 76 & BSCL2 & 9 & 214 & NR2F6 & 9 \\
\hline 77 & MPP2 & 9 & 215 & CPLX2 & 10 \\
\hline 78 & PPP2R2B & 10 & 216 & JAKMIP1 & 8 \\
\hline 79 & RAP1GDS1 & 9 & 217 & MYCBP2 & 9 \\
\hline 80 & GOT1 & 10 & 218 & DGKZ & 10 \\
\hline 81 & WASF1 & 10 & 219 & DOCK3 & 9 \\
\hline 82 & FAIM2 & 9 & 220 & KCNC3 & 7 \\
\hline 83 & FCH01 & 9 & 221 & HABP4 & 9 \\
\hline 84 & CDKN2D & 10 & 222 & PRKCQ & 9 \\
\hline 85 & EFR3B & 9 & 223 & SLC13A3 & 9 \\
\hline 86 & MBP & 10 & 224 & RAPGEF5 & 8 \\
\hline 87 & SNRPN & 10 & 225 & PET112L & 8 \\
\hline 88 & CA11 & 9 & 226 & $\mathrm{KCNC4}$ & 10 \\
\hline 89 & SERINC3 & 10 & 227 & GRM7 & 8 \\
\hline 90 & MICAL3 & 9 & 228 & NPY1R & 10 \\
\hline 91 & EFNA5 & 9 & 229 & CCKBR & 10 \\
\hline 92 & FGF13 & 9 & 230 & DLG1 & 10 \\
\hline 93 & IQSEC1 & 9 & 231 & GRM1 & 8 \\
\hline 94 & PAK1 & 10 & 232 & PEBP1 & 10 \\
\hline 95 & ULK2 & 9 & 233 & RNMT & 9 \\
\hline 96 & ATP2B1 & 10 & 234 & CCDC64 & 8 \\
\hline 97 & MAP2K4 & 10 & 235 & PEG3 & 10 \\
\hline 98 & GABARAPL1 & 9 & 236 & GRLF1 & 10 \\
\hline 99 & APBB1 & 10 & 237 & KLK3 & 10 \\
\hline 100 & ATP8A1 & 9 & 238 & NAV3 & 8 \\
\hline 101 & AUH & 10 & 239 & CLDN9 & 9 \\
\hline 102 & NIPAL3 & 10 & 240 & PRKAR1A & 10 \\
\hline 103 & DNM1L & 10 & 241 & CRHR2 & 8 \\
\hline 104 & EMX1 & 9 & 242 & PPP1R7 & 10 \\
\hline 105 & SCAMP1 & 10 & 243 & ICAM5 & 10 \\
\hline 106 & FAAH & 10 & 244 & CRELD1 & 8 \\
\hline 107 & LPGAT1 & 10 & 245 & PRKCE & 10 \\
\hline 108 & PTPRD & 10 & 246 & ARFGEF2 & 8 \\
\hline 109 & GHITM & 8 & 247 & PPFIA2 & 9 \\
\hline 110 & AAK1 & 9 & 248 & FABP6 & 9 \\
\hline 111 & DGK1 & 10 & 249 & PDIA2 & 9 \\
\hline 112 & CACNA1C & 10 & 250 & OSBPL1A & 9 \\
\hline 113 & FUT9 & 9 & 251 & RAPGEF3 & 10 \\
\hline 114 & GRIN2A & 10 & 252 & FAM190B & 10 \\
\hline 115 & PDS5B & 8 & 253 & CALM1 & 9 \\
\hline
\end{tabular}




\begin{tabular}{cccccc}
\hline $\begin{array}{c}\text { Gene Significance } \\
\text { Rank* }\end{array}$ & Gene Symbol & $\begin{array}{c}\text { Studies } \\
\text { (of } \mathbf{1 0})^{* *}\end{array}$ & $\begin{array}{c}\text { Gene Significance } \\
\text { Rank* }\end{array}$ & Gene Symbol & $\begin{array}{c}\text { Studies } \\
\text { (of 10)** }\end{array}$ \\
\hline $\mathbf{1 1 6}$ & KCNJ9 & 8 & $\mathbf{2 5 4}$ & LOC157627 & 8 \\
$\mathbf{1 1 7}$ & APBA1 & 10 & $\mathbf{2 5 5}$ & PCDH9 & 9 \\
$\mathbf{1 1 8}$ & DIP2C & 9 & $\mathbf{2 5 6}$ & DOCK9 & 9 \\
\hline $\mathbf{1 1 9}$ & IQSEC3 & 9 & $\mathbf{2 5 7}$ & FRMPD4 & 8 \\
\hline $\mathbf{1 2 0}$ & TYRO3 & 9 & $\mathbf{2 5 8}$ & HSPH1 & 10 \\
\hline $\mathbf{1 2 1}$ & KIAA0284 & 7 & $\mathbf{2 5 9}$ & C17orf108 & 9 \\
$\mathbf{1 2 2}$ & HK1 & 7 & $\mathbf{2 6 0}$ & SEPT11 & 9 \\
\hline $\mathbf{1 2 3}$ & PAFAH1B1 & 10 & $\mathbf{2 6 1}$ & DNAJC6 & 9 \\
$\mathbf{1 2 4}$ & FXYD1 & 9 & $\mathbf{2 6 2}$ & GDE1 & 9 \\
$\mathbf{1 2 5}$ & SLC25A4 & 10 & $\mathbf{2 6 3}$ & EXOC6B & 7 \\
\hline $\mathbf{1 2 6}$ & KHDRBS2 & 7 & $\mathbf{2 6 4}$ & CAMK2G & 10 \\
\hline $\mathbf{1 2 7}$ & HRAS & 10 & $\mathbf{2 6 5}$ & OPTN & 9 \\
$\mathbf{1 2 8}$ & ACTR1A & 10 & $\mathbf{2 6 6}$ & ANXA3 & 9 \\
\hline $\mathbf{1 2 9}$ & AP3M2 & 10 & $\mathbf{2 6 7}$ & PPFIA3 & 9 \\
\hline $\mathbf{1 3 0}$ & MEF2C & 10 & $\mathbf{2 6 8}$ & NDEL1 & 9 \\
\hline $\mathbf{1 3 1}$ & CLTB & 9 & $\mathbf{2 6 9}$ & CDC42 & 9 \\
\hline $\mathbf{1 3 2}$ & ATP2B3 & 10 & $\mathbf{2 7 0}$ & CDH8 & 10 \\
\hline $\mathbf{1 3 3}$ & TLN2 & 10 & $\mathbf{2 7 1}$ & ARPP19 & 9 \\
\hline $\mathbf{1 3 4}$ & SEC14L5 & 9 & $\mathbf{2 7 2}$ & DTNB & 9 \\
\hline $\mathbf{1 3 5}$ & SLC6A12 & 10 & $\mathbf{2 7 3}$ & PPM1A & 10 \\
\hline $\mathbf{1 3 6}$ & RB1CC1 & 10 & $\mathbf{2 7 4}$ & ATP58 & 10 \\
\hline $\mathbf{1 3 7}$ & ATP5L & 7 & $\mathbf{2 7 5}$ & MTMR9 & 9 \\
$\mathbf{1 3 8}$ & SPOCK3 & 7 & & & \\
\hline & & & & & \\
\hline
\end{tabular}


Appendix Table 3. Comparison of Markov blanket genes across Grades I to IV Astrocytoma. Over-expressed genes are red; Underexpressed genes are blue. Genes highlighted in grey are Markov blanket genes for the corresponding tumor grade.

\begin{tabular}{|c|c|c|c|}
\hline PILOCYTIC & DIFFUSE & ANAPLASTIC & GLIOBLASTOMA \\
\hline ANK3 & ANK3 & ANK3 & ANK3 \\
\hline ANXA1 & ANXA1 & ANXA1 & ANXA1 \\
\hline ANXA2 & ANXA2 & ANXA2 & ANXA2 \\
\hline BTF3 & BTF3 & BTF3 & BTF3 \\
\hline BTN3A3 & BTN3A3 & BTN3A3 & BTN3A3 \\
\hline C1S & C1S & C1S & C1S \\
\hline CALCRL & CALCRL & CALCRL & CALCRL \\
\hline CCND2 & CCND2 & CCND2 & CCND2 \\
\hline CD44 & CD44 & CD44 & CD44 \\
\hline CD99 & CD99 & CD99 & CD99 \\
\hline $\mathrm{CDH} 11$ & $\mathrm{CDH} 11$ & $\mathrm{CDH} 11$ & $\mathrm{CDH} 11$ \\
\hline CDK4 & CDK4 & CDK4 & CDK4 \\
\hline CNTN2 & CNTN2 & CNTN2 & CNTN2 \\
\hline COL4A1 & COL4A1 & COL4A1 & COL4A1 \\
\hline DAB2 & DAB2 & DAB2 & DAB2 \\
\hline DPYSL3 & DPYSL3 & DPYSL3 & DPYSL3 \\
\hline DUSP7 & DUSP7 & DUSP7 & DUSP7 \\
\hline EGFR & EGFR & EGFR & EGFR \\
\hline EIF4A1 & EIF4A1 & EIF4A1 & EIF4A1 \\
\hline EMP1 & EMP1 & EMP1 & EMP1 \\
\hline FN1 & FN1 & FN1 & FN1 \\
\hline GABRA5 & GABRA5 & GABRA5 & GABRA5 \\
\hline HLAA & HLAA & HLAA & HLAA \\
\hline IGFBP5 & IGFBP5 & IGFBP5 & IGFBP5 \\
\hline LPL & LPL & $\mathrm{LPL}$ & LPL \\
\hline MARCKS & MARCKS & MARCKS & MARCKS \\
\hline MAST3 & MAST3 & MAST3 & MAST3 \\
\hline MCM3 & MCM3 & $\mathrm{MCM} 3$ & MCM3 \\
\hline MPP2 & MPP2 & MPP2 & MPP2 \\
\hline MTHFD2 & MTHFD2 & MTHFD2 & MTHFD2 \\
\hline NONO & NONO & NONO & NONO \\
\hline PPP2R2B & PPP2R2B & PPP2R2B & PPP2R2B \\
\hline PRDX4 & PRDX4 & PRDX4 & PRDX4 \\
\hline PTGER3 & PTGER3 & PTGER3 & PTGER3 \\
\hline RAB31 & RAB31 & RAB31 & RAB31 \\
\hline
\end{tabular}




\begin{tabular}{|c|c|c|c|}
\hline PILOCYTIC & DIFFUSE & ANAPLASTIC & GLIOBLASTOMA \\
\hline RAB3B & RAB3B & RAB3B & RAB3B \\
\hline RCAN2 & RCAN2 & RCAN2 & RCAN2 \\
\hline RUSC2 & RUSC2 & RUSC2 & RUSC2 \\
\hline SERBP1 & SERBP1 & SERBP1 & SERBP1 \\
\hline SERINC3 & SERINC3 & SERINC3 & SERINC3 \\
\hline SH3GL3 & SH3GL3 & SH3GL3 & SH3GL3 \\
\hline SNRPE & SNRPE & SNRPE & SNRPE \\
\hline SPARC & SPARC & SPARC & SPARC \\
\hline SRPX & SRPX & SRPX & SRPX \\
\hline SSR2 & SSR2 & SSR2 & SSR2 \\
\hline TIMP4 & TIMP4 & TIMP4 & TIMP4 \\
\hline TOP2A & TOP2A & TOP2A & TOP2A \\
\hline TPPP & TPPP & TPPP & TPPP \\
\hline VAMP1 & VAMP1 & VAMP1 & VAMP1 \\
\hline VCAN & VCAN & VCAN & VCAN \\
\hline WNT5A & WNT5A & WNT5A & WNT5A \\
\hline WNT10B & WNT10B & WNT10B & WNT10B \\
\hline
\end{tabular}


Appendix Table 4. Characteristics of Grade IV Glioblastoma Multiforme Markov blanket genes. References are listed below text of manuscript.

\begin{tabular}{|c|c|c|c|}
\hline Gene Symbol / Name & $\begin{array}{l}\text { Genomic Location / } \\
\text { Cellular Localization }\end{array}$ & Function & Cancer / Disease Link \\
\hline $\begin{array}{l}\text { COL4A1 } \\
\text { Collagen, type IV, } \\
\text { alpha } 1\end{array}$ & $\begin{array}{l}13 q 34 \\
\text { extracellular matrix }\end{array}$ & $\begin{array}{l}\text { Inhibits } \\
\text { angiogenesis and } \\
\text { tumor formation }\end{array}$ & $\begin{array}{l}\text { Are upregulated in malignant and metastatic brain tumors } \\
\qquad[32]\end{array}$ \\
\hline $\begin{array}{c}\text { EGFR } \\
\text { Epidermal growth } \\
\text { factor receptor }\end{array}$ & $\begin{array}{l}7 \mathrm{p} 12 \\
\text { membrane }\end{array}$ & Growth factor & $\begin{array}{l}\text { Consistently linked to development of glioblastoma [33]; Has been linked to } \\
\text { glioma tumor invasiveness, proliferation, and angiogenesis [34;35]; Mutations } \\
\text { have been found in EGFR in primary glioblastomas [36] and have been linked to } \\
\text { poor prognosis in GBM [37]. Its signaling has been shown to cooperate with loss } \\
\text { of tumor suppressor gene functions in promotion of gliomagenesis }\end{array}$ \\
\hline $\begin{array}{c}\text { BTF3 } \\
\text { Basic transcription } \\
\text { factor } 3\end{array}$ & $\begin{array}{l}5 q 13.2 \\
\text { nucleus }\end{array}$ & $\begin{array}{l}\text { Transcription } \\
\text { factor }\end{array}$ & $\begin{array}{l}\text { Found to be highly expressed in glioblastoma multiforme [38]; regulates tumor- } \\
\text { associated genes in pancreatic cancer cells [39] }\end{array}$ \\
\hline $\begin{array}{c}\text { MPP2 } \\
\text { Membrane protein, } \\
\text { palmitoylated } 2\end{array}$ & $\begin{array}{l}\text { 17q12-q21 } \\
\text { membrane }\end{array}$ & $\begin{array}{l}\text { Tumor suppressor; } \\
\text { Coupling of } \\
\text { cytoskeleton to cell } \\
\text { membrane }\end{array}$ & $\begin{array}{l}\text { Contributes to cell proliferation and resistance in cisplatin treatment in } \\
\text { medulloblastoma cells [40] }\end{array}$ \\
\hline $\begin{array}{c}\text { RAB31 } \\
\text { Member RAS } \\
\text { oncogene family }\end{array}$ & $\begin{array}{l}18 \mathrm{q} 11.3 \\
\text { membrane }\end{array}$ & $\begin{array}{l}\text { Vesicle and granule } \\
\text { targeting }\end{array}$ & $\begin{array}{l}\text { May have role in regulating EGFR in astrocyte development and oncogenesis ( } \mathrm{Ng} \\
\qquad \text { 2009) [41]; associated with survival in glioblastoma [42] }\end{array}$ \\
\hline $\begin{array}{c}\text { CDK4 } \\
\text { Cyclin-dependent } \\
\text { kinase } 4\end{array}$ & $\begin{array}{l}12 q 14 \\
\text { cytoplasm }\end{array}$ & $\begin{array}{l}\text { Cell cycle } \\
\text { regulation; inhibits } \\
\text { RB protein family } \\
\text { members }\end{array}$ & $\begin{array}{l}\text { Known target of glioblastoma anticancer therapy [43]; thought to be a driver } \\
\text { mutation gene in glioblastoma [44] }\end{array}$ \\
\hline $\begin{array}{l}\text { CD99 } \\
\text { CD99 molecule }\end{array}$ & $\begin{array}{l}\text { Xp22.32 } \\
\text { membrane }\end{array}$ & $\begin{array}{l}\text { Leukocyte } \\
\text { migration, T-cell } \\
\text { adhesion, protein } \\
\text { transport, and T- } \\
\quad \text { cell death }\end{array}$ & $\begin{array}{l}\text { May act as an oncosuppressor in osteosarcoma; Is a useful marker for diagnosis } \\
\text { of brain tumor types [45] }\end{array}$ \\
\hline $\begin{array}{c}\text { ANXA2 } \\
\text { Annexin A2 }\end{array}$ & $\begin{array}{l}15 q 22.2 \\
\text { Extracellular space, }\end{array}$ & $\begin{array}{l}\text { Regulation of cell } \\
\text { growth }\end{array}$ & $\begin{array}{l}\text { Involved in migration of neural stem cells to glioma sites [46]; potentially } \\
\text { involved in glioma invasion [47] }\end{array}$ \\
\hline
\end{tabular}




\begin{tabular}{|c|c|c|c|}
\hline Gene Symbol / Name & $\begin{array}{l}\text { Genomic Location / } \\
\text { Cellular Localization }\end{array}$ & Function & Cancer / Disease Link \\
\hline & $\begin{array}{c}\text { extracellular matrix, } \\
\text { membrane }\end{array}$ & & \\
\hline $\begin{array}{c}\text { TOP2A } \\
\text { Topoisomerase (DNA) } \\
\text { II alpha 170kDa }\end{array}$ & $\begin{array}{c}17 q 21-q 22 \\
\text { Cytosplasm, nucleus, } \\
\text { nucleoplasm }\end{array}$ & $\begin{array}{l}\text { Resolves } \\
\text { topological } \\
\text { problems in } \\
\text { genomic DNA } \\
\text { resulting from } \\
\text { replication, } \\
\text { transcription and } \\
\text { repair }\end{array}$ & $\begin{array}{l}\text { Is target of several anticancer agents; mutations in this gene have been } \\
\text { associated with development of drug resistance; common significantly altered } \\
\text { gene in cancer [48]; May be involved in network of genes controlling cell cycle } \\
\text { regulation in glioblastoma [49]; very high copy number gain in glioblastoma [50] }\end{array}$ \\
\hline $\begin{array}{c}\text { SERBP1 } \\
\text { SERPINE1 mRNA } \\
\text { binding protein } 1\end{array}$ & $\begin{array}{c}\text { 1p31 } \\
\text { Cytoplasm, nucleus }\end{array}$ & $\begin{array}{l}\text { Regulation of } \\
\text { mRNA stability }\end{array}$ & Significantly overexpressed in ovarian cancer, especially in advanced disease [51] \\
\hline
\end{tabular}


Appendix Table 5. List of 173 genes present in environmental gene databases and having mutations in Glioblastoma, with number of studies conducted on the gene in relation to Glioblastoma.

\begin{tabular}{|c|c|c|}
\hline $\begin{array}{c}\text { Gene } \\
\text { Symbol }\end{array}$ & Gene Name & $\begin{array}{c}\text { Number of } \\
\text { GBM } \\
\text { Studies } \\
\end{array}$ \\
\hline ABCA3 & ATP-binding cassette, sub-family A (ABC1), member 3 & 1 \\
\hline ABCB1 & ATP-binding cassette, sub-family B (MDR/TAP), member 1B & 80 \\
\hline ABCG2 & ATP-binding cassette, sub-family G (WHITE), member 2 & 16 \\
\hline ABL1 & c-abl oncogene 1 , non-receptor tyrosine kinase & 1 \\
\hline ABL2 & $\begin{array}{l}\text { v-abl Abelson murine leukemia viral oncogene homolog } 2 \text { (arg, Abelson- } \\
\text { related gene) }\end{array}$ & 0 \\
\hline ADAMTS13 & $\begin{array}{l}\text { a disintegrin-like and metallopeptidase (reprolysin type) with } \\
\text { thrombospondin type } 1 \text { motif, } 13\end{array}$ & 2 \\
\hline ADM & adrenomedullin & 13 \\
\hline AKT2 & thymoma viral proto-oncogene 2 & 6 \\
\hline ALDH1A2 & aldehyde dehydrogenase family 1 , subfamily A2 & 0 \\
\hline ALOX12 & arachidonate 12-lipoxygenase & 0 \\
\hline AOC3 & amine oxidase, copper containing 3 & 0 \\
\hline API5 & apoptosis inhibitor 5 & 0 \\
\hline APOBEC3G & Apoplipoprotein B mRNA-editing, enzyme-catalytic, polypeptide-like $3 \mathrm{G}$ & 0 \\
\hline ARNT & aryl hydrocarbon receptor nuclear translocator & 2 \\
\hline ATM & ataxia telangiectasia mutated homolog (human) & 23 \\
\hline ATRX & alpha thalassemia/mental retardation syndrome X-linked homolog (human) & 0 \\
\hline BAX & BCL2-associated X protein & 155 \\
\hline BCL2 & B-cell leukemia/lymphoma 2 & 25 \\
\hline BMI1 & Bmil polycomb ring finger oncogene & 12 \\
\hline BRAF & Braf transforming gene & 8 \\
\hline BRCA1 & breast cancer 1 & 7 \\
\hline BRCA2 & breast cancer 2 & 5 \\
\hline CALCA & calcitonin/calcitonin-related polypeptide, alpha & 1 \\
\hline CAPN3 & calpain 3 & 0 \\
\hline CASP9 & caspase 9 & 60 \\
\hline CCK & cholecystokinin & 5 \\
\hline CCND2 & cyclin D2 & 4 \\
\hline CDC7 & cell division cycle 7 (S. cerevisiae) & 0 \\
\hline CDH1 & cadherin 1 & 4 \\
\hline CDK4 & cyclin-dependent kinase 4 & 92 \\
\hline CDK6 & cyclin-dependent kinase 6 & 12 \\
\hline CDKN2A & cyclin-dependent kinase inhibitor $2 \mathrm{~A}$ & 177 \\
\hline CDKN2B & cyclin-dependent kinase inhibitor 2B ( 15 , inhibits CDK4) & 18 \\
\hline CDKN2C & cyclin-dependent kinase inhibitor $2 \mathrm{C}$ ( 18 , inhibits CDK4) & 7 \\
\hline CEACAM1 & carcinoembryonic antigen-related cell adhesion molecule 1 & 0 \\
\hline CES3 & carboxylesterase $3 \mathrm{~A}$ & 0 \\
\hline CHEK1 & checkpoint kinase 1 homolog (S. pombe) & 0 \\
\hline CHEK2 & CHK2 checkpoint homolog (S. pombe) & 2 \\
\hline CHRNA4 & cholinergic receptor, nicotinic, alpha polypeptide 4 & 0 \\
\hline CIZ1 & CDKN1A interacting zinc finger protein 1 & 0 \\
\hline CKS2 & $\mathrm{CDC} 28$ protein kinase regulatory subunit 2 & 1 \\
\hline
\end{tabular}




\begin{tabular}{|c|c|c|}
\hline $\begin{array}{c}\text { Gene } \\
\text { Symbol }\end{array}$ & Gene Name & $\begin{array}{c}\text { Number of } \\
\text { GBM } \\
\text { Studies }\end{array}$ \\
\hline CLSPN & claspin homolog (Xenopus laevis) & 0 \\
\hline $\mathrm{COCH}$ & coagulation factor $\mathrm{C}$ homolog (Limulus polyphemus) & 0 \\
\hline CPSF4 & cleavage and polyadenylation specific factor 4 & 0 \\
\hline CSF3R & colony stimulating factor 3 receptor (granulocyte) & 7 \\
\hline CSK & c-src tyrosine kinase & 4 \\
\hline CTNNB1 & catenin (cadherin associated protein), beta 1 & 44 \\
\hline CTNND2 & catenin (cadherin associated protein), delta 2 & 0 \\
\hline CYP1B1 & cytochrome $\mathrm{P} 450$, family 1 , subfamily b, polypeptide 1 & 1 \\
\hline CYP27B1 & cytochrome $\mathrm{P} 450$, family 27 , subfamily $\mathrm{b}$, polypeptide 1 & 7 \\
\hline CYP2C19 & cytochrome P450, family 2 , subfamily c, polypeptide 50 & 0 \\
\hline CYP2E1 & cytochrome $\mathrm{P} 450$, family 2 , subfamily e, polypeptide 1 & 1 \\
\hline CYP3A4 & cytochrome P450, family 3 , subfamily a, polypeptide $41 \mathrm{~A}$ & 15 \\
\hline DDB1 & damage specific DNA binding protein 1 & 0 \\
\hline DDC & dopa decarboxylase & 2 \\
\hline DDIT3 & DNA-damage inducible transcript 3 & 10 \\
\hline E2F4 & E2F transcription factor 4 & 4 \\
\hline EDNRA & endothelin receptor type A & 0 \\
\hline EGF & epidermal growth factor & 252 \\
\hline EGFR & epidermal growth factor receptor & 747 \\
\hline ELN & elastin & 1 \\
\hline ENO1 & enolase 1, alpha non-neuron & 1 \\
\hline ЕPHB6 & Eph receptor B6 & 1 \\
\hline ERBB2 & $\begin{array}{l}\text { v-erb-b2 erythroblastic leukemia viral oncogene homolog } 2 \\
\text { neuro/glioblastoma derived oncogene homolog (avian) }\end{array}$ & 73 \\
\hline ERCC5 & $\begin{array}{l}\text { excision repair cross-complementing rodent repair deficiency, } \\
\text { complementation group } 5\end{array}$ & 0 \\
\hline ESR1 & estrogen receptor 1 (alpha) & 3 \\
\hline F13A1 & coagulation factor XIII, A1 subunit & 0 \\
\hline F13B & coagulation factor XIII, beta subunit & 0 \\
\hline F2RL1 & coagulation factor II (thrombin) receptor-like 1 & 0 \\
\hline F3 & contactin 1 & 5 \\
\hline FANCA & Fanconi anemia, complementation group A & 2 \\
\hline FGF2 & fibroblast growth factor 2 & 68 \\
\hline FGFR1 & fibroblast growth factor receptor 1 & 20 \\
\hline FGFR2 & fibroblast growth factor receptor 2 & 11 \\
\hline FGFR3 & fibroblast growth factor receptor 3 & 3 \\
\hline FOXA2 & forkhead box A2 & 0 \\
\hline FOXM1 & forkhead box M1 & 9 \\
\hline FUT2 & fucosyltransferase 2 & 0 \\
\hline GABPA & GA repeat binding protein, alpha & 0 \\
\hline GAD2 & glutamic acid decarboxylase 2 & 0 \\
\hline GADD45G & growth arrest and DNA-damage-inducible 45 gamma & 0 \\
\hline GAS6 & growth arrest specific 6 & 3 \\
\hline GATA3 & GATA binding protein 3 & 1 \\
\hline GCLC & glutamate-cysteine ligase, catalytic subunit & 0 \\
\hline GYPC & glycophorin C & 0 \\
\hline
\end{tabular}




\begin{tabular}{|c|c|c|}
\hline $\begin{array}{c}\text { Gene } \\
\text { Symbol }\end{array}$ & Gene Name & $\begin{array}{c}\text { Number of } \\
\text { GBM } \\
\text { Studies }\end{array}$ \\
\hline HGF & hepatocyte growth factor & 58 \\
\hline IFNA1 & interferon alpha 1 & 0 \\
\hline IFNAR1 & interferon (alpha and beta) receptor 1 & 0 \\
\hline IGF1R & insulin-like growth factor I receptor & 45 \\
\hline IGF2 & insulin-like growth factor 2 & 7 \\
\hline IGFBP7 & insulin-like growth factor binding protein 7 & 5 \\
\hline IKBKE & inhibitor of kappaB kinase epsilon & 3 \\
\hline IL17B & interleukin 17B & 0 \\
\hline IL3 & interleukin 3 & 1 \\
\hline IL4R & interleukin 4 receptor, alpha & 6 \\
\hline IL6 & interleukin 6 & 12 \\
\hline ITGAL & integrin alpha $\mathrm{L}$ & 1 \\
\hline ITM2B & integral membrane protein $2 \mathrm{~B}$ & 0 \\
\hline JUNB & Jun-B oncogene & 3 \\
\hline KEL & Kell blood group & 0 \\
\hline KLF4 & Kruppel-like factor 4 (gut) & 0 \\
\hline МАР3К8 & mitogen-activated protein kinase kinase kinase 8 & 0 \\
\hline МАРК9 & mitogen-activated protein kinase 9 & 0 \\
\hline MDM2 & transformed mouse $3 \mathrm{~T} 3$ cell double minute 2 & 114 \\
\hline MDM4 & transformed mouse $3 \mathrm{~T} 3$ cell double minute 4 & 4 \\
\hline MLH1 & mutL homolog 1 (E. coli) & 22 \\
\hline MLL & myeloid/lymphoid or mixed-lineage leukemia 1 & 3 \\
\hline MMP10 & matrix metallopeptidase 10 & 0 \\
\hline MMP15 & matrix metallopeptidase 15 & 2 \\
\hline MMP2 & matrix metallopeptidase 2 & 23 \\
\hline MN1 & meningioma 1 & 0 \\
\hline MSH2 & mutS homolog 2 (E. coli) & 17 \\
\hline MSH6 & mutS homolog 6 (E. coli) & 12 \\
\hline MUC5AC & mucin 5, subtypes A and C, tracheobronchial/gastric & 1 \\
\hline МYВРС3 & myosin binding protein $\mathrm{C}$, cardiac & 0 \\
\hline MYC & myelocytomatosis oncogene & 132 \\
\hline NCOA1 & nuclear receptor coactivator 1 & 1 \\
\hline NF1 & neurofibromatosis 1 & 44 \\
\hline NOS3 & nitric oxide synthase 3 , endothelial cell & 1 \\
\hline NRAS & neuroblastoma ras oncogene & 3 \\
\hline PARK2 & Parkinson disease (autosomal recessive, juvenile) 2, parkin & 3 \\
\hline PDIA2 & protein disulfide isomerase associated 2 & 0 \\
\hline PGR & progesterone receptor & 3 \\
\hline PMS1 & postmeiotic segregation increased 1 (S. cerevisiae) & 0 \\
\hline PMS2 & postmeiotic segregation increased 2 (S. cerevisiae) & 11 \\
\hline POLD1 & polymerase (DNA directed), delta 1, catalytic subunit & 0 \\
\hline POLE & polymerase (DNA directed), epsilon & 4 \\
\hline POLG2 & polymerase (DNA directed), gamma 2 , accessory subunit & 0 \\
\hline POR & P450 (cytochrome) oxidoreductase & 16 \\
\hline PPARA & peroxisome proliferator activated receptor alpha & 0 \\
\hline PRKCB1 & protein kinase $\mathrm{C}$, beta & 1 \\
\hline
\end{tabular}




\begin{tabular}{|c|c|c|}
\hline $\begin{array}{l}\text { Gene } \\
\text { Symbol }\end{array}$ & Gene Name & $\begin{array}{c}\text { Number of } \\
\text { GBM } \\
\text { Studies }\end{array}$ \\
\hline PRKDC & protein kinase, DNA activated, catalytic polypeptide & 36 \\
\hline PROM1 & prominin 1 & 2 \\
\hline РТСН2 & patched homolog 2 & 0 \\
\hline PTEN & phosphatase and tensin homolog & 391 \\
\hline PTGDR & prostaglandin D receptor & 0 \\
\hline PTGS2 & prostaglandin-endoperoxide synthase 2 & 57 \\
\hline RAD52 & RAD52 homolog (S. cerevisiae) & 1 \\
\hline RAP1B & RAS related protein $1 \mathrm{~b}$ & 2 \\
\hline RB1 & retinoblastoma 1 & 25 \\
\hline RFC2 & replication factor $\mathrm{C}$ (activator 1$) 2$ & 2 \\
\hline SEMA7A & $\begin{array}{l}\text { sema domain, immunoglobulin domain (Ig), and GPI membrane anchor, } \\
\text { (semaphorin) 7A }\end{array}$ & 0 \\
\hline SERPINE1 & serine (or cysteine) peptidase inhibitor, clade E, member 1 & 23 \\
\hline SERPING1 & serine (or cysteine) peptidase inhibitor, clade G, member 1 & 0 \\
\hline SFTPB & surfactant associated protein $B$ & 0 \\
\hline SHH & sonic hedgehog & 11 \\
\hline SLC14A1 & solute carrier family 14 (urea transporter), member 1 & 0 \\
\hline SLC4A1 & solute carrier family 4 (anion exchanger), member 1 & 0 \\
\hline SMARCB1 & $\begin{array}{l}\text { SWI/SNF related, matrix associated, actin dependent regulator of } \\
\text { chromatin, subfamily } b \text {, member } 1\end{array}$ & 6 \\
\hline STAT1 & signal transducer and activator of transcription 1 & 20 \\
\hline STAT3 & signal transducer and activator of transcription 3 & 89 \\
\hline TAF1 & $\begin{array}{l}\text { TAF1 RNA polymerase II, TATA box binding protein (TBP)-associated } \\
\text { factor }\end{array}$ & 0 \\
\hline TAF6 & $\begin{array}{l}\text { TAF6 RNA polymerase II, TATA box binding protein (TBP)-associated } \\
\text { factor }\end{array}$ & 0 \\
\hline TERT & telomerase reverse transcriptase & 25 \\
\hline TGFBR2 & transforming growth factor, beta receptor II & 1 \\
\hline TGM1 & transglutaminase $1, \mathrm{~K}$ polypeptide & 0 \\
\hline TNFAIP2 & tumor necrosis factor, alpha-induced protein 2 & 0 \\
\hline TNFRSF11B & tumor necrosis factor receptor superfamily, member $11 \mathrm{~b}$ (osteoprotegerin) & 1 \\
\hline TNFRSF1A & tumor necrosis factor receptor superfamily, member 1a & 1 \\
\hline TNFRSF1B & tumor necrosis factor receptor superfamily, member $1 \mathrm{~b}$ & 0 \\
\hline TNFRSF25 & tumor necrosis factor receptor superfamily, member 25 & 0 \\
\hline TNFRSF8 & tumor necrosis factor receptor superfamily, member 8 & 0 \\
\hline TNFRSF9 & tumor necrosis factor receptor superfamily, member 9 & 1 \\
\hline TP53 & transformation related protein 53 & 211 \\
\hline TRPM2 & transient receptor potential cation channel, subfamily M, member 2 & 4 \\
\hline TRPV5 & transient receptor potential cation channel, subfamily $\mathrm{V}$, member 5 & 0 \\
\hline UGT1A1 & UDP glucuronosyltransferase 1 family, polypeptide A1 & 1 \\
\hline UNG & uracil DNA glycosylase & 4 \\
\hline VCAM1 & vascular cell adhesion molecule 1 & 0 \\
\hline VDR & vitamin $\mathrm{D}$ receptor & 2 \\
\hline VLDLR & very low density lipoprotein receptor & 0 \\
\hline VWF & Von Willebrand factor homolog & 17 \\
\hline XDH & xanthine dehydrogenase & 1 \\
\hline
\end{tabular}


Appendix Table 6. List of genes mutated in Glioblastoma and showing mutagenic actions in response to chemicals in studies curated in the Comparative Toxicology Database.

\begin{tabular}{|c|c|c|c|c|c|}
\hline $\begin{array}{c}\text { Gene } \\
\text { Symbol }\end{array}$ & Chemical Name & Organism & Interaction & Interaction Actions & PubMed IDs \\
\hline ATRX & Ethylnitrosourea & $\mathrm{Rn}$ & $\begin{array}{l}\text { Ethylnitrosourea results in increased mutagenesis of } \\
\text { ATRX gene }\end{array}$ & $\begin{array}{l}\text { increases } \\
\text { mutagenesis }\end{array}$ & 16495775 \\
\hline CYP2E1 & Vinyl Chloride & Hs & $\begin{array}{l}\text { CYP2E1 gene polymorphism promotes the reaction [Vinyl } \\
\text { Chloride affects the mutagenesis of KRAS gene] }\end{array}$ & $\begin{array}{l}\text { affects mutagenesis } \\
\text { |increases reaction }\end{array}$ & 12705718 \\
\hline CYP2E1 & Vinyl Chloride & Hs & $\begin{array}{l}\text { CYP2E1 gene polymorphism promotes the reaction [Vinyl } \\
\text { Chloride affects the mutagenesis of TP53 gene] }\end{array}$ & $\begin{array}{l}\text { affects mutagenesis } \\
\text { increases reaction }\end{array}$ & 12705718 \\
\hline CYP2E1 & Vinyl Chloride & Hs & $\begin{array}{l}\text { CYP2E1 gene polymorphism promotes the reaction [Vinyl } \\
\text { Chloride results in increased mutagenesis of KRAS gene] }\end{array}$ & $\begin{array}{c}\text { increases } \\
\text { mutagenesis } \\
\text { increases reaction }\end{array}$ & 17384900 \\
\hline CYP2E1 & Vinyl Chloride & Hs & $\begin{array}{l}\text { CYP2E1 gene polymorphism promotes the reaction [Vinyl } \\
\text { Chloride results in increased mutagenesis of TP53 gene] }\end{array}$ & $\begin{array}{c}\text { increases } \\
\text { mutagenesis } \\
\text { increases reaction }\end{array}$ & $\begin{array}{l}12010862 \mid 1738490 \\
0\end{array}$ \\
\hline EGFR & Ethylnitrosourea & $\mathrm{Mm}$ & $\begin{array}{l}\text { Ethylnitrosourea results in increased mutagenesis of EGFR } \\
\text { gene }\end{array}$ & $\begin{array}{l}\text { increases } \\
\text { mutagenesis }\end{array}$ & $\begin{array}{l}15366372 \mid 1672432 \\
7\end{array}$ \\
\hline ERBB2 & Ethylnitrosourea & $\mathrm{Rn}$ & $\begin{array}{l}\text { Ethylnitrosourea results in increased mutagenesis of } \\
\text { ERBB2 gene }\end{array}$ & $\begin{array}{l}\text { increases } \\
\text { mutagenesis }\end{array}$ & 16651423 \\
\hline IGF1R & Ethylnitrosourea & $\mathrm{Mm}$ & $\begin{array}{l}\text { Ethylnitrosourea results in increased mutagenesis of } \\
\text { IGF1R gene }\end{array}$ & $\begin{array}{l}\text { increases } \\
\text { mutagenesis }\end{array}$ & 16461637 \\
\hline MLL & Genistein & Hs & Genistein results in increased mutagenesis of MLL gene & $\begin{array}{l}\text { increases } \\
\text { mutagenesis }\end{array}$ & 17468513 \\
\hline MLL & kaempferol & Hs & kaempferol results in increased mutagenesis of MLL gene & $\begin{array}{l}\text { increases } \\
\text { mutagenesis }\end{array}$ & 17468513 \\
\hline MLL & Permethrin & Hs & Permethrin results in increased mutagenesis of MLL gene & $\begin{array}{l}\text { increases } \\
\text { mutagenesis }\end{array}$ & 12937054 \\
\hline MLL & Quercetin & Hs & Quercetin results in increased mutagenesis of MLL gene & $\begin{array}{l}\text { increases } \\
\text { mutagenesis }\end{array}$ & 17468513 \\
\hline MSH2 & Ethylnitrosourea & $\mathrm{Rn}$ & $\begin{array}{l}\text { Ethylnitrosourea results in increased mutagenesis of } \\
\qquad \mathrm{MSH} 2 \text { gene }\end{array}$ & $\begin{array}{l}\text { increases } \\
\text { mutagenesis }\end{array}$ & 16495775 \\
\hline
\end{tabular}




\begin{tabular}{|c|c|c|c|c|c|}
\hline $\begin{array}{c}\text { Gene } \\
\text { Symbol }\end{array}$ & Chemical Name & Organism & Interaction & Interaction Actions & PubMed IDs \\
\hline MSH6 & Ethylnitrosourea & $\mathrm{Rn}$ & $\begin{array}{c}\text { Ethylnitrosourea results in increased mutagenesis of } \\
\text { MSH6 gene }\end{array}$ & $\begin{array}{l}\text { increases } \\
\text { mutagenesis }\end{array}$ & $\begin{array}{c}16495775 \mid 1841748 \\
1\end{array}$ \\
\hline MYC & Estradiol & $\mathrm{Mm}$ & $\begin{array}{l}\text { AICDA protein affects the reaction [Estradiol results in } \\
\text { increased mutagenesis of MYC gene] }\end{array}$ & $\begin{array}{l}\text { affects reaction } \\
\text { increases } \\
\text { mutagenesis }\end{array}$ & 19139166 \\
\hline MYC & Estradiol & $\mathrm{Mm}$ & Estradiol results in increased mutagenesis of MYC gene & $\begin{array}{l}\text { increases } \\
\text { mutagenesis }\end{array}$ & 19139166 \\
\hline PARK2 & Ethylnitrosourea & $\mathrm{Ol}$ & $\begin{array}{l}\text { Ethylnitrosourea results in increased mutagenesis of } \\
\text { PARK2 exon }\end{array}$ & $\begin{array}{l}\text { increases } \\
\text { mutagenesis }\end{array}$ & 17156454 \\
\hline PTEN & Ethylnitrosourea & $\mathrm{Mm}$ & $\begin{array}{l}\begin{array}{l}\text { Ethylnitrosourea results in increased mutagenesis of PTEN } \\
\text { gene }\end{array}\end{array}$ & $\begin{array}{l}\text { increases } \\
\text { mutagenesis }\end{array}$ & $\begin{array}{c}15755804 \mid 1672432 \\
7\end{array}$ \\
\hline SHH & Ethylnitrosourea & $\mathrm{Mm}$ & $\begin{array}{l}\text { Ethylnitrosourea results in increased mutagenesis of SHH } \\
\text { enhancer }\end{array}$ & $\begin{array}{l}\text { increases } \\
\text { mutagenesis }\end{array}$ & 17049204 \\
\hline SLC4A1 & Ethylnitrosourea & $\mathrm{Mm}$ & $\begin{array}{l}\text { Ethylnitrosourea results in increased mutagenesis of } \\
\text { SLC4A1 gene }\end{array}$ & $\begin{array}{l}\text { increases } \\
\text { mutagenesis }\end{array}$ & 16724327 \\
\hline STAT1 & Ethylnitrosourea & $\mathrm{Mm}$ & $\begin{array}{l}\text { Ethylnitrosourea results in increased mutagenesis of } \\
\text { STAT1 gene }\end{array}$ & $\begin{array}{l}\text { increases } \\
\text { mutagenesis }\end{array}$ & $\begin{array}{c}16688530 \mid 1672432 \\
7\end{array}$ \\
\hline TP53 & 2,4,6-trichlorophenol & $\operatorname{Dr}$ & $\begin{array}{l}\text { 2,4,6-trichlorophenol results in increased mutagenesis of } \\
\text { TP53 gene }\end{array}$ & $\begin{array}{l}\text { increases } \\
\text { mutagenesis }\end{array}$ & 18939895 \\
\hline TP53 & 2-phenylphenol & Hs & $\begin{array}{c}\text { [2-phenylphenol metabolite co-treated with NAD co- } \\
\text { treated with Copper] results in increased mutagenesis of } \\
\text { TP53 gene }\end{array}$ & $\begin{array}{l}\text { affects cotreatment } \\
\text { increases } \\
\text { mutagenesis }\end{array}$ & 10334203 \\
\hline TP53 & 2-phenylphenol & Hs & $\begin{array}{l}\text { bathocuproine inhibits the reaction [[2-phenylphenol } \\
\text { metabolite co-treated with NAD co-treated with Copper] } \\
\text { results in increased mutagenesis of TP53 gene] }\end{array}$ & $\begin{array}{l}\text { affects cotreatment } \\
\text { decreases reaction } \\
\text { increases } \\
\text { mutagenesis }\end{array}$ & 10334203 \\
\hline TP53 & 2-phenylphenol & Hs & $\begin{array}{l}\text { CAT protein inhibits the reaction [[2-phenylphenol } \\
\text { metabolite co-treated with NAD co-treated with Copper] } \\
\text { results in increased mutagenesis of TP53 gene] }\end{array}$ & $\begin{array}{l}\text { affects cotreatment } \\
\text { decreases reaction } \\
\text { increases } \\
\text { mutagenesis }\end{array}$ & 10334203 \\
\hline TP53 & Acrolein & Hs & Acrolein results in increased mutagenesis of TP53 gene & increases & 17030796 \\
\hline
\end{tabular}




\begin{tabular}{|c|c|c|c|c|c|}
\hline $\begin{array}{c}\text { Gene } \\
\text { Symbol }\end{array}$ & Chemical Name & Organism & Interaction & Interaction Actions & PubMed IDs \\
\hline & & & & mutagenesis & \\
\hline TP53 & Acrylamide & Hs & Acrylamide results in increased mutagenesis of TP53 gene & $\begin{array}{l}\text { increases } \\
\text { mutagenesis }\end{array}$ & 15240786 \\
\hline TP53 & Aflatoxin B1 & Hs & $\begin{array}{c}\text { Aflatoxin B1 results in increased mutagenesis of TP53 } \\
\text { gene }\end{array}$ & $\begin{array}{l}\text { increases } \\
\text { mutagenesis }\end{array}$ & $\begin{array}{c}12619106 \mid 1594649 \\
7\end{array}$ \\
\hline TP53 & Aflatoxins & Hs & Aflatoxins results in increased mutagenesis of TP53 gene & $\begin{array}{l}\text { increases } \\
\text { mutagenesis }\end{array}$ & 16007211 \\
\hline TP53 & Arsenic & Hs & Arsenic results in increased mutagenesis of TP53 gene & $\begin{array}{l}\text { increases } \\
\text { mutagenesis }\end{array}$ & 15967209 \\
\hline TP53 & Arsenic & $\mathrm{Hl}$ & Arsenic results in increased mutagenesis of TP53 gene & $\begin{array}{l}\text { increases } \\
\text { mutagenesis }\end{array}$ & 19203779 \\
\hline TP53 & Arsenic & Of & Arsenic results in increased mutagenesis of TP53 gene & $\begin{array}{l}\text { increases } \\
\text { mutagenesis }\end{array}$ & 19203779 \\
\hline TP53 & bathocuproine & Hs & $\begin{array}{l}\text { bathocuproine inhibits the reaction [[2-phenylphenol } \\
\text { metabolite co-treated with NAD co-treated with Copper] } \\
\text { results in increased mutagenesis of TP53 gene] }\end{array}$ & $\begin{array}{l}\text { affects cotreatment } \\
\text { decreases reaction } \\
\text { increases } \\
\text { mutagenesis }\end{array}$ & 10334203 \\
\hline TP53 & bathocuproine & $\mathrm{Hs}$ & $\begin{array}{l}\text { bathocuproine inhibits the reaction [[phenylhydroquinone } \\
\text { co-treated with Copper] results in increased mutagenesis } \\
\text { of TP53 gene] }\end{array}$ & $\begin{array}{l}\text { affects cotreatment } \\
\text { decreases reaction } \\
\text { increases } \\
\text { mutagenesis }\end{array}$ & 10334203 \\
\hline TP53 & chlorophyllin & $\mathrm{Rn}$ & $\begin{array}{l}\text { chlorophyllin inhibits the reaction [Cyclophosphamide } \\
\text { results in increased mutagenesis of TP53 exon] }\end{array}$ & $\begin{array}{l}\text { decreases reaction } \\
\text { increases } \\
\text { mutagenesis }\end{array}$ & 19227835 \\
\hline TP53 & NAD & $\mathrm{Hs}$ & $\begin{array}{c}\text { [2-phenylphenol metabolite co-treated with NAD co- } \\
\text { treated with Copper] results in increased mutagenesis of } \\
\text { TP53 gene }\end{array}$ & $\begin{array}{l}\text { affects cotreatment } \\
\text { increases } \\
\text { mutagenesis }\end{array}$ & 10334203 \\
\hline TP53 & NAD & $\mathrm{Hs}$ & $\begin{array}{l}\text { bathocuproine inhibits the reaction [[2-phenylphenol } \\
\text { metabolite co-treated with NAD co-treated with Copper] } \\
\text { results in increased mutagenesis of TP53 gene] }\end{array}$ & $\begin{array}{l}\text { affects cotreatment } \\
\text { decreases reaction } \\
\text { increases } \\
\text { mutagenesis }\end{array}$ & 10334203 \\
\hline
\end{tabular}




\begin{tabular}{|c|c|c|c|c|c|}
\hline $\begin{array}{c}\text { Gene } \\
\text { Symbol }\end{array}$ & Chemical Name & Organism & Interaction & Interaction Actions & PubMed IDs \\
\hline TP53 & NAD & Hs & $\begin{array}{l}\text { CAT protein inhibits the reaction [[2-phenylphenol } \\
\text { metabolite co-treated with NAD co-treated with Copper] } \\
\text { results in increased mutagenesis of TP53 gene] }\end{array}$ & $\begin{array}{l}\text { affects cotreatment } \\
\text { decreases reaction } \\
\text { increases } \\
\text { mutagenesis }\end{array}$ & 10334203 \\
\hline TP53 & Copper & Hs & $\begin{array}{l}\text { [2-phenylphenol metabolite co-treated with NAD co- } \\
\text { treated with Copper] results in increased mutagenesis of } \\
\text { TP53 gene }\end{array}$ & $\begin{array}{l}\text { affects cotreatment } \\
\text { increases } \\
\text { mutagenesis }\end{array}$ & 10334203 \\
\hline TP53 & Copper & $\mathrm{Hs}$ & $\begin{array}{l}\text { bathocuproine inhibits the reaction [[2-phenylphenol } \\
\text { metabolite co-treated with NAD co-treated with Copper] } \\
\text { results in increased mutagenesis of TP53 gene] }\end{array}$ & $\begin{array}{l}\text { affects cotreatment } \\
\text { decreases reaction } \\
\text { increases } \\
\text { mutagenesis }\end{array}$ & 10334203 \\
\hline TP53 & Copper & $\mathrm{Hs}$ & $\begin{array}{l}\text { bathocuproine inhibits the reaction [[phenylhydroquinone } \\
\text { co-treated with Copper] results in increased mutagenesis } \\
\text { of TP53 gene] }\end{array}$ & $\begin{array}{l}\text { affects cotreatment } \\
\text { decreases reaction } \\
\text { increases } \\
\text { mutagenesis }\end{array}$ & 10334203 \\
\hline TP53 & Copper & $\mathrm{Hs}$ & $\begin{array}{l}\text { CAT protein inhibits the reaction [[2-phenylphenol } \\
\text { metabolite co-treated with NAD co-treated with Copper] } \\
\text { results in increased mutagenesis of TP53 gene] }\end{array}$ & $\begin{array}{l}\text { affects cotreatment } \\
\text { decreases reaction } \\
\text { increases } \\
\text { mutagenesis }\end{array}$ & 10334203 \\
\hline TP53 & Copper & Hs & $\begin{array}{l}\text { CAT protein inhibits the reaction [[phenylhydroquinone } \\
\text { co-treated with Copper] results in increased mutagenesis } \\
\text { of TP53 gene] }\end{array}$ & $\begin{array}{l}\text { affects cotreatment } \\
\text { decreases reaction } \\
\text { increases } \\
\text { mutagenesis }\end{array}$ & 10334203 \\
\hline TP53 & Copper & Hs & $\begin{array}{l}\text { [N-hydroxy-4-aminobiphenyl co-treated with Copper] } \\
\text { results in increased mutagenesis of TP53 gene }\end{array}$ & $\begin{array}{l}\text { affects cotreatment } \\
\text { increases } \\
\text { mutagenesis }\end{array}$ & 11275476 \\
\hline TP53 & Copper & Hs & $\begin{array}{l}\text { [phenylhydroquinone co-treated with Copper] results in } \\
\text { increased mutagenesis of TP53 gene }\end{array}$ & $\begin{array}{l}\text { affects cotreatment } \\
\text { increases } \\
\text { mutagenesis }\end{array}$ & 10334203 \\
\hline
\end{tabular}




\begin{tabular}{|c|c|c|c|c|c|}
\hline $\begin{array}{l}\text { Gene } \\
\text { Symbol }\end{array}$ & Chemical Name & Organism & Interaction & Interaction Actions & PubMed IDs \\
\hline TP53 & Curcumin & $\mathrm{Rn}$ & $\begin{array}{l}\text { Curcumin inhibits the reaction [Cyclophosphamide results } \\
\text { in increased mutagenesis of TP53 exon] }\end{array}$ & $\begin{array}{l}\text { decreases reaction } \\
\text { increases } \\
\text { mutagenesis }\end{array}$ & 19227835 \\
\hline TP53 & Cyclophosphamide & $\mathrm{Rn}$ & $\begin{array}{l}\text { chlorophyllin inhibits the reaction [Cyclophosphamide } \\
\text { results in increased mutagenesis of TP53 exon] }\end{array}$ & $\begin{array}{l}\text { decreases reaction } \\
\text { increases } \\
\text { mutagenesis }\end{array}$ & 19227835 \\
\hline TP53 & Cyclophosphamide & $\mathrm{Rn}$ & $\begin{array}{l}\text { Curcumin inhibits the reaction [Cyclophosphamide results } \\
\text { in increased mutagenesis of TP53 exon] }\end{array}$ & $\begin{array}{l}\text { decreases reaction } \\
\text { increases } \\
\text { mutagenesis }\end{array}$ & 19227835 \\
\hline TP53 & Cyclophosphamide & $\mathrm{Rn}$ & $\begin{array}{l}\text { Cyclophosphamide results in increased mutagenesis of } \\
\text { TP53 exon }\end{array}$ & $\begin{array}{l}\text { increases } \\
\text { mutagenesis }\end{array}$ & 19227835 \\
\hline TP53 & Ethylnitrosourea & $\mathrm{Ol}$ & $\begin{array}{l}\text { Ethylnitrosourea results in increased mutagenesis of TP53 } \\
\text { exon }\end{array}$ & $\begin{array}{l}\text { increases } \\
\text { mutagenesis }\end{array}$ & 17156454 \\
\hline TP53 & Ethylnitrosourea & $\mathrm{Rn}$ & $\begin{array}{l}\text { Ethylnitrosourea results in increased mutagenesis of TP53 } \\
\text { gene }\end{array}$ & $\begin{array}{l}\text { increases } \\
\text { mutagenesis }\end{array}$ & 16495775 \\
\hline TP53 & glycidamide & $\mathrm{Hs}$ & $\begin{array}{c}\text { glycidamide results in increased mutagenesis of TP53 } \\
\text { gene }\end{array}$ & $\begin{array}{l}\text { increases } \\
\text { mutagenesis }\end{array}$ & 15240786 \\
\hline TP53 & $\begin{array}{l}\text { N-hydroxy-4- } \\
\text { aminobiphenyl }\end{array}$ & $\mathrm{Hs}$ & $\begin{array}{l}\text { [N-hydroxy-4-aminobiphenyl co-treated with Copper] } \\
\text { results in increased mutagenesis of TP53 gene }\end{array}$ & $\begin{array}{l}\text { affects cotreatment } \\
\text { increases } \\
\text { mutagenesis }\end{array}$ & 11275476 \\
\hline TP53 & Nitrofurazone & $\mathrm{Hs}$ & $\begin{array}{c}\text { Nitrofurazone results in increased mutagenesis of TP53 } \\
\text { gene }\end{array}$ & $\begin{array}{l}\text { increases } \\
\text { mutagenesis }\end{array}$ & 15488632 \\
\hline TP53 & phenylhydroquinone & Hs & $\begin{array}{l}\text { bathocuproine inhibits the reaction [[phenylhydroquinone } \\
\text { co-treated with Copper] results in increased mutagenesis } \\
\text { of TP53 gene] }\end{array}$ & $\begin{array}{l}\text { affects cotreatment } \\
\text { decreases reaction } \\
\text { increases } \\
\text { mutagenesis }\end{array}$ & 10334203 \\
\hline TP53 & phenylhydroquinone & $\mathrm{Hs}$ & $\begin{array}{l}\text { CAT protein inhibits the reaction [[phenylhydroquinone } \\
\text { co-treated with Copper] results in increased mutagenesis } \\
\text { of TP53 gene] }\end{array}$ & $\begin{array}{l}\text { affects cotreatment } \\
\text { decreases reaction } \\
\text { increases } \\
\text { mutagenesis }\end{array}$ & 10334203 \\
\hline
\end{tabular}




\begin{tabular}{|c|c|c|c|c|c|}
\hline $\begin{array}{c}\text { Gene } \\
\text { Symbol }\end{array}$ & Chemical Name & Organism & Interaction & Interaction Actions & PubMed IDs \\
\hline TP53 & phenylhydroquinone & $\mathrm{Hs}$ & $\begin{array}{l}\text { [phenylhydroquinone co-treated with Copper] results in } \\
\text { increased mutagenesis of TP53 gene }\end{array}$ & $\begin{array}{l}\text { affects cotreatment } \\
\text { increases } \\
\text { mutagenesis }\end{array}$ & 10334203 \\
\hline TP53 & $\begin{array}{l}\text { potassium } \\
\text { diazoacetate }\end{array}$ & $\mathrm{Hs}$ & $\begin{array}{c}\text { potassium diazoacetate results in increased mutagenesis of } \\
\text { TP53 gene }\end{array}$ & $\begin{array}{l}\text { increases } \\
\text { mutagenesis }\end{array}$ & 16926174 \\
\hline TP53 & $\begin{array}{l}\text { Tobacco Smoke } \\
\text { Pollution }\end{array}$ & Hs & $\begin{array}{c}\text { Tobacco Smoke Pollution results in increased mutagenesis } \\
\text { of TP53 gene }\end{array}$ & $\begin{array}{l}\text { increases } \\
\text { mutagenesis }\end{array}$ & 10824542 \\
\hline TP53 & Vinyl Chloride & $\mathrm{Hs}$ & $\begin{array}{l}\text { CYP2E1 gene polymorphism promotes the reaction [Vinyl } \\
\text { Chloride affects the mutagenesis of TP53 gene] }\end{array}$ & $\begin{array}{l}\text { affects mutagenesis } \\
\text { increases reaction }\end{array}$ & 12705718 \\
\hline TP53 & Vinyl Chloride & Hs & $\begin{array}{l}\text { CYP2E1 gene polymorphism promotes the reaction [Vinyl } \\
\text { Chloride results in increased mutagenesis of TP53 gene] }\end{array}$ & $\begin{array}{c}\text { increases } \\
\text { mutagenesis } \\
\text { increases reaction }\end{array}$ & $\begin{array}{c}12010862 \mid 1738490 \\
0\end{array}$ \\
\hline TP53 & Vinyl Chloride & $\mathrm{Hs}$ & $\begin{array}{l}\text { GSTM1 gene polymorphism affects the reaction [XRCC1 } \\
\text { gene polymorphism affects the reaction [Vinyl Chloride } \\
\text { affects the mutagenesis of TP53 gene]] }\end{array}$ & $\begin{array}{l}\text { affects mutagenesis } \\
\text { affects reaction }\end{array}$ & 16097394 \\
\hline TP53 & Vinyl Chloride & $\mathrm{Hs}$ & $\begin{array}{l}\text { GSTT1 gene polymorphism affects the reaction [XRCC1 } \\
\text { gene polymorphism affects the reaction [Vinyl Chloride } \\
\text { affects the mutagenesis of TP53 gene]] }\end{array}$ & $\begin{array}{l}\text { affects mutagenesis } \\
\text { affects reaction }\end{array}$ & 16097394 \\
\hline TP53 & Vinyl Chloride & $\mathrm{Hs}$ & $\begin{array}{l}\text { Vinyl Chloride results in increased mutagenesis of TP53 } \\
\text { gene }\end{array}$ & $\begin{array}{l}\text { increases } \\
\text { mutagenesis }\end{array}$ & $\begin{array}{l}12010862 \mid 1267051 \\
9|16881598| 173849 \\
00\end{array}$ \\
\hline TP53 & Vinyl Chloride & $\mathrm{Hs}$ & $\begin{array}{l}\text { XRCC1 gene polymorphism affects the reaction [Vinyl } \\
\text { Chloride affects the mutagenesis of TP } 53 \text { gene] }\end{array}$ & $\begin{array}{l}\text { affects mutagenesis } \\
\text { affects reaction }\end{array}$ & 16097394 \\
\hline TP53 & Vinyl Chloride & $\mathrm{Hs}$ & $\begin{array}{l}\text { XRCC1 gene polymorphism promotes the reaction [Vinyl } \\
\text { Chloride affects the mutagenesis of TP53 gene] }\end{array}$ & $\begin{array}{l}\text { affects mutagenesis } \\
\text { increases reaction }\end{array}$ & 14602524 \\
\hline TP53 & Vinyl Chloride & $\mathrm{Hs}$ & $\begin{array}{l}\text { XRCC1 gene polymorphism promotes the reaction [Vinyl } \\
\text { Chloride results in increased mutagenesis of TP53 gene] }\end{array}$ & $\begin{array}{l}\text { increases } \\
\text { mutagenesis } \\
\text { increases reaction }\end{array}$ & $\begin{array}{c}12010862 \mid 1688159 \\
8\end{array}$ \\
\hline
\end{tabular}


Appendix Figure 1. Results of PathJam analysis of Grade 1 Astrocytoma Markov genes. Arcs represent interactions between genes and pathways. Databases for curated pathways and gene ontology terms are identified by their respective emblems. See Additional File 1.

Appendix Figure 2. Results of PathJam analysis of Grade 2 Astrocytoma Markov genes. Arcs represent interactions between genes and pathways. Databases for curated pathways and gene ontology terms are identified by their respective emblems. See Additional File 2.

Appendix Figure 3. Results of PathJam analysis of Grade 3 Astrocytoma Markov genes. Arcs represent interactions between genes and pathways. Databases for curated pathways and gene ontology terms are identified by their respective emblems. See Additional File 3.

Appendix Figure 4. Results of PathJam analysis of Grade 4 Astrocytoma Markov genes. Arcs represent interactions between genes and pathways. Databases for curated pathways and gene ontology terms are identified by their respective emblems. See Additional File 4. 


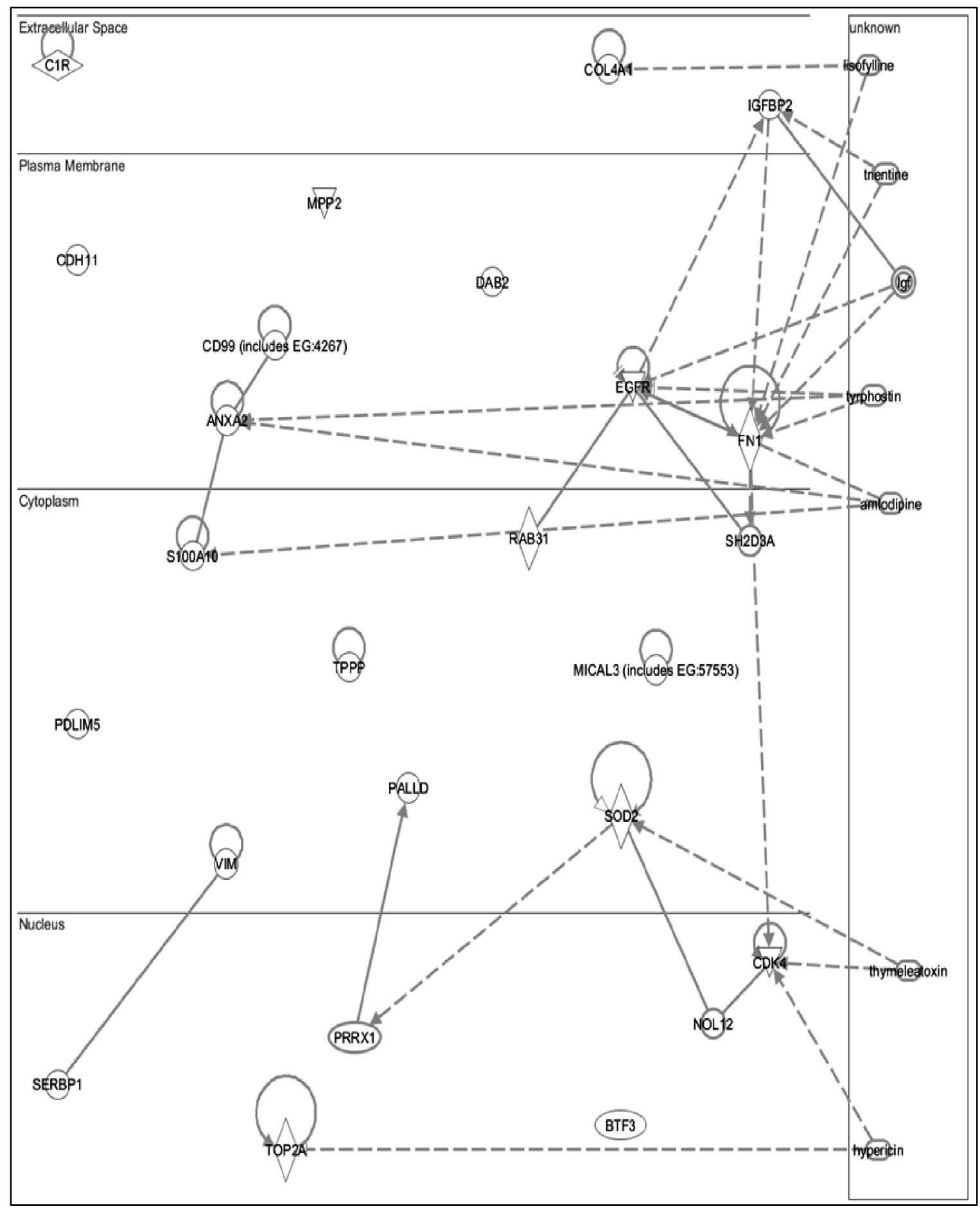

Figure 5. IPA connections of Grade IV Glioblastoma Markov genes. Direct interactions between genes (genes/gene products make direct physical contact with each other) are represented by solid lines. Indirect interactions (genes/gene products do not make direct physical contact with each other but instead may influence each other through some intermediate factor) are represented as dotted lines. 


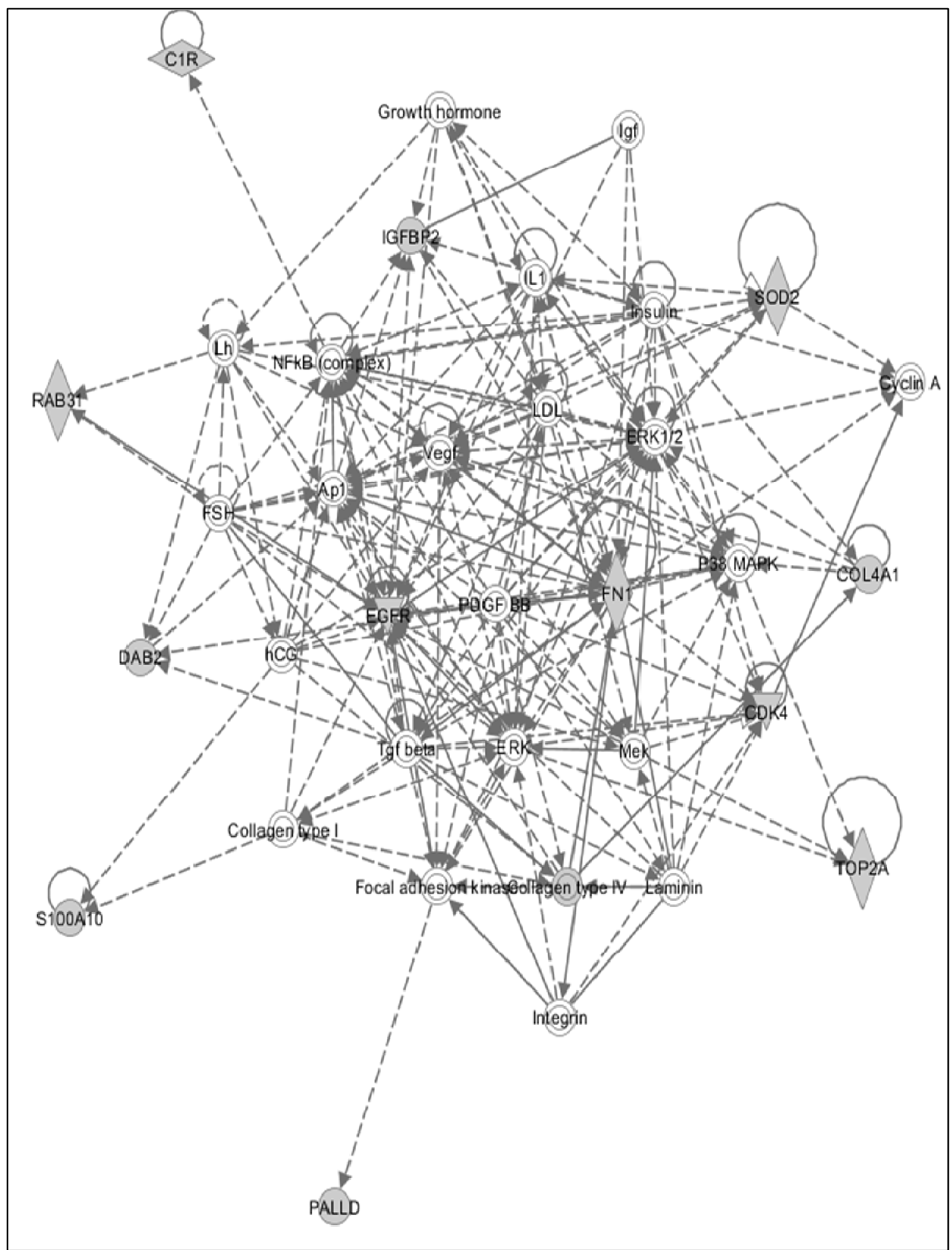

Figure 6. Top IPA Grade IV Glioblastoma Markov genes network. IPA defined the network as related to 'cancer, neurological disease, and cellular movement'. Shaded genes represent our Markov genes. Non-shaded molecules were added by IPA during the analyses. 
Appendix Figure 7. KEGG Pathway 'Pathways in Cancer' found to contain 42 genes from our GEI Glioblastoma alterations list. Analyses run using DAVID. Stars represent genes in the GEI gene list and pathways significantly represented in the GEI gene list.

See Additional File 5.

Appendix Figure 8. KEGG Pathway 'Glioma' found to contain 13 genes from our GEI Glioblastoma alterations list. Analyses run using DAVID. Stars represent genes in the GEI gene list and pathways significantly represented in the GEI gene list. See Additional File 6.

Appendix Figure 9. KEGG Pathway 'Pathways in Cancer' found to contain 123 genes from our Glioblastoma alterations list. Analyses run using DAVID. Stars represent genes in the GBM gene list and pathways significantly represented in the GBM gene list.

See Additional File 7.

Appendix Figure 10. KEGG Pathway 'Glioma' found to contain 30 genes from our Glioblastoma alterations list. Analyses run using DAVID. Stars represent genes in the GBM gene list and pathways significantly represented in the GBM gene list.

See Additional File 8 


\section{VITA}

\section{BRIAN WILLIAM KUNKLE}

June 12, 1976

1998

2005
Born, Lehighton, Pennsylvania

B.S., Geo-environmental Studies

Shippensburg University

Shippensburg, PA

M.P.H., Epidemiology, Environmental Health Florida International University

Miami, FL

\section{PUBLICATIONS AND PRESENTATIONS}

Kunkle B, Sandberg D, Jayakar P, Felty Q, Roy D. Environment, genetic and epigenetic alterations, and pediatric central nervous system tumors. The Encyclopedia of Environmental Health, Five-Volume Set, Jerome Nriagu, Elsevier, New York, 2011.

Kunkle B, Sandberg D, Jayakar P, Felty Q, Roy D. Gene-environment interaction and susceptibility to pediatric brain tumors. Environmental Factors, Genes, and the Development of Human Cancers', Deodutta Roy and M. Tevfik Dorak, Elsevier, New York, 2010

Kunkle B, Felty Q, Narasimhan G, Trevino F, Roy D. Meta-analysis of brain tumor microarray data using Oncomine identifies NRF1, Tfam and Myc co-expressed $\backslash$ genes: its implications in the development of childhood brain tumors. Proceedings of the $18^{\text {th }}$ World IMACS/MODSIM Congress, Cairns, Australia 13-17 July 2009.

Kunkle B, Felty Q, Trevino F, Roy D. Oncomine meta-analysis of breast cancer microarray data identifies upregulation of NRF1 expression in human breast carcinoma. Proceedings of the $18^{\text {th }}$ World IMACS/MODSIM Congress, Cairns, Australia 13-17 July 2009.

Kunkle B and Roy D. Developmental pathways and growth of astrocytic tumors. Presented at 2009 Society of Toxicology Meeting, Miami Beach, FL.

Kunkle B and Roy D. Differential expression of NRF1 in breast cancer by estrogen receptor status, histological grade, and prognosis. Presented at 2009 FIU Breast Cancer Symposium, Miami, FL. 
Kunkle B, Melchior M, Sukhram S, Sukhram A, and Gasana J. Comprehensive Review of Bronchial Asthma in Children as Related to House Dust Mite Exposure. Presented at the 2008 Florida Environmental Health Association Conference, Palm Beach, FL.

Sukhram S, Nair R, Villalba K, Melchior M, Kunkle B, and Gasana J. Association Between Exposure To Cats And Dogs And Risk Of Asthma. Presented at the 2008 Florida Environmental Health Association Conference, Palm Beach, FL.

Smith B, Wiegering D, Sukhram S, Kunkle B, Melchior M, and Gasana J. The Relationship Between Asthma and Cockroach Allergens. Presented at the 2008 Florida Environmental Health Association Conference, Palm Beach, FL.

Dillikar D, Sukhram A, Melchior M, Kunkle B, Sukhram S, and Gasana J. Comprehensive Review of Bronchial Asthma in Children Due to Dampness and Mold. Presented at the 2008 Florida Environmental Health Association Conference, Palm Beach, FL.

Kunkle B and Roy D. Is in utero imprinting of the brain by pesticides involved in childhood brain cancer development: A meta-analysis. Oral Presentation at 2007 International Society for Environmental Epidemiology Conference, Mexico City, Mexico.

Kunkle B and Roy D. Meta-analysis of manganese superoxide dismutase (MnSOD) polymorphisms, oral contraceptives, and risk of breast cancer. Presented at 2006 American Public Health Association Conference, Boston, MA.

Kunkle B. Minimizing health risks to environmental toxins during disaster responses: lessons learned from the collapse of the World Trade Center. Presented at 2005 Florida Public Health Association Conference. Orlando, FL.

Murunga V, Kunkle B, Cherry S, Trepka MJ, Huffman F, Dixon Z. Exploring food safety knowledge, attitudes and behaviors among women attending a Women, Infants and Children (WIC) Clinic in Miami-Dade County, Florida.Presented at 2005 Florida Dietetics Association Conference, Naples, FL.

Cherry S, Trepka MJ, Murunga V, Kunkle B. Use of focus groups in designing food safety education programs for WIC clients. Presented at 2005 American Public Health Association Conference, Philadelphia, PA. 